\title{
Regulation of Polycomb Group proteins : the complex, the kinase and the interactor
}

Citation for published version (APA):

Niessen, H. E. C. (2009). Regulation of Polycomb Group proteins : the complex, the kinase and the interactor. [Doctoral Thesis, Maastricht University]. Maastricht University. https://doi.org/10.26481/dis.20091113hn

Document status and date:

Published: 01/01/2009

DOI:

10.26481/dis.20091113hn

Document Version:

Publisher's PDF, also known as Version of record

\section{Please check the document version of this publication:}

- A submitted manuscript is the version of the article upon submission and before peer-review. There can be important differences between the submitted version and the official published version of record.

People interested in the research are advised to contact the author for the final version of the publication, or visit the DOI to the publisher's website.

- The final author version and the galley proof are versions of the publication after peer review.

- The final published version features the final layout of the paper including the volume, issue and page numbers.

Link to publication

\footnotetext{
General rights rights.

- You may freely distribute the URL identifying the publication in the public portal. please follow below link for the End User Agreement:

www.umlib.nl/taverne-license

Take down policy

If you believe that this document breaches copyright please contact us at:

repository@maastrichtuniversity.nl

providing details and we will investigate your claim.
}

Copyright and moral rights for the publications made accessible in the public portal are retained by the authors and/or other copyright owners and it is a condition of accessing publications that users recognise and abide by the legal requirements associated with these

- Users may download and print one copy of any publication from the public portal for the purpose of private study or research.

- You may not further distribute the material or use it for any profit-making activity or commercial gain

If the publication is distributed under the terms of Article $25 \mathrm{fa}$ of the Dutch Copyright Act, indicated by the "Taverne" license above, 


\title{
Regulation of Polycomb Group proteins
}

\author{
The complex, the kinase and the
} interactor 
Printed by GVO printers \& designers B.V. | Ponsen \& Looijen ISBN 978-90-6464-370-5

(C) Hanneke Niessen, Maastricht 2009 


\title{
Regulation of Polycomb Group proteins
}

\section{The complex, the kinase and the interactor}

\author{
PROEFSCHRIFT \\ ter verkrijging van de graad van doctor \\ aan de Universiteit Maastricht, \\ op gezag van de Rector Magnificus, \\ Prof. mr. G.P.M.F. Mols \\ volgens het besluit van het College van Decanen, \\ in het openbaar te verdedigen \\ op vrijdag 13 november 2009 om 12.00 uur \\ door \\ Hanneke Elisabeth Catharina Niessen \\ Geboren te Roermond op 10 juni 1980
}




\section{Promotores:}

Prof. dr. J.P.M. Geraedts

Prof. dr. M.H. Hofker

\section{Copromotor:}

Dr. J.W. Voncken

\section{Beoordelingscommissie:}

Prof. dr. J. de Haan (voorzitter)

Prof. dr. R. van Driel (UvA - Amsterdam)

Dr. F. Peronnet (CNRS / UPMC - Paris)

Prof. dr. F.C.S. Ramaekers

Dr. J. Theys

This research was supported by NWO.

Printing of this thesis was financially supported by:

Greiner bio-one

GC biotech 


\section{Contents}

Chapter 1

$\begin{array}{ll}\text { General Introduction } & 10 \\ \text { Aim of the thesis } & 10\end{array}$

$\begin{array}{ll}\text { Chapter } 2 & 15\end{array}$

Polycomb Group proteins in tumorigenesis

Chapter $3 \quad 45$

Talking to chromatin: post-translational modulation of Polycomb Group function

Chapter 4

MAPKAP kinase $3 p K$ phosphorylates and regulates chromatin association of the Polycomb Group protein Bmi1

Chapter 5

95

MK3 controls proliferation by an epigenetic switch-mechanism involving Polycomb function

\section{Chapter 6}

Cell stress-induced association of Polycomb Repressive Complex 1 with the chromatin factor KAP1

\section{Chapter 7}

General Discussion

Summary

Dankwoord

Curriculum Vitae 

Chapter 1

General Introduction 


\section{Introduction}

The human genome stores the information that a cell needs to produce the molecules it requires. Even though the DNA sequence is the same in all somatic cells of a human body, cells have a specific phenotype, depending on the developmental stage and tissue type in which they reside. The celltype-specific functions are determined by the set of genes that are transcribed and translated within the cell. Gene transcription in itself is not only determined by the availability and activity of transcriptional machinery, but also by the accessibility of the DNA and genes. Therefore, packing the genome into chromatin, making DNA accessible or inaccessible, is an important contributor to determining cell fate and function. The building blocks of chromatin are nucleosomes, which consist of DNA and histones ${ }^{1}$. Each nucleosome contains two copies of each of the core histones ( $\mathrm{H} 2 \mathrm{~A}, \mathrm{H} 2 \mathrm{~B}, \mathrm{H} 3$ and $\mathrm{H} 4)$, together comprising an octomer, around which the DNA is wrapped (Fig. 1.1). The $\mathrm{N}$-terminal histone tails protrude from the nucleosome ${ }^{2}$. Condensation of nucleosomes into open or closed chromatin structures or states ultimately determines whether genes are accessible or not.

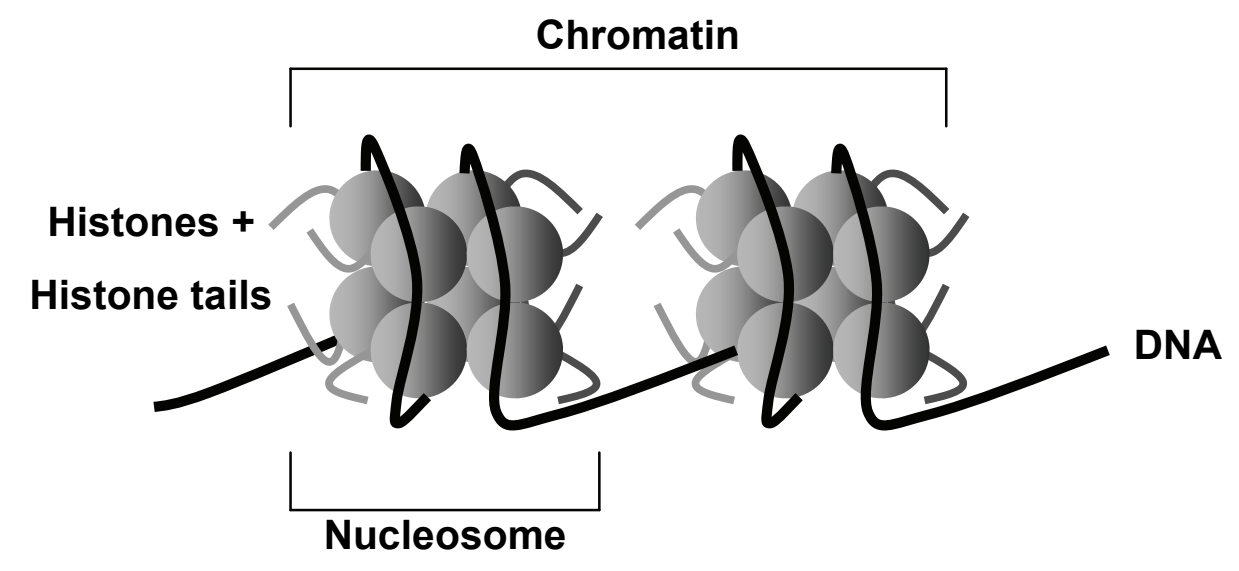

Figure 1.1. Organization of chromatin

DNA is stored in the nucleus as chromatin. The building unit of chromatin is the nucleosome, which consists of eight histones (two each of $\mathrm{H} 2 \mathrm{~A}, \mathrm{H} 2 \mathrm{~B}, \mathrm{H} 3$ and $\mathrm{H} 4$ ) with 147 base pairs of DNA wrapped around it. The histone tails protrude from the nucleosome and are available for posttranslational modification.

\section{Epigenetics}

The study of heritable gene expression changes, and hence heritable phenotypes, that occur without changing the underlying DNA nucleotide sequence is referred to as epigenetics ${ }^{3}$. Modifications that (stably) alter the chromatin structure, and thereby gene expression are important epigenetic 
regulators of development and disease. Epigenetic regulation occurs at several macromolecular levels: at the RNA, DNA and protein level. They all have in common that they ultimately affect gene expression. Non-coding RNA molecules play important roles in epigenetic regulatory mechanisms, of which the best known example is the coating of the inactive $X$ chromosome by a large non-coding RNA: Xist ${ }^{4}$. There is increasing evidence that also small non-coding RNAs play an important role in epigenetic regulation of gene expression ${ }^{5}$. Perhaps the best known mechanism of epigenetic silencing is DNA methylation. It is catalyzed by DNA methyltransferases (DNMTs), occurs on cytosine bases in the context of $\mathrm{CpG}$ dinucleotides and is associated with repressed chromatin states $^{6}$. At the protein level, nucleosomes are targets and coordinators of epigenetic regulation. Histones are mostly modified on their $\mathrm{N}$-terminal tails, which are subject to i.a. acetylation, methylation, phosphorylation and ubiquitylation ${ }^{7,8}$. Another level of complexity is added since methylation can occur as mono-, di-, or trimethylation on lysines, and as mono- or di- (symmetric or asymmetric) methylation on argenines ${ }^{8}$. For some modifications the relation to transcription is understood. Histone acetylation mostly correlates with transcriptional activation. Histone methylation, however, correlates with both activation and repression, depending on the target residue. The multiple combinations of these histone modifications form a gene expression status index, which is also referred to as the histone code ${ }^{9}$. The 'writers' of this code are enzymes that catalyze the post-translational modifications of histones, such as histone acetyl transferases (HATs), histone methyl transferases (HMTs), kinases and ubiquitin ligases. The 'erasers' are enzymes that remove these modifications, such as histone deacetylases (HDACs), histone demethylases, phosphatases and de-ubiquitinating enzymes (DUBs). The 'readers' are proteins that through specific domains (e.g. PHD-, chromo- and bromo- domain) interact with specific histone modifications ${ }^{8}$. Many chromatin-associated complexes, being transcriptionally activating or repressive, either harbor or are associated with such catalytic activities.

\section{Polycomb Group proteins}

One chromatin-associated group of proteins are the Polycomb Group (PcG) proteins. They maintain transcriptional silencing via epigenetic mechanisms. PcG proteins fulfill a crucial role in antero-posterior patterning during development by repressing their classical targets, the HOX genes ${ }^{10}$. The mechanisms that contribute to PcG-mediated silencing are unfolding (Fig. 1.2). PcG proteins function in two complexes, Polycomb Repressive Complex 1 and 2 (PRC1, PRC2). The PRC2 complex contains EED, SUZ12 and EZH2, an HMT that installs trimethylation on lysine 27 of histone 3 (H3K27me3) ${ }^{11-14}$. Members of PRC2 also 
associate with DNMTs, HDACs, kinases and DUBs ${ }^{15-18}$. PRC1 is made up of several proteins, including BMI1, RNF2, PHC and CBX proteins ${ }^{19}{ }^{20}$. Some CBX proteins specifically bind to the $\mathrm{H} 3 \mathrm{~K} 27 \mathrm{me} 3$ mark, thereby recruiting the PRC1 complex ${ }^{21}$, 22. RNF2 is a E3 ubiquitin ligase involved in the ubiquitylation of $\mathrm{H} 2 \mathrm{~A}$ on lysine $119^{23-25}$. Furthermore PRC1 also associates with another $\mathrm{HMT}^{26}$. These catalytic activities, in combination with extensive interaction among PCG members and other chromatin factors, generate a repressive higher-order chromatin structure inaccessible to transcriptional activators.

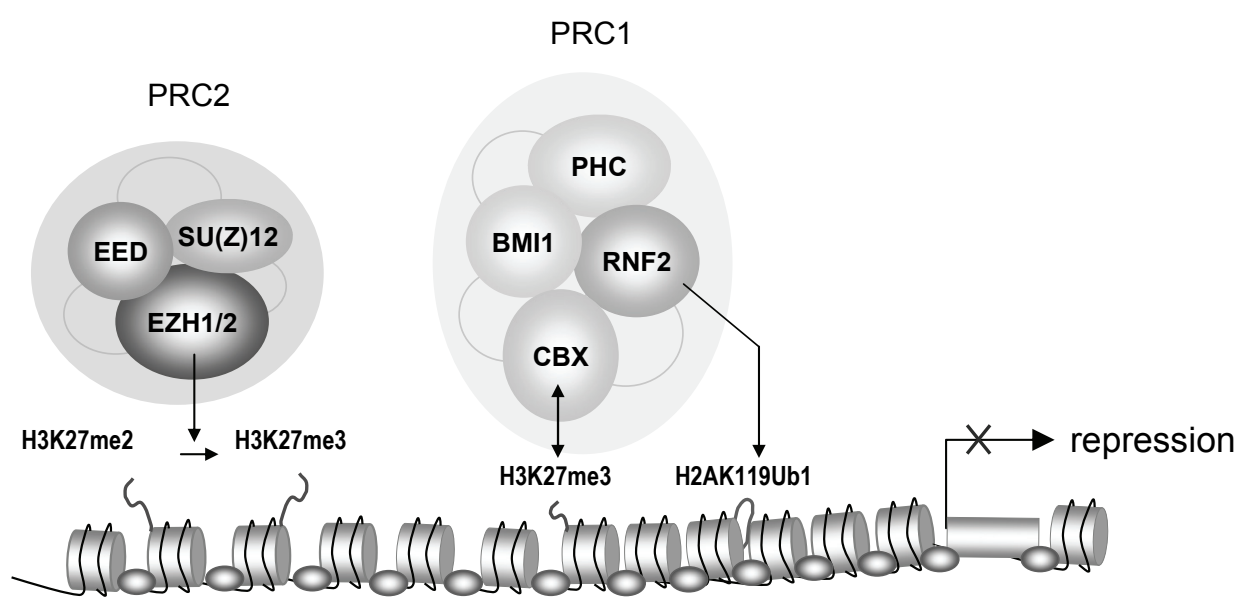

Figure 1.2. Schematic drawing of Polycomb-mediated silencing.

\section{Aim of the thesis}

Although progress has been made in understanding the mechanisms that contribute to PcG-mediated repression, many aspects of Polycomb Group biology in mammals are still elusive: What processes control PcG complex formation, how is complex composition determined, what factors determine chromatin interaction at a specific site, and how is target gene specificity determined? And importantly: how is Polycomb Group function regulated?

We know that PCG proteins are post-translationally modified. At the beginning of this project it was known that at least some PcG proteins are phosphorylated and that this phosphorylation correlates with chromatin dissociation in a cell cycle-dependent fashion ${ }^{27}$. Phosphorylation of PcG proteins might alter proteinprotein interactions, subcellular localization, enzymatic activity and overall function. The working hypothesis of the research described in this thesis is that phosphorylation of PcG proteins leads to PcG dissociation from chromatin, giving the cell an opportunity to change its transcriptional status. 
The research described in this thesis aimed at the identification of 1) kinases that are responsible for PcG phosphorylation;

2) PcG amino acid residues that are phosphorylated;

3) potential changes of the PcG complex composition upon phosphorylation and 4) the biological relevance of these phosphorylation events.

A detailed review of PcG complexes function and how PcG proteins contribute to tumorigenesis is presented in Chapter 2. The current knowledge of PcG posttranslational modifications and PcG enzymatic activities are summarized in Chapter 3. The identification of a PcG kinase is presented in Chapter 4. The biological relevance of this kinase in terms of cellular function and PcG involvement is revealed in Chapter 5. The identification of PcG phosphorylation sites is described in Chapter 6, in which the complex composition of PRC1 was studied during phosphorylated conditions. The results obtained in these studies and their implications for PcG function are discussed in Chapter 7. 


\section{References}

1. Kornberg RD, Lorch Y. Twenty-five years of the nucleosome, fundamental particle of the eukaryote chromosome. Cell. Aug 6 1999;98(3):285-294.

2. Luger K, Richmond TJ. The histone tails of the nucleosome. Curr Opin Genet Dev. Apr 1998;8(2):140-146.

3. Goldberg $A D$, Allis $C D$, Bernstein E. Epigenetics: a landscape takes shape. Cell. Feb 23 2007;128(4):635-638.

4. Avner P, Heard E. X-chromosome inactivation: counting, choice and initiation. Nat Rev Genet. Jan 2001;2(1):59-67.

5. Zaratiegui M, Irvine DV, Martienssen RA. Noncoding RNAs and gene silencing. Cell. Feb 23 2007;128(4):763-776.

6. Klose RJ, Bird AP. Genomic DNA methylation: the mark and its mediators. Trends Biochem Sci. Feb 2006;31(2):89-97.

7. Bernstein BE, Meissner A, Lander ES. The mammalian epigenome. Cell. Feb 23 2007;128(4):669-681.

8. Kouzarides T. Chromatin modifications and their function. Cell. Feb 23 2007;128(4):693-705.

9. Strahl BD, Allis CD. The language of covalent histone modifications. Nature. Jan 6 2000;403(6765):41-45.

10. van Lohuizen M. Functional analysis of mouse Polycomb group genes. Cell Mol Life Sci. Jan 1998;54(1):71-79.

11. Cao R, Wang L, Wang $\mathrm{H}$, et al. Role of Histone $\mathrm{H} 3$ Lysine 27 Methylation in Polycomb-Group Silencing. Science. 2002;26:1039-1043.

12. Muller J, Hart CM, Francis NJ, et al. Histone Methyltransferase Activity of a Drosophila Polycomb Group Repressor Complex. Cell. 2002;111(2):197-208.

13. Czermin B, Melfi R, McCabe D, et al. Drosophila Enhancer of Zeste/ESC Complexes Have a Histone H3 Methyltransferase Activity that Marks Chromosomal Polycomb Sites. Cell. 2002;111(2):185-196.

14. Kuzmichev A, Nishioka K, Erdjument-Bromage $\mathrm{H}$, et al. Histone methyltransferase activity associated with a human multiprotein complex containing the Enhancer of Zeste protein. Genes Dev. Nov 15 2002;16(22):2893-2905.

15. Vire E, Brenner C, Deplus R, et al. The Polycomb group protein EZH2 directly controls DNA methylation. Nature. Feb 16 2006;439(7078):871-874.

16. van der Vlag J, Otte AP. Transcriptional repression mediated by the human polycomb-group protein EED involves histone deacetylation. Nat Genet. Dec 1999;23(4):474-478.

17. Cha TL, Zhou BP, Xia W, et al. Akt-mediated phosphorylation of EZH2 suppresses methylation of lysine 27 in histone H3. Science. Oct 14 2005;310(5746):306-310.

18. Higa LA, Wu M, Ye T, et al. CUL4-DDB1 ubiquitin ligase interacts with multiple WD40-repeat proteins and regulates histone methylation. Nat Cell Biol. Nov 2006;8(11):1277-1283.

19. Levine SS, Weiss A, Erdjument-Bromage $H$, et al. The core of the polycomb repressive complex is compositionally and functionally conserved in flies and humans. Mol Cell Biol. Sep 2002;22(17):6070-6078.

20. Alkema MJ, Bronk M, Verhoeven E, et al. Identification of Bmi1-interacting proteins as constituents of a multimeric mammalian polycomb complex. Genes Dev. Jan 15 $1997 ; 11(2): 226-240$. 
21. Min J, Zhang $Y, X u$ RM. Structural basis for specific binding of Polycomb chromodomain to histone $\mathrm{H} 3$ methylated at Lys 27. Genes Dev. Aug 1 2003;17(15):1823-1828.

22. Fischle $\mathrm{W}$, Wang $\mathrm{Y}$, Jacobs $\mathrm{SA}$, et al. Molecular basis for the discrimination of repressive methyl-lysine marks in histone $\mathrm{H} 3$ by Polycomb and HP1 chromodomains. Genes Dev. Aug 1 2003;17(15):1870-1881.

23. Cao R, Tsukada YI, Zhang Y. Role of Bmi-1 and Ring1A in H2A Ubiquitylation and Hox Gene Silencing. Mol Cell. Dec 22 2005;20(6):845-854.

24. de Napoles M, Mermoud JE, Wakao R, et al. Polycomb Group Proteins Ring1A/B Link Ubiquitylation of Histone H2A to Heritable Gene Silencing and X Inactivation. Developmental Cell. 2004/11 2004;7(5):663-676.

25. Wang $\mathrm{H}$, Wang $\mathrm{L}$, Erdjument-Bromage $\mathrm{H}$, et al. Role of histone $\mathrm{H} 2 \mathrm{~A}$ ubiquitination in Polycomb silencing. Nature. Sep 22 2004;431:873-878.

26. Sewalt RG, Lachner $M$, Vargas $M$, et al. Selective interactions between vertebrate polycomb homologs and the SUV39H1 histone lysine methyltransferase suggest that histone H3-K9 methylation contributes to chromosomal targeting of Polycomb group proteins. Mol Cell Biol. Aug 2002;22(15):5539-5553.

27. Voncken JW, Schweizer D, Aagaard L, et al. Chromatin-association of the Polycomb group protein BMI1 is cell cycle-regulated and correlates with its phosphorylation status. J Cell Sci. Dec 1999;112 ( Pt 24):4627-4639. 



\section{Chapter 2}

\section{Polycomb Group proteins in tumorigenesis}




\section{Short general introduction}

The molecular mechanisms underlying cancer development have since long been a subject of study. Traditionally, cancer is thought of as a multi-step disease, largely based on accumulation of genetic abnormalities, such as amplifications, mutations and deletions, leading to gain-of-function of oncogenes, or loss-of-function of tumor suppressor genes ${ }^{1}$. In recent years it has become evident that not only changes at the genomic level but also at the epigenomic level contribute to cancer development. It is now clear that abnormal epigenetic regulation may act as an alternative mechanism for, e.g., loss of tumor suppressor function in cancer cells. One of the best-known examples is the inactivation of tumor suppressor genes, such as $p 16^{\mathrm{INK} 4 \mathrm{~A}}$ and BRCA1, by DNA methylation ${ }^{2}$. In this way, DNA-methylation-dependent gene silencing contributes to biallelic loss of tumor suppressor function, as proposed in the "two-hit" model, by Knudson ${ }^{3}$. Processes or proteins that orchestrate epigenetic regulation may affect expression or regulation of tumor suppressor or oncogenes, and in doing so contribute to tumorigenesis. In this chapter, we specifically focus on a group of epigenetic regulators, the Polycomb group proteins and their role in normal development and in tumorigenesis.

\section{PcG introduction}

Epigenetic regulation of gene expression in essence centers on processes that modify chromatin structure (Box 2.1). Epigenetic chromatin remodeling may take place at any higher-order chromatin structure level (i.e., ranging from posttranslational changes on nucleosomes to chromatin compaction levels beyond the $30 \mathrm{~nm}$ solenoid fiber). As all DNA-templated processes require modification of chromatin structure in order to allow access to DNA, the epigenetic mechanisms that regulate DNA access and gene expression are pivotal to maintenance of cell identity throughout differentiation and hence normal development. PcG proteins play a key role in the maintenance of gene silencing patterns, whereas their biological counterparts, the trithorax Group (trxG) proteins, generally are or associate with transcription activators ${ }^{4}$. PcG proteins were first identified as repressors of Hox genes in Drosophila melanogaster. The descriptive name Polycomb derives from a class of homeotic phenotypes in the fruit fly, which have the common property of determining the number or positioning of a structure called the sex comb, of which male flies normally have only one on each front leg. The phenotypic characteristics of fly extremities (e.g., antennae, legs, wings, halteres) and their positioning (i.e., anteroposterior (A-P) axial patterning) are controlled by the homeotic complex of genes $(\mathrm{HOM}-\mathrm{C})^{5,6}$. An oversimplified delineation of HOM-C dependent A-P patterning argues that segment/extremity identity is determined by the 
combination of HOM-C genes active in any given A-P position. The fly HOM-C genes are structurally conserved throughout evolution. In addition, the organization of HOM-C is conserved from primitive chordates to humans, as is the co-linear regulation of HOM-C gene expression ${ }^{5}$. PcG proteins were identified as a HOM-C repressive activity almost 30 years $\mathrm{ago}^{7}$. Whereas initiation of silencing or activation is not dependent on PcG proteins, Drosophila PcG mutants typically mis-express specific HOM-C genes at later stages; this, combined with unaltered expression initiation of HOM-C genes in PcG-mutants led to the proposition that maintenance of HOM-C expression boundaries (i.e., silencing) was affected in these mutants. Also PcG and trxG proteins appeared conserved throughout evolution and even their antagonistic properties ${ }^{8,} 9$. Hence, it would seem likely that their regulatory function and mode of action on the mammalian Hox gene clusters (counterparts of the fly HOM-C) would also be conserved. Indeed Hox and PCG genes are involved in A-P axial patterning in vertebrates, exemplified by typical skeletal abnormalities in PcG mutant mice, which are accompanied by defective maintenance of Hox-gene expression boundaries $^{10,11}$. Also it is now clear that besides Hox genes, PcG proteins repress many other genes, among which genes that are directly relevant for cell proliferation and survival, and thus oncogenesis. Relevantly, the first mammalian PcG gene, BMI1, was identified as an oncogene in a murine model for oncogene cooperativity in leukemia ${ }^{12,13}$. Besides transcriptional regulation, PcG proteins are implicated in diverse biological processes, such as $\mathrm{X}$ inactivation, genomic imprinting, cell cycle regulation, and stem cell maintenance ${ }^{14-18}$. Some of these properties, when deregulated, are likely to contribute to tumorigenesis. Our understanding of the molecular details of PcG repression is still incomplete, however, in recent years our insight in the silencing mechanisms that PcG proteins impinge on has increased significantly.

\section{PcG biology}

\section{Mechanisms in PcG silencing}

We now know that PcG proteins function in large multi-protein complexes. PcG biochemistry appears highly conserved among fruit flies and higher eukaryotes, like mice and men. The two most studied Polycomb repressive complexes (PRCs) are PRC1 and $\mathrm{PRC}^{19,}{ }^{20}$. Reconstitution studies using recombinant proteins identified the core complex of Drosophila PRC1, which consists of Polycomb $(\mathrm{Pc})$, Polyhomeotic (Ph), Posterior sex combs (Psc), and dRing/Sex combs extra $(\mathrm{Sce})^{21-23}$. As was the case with evolutionary duplication of HOM-C between Drosophila and human (the human genome harbors four Hox gene clusters), mostly single fly PcG genes were also duplicated. Mammalian PRC1 genes comprise multiple orthologues of the Drosophila core components: HPC2 and 3, 
Box 2.1. Epigenetic mechanisms in gene expression

DNA, the macromolecule in which our genetic make-up is hardwired, is tightly packed inside the eukaryotic nucleus. This packing fits $2 \mathrm{~m}$ of DNA into a nucleus of approximately $2 \mathrm{~mm}$ in diameter. The macromolecular DNA/protein structure in which DNA is packed is called chromatin. The consequence of this packing is that DNA (genes) is not naked and therefore not freely accessible. For transcription factors and DNA-dependent RNA polymerases to access DNA, for example to activate gene expression, chromatin structure has to be remodeled. Thus, chromatin structure regulation is essential for many, if not all, important biological processes, which are DNA templated (e.g., DNA replication, transcription, recombination, repair, chromosome segregation). The direct consequence of chromatin packing is that expression of genes and genetic traits is not solely dependent on the genetic blueprint, as it is stored in the base pair sequence in the DNA. Complex eukaryotic cells have a second, epigenetic, layer of control on top of the genetic blue print; access to DNA (i.e., expression of genetic traits) is controlled by chromatin structure modification: whether a gene is used or not is what matters. Epigenetic regulation explains cellular diversity in our body (despite genetically identical cells). Epigenetics is also what makes genetically identical monozygotic twins different in terms of susceptibility to disease (i.e., neurological, cancer, metabolic disorders). Evidence is accumulating that epigenetic information is also heritable, and that epigenetic inheritance may even contribute to heritable, multifactorial disease. Epigenetic regulation of gene expression occurs at least at three macromolecular levels: (1) at the DNA level-covalent modification of DNA by coupling methyl-groups to specific nucleotides in DNA (2) at the RNA level-noncoding RNAs may either target genes or mRNAs, and directly regulate their expression, and (3) at the protein level, for instance by covalent modification of the $\mathrm{N}$-terminal tails of histone proteins. DNA is wrapped almost twice around a nucleosome, an octamer of four different histone proteins. The protruding $\mathrm{N}$-terminal histone tails are accessible to many regulatory proteins. Depending on the modification (i.e., metyl, acetyl, phosphoryl, ubiquityl groups), novel protein binding sites are generated and protein complexes are recruited that either open-up chromatin or compact its structure. Combined, these histone-tail modifications function as an epigenetic register. The epigenetic register is "written" by histone-modifying enzymes. Many proteins have been identified which can "read" the register and thereby become recruited to chromatin to write additional modifications or change its configuration. Many histone-modifying complexes combine writing and reading properties. Recent studies suggest that at least some of these histone-tail-marks recruit nucleosome-remodeling machineries. For a gene to become transcriptionally active, RNA-polymerase has to gain access to the naked DNA. For this to occur, nucleosomes are quite literally moved aside, by ATP-dependent nucleosome remodeling machineries, to bear the DNA elements required for binding, and transcription initiation. Gene silencing reverses most of these processes.

$\mathrm{HPH} 1,2$, and 3, BMI1, and RING1A and RING1B/RNF2, respectively (Box 2.2) ${ }^{24}$. Biochemical purification of Drosophila PRC2 members identified Enhancer of zeste $(E(z))$, Extra sex combs (ESC), and Suppressor of zeste-12 (Su(z)12) as the main core complex members ${ }^{25}$. The mammalian orthologues of PRC2 are EZH2, EED, and SUZ12. As PCG proteins are equipped with multiple protein-interaction domains, and many if not all mammalian homologues are known to homo- or heterodimerize, many different protein-protein binding modalities are expected to contribute to complex composition and diversity. Several observations suggest that also spatio-temporal expression patterns of PcG proteins may not 
only determine PcG complex composition but also allow composition to change throughout development [20]. Studies of early fly development suggest that the PRC2 complex initiates PCG-mediated repression. The most compelling evidence for this is provided by temporally restricted sequential expression patterns of the fly PRC2 and PRC1 complexes, respectively ${ }^{26-28}$. One study revealed a transient physical interaction between PRC2 and PRC1 complexes, which was interpreted as perhaps being required to transfer PcG-mediated transcriptional silencing from initiation to maintenance state $^{29}$. Mammalian PcG complex collaboration may not be entirely similar, yet a sequential collaborative action was suggested by recent biochemical studies. EZH2 contains histone methyl transferase (HMT) activity within its SET domain, which mediates methylation of other proteins. Drosophila $\mathrm{E}(\mathrm{z})$ and its mammalian orthologue $\mathrm{EZH} 2$ specifically trimethylate histone $\mathrm{H} 3$ on lysine $\mathrm{K} 27$ (H3K27me3) and, to a lesser extent, lysine 9 (H3K9me3) ${ }^{25}, 30-32$. EZH2 thus writes the epigenetic register (Box 2.1). Other PRC2 proteins read epigenetic markings on other histones. As WD40 domains have been implicated in binding specific histone methyl-lysine marks in other proteins $^{33-35}$, EED may likewise read specific methylated histone marks via its WD40 repeat and contribute to sequential recruitment of other histonemodifying enzymes and, as such, provide additional regulation ${ }^{33}$. The H3K27me3 mark is a PcG-associated silencing mark, as it recruits the PRC1 maintenance complex via binding of the chromodomain of the Drosophila Pc protein ${ }^{36,37}$. Crystallography studies have provided compelling evidence for a differential fit of the H3K9me3 and H3K27me3 in the chromodomains of HP1 and Pc, respectively ${ }^{36,37}$. This represents a functional biochemical bridging mechanism between PRC2 and PRC1 complexes. Biochemical interactions and repressive mechanisms in mammalian systems are assumed to function similarly to some extent (based in part on experimental data, in part on inference), in that the SET domain HMTases Ezh1/2 write an epigenetic H3K27me3 mark, to which mammalian Pc orthologs HPc2/3 and possibly other CBXs are recruited ${ }^{19,}{ }^{38}$. Recent studies suggest, however, that the H3K27me3 mark by itself may not be sufficient for HPC2 recruitment, as RNF2 depletion also disrupts HPC2 chromatin binding, whereas the H3K27me3 motif remains ${ }^{39}$. HPC2 itself is a SUMO-E3 ligase, which sumoylates transcription factors and, as such, may provide additional regulation ${ }^{40,41}$. RING finger domain proteins within PRC1 may all be E3 ubiquitin ligases, yet so far only RNF2 was show to be responsible for histone $\mathrm{H} 2 \mathrm{~A}$ monoubiquitylation of K119 (H2AK119ub1) ${ }^{39,42,43}$. Although its exact enzymatic substrate is currently not known, BMI1-association somehow stimulates the E3 ligase activity of RNF2 toward $\mathrm{H}_{2} \mathrm{~A}^{44,45}$. In addition, recent studies of X-inactivation revealed that RNF2 is recruited to and marks nucleosomes on the inactivated $X$-chromosome in female cells, independent of prior PRC2 activity ${ }^{46}$. Clearly, the above studies have only just begun to unravel 
the complexity and multiple layers of regulation of PcG repressive activity. Finally, PRC complexes also associate with other chromatin-modifying enzymes (Box 2.2). The EED protein interacts with histone deacetylases (HDACs) and deubiquitinases (DUBs), and HPC2 brings HMT SUV39H1 activity to local chromatin, which may help silencing marks spread-out over regulatory and into coding sequences ${ }^{33,47,48}$. EZH2 recruits DNA methyltransferases (DNMTs) to specific target genes, suggesting intersection of epigenetic mechanisms at the chromatin level, which may ultimately serve to stabilize repression ${ }^{49,}{ }^{50}$. Two PRC2-like complexes were identified recently, termed PRC3 and PRC4, which incorporate different EED isoforms (RNA splice variants) ${ }^{51,52}$. These isoforms were suggested to differentially target HMT activity toward histone H3K27me or histone $\mathrm{H} 1 \mathrm{~K} 26 \mathrm{me}^{51}$, although other studies found no support for such concept $^{53}$. PcG expression may also influence complex composition through mechanisms other than spatio-temporal presence of complex members: PRC4 is formed when EZH2 is overexpressed in cultured cells and it comprises the NAD ${ }^{+}$dependent histone deacetylase SirT1 and EED-isoform 2. PRC4 appears preferentially expressed in cancer and undifferentiated embryonic stem (ES) cells $s^{52}$.

Recently, a third PRC complex, Pleiohomeotic (Pho) repressive complex (PhoRC) has been identified in Drosophila ${ }^{54}$. It contains Pho and the SFMBT protein $(\mathrm{Scm}$ related gene containing four malignant brain tumor domains). Pho is one of the two PcG proteins, together with pleiohomeotic-like (Phol) that has sequencespecific DNA-binding properties ${ }^{55-57}$. The MBT repeats of SFMBT bind mono- and dimethylated $\mathrm{H} 3-\mathrm{K} 9$ and $\mathrm{H} 4-\mathrm{K}_{2} \mathrm{O}^{54}$. So far, the only mammalian orthologue with apparent direct DNA-binding activity is YY1. YY1 interacts with both PRC2 and PRC1 complexes ${ }^{58,}{ }^{59}$. Whether this dual interaction acts in integrating or bridging silencing by PRC2 and PRC1 is still speculative.

\section{PcG-mediated higher-order chromatin structure remodeling}

The PRC1 complex inhibits chromatin remodeling and transcription in vitro ${ }^{21,23,}$ 24,60 . In addition, a reconstituted PRC1 core complex induced in vitro compaction of nucleosomal arrays ${ }^{61}$. Although EEDs' ability to target PRC2-HMT activity to linker histone $\mathrm{H} 1$ may point to a possible involvement in higher-order remodeling, there is to date no in vivo data that suggests PcG binding leads to transcriptional silencing by higher-order chromatin compaction. In $D$. melanogaster elements have been identified in regulatory regions of PcG target genes (i.a. HOX genes) that are necessary for PcG-mediated silencing, termed Polycomb response elements or PREs. PREs are cis-acting elements typically several hundred base pairs in size. Although there is apparent variation between PREs in sequence, size, or distance from possible PcG-target genes, they share 
the functional characteristic that they confer PcG-responsiveness on transgenes ${ }^{62}$. Multiple studies have concentrated on the role of PREs in PcGmediated silencing. Strangely, PREs appear to be nearly void of nucleosomes and hence of PcG-mediated trimethyl marks ${ }^{62,63}$. Recent insights may, however, have uncovered a mechanistic role for PREs in PcG-dependent silencing in the fly: the PhoRC complex is recruited to PREs, via DNA consensus recognition; Pho biochemically interacts with PRC2 and PRC1 ${ }^{64}$. The PRC2 complex mediates trimethylation of $\mathrm{H} 3 \mathrm{~K} 27$ and $\mathrm{H} 3 \mathrm{~K} 9$ in upstream regulatory regions, the promoter region and in the coding region of target genes. This in turn would recruit PRC1 complexes via chromodomain binding; via recruitment of yet additional HMTase activity, PcG-dependent silencing would spread over larger chromatin areas ${ }^{63-66}$. The Pho-PRC2 interaction at PREs may provide PREs with the capacity to function as cis- or trans-acting repressive nucleation sites for adjacent or remote

\begin{tabular}{|c|c|c|c|c|}
\hline $\begin{array}{l}\text { PcG } \\
\text { complex }\end{array}$ & Drosophila & Human & $\begin{array}{l}\text { Protein } \\
\text { domains }\end{array}$ & Biochemical activity \\
\hline \multirow[t]{4}{*}{ PRC2 } & \multirow[t]{2}{*}{$E(z)$} & EZH1 & \multirow[t]{2}{*}{ SET } & \multirow{2}{*}{$\begin{array}{l}\text { Histone methyl } \\
\text { transferase for H3K27 }\end{array}$} \\
\hline & & EZH2 & & \\
\hline & Esc & EED & WD40 & \multirow[t]{2}{*}{$\begin{array}{l}\text { Cofactor for } \mathrm{E}(\mathrm{z}) \text {; methyl- } \\
\text { lysine binding motif? }\end{array}$} \\
\hline & $\operatorname{Su}(z) 12$ & SUZ12 & Zinc-finger & \\
\hline \multirow[t]{12}{*}{ PRC1 } & \multirow[t]{5}{*}{$\mathrm{Pc}$} & $\mathrm{CBX2/HPC1}$ & \multirow[t]{5}{*}{ Chromodomain } & \multirow{5}{*}{$\begin{array}{l}\text { HPc2: binding to } \\
\text { H3K27me3, RNA binding, } \\
\text { Sumo-E3 ligase }\end{array}$} \\
\hline & & $\mathrm{CBX} 4 / \mathrm{HPC2}$ & & \\
\hline & & CBX6 & & \\
\hline & & CBX7 & & \\
\hline & & CBX8/HPC3 & & \\
\hline & \multirow[t]{3}{*}{$\mathrm{Ph}$} & HPH1/EDR1/PHC1 & \multirow[t]{3}{*}{ SAM } & \multirow[t]{3}{*}{ Currently unknown } \\
\hline & & HPH2/EDR2/PHC2 & & \\
\hline & & HPH3/EDR3/PHC3 & & \\
\hline & \multirow[t]{2}{*}{ Sce/dRing } & RING1/RNF1/RING1A & \multirow[t]{2}{*}{ RING-finger } & \multirow{2}{*}{$\begin{array}{l}\text { E3 Ubiquitin ligase for } \\
\text { H2AK119 }\end{array}$} \\
\hline & & RNF2/RING1B/RING2 & & \\
\hline & \multirow[t]{2}{*}{ Psc } & BMI1/PCGF4 /RNF51 & \multirow[t]{2}{*}{ RING-finger } & \multirow{2}{*}{$\begin{array}{l}\text { Cofactor for } \\
\text { RING proteins }\end{array}$} \\
\hline & & PCGF2/RNF110/MEL18 & & \\
\hline PhoRC & Pho & YY1 & Zinc-finger & $\begin{array}{l}\text { Sequence specific DNA } \\
\text { binding }\end{array}$ \\
\hline \multicolumn{5}{|c|}{$\begin{array}{l}\text { Due to the large number of PCG orthologues, this table is limited to core complex members. } \\
\text { Gene names according to HUGO gene nomenclature are shown in bold. BMI, B lymphoma mo- } \\
\text { MLV insertion region; CBX, chromobox homologue; EDR, early development regulator; EED, } \\
\text { embryonic ectoderm development; ESC, extra sex combs; E(z), enhancer of zeste; HPC, homolog } \\
\text { of polycomb; HPH, homolog of polyhomeotic; Pc, polycomb; PCGF, polycomb group ring finger; } \\
\text { Ph, polyhomeotic; PHC, polyhomeotic-like; Pho, pleiohomeotic; Psc, posterior sex combs; RING, } \\
\text { really interesting new gene; RNF, ring finger protein; SAM, self association motif; Sce, sex combs } \\
\text { extra; Su(z), suppressor of zeste; YY, yin-yang transcription factor. }\end{array}$} \\
\hline
\end{tabular}




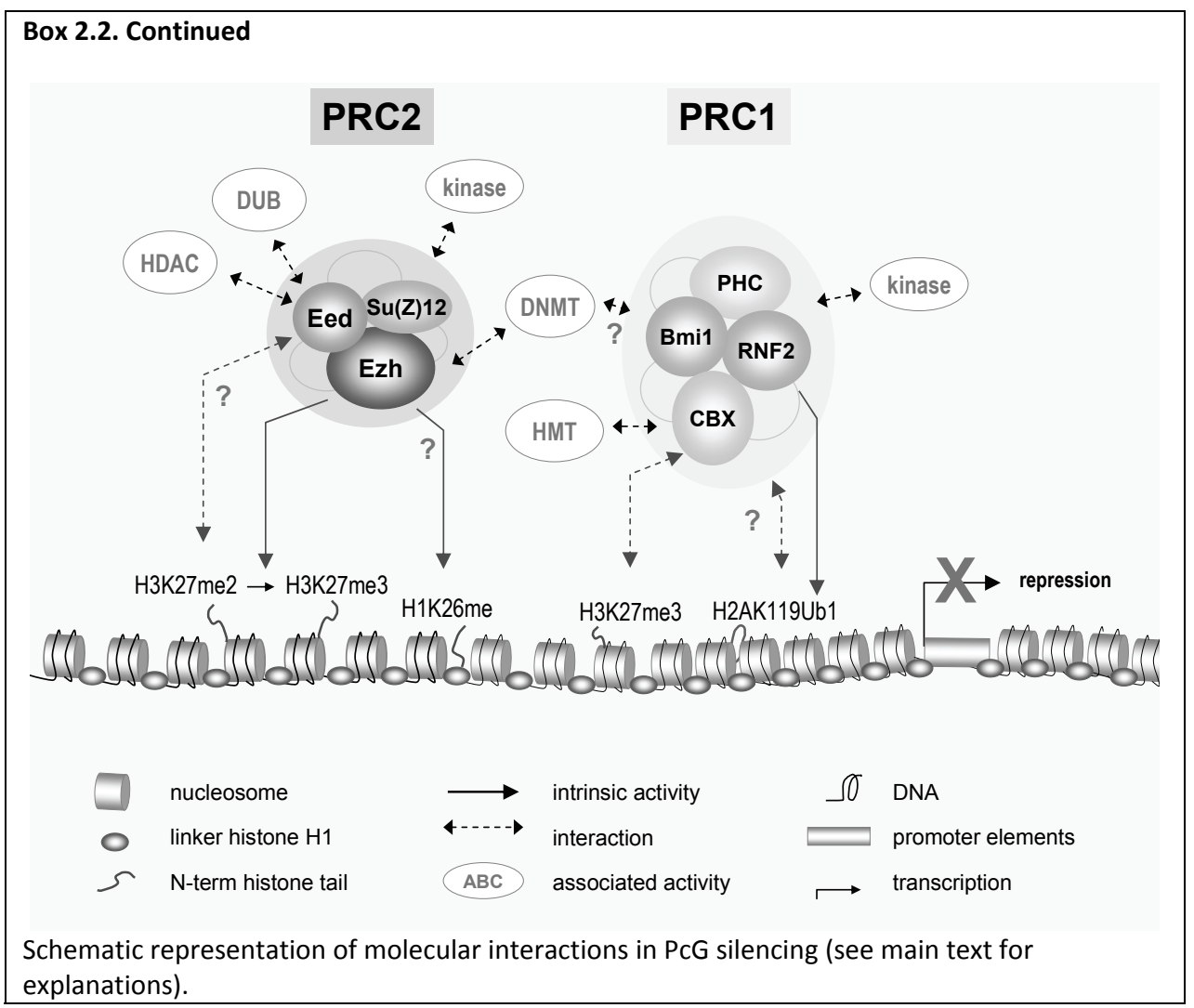

promoters. This mode of action would show resemblance to Sir proteinmediated telomere-proximity silencing in yeast ${ }^{63,67,68}$. Paradoxically, many active promoters in Drosophila appear "preoccupied" with Pc, as if on standby, waiting on other local epigenetic events that signal (progressive) silencing; indeed many Drosophila PRE and promoters simultaneously bind PcG and trxG proteins, in support of this "bivalent standby" notion ${ }^{66,69}$. Indeed the presence of the trxG protein Ash1 within the promoter and coding regions of a transcriptionally active Ubx locus (one of Drosophila's HOM-C clusters) correlates with loss of $\mathrm{H} 3 \mathrm{~K} 27, \mathrm{H} 3 \mathrm{~K} 9$, and H4K2O methylation marks and suggest a model in which recruitment of trxG proteins prevents silencing ${ }^{66}$. To date, no mammalian PREs have been identified. However, recent studies have revealed highly conserved noncoding elements (HCNE) in higher eukaryotes, which display specific PCG protein association and may orchestrate PcG-dependence in regulation of developmental programs ${ }^{70}$. The epigenetic indexing on and around these HCNEs is peculiar in that it contains both activating and inactivating histone modifications (e.g., $\mathrm{H} 3 \mathrm{~K} 4 \mathrm{me} 3 / \mathrm{H} 3 \mathrm{~K} 27 \mathrm{me} 3$ ), and hence represent "bivalently" marked nuclear elements (see below). These findings are 
supported by reports that H3K27me3-marking does not necessarily correlate with transcriptional silencing but rather precedes silencing ${ }^{71}$. ${ }^{72}$. A somewhat antiquated model suggested PcG-mediated silencing involved sterical blockage of DNA-access for transcription factors; recent insights, however, have superseded this view and suggest a role in interference with events that either control pre-initiation complex formation and transcription initiation, despite transcription machinery recruitment and elongation processes ${ }^{62,66,73}$. Recent technological advances have enabled us to directly examine PcG and trxG occupation around and within genes and interrogate epigenetic marking and promoter occupation, PcG complex composition and other relevant aspects of chromatin mediated silencing. Although PcG-mediated transcriptional silencing already appears a much more complex process than anticipated, ongoing studies will help refine positioning of PcG function in the proper cellular context.

\section{PcG in stem cells and differentiation}

Stem cells have two key properties: the ability to self-renew and the ability to differentiate along any given differentiation program. Through asymmetric division, a dividing stem cell will give rise to one new stem cell and one cell that will differentiate into a mature cell of a certain lineage. Two main categories of mammalian stem cells are ES cells and adult stem cells. ES cells are pluripotent, which refers to their capacity to differentiate into any cell type of the adult organism. Adult stem cells, such as hematopoietic stem cells, in contrast, are restricted in their differentiation range. PcG proteins are involved in the maintenance of embryonic and adult stem cells ${ }^{18,74}$. In adult stem cells PcG proteins regulate self-renewal of hematopoietic and neuronal stem cells. BMI1, RAE28/MPH1, and EZH2 all have a role in murine hematopoietic stem cell (HSC) selfrenewal. HSCs have the capacity to regenerate fully functional bone marrow, as illustrated by serial transplantation experiments with limited numbers of cells in mice. Both BMI1 and RAE28/MPH1 deficient HSCs are defective in their proliferative and self-renewal capacity, whereas EZH2 overexpression in HSCs prevents hematopoietic stem cell exhaustion ${ }^{75-79}$. BMI1 is also required for the self-renewal of stem cells in the peripheral and central nervous systems ${ }^{80}$. The dependence of self-renewal of these stem cells on BMI1 is believed to contribute to the murine $\mathrm{BMI}^{--}$phenotype; besides skeletal transformations, mice show a gradual depletion of progenitor and mature cells in haematopoietic and neural lineages ${ }^{81}$. The observation that EZH2 deficient ES cells cannot be established in vitro, indicates involvement of PCG in ES cell biology ${ }^{82}$. Functional PcG gene ablation studies in mice show that EZH2, EED, SUZ12, and RNF2 are essential for early embryonic development ${ }^{82-85}$. Even though both $\mathrm{EED}^{-1-}$ and $\mathrm{SUZ}_{12}{ }^{--}$ES cells can be established in tissue culture, they display aberrant activation of differentiation specific genes ${ }^{86,87}$. For a long time we have known 
that PcG proteins repress Hox clusters. Due to their involvement in diverse biological processes, it was expected that PcG proteins bind to and repress many other genes in addition to HOX genes. A number of studies have recently identified genome-wide binding patterns for PcG proteins in human, mouse, and Drosophila cells ${ }^{70,87-92}$. Indeed, in all organisms PcG proteins target a large number of loci. Most PcG target genes, as studied in human embryonic fibroblasts and both human and mouse ES cells, constitute developmental regulators ${ }^{87-89}$. Among the PcG target genes transcription factors and components of signaling pathways are highly represented. Transcription factor PcG target genes include homeodomain genes of the Dlx, Irx, Lhx, and Pax gene families, and FOX, SOX, and TBX gene families, which all control differentiation. Signaling pathways, identified as PcG-regulated, include Wnt, Hedgehog, Notch, TGF-b, FGF, and BMP signaling. Differentiation activates some of these signaling pathways, which corresponds to decreased H3K27me3 and PCG binding at the PcG target genes that regulate the specific developmental process ${ }^{70,87-89,} 93$. Recent studies have focused on identifying molecular signatures for pluripotency ${ }^{94}$. In ES cells many promoters of developmental regulators are occupied by the transcription factors OCT4, SOX2, and NANOG, all key factors in maintaining ES cell pluripotency ${ }^{95}$. Interestingly, almost all repressed developmental regulators that are occupied by OCT4, SOX2, and NANOG are cooccupied by PcG proteins ${ }^{89}$. Many nontranscribed genes in ES cells have a bivalent chromatin state, harboring both H3K4me3 (catalyzed by trxG proteins) and H3K27me3 epigenetic marks (a PRC2-installed mark), normally associated with gene transcription and gene repression, respectively. Many of these bivalently marked regulatory regions occur in CpG-rich promoters, which in turn are often found in genes expressed during embryogenesis and in "housekeeping" genes ${ }^{70,} 71,93$. Housekeeping genes are, however, mostly marked with $\mathrm{H} 3 \mathrm{~K} 4 \mathrm{me} 3$ only (i.e., void of PRC-association) and their transcriptional status is mostly "on." Bivalent marking is thought to keep developmental control genes (e.g., key developmental factors, morphogens, surface molecules, microRNAs) transcriptionally silent in ES cells, while preserving their potential to become activated upon lineage commitment and during differentiation ${ }^{70,71,93}$. So PcG proteins occupy a set of developmental genes in ES cells that need to be repressed to maintain pluripotency and that are poised for activation during ES cell differentiation. A model of PCG protein functioning during differentiation, which is gaining acceptance and support by empirical observation, is that in undifferentiated cells PcG proteins activate and maintain gene repression by instating and binding to H3K27me3 marks. Upon lineage commitment or during differentiation, PcG proteins are displaced from critical developmental control genes by as yet unidentified mechanisms. These genes will now become actively transcribed; corresponding regulatory regions 
will lose their bivalent marking; lineage "nonrelevant" developmental genes will lose their activating marks (i.e., H3K4me3) and will become truly PcG-repressed targets; a third class of high $\mathrm{CpG}$-content promoters loses both me3 marks; these will eventually be shut-down transcriptionally. Despite this emerging modus operandi many questions remain. Several studies have reported that transcriptional activity is lost upon loss of Polycomb function or that transcription occurs, despite PRC-occupance, suggesting involvement of other spatio-temporal factors or aspects of chromatin status ${ }^{71,96-98}$. In addition, some PcG proteins may harbor as of yet unknown biochemical activity which may not be directly linked to epigenetic indexing of genes; in breast cancer cells, Ezh2 appears to transactivate gene expression in estrogen and Wnt signaling pathways in a SET domain independent manner ${ }^{99}$. Combined, these findings clearly stress that PcG-mediated repression is controlled by mechanisms currently far from completely understood. Delineation of chromatin contexts, identification of interaction partners, and associated enzymatic activity in a cell context-dependent manner will undoubtedly help further our understanding of the molecular nature of PcG-mediated processes.

\section{PcG regulation}

Signaling molecules in cancer pathways often comprise both oncogenic as well as tumor suppressive activity. Knowing the biochemical relationships between signaling proteins and their regulation is crucial for our understanding of how mutations in these gene products contribute to cancer and how oncogenesis signaling may be averted. Regulation of PcG function is currently poorly understood. Several levels of regulation may be anticipated: transcriptional, posttranscriptional, translational and posttranslational. Very little is known about transcriptional regulation of PcG genes themselves. A number of reports address possible pathways and transcription factors that control expression of specific PcG genes ${ }^{98,100-102}$. Some of these proteins are known to be involved in cancer as well and may therefore be involved in exposing tumorigenic properties of PcG proteins. Activated JNK signaling in Drosophila during transdetermination of imaginal discs (larval structures that form extremities) leads to downregulation of PcG genes ${ }^{103}$. Studies in the flies and mammalian systems also indicate that expression of PcG genes is dependent on PcG proteins ${ }^{88,104-106}$. Changes in cellular expression levels may drive differential PcG complex composition, consequently overexpression of particular PcG proteins in cancer may contribute to tumorigenesis. At the posttranscriptional level, i.e., mRNA processing, stability or translation, virtually nothing is known about PcG mRNA regulation. Interestingly though, genetic ablation of Sf3b1, a factor involved in mRNA splicing, evokes a Polycomb phenotype in mice, suggesting a connection with either translation of PcG proteins or their targets ${ }^{9}$. Also TrxG members 
have been associated with RNA processing: the association of the SWI/SNFprotein $\mathrm{Brm}$ with snRNAs and spliceosome factors and the observation that loss of Brm function affects mRNA elongation and inclusion of variant exons, suggests a direct role in RNA-splicing and possibly points toward a more fundamental role of PcG and trxG proteins in chromatin structure dependent processes ${ }^{107}$. Regulation of PcG function at the posttranslational level is slowly emerging. As discussed in the preceding paragraphs, PcG complex composition varies between cell types and over time (hematopoiesis). A little over a decade ago, large, functionally distinct complexes, like PcG or trxG complexes, which shared conserved interaction modules and other domains, were tentatively viewed as large bulky multiprotein masses that modified chromatin structure at least in part by binding and physically interfering with accessibility. As we begin to uncover and understand more about the properties of individual PcG proteins, it is now clear that many PcG proteins have specific catalytic or binding activities, relevant to epigenetic regulation. Studies on their posttranslational regulation are slowly emerging, but our knowledge on PcG-regulation is of yet far from complete. Several PcG proteins are regulated by posttranslational modification. Self-ubiquitylation of RNF2 is required to monoubiquitylate $\mathrm{H} 2 \mathrm{~A}$ at lysine 119, which in turn is required for PRC1 repression ${ }^{39,108}$. RNF2 and BMI1 are both ubiquitylated by an as of yet unknown E3 ligase; this results in their proteolytic breakdown ${ }^{108}$. As RNF2 and BMI1 are often found overexpressed in cancers, abnormal ubiquitylation is likely to contribute to tumorigenic processes. EZH2 is phosphorylated by AKT, which controls survival signaling in cells $^{109}$. Although EZH2 overexpression marks malignant progression in some tumors, paradoxically, the tumorigenic action of EZH2 may not solely depend on its chromatin repressive properties, as phosphorylation by AKT inhibits its HMTactivity by impeding $\mathrm{H} 3$ binding ${ }^{109}$. Two recent mass spectrometric studies identified kinase activity associated with PRC1 complex members CBX8 and RNF2 ${ }^{110,111}$. In addition, a recent study identified the PRC1 complex as targets of canonical MAPK signaling pathways, and identified MAPKAPKs as interaction partners of the PcG complexes ( ${ }^{112}$, see Chapter 4 of this thesis). Relevantly, phosphorylation of PRC1 correlates with chromatin dissociation, and activation of repressed tumor suppressors ${ }^{112}$. Although the above observations suggest a link between tumorigenic pathways and regulation of PcG function, clearly much work remains to fully understand the significance of these connections with cancer, and whether or not these regulatory processes provide entries for therapeutic applications. 


\section{Cross-talk between PcG and other epigenetic mechanisms}

Several levels of epigenetic regulation exist. At its most fundamental level, epigenetic regulation of gene expression occurs at the level of DNA (e.g., DNA methylation), RNA (e.g., RNA interference) and at the protein level (e.g., histone modifications; chromatin structure; Box 2.1). Recent epigenetic studies suggest cross-talk between these processes. PcG function most directly impinges on epigenetic regulation at the protein level. However, several reports indicate that epigenetic mechanisms involving DNA and RNA may intersect with PcGmediated epigenetics. In Arabidopsis and C. elegans RNA interference is defective in a PcG mutant background ${ }^{113-115}$. In Drosophila PcG-chromatin association and silencing is dependent on components of the RNAi machinery ${ }^{116}$. Chromodomains, which are also used by PCG CBX proteins (Box 2.2), are RNA binding moieties; chromatin association of HP1, a structural relative (chromodomain protein which binds H3K9me3) of the PcG CBX proteins, is dependent on RNA components ${ }^{117-119}$. X-inactivation is dependent on coating of the inactive $X$ chromosome with a noncoding RNA, Xist, which is at least in part responsible for recruitment of $\mathrm{PRC1}^{46}$. At the DNA-methylation level, several observations suggest a direct link with PcG-mediated silencing: EZH2 binds directly to DNMTs (de novo DNA methyl transferases) and DNA methylation at EZH2 target genes is dependent on $\mathrm{EZH} 2^{50}$. Notably, PcG target genes are up to 12 times more likely to have cancer-specific promoter DNA hypermethylation than nontargets ${ }^{120,}{ }^{121}$. RNA, DNA, and protein-mediated epigenetic repressive mechanisms have all been implicated in cancer; therefore these biochemical connections are likely to become increasingly relevant for our understanding of tumorigenic processes and treatment options.

\section{PcG in cancer}

Cancer is also an epigenetic disease. It is well established that tumorigenesis is accompanied by global hypomethylation of DNA at CpG dinucleotide sequences, and local hypermethylation at CpG-islands. Loss or mutation of tumor suppressor genes is one of the hallmarks of cancer; tumor suppressors are also targets of aberrant DNA methylation in cancers ${ }^{1,2,122}$. The first indication that PcG proteins are involved in tumorigenesis came from studies that searched for oncogenes that cooperated with c-Myc in lymphomagenesis. In this way the $B M I 1$ gene (B lymphoma Mo-MLV Insertion region 1 ) was identified as an oncogene ${ }^{12,13}$. Subsequently, the murine knock-out model revealed an inverse correlation between BMI1 expression and INK4A/ARF expression ${ }^{123}$. INK4A/ARF encodes two cell cycle inhibitory proteins, P16 ${ }^{\text {INK4A }}$ and P14 ${ }^{\text {ARF }}$ ( $\mathrm{p} 19^{\text {Arf }}$ in mice) $)^{123}$, that regulate the PRb and TP53 pathways, respectively (Box 2.3) ${ }^{124} \cdot \mathrm{P} 16^{\mathrm{INK} 4 \mathrm{~A}}$ is a cyclin-dependent kinase inhibitor (CKI), which inhibits cyclinD-CDK4/6-mediated 
phosphorylation of $\mathrm{PRb}$, whereas $\mathrm{P} 14^{\mathrm{ARF}}$ inhibits interaction between MDM2 and TP53, thereby stabilizing TP53. BMI1's ability to downregulate INK4A/ARF expression has obvious etiological consequences for tumorigenesis. Indeed this property provided an explanation for its cooperative oncogenic action with cMyc, as c-Myc-induced P14 ${ }^{A R F}$-dependent apoptosis was suppressed by BMI1, effectively favoring proliferation ${ }^{125}$. Although it is believed that overexpression of BMI1 may be functionally equivalent to loss of PRb and TP53, and therefore reflects distinctive tumor etiology, recent reports on simultaneous overexpression of P16INK4A as well as BMI1 in some tumors clearly suggests other relevant players ${ }^{126,127}$. Recent studies revealed an antagonistic action of MEL18 and BMI1 on AKT/PKB-activation, a known tumor promoting signal transduction molecule, suggesting multiple genetic interactions of PRC function and the PI3KAKT/mTOR pathway ${ }^{109,128}$. The intuitive notion that there must be many more oncogenic PcG targets is further supported by the recent identification of several thousand Polycomb targets in human fibroblasts ${ }^{88}$.

\footnotetext{
Box 2.3. Basic mechanisms in cancer

Cumulative scientific evidence over the last decades demonstrates that multiple steps are required for a normal cell, with a limited proliferative life span, to by-pass this limitation and eventually become a fully transformed cancerous cell. Proliferative longevity and controlled proliferation of human cells are kept in check by multiple so-called checkpoints. These checkpoints evaluate and integrate input from a myriad of pathways, which collectively provide crucial information on the cell and its relationship with its environment. This input includes replicative age of a cell, the presence of DNA damage, availability of nutrients, metabolic status, environmental cues important for cell cycle entry, arrest or exit, such as growth factor signaling-input, cell-cell, or cell-matrix contacts, etc. Checkpoints provide failsafe mechanisms to protect a cell from genome integrity breaches and unwarranted, potentially malignant proliferation. Inevitably, the outcome of checkpoint activation is cell cycle arrest/quiescence, senescence, or apoptosis. As a cancer becomes increasingly malignant, many of these checkpoints appear to have been compromised. Weinberg's Hallmarks of cancer describe a biologically defined set of common tumorigenic events which ultimately occur in most if not all cancers ${ }^{1}$. Human cells need to lose at least three checkpoints to gain proliferative immortality and require a fourth oncogenic event (e.g., activation of $\mathrm{H}$-RAS) to become fully transformed. A common property of many cancer cells is enhanced telomerase (hTERT) activity, which protects telomere repeats at the ends of chromosomes from further "erosion." Telomere length effectively mirrors replicative age and telomere erosion eventually leads to replicative senescence ${ }^{129}$. Senescence bypass is an important mechanism in the onset and development of cancer. Two tumor-suppressor pathways are pivotal in establishing arrest/quiescence, senescence, or apoptosis in response to many potentially dangerous situations (including nontelomeric signals) when left unchecked. These are the PRb and the TP53 pathways, which control cell cycle entry and progression. Loss or inactivation of PRb and TP53, or mutation of effector or affector molecules in the PRb and TP53 pathways are common to most cancers.

These same antitumor pathways, which control senescence in normal cells, also limit the life span of stem cells. Increasing scientific evidence supports the presence of cancer stem cells (CSC) in many different tumors. These CSC are held responsible for tumor maintenance,
} 


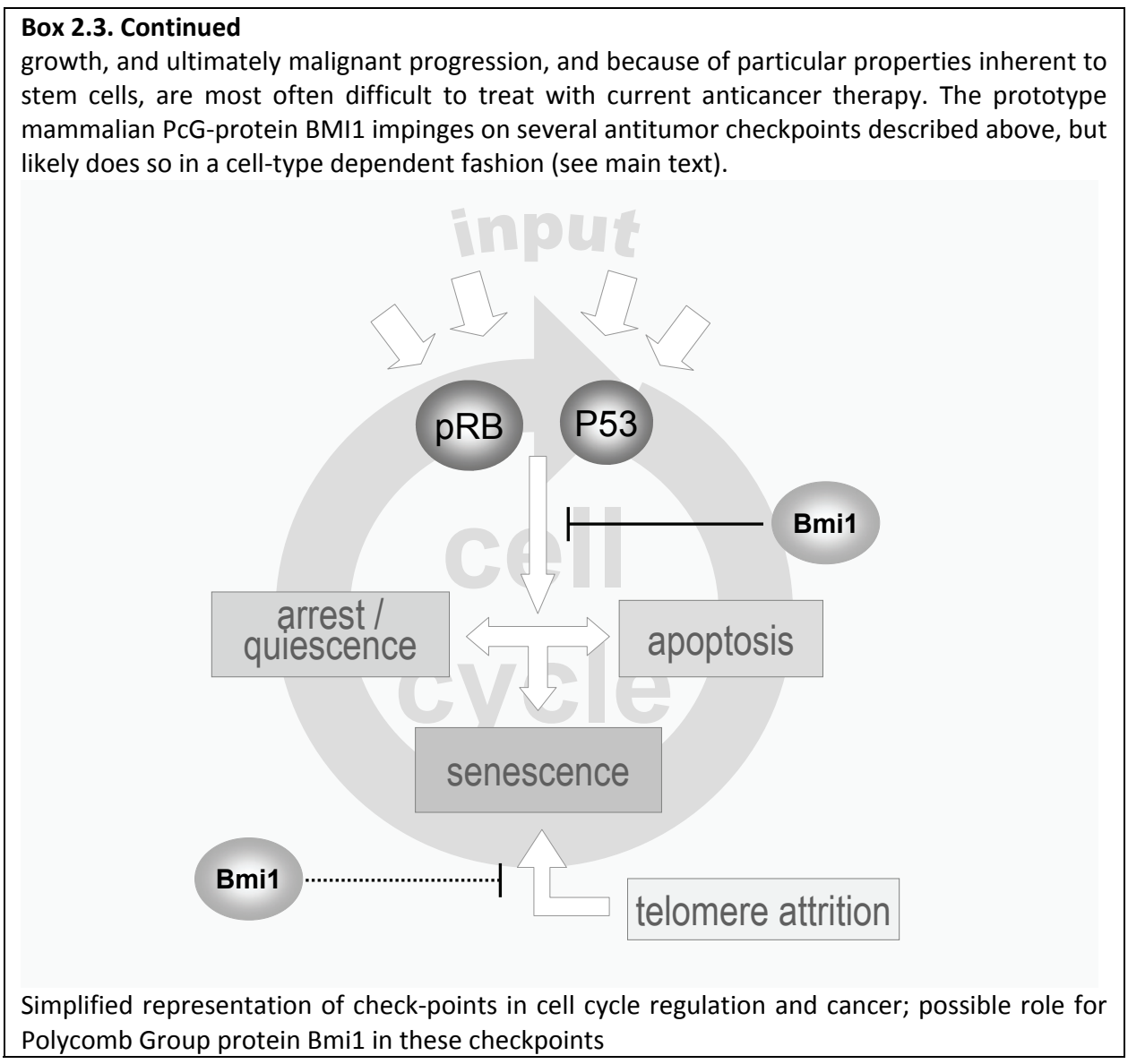

BMI1 is not the only PcG protein that has been linked to tumorigenesis. Since $\mathrm{EZH} 2$ was recognized as a marker for the progression of prostate cancer, it has been linked to a variety of other cancers, such as breast cancer and several lymphomas $^{130-135}$ (see Table 2.1). Although BMI1 and EZH2 have received most attention, a general notion of the tumorigenic potential of other PcG proteins is slowly emerging. The use of tissue microarrays to study PcG expression in normal and tumor tissues will greatly enhance our understanding of PcG in cancer ${ }^{136}$. This particular study analyzed PcG-expression immuno-histologically in different normal and tumor tissues; several tumors show very distinctive and sometimes unique PcG expression profiles, pointing to specific etiology. To fully understand the role of PcG in tumorigenesis, it will be crucial to chart all PcG proteins implicated in tumor development, and thoroughly examine their mode of action, cq their relative contribution to different types of cancer in years to come. Not only do PcG proteins appear overexpressed in various cancer types 
Chapter 2

Table 2.1 Deregulated PcG Expression in Human Cancers

\begin{tabular}{|c|c|c|c|}
\hline PcG complex & PcG Protein & Cancer type & References \\
\hline \multirow[t]{14}{*}{ PRC2 } & \multirow[t]{11}{*}{$\mathrm{EZH} 2$} & B-cell non-Hodgkin lymphoma & 137 \\
\hline & & Bladder & $138-140$ \\
\hline & & Breast & $130-133$ \\
\hline & & Colon & 141 \\
\hline & & Endometrium & 130 \\
\hline & & Hodgkin lymphoma & 134 \\
\hline & & Liver & 142 \\
\hline & & Mantle cell lymphoma & 135 \\
\hline & & Melanoma & 130 \\
\hline & & Prostate & $130,143-146$ \\
\hline & & Stomach & 147,148 \\
\hline & \multirow[t]{3}{*}{ SUZ12 } & Breast & 149 \\
\hline & & Colon & 149 \\
\hline & & Liver & 149 \\
\hline \multirow[t]{21}{*}{ PRC1 } & CBX7 & Follicular lymphoma & 150 \\
\hline & RING1 & Prostate & 146 \\
\hline & \multirow[t]{4}{*}{ RNF2 } & Colon & 136 \\
\hline & & Diffuse large B cell lymphoma & 136 \\
\hline & & Hodgkin lymphoma & 136 \\
\hline & & Stomach & 136 \\
\hline & \multirow[t]{14}{*}{ BMI1 } & B-cell non-Hodgkin lymphoma & 137 \\
\hline & & Breast & 151 \\
\hline & & Colon & 152 \\
\hline & & Diffuse large B cell lymphoma & 136,153 \\
\hline & & Hodgkin lymphoma & $134,136,154$ \\
\hline & & Leukaemia & 155 \\
\hline & & Mantle cell lymphoma & 136,156 \\
\hline & & Medulloblastoma & 102 \\
\hline & & Neuroblastoma & 157 \\
\hline & & Non-small cell lung cancer & 158 \\
\hline & & Oral squamous cell carcinoma & 159 \\
\hline & & Parathyroid adenoma & 136 \\
\hline & & Pituitary adenoma & 136 \\
\hline & & Prostate & 144,146 \\
\hline & PHC1 & Acute lymphoblastic leukaemia & 160 \\
\hline
\end{tabular}

but also expression is often correlated with specific aspects of tumor biology: a more progressive disease state, metastasis, and ultimately poor prognosis. In prostate cancer, EZH2 staining intensity increased from benign, prostatic atrophy, prostatic intraepithelial neoplasia, clinically localized prostate cancer to 
metastatic prostate cancer ${ }^{143}$. In this study, EZH2 expression was a better predictor of clinical outcome than surgical margin status, maximum tumor dimension, Gleason score, and preoperative PSA ${ }^{143}$. Indeed, malignant tumor progression could be mimicked in vitro by overexpression of EZH2. Thus EZH2 protein expression in prostate specimens may be a valuable prognostic marker. EZH2 overexpression is associated with a poor prognosis in prostate, breast, gastric, and colon cancers as is BMI1 overexpression in different leukaemia's ${ }^{132}$, $143,147,153,161$. Moreover, EZH2 was even upregulated in preneoplastic lesions in breast tissue ${ }^{162}$. In this respect EZH2 may help identify patients at risk for developing breast cancer ${ }^{163}$. Recently, microarray-based gene expression profiling was used to identify a death-from-cancer signature, which is partly based on BMI1- regulated genes and consists of 11 genes $^{164}$. A stem cell-like expression profile of this signature in primary tumors was a powerful predictor of a short interval to disease recurrence, distant metastasis, and death after therapy in 11 different cancer types ${ }^{164}$. Interestingly, EZH2 also embodies a direct bridge between epigenetic mechanisms at the protein level (histone-tail modifications) and the DNA level; recent reports provided experimental evidence for a biochemical and functional link between PcG-mediated silencing and DNA methylation at tumor suppressor genes, persuasively arguing that the PRC2 complex may contribute to carcinogenesis through disabling check-points by silencing tumor suppressor genes ${ }^{50,165}$. Although sparse information is available on overexpression of YY1 in human cancers, its positive association with DNA-repair and inverse correlation with cellular TP53 homeostasis suggests a potential oncogenic role for this PcG and trxG associated factor ${ }^{166,167}$. These observations together imply that screening for altered PcG expression in certain cancer types may in the near future enable physicians to more accurately predict prognosis and personalize patient treatment strategies.

\section{PcG and senescence}

Cellular senescence, an irreversible proliferative arrest, can be induced in vitro by diverse stresses, such as telomere shortening, DNA damage, and strong mitogenic signaling by activated oncogenes ${ }^{168,169}$. As cellular senescence limits the proliferative capacity of cells, bypass of senescence is an important step in tumorigenesis (Box 2.3). Senescence was recently shown to occur in vivo in premalignant or benign conditions ${ }^{170}$. Although diverse stimuli induce senescence, its regulation converges on the TP53 and PRb pathways. Recent studies advanced our knowledge of how PcG proteins regulate expression of the INK4A/ARF locus and senescence. Until recently, mechanistic insights in repression of the INK4A/ARF locus by PCG proteins as BMI1 and CBX7 was inferred from inverse correlation between PcG and INK4A/ARF expression ${ }^{123,171}$. However, chromatin immunoprecipitation (ChIP) experiments identified both 
PRC2 members, SUZ12 and EZH2, and PRC1 members, BMI1, CBX4, CBX7, CBX8, and RNF2 as direct interactors of the INK4A/ARF locus ${ }^{110,172,173}$. In senescing fibroblasts EZH2 expression was downregulated, which coincided with decreased H3K27me3 levels, BMI1 displacement and activation of P16 ${ }^{\text {INK4A }}$ transcription ${ }^{172}$. Thus, PCG binding to INK4A/ARF regulates senescence. Overexpression of the PCG proteins BMI1, CBX7, and CBX8 can overcome senescence ${ }^{110,123,171}$. CBX7 can promote proliferation in the absence of BMI1, whereas the function of CBX8 is dependent on BMI1, indicating that CBX7 might be part of PRC1 complexes that do not include BMI1 ${ }^{110,}{ }^{171}$. BMI1 is also implicated in a different mechanism of bypassing senescence. In human mammary epithelial cells (HMECs) overexpression of BMI1 led to activation of human telomerase reverse transcriptase (hTERT) transcription and induction of telomerase activity ${ }^{174}$. For now this has only been detected in HMECs, and does not appear to contribute to immortalization in human fibroblasts or in normal human oral keratinocytes ${ }^{175,176}$, and even so, telomere shortening does occur in BMI1-immortalized HMEC ${ }^{174}$. Clearly, PCG proteins regulate senescence via INK4A/ARF-dependent and independent mechanisms and they do so in a cell type-dependent fashion, presumably reflecting cell type-specific molecular networks and underlying epigenetic profiles and chromatin status. As PcG proteins are upregulated in many different cancers, it is tempting to speculate that PcG-mediated senescence bypass represents an early event in tumorigenesis.

\section{PcG and cancer stem cells}

Stem cells have also been detected in cancers, where they can give rise to more cancer stem cells (CSCs) and also nontumorigenic cancer cells ${ }^{177}$. This explains at least in part the heterogeneity often observed in tumors. The identification of cancer stem cells has direct implications for cancer treatment. As CSCs are emerging as the main driving tumorigenic entities, to treat cancer effectively, preferably CSCs should be targeted. Hence, it is crucial to understand the processes that define stem cellness, and the pathways or proteins that are deregulated in CSCs. PCG proteins are also implicated in the self-renewal of CSCs. In a recent study, $\mathrm{BMI}^{-1-}$ bone marrow cells were transduced to develop acute myeloid leukemia (AML). Importantly, primary recipients developed $A M L$, whereas $\mathrm{BMI}^{-1-} \mathrm{AML}$, in contrast to wild-type derived $\mathrm{AML}$, failed to repopulate secondary recipients ${ }^{77}$. This establishes BMI1 as an important regulator of the proliferative activity of not only normal but also leukemic HSCs. As overexpression of BMI1 is often seen in leukemias, a comprehensive understanding of the regulation of stem cell biology by PcG proteins is a very important aspect of hematologic oncology. 


\section{Perspectives}

Recent research position PCG proteins as master regulators of development. Their suppressive action is necessary for proper embryonic development, cell proliferation, and stem cell biology. The initial view that PcG proteins act as stable repressors throughout cell division and differentiation has been adapted to a more dynamic regulation of PcG binding and repression. As with all proteins that regulate normal proliferation, deregulated PcG protein expression levels have been detected in cancer. Putative mechanisms of how PcG proteins contribute to tumorigenesis are bypass of senescence and maintenance of CSCs. Many questions remain. How do PcG proteins exactly function in tumorigenesis? How are PcG binding patterns changed upon differentiation? Which enzymatic activities are associated with PcG complexes and which unknown enzymatic activities do they harbor themselves? How do posttranslational modifications alter PcG function? Answers to these questions will determine whether PcG proteins can become suitable targets for therapeutic intervention. In this respect it is promising that e.g., loss of BMI1 seems to promote cancer specific cell death ${ }^{178}$. For now, the use of PcG expression as a biomarker for tumor progression and patient prognosis is a far more attainable concept. First these concepts have to be validated and detection methods require standardization before it can be translated to clinical application. Considering the speed at which the PcG research field is developing, it can be anticipated that many novel aspects of PcG function and regulation will be elucidated in the next few years. 


\section{References}

1. Hanahan D, Weinberg RA. The hallmarks of cancer. Cell. Jan 7 2000;100(1):57-70.

2. Esteller M. Cancer epigenomics: DNA methylomes and histone-modification maps. Nat Rev Genet. Apr 2007;8(4):286-298.

3. Knudson AG, Jr. Hereditary Cancer, Oncogenes, and Antioncogenes. Cancer Res. April 1, 1985 1985;45(4):1437-1443.

4. Francis NJ, Kingston RE. Mechanisms of transcriptional memory. Nat Rev Mol Cell Biol. Jun 2001;2(6):409-421.

5. Krumlauf R. Hox genes in vertebrate development. Cell. 7/29/1994 1994;78(2):191201.

6. McGinnis W, Krumlauf R. Homeobox genes and axial patterning. Cell. Jan 24 1992;68(2):283-302.

7. Lewis EB. A gene complex controlling segmentation in Drosophila. Nature. 12/7/1978 1978;276(5688):565-570.

8. Hanson RD, Hess JL, Yu BD, et al. Mammalian Trithorax and polycomb-group homologues are antagonistic regulators of homeotic development. Proc.Natl.Acad.Sci.U.S.A. 12/7/1999 1999;96(25):14372-14377.

9. Isono K, Mizutani-Koseki $\mathrm{Y}$, Komori $\mathrm{T}$, et al. Mammalian polycomb-mediated repression of Hox genes requires the essential spliceosomal protein Sf3b1. Genes Dev. Mar 1 2005;19(5):536-541.

10. Deschamps J, van den Akker E, Forlani S, et al. Initiation, establishment and maintenance of Hox gene expression patterns in the mouse. Int J Dev Biol. 1999;43(7):635-650.

11. van Lohuizen M. Functional analysis of mouse Polycomb group genes. Cell Mol Life Sci. 1998;54(1):71-79.

12. Haupt $Y$, Alexander WS, Barri G, et al. Novel zinc finger gene implicated as myc collaborator by retrovirally accelerated lymphomagenesis in E mu-myc transgenic mice. Cell. 5/31/1991 1991;65(5):753-763.

13. van Lohuizen $M$, Verbeek $S$, Scheijen $B$, et al. Identification of cooperating oncogenes in E mu-myc transgenic mice by provirus tagging. Cell. 5/31/1991 1991;65(5):737-752.

14. Delaval K, Feil R. Epigenetic regulation of mammalian genomic imprinting. Curr Opin Genet Dev. Apr 2004;14(2):188-195.

15. Heard E. Delving into the diversity of facultative heterochromatin: the epigenetics of the inactive X chromosome. Curr Opin Genet Dev. Oct 2005;15(5):482-489.

16. Martinez AM, Cavalli G. The Role of Polycomb Group Proteins in Cell Cycle Regulation during Development. Cell Cycle. Jun 1 2006;5(11).

17. Sparmann A, van Lohuizen M. Polycomb silencers control cell fate, development and cancer. Nat Rev Cancer. 2006;6(11):846-856.

18. Valk-Lingbeek ME, Bruggeman SW, Van Lohuizen M. Stem cells and cancer; the polycomb connection. Cell. Aug 20 2004;118(4):409-418.

19. Lund $\mathrm{AH}$, van Lohuizen $\mathrm{M}$. Polycomb complexes and silencing mechanisms. Current Opinion in Cell Biology. 2004/6 2004;16(3):239-246.

20. Otte AP, Kwaks THJ. Gene repression by Polycomb group protein complexes: a distinct complex for every occasion? Current Opinion in Genetics \& Development. 2003;13(5):448-454. 
21. Francis NJ, Saurin AJ, Shao Z, et al. Reconstitution of a functional core polycomb repressive complex. Mol Cell. 2001;8(3):545-556.

22. Saurin AJ, Shao Z, Erdjument-Bromage $\mathrm{H}$, et al. A Drosophila Polycomb group complex includes Zeste and dTAFII proteins. Nature. Aug 9 2001;412(6847):655660.

23. Shao Z, Raible F, Mollaaghababa R, et al. Stabilization of chromatin structure by PRC1, a Polycomb complex. Cell. 7/9/1999 1999;98(1):37-46.

24. Levine SS, Weiss A, Erdjument-Bromage $H$, et al. The core of the polycomb repressive complex is compositionally and functionally conserved in flies and humans. Mol Cell Biol. 2002;22(17):6070-6078.

25. Muller J, Hart CM, Francis NJ, et al. Histone Methyltransferase Activity of a Drosophila Polycomb Group Repressor Complex. Cell. 2002;111(2):197-208.

26. Bienz M, Muller J. Transcriptional silencing of homeotic genes in Drosophila. Bioessays. 1995;17(9):775-784.

27. Kennison JA, Tamkun JW. Dosage-dependent modifiers of polycomb and antennapedia mutations in Drosophila. Proc Natl Acad Sci $U S$ A. Nov 1988;85(21):8136-8140.

28. Paro R. Imprinting a determined state into the chromatin of Drosophila. Trends Genet. 12/1990 1990;6(12):416-421.

29. Poux S, Melfi R, Pirrotta V. Establishment of Polycomb silencing requires a transient interaction between PC and ESC. Genes Dev. 2001;15(19):2509-2514.

30. Cao R, Wang L, Wang $\mathrm{H}$, et al. Role of Histone H3 Lysine 27 Methylation in Polycomb-Group Silencing. Science. 2002;26:1039-1043.

31. Czermin B, Melfi R, McCabe D, et al. Drosophila Enhancer of Zeste/ESC Complexes Have a Histone H3 Methyltransferase Activity that Marks Chromosomal Polycomb Sites. Cell. 2002;111(2):185-196.

32. Kuzmichev A, Nishioka $\mathrm{K}$, Erdjument-Bromage $\mathrm{H}$, et al. Histone methyltransferase activity associated with a human multiprotein complex containing the Enhancer of Zeste protein. Genes Dev. Nov 15 2002;16(22):2893-2905.

33. Higa LA, Wu M, Ye T, et al. CUL4-DDB1 ubiquitin ligase interacts with multiple WD40-repeat proteins and regulates histone methylation. Nat Cell Biol. 2006;8(11):1277-1283.

34. Ruthenburg AJ, Wang W, Graybosch DM, et al. Histone H3 recognition and presentation by the WDR5 module of the MLL1 complex. Nat Struct Mol Biol. 2006;13(8):704-712.

35. Wysocka J, Swigut T, Milne TA, et al. WDR5 associates with histone H3 methylated at $\mathrm{K} 4$ and is essential for H3 K4 methylation and vertebrate development. Cell. Jun 17 2005;121(6):859-872.

36. Fischle $\mathrm{W}$, Wang $\mathrm{Y}$, Jacobs $\mathrm{SA}$, et al. Molecular basis for the discrimination of repressive methyl-lysine marks in histone $\mathrm{H} 3$ by Polycomb and HP1 chromodomains. Genes Dev. Aug 1 2003;17(15):1870-1881.

37. Min J, Zhang $Y, X u$ RM. Structural basis for specific binding of Polycomb chromodomain to histone $\mathrm{H} 3$ methylated at Lys 27. Genes Dev. Aug 1 2003;17(15):1823-1828.

38. Kim SY, Paylor SW, Magnuson T, et al. Juxtaposed Polycomb complexes co-regulate vertebral identity. Development. December 15, 2006 2006;133(24):4957-4968. 
39. Wang $\mathrm{H}$, Wang $\mathrm{L}$, Erdjument-Bromage $\mathrm{H}$, et al. Role of histone $\mathrm{H} 2 \mathrm{~A}$ ubiquitination in Polycomb silencing. Nature. Sep 22 2004;431:873-878.

40. Kagey MH, Melhuish TA, Wotton D. The polycomb protein Pc2 is a SUMO E3. Cell. Apr 4 2003;113(1):127-137.

41. Long J, Zuo D, Park M. Pc2-mediated Sumoylation of Smad-interacting Protein 1 Attenuates Transcriptional Repression of E-cadherin. J. Biol. Chem. October 21, 2005 2005;280(42):35477-35489.

42. Cao R, Tsukada YI, Zhang Y. Role of Bmi-1 and Ring1A in H2A Ubiquitylation and Hox Gene Silencing. Mol Cell. Dec 22 2005;20(6):845-854.

43. de Napoles M, Mermoud JE, Wakao R, et al. Polycomb Group Proteins Ring1A/B Link Ubiquitylation of Histone $\mathrm{H} 2 \mathrm{~A}$ to Heritable Gene Silencing and X Inactivation. Developmental Cell. 2004/11 2004;7(5):663-676.

44. Buchwald G, van der Stoop P, Weichenrieder O, et al. Structure and E3-ligase activity of the Ring-Ring complex of Polycomb proteins Bmi1 and Ring1b. Embo J. Jun 7 2006;25(11):2465-2474.

45. Li Z, Cao R, Wang M, et al. Structure of a BMI-1-ring1B polycomb group ubiquitin ligase complex. J Biol Chem. May 182006.

46. Schoeftner S, Sengupta AK, Kubicek S, et al. Recruitment of PRC1 function at the initiation of $X$ inactivation independent of PRC2 and silencing. Embo J. Jun 82006.

47. Sewalt RG, Lachner $M$, Vargas $M$, et al. Selective interactions between vertebrate polycomb homologs and the SUV39H1 histone lysine methyltransferase suggest that histone H3-K9 methylation contributes to chromosomal targeting of Polycomb group proteins. Mol Cell Biol. 2002;22(15):5539-5553.

48. van der Vlag J, Otte AP. Transcriptional repression mediated by the human polycomb-group protein EED involves histone deacetylation. Nat.Genet. 12/1999 1999;23(4):474-478.

49. Reynolds PA, Sigaroudinia M, Zardo G, et al. Tumor suppressor P16INK4A regulates polycomb-mediated DNA hypermethylation in human mammary epithelial cells. $J$ Biol Chem. Jun 92006.

50. Vire E, Brenner C, Deplus R, et al. The Polycomb group protein EZH2 directly controls DNA methylation. Nature. Feb 16 2006;439(7078):871-874.

51. Kuzmichev $A$, Jenuwein $T$, Tempst $P$, et al. Different EZH2-containing complexes target methylation of histone $\mathrm{H} 1$ or nucleosomal histone H3. Mol Cell. Apr 23 2004;14(2):183-193.

52. Kuzmichev A, Margueron R, Vaquero A, et al. Composition and histone substrates of polycomb repressive group complexes change during cellular differentiation. Proc Natl Acad Sci U S A. Feb 8 2005;102(6):1859-1864.

53. Martin C, Cao R, Zhang $Y$. Substrate preferences of the EZH2 histone methyltransferase complex. J Biol Chem. Mar 31 2006;281(13):8365-8370.

54. Klymenko $T$, Papp B, Fischle $W$, et al. A Polycomb group protein complex with sequence-specific DNA-binding and selective methyl-lysine-binding activities. Genes Dev. May 1 2006;20(9):1110-1122.

55. Brown JL, Fritsch C, Mueller J, et al. The Drosophila pho-like gene encodes a YY1related DNA binding protein that is redundant with pleiohomeotic in homeotic gene silencing. Development. Jan 2003;130(2):285-294. 
56. Brown JL, Mucci D, Whiteley $\mathrm{M}$, et al. The Drosophila Polycomb group gene pleiohomeotic encodes a DNA binding protein with homology to the transcription factor YY1. Mol.Cell. 6/1998 1998;1(7):1057-1064.

57. Fritsch $\mathrm{C}$, Brown JL, Kassis JA, et al. The DNA-binding polycomb group protein pleiohomeotic mediates silencing of a Drosophila homeotic gene. Development. 9/1999 1999;126(17):3905-3913.

58. Garcia E, Marcos-Gutierrez C, del Mar Lorente M, et al. RYBP, a new repressor protein that interacts with components of the mammalian Polycomb complex, and with the transcription factor YY1. Embo J. 1999;18(12):3404-3418.

59. Satijn DP, Hamer KM, den Blaauwen JJ, et al. The Polycomb Group Protein EED Interacts with YY1, and Both Proteins Induce Neural Tissue in Xenopus Embryos. Mol.Cell Biol. 2/15/2001 2001;21(4):1360-1369.

60. King IF, Francis NJ, Kingston RE. Native and recombinant polycomb group complexes establish a selective block to template accessibility to repress transcription in vitro. Mol Cell Biol. Nov 2002;22(22):7919-7928.

61. Francis NJ, Kingston RE, Woodcock CL. Chromatin compaction by a polycomb group protein complex. Science. Nov 26 2004;306(5701):1574-1577.

62. Schwartz YB, Pirrotta V. Polycomb silencing mechanisms and the management of genomic programmes. Nat Rev Genet. Jan 2007;8(1):9-22.

63. Mohd-Sarip A, van der Knaap JA, Wyman C, et al. Architecture of a Polycomb Nucleoprotein Complex. Molecular Cell. 2006;24(1):91-100.

64. Wang L, Brown JL, Cao R, et al. Hierarchical recruitment of polycomb group silencing complexes. Mol Cell. Jun 4 2004;14(5):637-646.

65. Moehrle A, Paro R. Spreading the silence: epigenetic transcriptional regulation during Drosophila development. Dev Genet. 1994;15(6):478-484.

66. Papp B, Muller J. Histone trimethylation and the maintenance of transcriptional ON and OFF states by trxG and PcG proteins. Genes Dev. Aug 1 2006;20(15):2041-2054.

67. Gartenberg MR. The Sir proteins of Saccharomyces cerevisiae: mediators of transcriptional silencing and much more. Current Opinion in Microbiology. 2000;3(2):132-137.

68. Kahn TG, Schwartz YB, Dellino GI, et al. Polycomb complexes and the propagation of the methylation mark at the Drosophila ubx gene. J Biol Chem. Sep 29 2006;281(39):29064-29075.

69. Orlando V. Polycomb, epigenomes, and control of cell identity. Cell. Mar 7 2003;112(5):599-606.

70. Bernstein BE, Mikkelsen TS, Xie X, et al. A bivalent chromatin structure marks key developmental genes in embryonic stem cells. Cell. Apr 21 2006;125(2):315-326.

71. Azuara V, Perry $P$, Sauer $S$, et al. Chromatin signatures of pluripotent cell lines. Nat Cell Biol. 2006;8(5):532-538.

72. Kohlmaier A, Savarese F, Lachner M, et al. A chromosomal memory triggered by Xist regulates histone methylation in X inactivation. PLoS Biol. Jul 2004;2(7):E171.

73. Dellino $\mathrm{GI}$, Schwartz YB, Farkas G, et al. Polycomb silencing blocks transcription initiation. Mol Cell. Mar 26 2004;13(6):887-893.

74. Park IK, Morrison SJ, Clarke MF. Bmi1, stem cells, and senescence regulation. J Clin Invest. Jan 2004;113(2):175-179. 
75. Kamminga LM, Bystrykh LV, de Boer A, et al. The Polycomb group gene Ezh2 prevents hematopoietic stem cell exhaustion. Blood. March 1, 2006 2006;107(5):2170-2179.

76. Kim JY, Sawada A, Tokimasa S, et al. Defective long-term repopulating ability in hematopoietic stem cells lacking the Polycomb-group gene rae28. Eur J Haematol. Aug 2004;73(2):75-84.

77. Lessard J, Sauvageau G. Bmi-1 determines the proliferative capacity of normal and leukaemic stem cells. Nature. May 15 2003;423(6937):255-260.

78. Ohta $\mathrm{H}$, Sawada A, Kim JY, et al. Polycomb group gene rae28 is required for sustaining activity of hematopoietic stem cells. J Exp Med. Mar 18 2002;195(6):759770.

79. Park IK, Qian D, Kiel $M$, et al. Bmi-1 is required for maintenance of adult selfrenewing haematopoietic stem cells. Nature. May 15 2003;423(6937):302-305.

80. Molofsky AV, Pardal R, Iwashita $\mathrm{T}$, et al. Bmi-1 dependence distinguishes neural stem cell self-renewal from progenitor proliferation. Nature. Oct 30 2003;425(6961):962-967.

81. van der Lugt NM, Domen J, Linders K, et al. Posterior transformation, neurological abnormalities, and severe hematopoietic defects in mice with a targeted deletion of the bmi-1 proto-oncogene. Genes Dev. 4/1/1994 1994;8(7):757-769.

82. O'Carroll D, Erhardt S, Pagani $M$, et al. The Polycomb-Group Gene Ezh2 Is Required for Early Mouse Development. Mol. Cell. Biol. July 1, 2001 2001;21(13):4330-4336.

83. Pasini $D$, Bracken AP, Jensen MR, et al. Suz12 is essential for mouse development and for EZH2 histone methyltransferase activity. Embo J. Oct 13 2004;23(20):40614071.

84. Schumacher A, Faust C, Magnuson T. Positional cloning of a global regulator of anterior-posterior patterning in mice. Nature. 9/19/1996 1996;383(6597):250-253.

85. Voncken JW, Roelen BA, Roefs M, et al. Rnf2 (Ring1b) deficiency causes gastrulation arrest and cell cycle inhibition. Proc Natl Acad Sci U S A. Mar 4 2003;100(5):24682473.

86. Pasini $D$, Bracken AP, Hansen JB, et al. The polycomb group protein suz12 is required for embryonic stem cell differentiation. Mol Cell Biol. May 2007;27(10):3769-3779.

87. Boyer LA, Plath K, Zeitlinger J, et al. Polycomb complexes repress developmental regulators in murine embryonic stem cells. Nature. May 18 2006;441(7091):349353.

88. Bracken AP, Dietrich N, Pasini D, et al. Genome-wide Mapping of Polycomb Target Genes Unravels Their Roles in Cell Fate Transitions. Genes and Development. May 1 2006;20(9):1123-1136.

89. Lee $\mathrm{TI}$, Jenner RG, Boyer LA, et al. Control of developmental regulators by polycomb in human embryonic stem cells. Cell. Apr 21 2006;125(2):301-313.

90. Negre N, Hennetin J, Sun LV, et al. Chromosomal distribution of PcG proteins during Drosophila development. PLOS Biol. Jun 2006;4(6):e170.

91. Schwartz YB, Kahn TG, Nix DA, et al. Genome-wide analysis of Polycomb targets in Drosophila melanogaster. Nat Genet. Jun 2006;38(6):700-705.

92. Tolhuis B, de Wit E, Muijrers I, et al. Genome-wide profiling of PRC1 and PRC2 Polycomb chromatin binding in Drosophila melanogaster. Nat Genet. Jun 2006;38(6):694-699. 
93. Mikkelsen TS, Ku M, Jaffe DB, et al. Genome-wide maps of chromatin state in pluripotent and lineage-committed cells. Nature. Aug 2 2007;448(7153):553-560.

94. Spivakov M, Fisher AG. Epigenetic signatures of stem-cell identity. Nat Rev Genet. Apr 2007;8(4):263-271.

95. Boyer LA, Lee TI, Cole MF, et al. Core transcriptional regulatory circuitry in human embryonic stem cells. Cell. Sep 23 2005;122(6):947-956.

96. LaJeunesse $D$, Shearn A. E(z): a polycomb group gene or a trithorax group gene? Development. Jul 1996;122(7):2189-2197.

97. Kirmizis A, Bartley SM, Kuzmichev A, et al. Silencing of human polycomb target genes is associated with methylation of histone H3 Lys 27. Genes Dev. July 1, 2004 2004;18(13):1592-1605.

98. Bracken AP, Pasini D, Capra $\mathrm{M}$, et al. EZH2 is downstream of the pRB-E2F pathway, essential for proliferation and amplified in cancer. Embo J. Oct 15 2003;22(20):5323-5335.

99. Shi B, Liang J, Yang X, et al. Integration of estrogen and Wnt signaling circuits by the polycomb group protein EZH2 in breast cancer cells. Mol Cell Biol. Jul 2007;27(14):5105-5119.

100. Guney I, Wu S, Sedivy JM. Reduced c-Myc signaling triggers telomere-independent senescence by regulating Bmi-1 and p16INK4a. Proc Natl Acad Sci U S A. Mar 7 2006;103(10):3645-3650.

101. Kranc KR, Bamforth SD, Braganca J, et al. Transcriptional coactivator Cited2 induces Bmi1 and Mel18 and controls fibroblast proliferation via Ink4a/ARF. Mol Cell Biol. Nov 2003;23(21):7658-7666.

102. Leung $C$, Lingbeek $M$, Shakhova $O$, et al. Bmi1 is essential for cerebellar development and is overexpressed in human medulloblastomas. Nature. Mar 18 2004;428(6980):337-341.

103. Lee N, Maurange C, Ringrose L, et al. Suppression of Polycomb group proteins by JNK signalling induces transdetermination in Drosophila imaginal discs. Nature. Nov 10 2005;438(7065):234-237.

104. Ali JY, Bender W. Cross-regulation among the polycomb group genes in Drosophila melanogaster. Mol Cell Biol. Sep 2004;24(17):7737-7747.

105. Bloyer S, Cavalli G, Brock HW, et al. Identification and characterization of polyhomeotic PREs and TREs. Dev Biol. Sep 15 2003;261(2):426-442.

106. Guo W-J, Datta S, Band V, et al. Mel-18, a Polycomb Group Protein, Regulates Cell Proliferation and Senescence via Transcriptional Repression of Bmi-1 and c-Myc Oncoproteins. Mol. Biol. Cell. February 1, 2007 2007;18(2):536-546.

107. Batsche $E$, Yaniv M, Muchardt $C$. The human SWI/SNF subunit Brm is a regulator of alternative splicing. Nat Struct Mol Biol. Jan 2006;13(1):22-29.

108. Ben-Saadon R, Zaaroor D, Ziv T, et al. The Polycomb Protein Ring1B Generates Self Atypical Mixed Ubiquitin Chains Required for Its In Vitro Histone H2A Ligase Activity. Molecular Cell. 2006;24(5):701-711.

109. Cha TL, Zhou BP, Xia W, et al. Akt-mediated phosphorylation of EZH2 suppresses methylation of lysine 27 in histone H3. Science. Oct 14 2005;310(5746):306-310.

110. Dietrich N, Bracken AP, Trinh E, et al. Bypass of senescence by the polycomb group protein $\mathrm{CBX} 8$ through direct binding to the INK4A-ARF locus. Embo J. Mar 21 2007;26(6):1637-1648. 
111. Sanchez C, Sanchez I, Demmers JA, et al. Proteomics analysis of Ring1B/Rnf2 interactors identifies a novel complex with the Fbxl10/Jhdm1B histone demethylase and the Bcl6 interacting corepressor. Mol Cell Proteomics. May 2007;6(5):820-834.

112. Voncken JW, Niessen $H$, Neufeld B, et al. MAPKAP kinase $3 p K$ phosphorylates and regulates chromatin-association of the polycomb-group protein Bmi1. J Biol Chem. Feb 18 2005;280(7):5178-5187.

113. Dudley NR, Labbe JC, Goldstein B. Using RNA interference to identify genes required for RNA interference. Proc Natl Acad Sci U S A. Apr 2 2002;99(7):41914196.

114. Kavi HH, Fernandez HR, Xie W, et al. RNA silencing in Drosophila. FEBS Lett. Oct 31 2005;579(26):5940-5949.

115. Kidner CA, Martienssen RA. The role of ARGONAUTE1 (AGO1) in meristem formation and identity. Developmental Biology. 2005;280(2):504-517.

116. Grimaud C, Bantignies F, Pal-Bhadra M, et al. RNAi Components Are Required for Nuclear Clustering of Polycomb Group Response Elements. Cell. Mar 10 2006;124(5):957-971.

117. Akhtar A, Zink D, Becker PB. Chromodomains are protein-RNA interaction modules. Nature. Sep 21 2000;407(6802):405-409.

118. Lachner M, O'Carroll D, Rea S, et al. Methylation of histone H3 lysine 9 creates a binding site for HP1 proteins. Nature. 2001;410(6824):116-120.

119. Maison C, Bailly D, Peters $A H$, et al. Higher-order structure in pericentric heterochromatin involves a distinct pattern of histone modification and an RNA component. Nat Genet. Mar 2002;30(3):329-334.

120. Schlesinger $Y$, Straussman R, Keshet I, et al. Polycomb-mediated methylation on Lys 27 of histone H3 pre-marks genes for de novo methylation in cancer. Nat Genet. 2007;39(2):232-236.

121. Widschwendter $M$, Fiegl $H$, Egle $D$, et al. Epigenetic stem cell signature in cancer. Nat Genet. Feb 2007;39(2):157-158.

122. Egger $G$, Liang $G$, Aparicio $A$, et al. Epigenetics in human disease and prospects for epigenetic therapy. Nature. May 27 2004;429(6990):457-463.

123. Jacobs JJ, Kieboom K, Marino S, et al. The oncogene and Polycomb-group gene bmi1 regulates cell proliferation and senescence through the ink4a locus. Nature. 1/14/1999 1999;397(6715):164-168.

124. Sherr CJ. The INK4a/ARF network in tumour suppression. Nat Rev Mol Cell Biol. Oct 2001;2(10):731-737.

125. Jacobs JJ, Scheijen B, Voncken JW, et al. Bmi-1 collaborates with c-Myc in tumorigenesis by inhibiting c-Myc- induced apoptosis via INK4a/ARF. Genes Dev. 10/15/1999 1999;13(20):2678-2690.

126. Breuer RH, Snijders PJ, Sutedja GT, et al. Expression of the p16(INK4a) gene product, methylation of the p16(INK4a) promoter region and expression of the polycomb-group gene BMI-1 in squamous cell lung carcinoma and premalignant endobronchial lesions. Lung Cancer. Jun 2005;48(3):299-306.

127. Raaphorst FM, Vermeer $M$, Fieret $E$, et al. Site-specific expression of polycombgroup genes encoding the HPC-HPH/PRC1 complex in clinically defined primary nodal and cutaneous large B-cell lymphomas. Am J Pathol. Feb 2004;164(2):533542. 
128. Guo WJ, Zeng MS, Yadav A, et al. Mel-18 acts as a tumor suppressor by repressing Bmi-1 expression and down-regulating Akt activity in breast cancer cells. Cancer Res. Jun 1 2007;67(11):5083-5089.

129. Hayflick L. The Limited in Vitro Lifetime of Human Diploid Cell Strains. Exp Cell Res. Mar 1965;37:614-636.

130. Bachmann IM, Halvorsen OJ, Collett $\mathrm{K}$, et al. EZH2 expression is associated with high proliferation rate and aggressive tumor subgroups in cutaneous melanoma and cancers of the endometrium, prostate, and breast. J Clin Oncol. Jan 10 2006;24(2):268-273.

131. Collett K, Eide GE, Arnes J, et al. Expression of enhancer of zeste homologue 2 is significantly associated with increased tumor cell proliferation and is a marker of aggressive breast cancer. Clin Cancer Res. Feb 15 2006;12(4):1168-1174.

132. Kleer CG, Cao Q, Varambally $\mathrm{S}$, et al. EZH2 is a marker of aggressive breast cancer and promotes neoplastic transformation of breast epithelial cells. Proc Natl Acad Sci U S A. Sep 30 2003;100(20):11606-11611.

133. Raaphorst FM, Meijer CJ, Fieret E, et al. Poorly differentiated breast carcinoma is associated with increased expression of the human polycomb group EZH2 gene. Neoplasia. Nov-Dec 2003;5(6):481-488.

134. Raaphorst FM, van Kemenade FJ, Blokzijl T, et al. Coexpression of BMI-1 and EZH2 polycomb group genes in Reed-Sternberg cells of Hodgkin's disease. Am J Pathol. Sep 2000;157(3):709-715.

135. Visser HP, Gunster MJ, Kluin-Nelemans HC, et al. The Polycomb group protein EZH2 is upregulated in proliferating, cultured human mantle cell lymphoma. $\mathrm{Br} J$ Haematol. Mar 2001;112(4):950-958.

136. Sanchez-Beato M, Sanchez E, Gonzalez-Carrero J, et al. Variability in the expression of polycomb proteins in different normal and tumoral tissues. A pilot study using tissue microarrays. Mod Pathol. May 2006;19(5):684-694.

137. van Kemenade FJ, Raaphorst FM, Blokzijl T, et al. Coexpression of BMI-1 and EZH2 polycomb-group proteins is associated with cycling cells and degree of malignancy in B-cell non-Hodgkin lymphoma. Blood. Jun 15 2001;97(12):3896-3901.

138. Arisan S, Buyuktuncer ED, Palavan-Unsal N, et al. Increased expression of EZH2, a polycomb group protein, in bladder carcinoma. Urol Int. 2005;75(3):252-257.

139. Raman JD, Mongan NP, Tickoo SK, et al. Increased expression of the polycomb group gene, EZH2, in transitional cell carcinoma of the bladder. Clin Cancer Res. Dec 15 2005;11(24 Pt 1):8570-8576.

140. Weikert S, Christoph F, Kollermann J, et al. Expression levels of the EZH2 polycomb transcriptional repressor correlate with aggressiveness and invasive potential of bladder carcinomas. Int J Mol Med. Aug 2005;16(2):349-353.

141. Mimori $K$, Ogawa $K$, Okamoto $M$, et al. Clinical significance of enhancer of zeste homolog 2 expression in colorectal cancer cases. Eur J Surg Oncol. May 2005;31(4):376-380.

142. Sudo $T$, Utsunomiya $T$, Mimori $K$, et al. Clinicopathological significance of EZH2 mRNA expression in patients with hepatocellular carcinoma. $\mathrm{Br} J$ Cancer. May 9 2005;92(9):1754-1758.

143. Varambally S, Dhanasekaran SM, Zhou M, et al. The polycomb group protein EZH2 is involved in progression of prostate cancer. Nature. Oct 10 2002;419(6907):624629. 
144. Berezovska OP, Glinskii AB, Yang Z, et al. Essential role for activation of the Polycomb group (PcG) protein chromatin silencing pathway in metastatic prostate cancer. Cell Cycle. Aug 2006;5(16):1886-1901.

145. Saramaki OR, Tammela TL, Martikainen PM, et al. The gene for polycomb group protein enhancer of zeste homolog $2(\mathrm{EZH} 2)$ is amplified in late-stage prostate cancer. Genes Chromosomes Cancer. Jul 2006;45(7):639-645.

146. van Leenders GJ, Dukers D, Hessels D, et al. Polycomb-group oncogenes EZH2, $\mathrm{BMI} 1$, and RING1 are overexpressed in prostate cancer with adverse pathologic and clinical features. Eur Urol. Aug 2007;52(2):455-463.

147. Matsukawa $\mathrm{Y}$, Semba $\mathrm{S}$, Kato $\mathrm{H}$, et al. Expression of the enhancer of zeste homolog 2 is correlated with poor prognosis in human gastric cancer. Cancer Sci. Jun 2006;97(6):484-491.

148. Mattioli $E$, Vogiatzi $P$, Sun $A$, et al. Immunohistochemical analysis of $p R b 2 / p 130$, VEGF, EZH2, p53, p16(INK4A), p27(KIP1), p21(WAF1), Ki-67 expression patterns in gastric cancer. J Cell Physiol. Jan 2007;210(1):183-191.

149. Kirmizis A, Bartley SM, Farnham PJ. Identification of the Polycomb Group Protein SU(Z)12 as a Potential Molecular Target for Human Cancer Therapy. Mol Cancer Ther. January 1, 2003 2003;2(1):113-121.

150. Scott CL, Gil J, Hernando E, et al. Role of the chromobox protein CBX7 in lymphomagenesis. Proc Natl Acad Sci U S A. Mar 27 2007;104(13):5389-5394.

151. Silva J, Garcia JM, Pena C, et al. Implication of polycomb members Bmi-1, Mel-18, and Hpc-2 in the regulation of p16INK4a, p14ARF, h-TERT, and c-Myc expression in primary breast carcinomas. Clin Cancer Res. Dec 1 2006;12(23):6929-6936.

152. Kim JH, Yoon SY, Kim CN, et al. The Bmi-1 oncoprotein is overexpressed in human colorectal cancer and correlates with the reduced p16INK4a/p14ARF proteins. Cancer Lett. Jan 20 2004;203(2):217-224.

153. van Galen JC, Muris JJ, Oudejans JJ, et al. Expression of the polycomb-group gene BMI1 is related to an unfavourable prognosis in primary nodal DLBCL. J Clin Pathol. Feb 2007;60(2):167-172.

154. Dutton A, Woodman CB, Chukwuma MB, et al. Bmi-1 is induced by the Epstein-Barr virus oncogene LMP1 and regulates the expression of viral target genes in Hodgkin lymphoma cells. Blood. Mar 15 2007;109(6):2597-2603.

155. Sawa M, Yamamoto $\mathrm{K}$, Yokozawa $\mathrm{T}$, et al. BMI-1 is highly expressed in M0-subtype acute myeloid leukemia. Int J Hematol. Jul 2005;82(1):42-47.

156. Bea S, Tort $\mathrm{F}$, Pinyol $\mathrm{M}$, et al. BMI-1 gene amplification and overexpression in hematological malignancies occur mainly in mantle cell lymphomas. Cancer Res. 2001;61(6):2409-2412.

157. Nowak K, Kerl K, Fehr D, et al. BMI1 is a target gene of E2F-1 and is strongly expressed in primary neuroblastomas. Nucleic Acids Res. 2006;34(6):1745-1754.

158. Vonlanthen S, Heighway J, Altermatt HJ, et al. The bmi-1 oncoprotein is differentially expressed in non-small cell lung cancer and correlates with INK4A-ARF locus expression. Br J Cancer. May 18 2001;84(10):1372-1376.

159. Kang MK, Kim RH, Kim SJ, et al. Elevated Bmi-1 expression is associated with dysplastic cell transformation during oral carcinogenesis and is required for cancer cell replication and survival. Br J Cancer. Jan 15 2007;96(1):126-133. 
160. Tokimasa S, Ohta H, Sawada A, et al. Lack of the Polycomb-group gene rae28 causes maturation arrest at the early B-cell developmental stage. Exp Hematol. Jan 2001;29(1):93-103.

161. Chowdhury M, Mihara K, Yasunaga S, et al. Expression of Polycomb-group (PcG) protein BMI-1 predicts prognosis in patients with acute myeloid leukemia. Leukemia. Mar 222007.

162. Ding L, Erdmann C, Chinnaiyan AM, et al. Identification of EZH2 as a molecular marker for a precancerous state in morphologically normal breast tissues. Cancer Res. Apr 15 2006;66(8):4095-4099.

163. Ding L, Kleer CG. Enhancer of zeste 2 as a marker of preneoplastic progression in the breast. Cancer Res. Oct 1 2006;66(19):9352-9355.

164. Glinsky GV, Berezovska O, Glinskii AB. Microarray analysis identifies a death-fromcancer signature predicting therapy failure in patients with multiple types of cancer. J Clin Invest. Jun 2005;115(6):1503-1521.

165. Beke L, Nuytten M, Van Eynde A, et al. The gene encoding the prostatic tumor suppressor PSP94 is a target for repression by the Polycomb group protein EZH2. Oncogene. Jul 5 2007;26(31):4590-4595.

166. Oei SL, Shi Y. Transcription factor Yin Yang 1 stimulates poly(ADP-ribosyl)ation and DNA repair. Biochem Biophys Res Commun. Jun 8 2001;284(2):450-454.

167. Sui G, Affar el B, Shi Y, et al. Yin Yang 1 is a negative regulator of p53. Cell. Jun 25 2004;117(7):859-872.

168. Campisi J. Senescent cells, tumor suppression, and organismal aging: good citizens, bad neighbors. Cell. Feb 25 2005;120(4):513-522.

169. Dimri GP. What has senescence got to do with cancer? Cancer Cell. Jun 2005;7(6):505-512.

170. Narita M, Lowe SW. Senescence comes of age. Nat Med. Sep 2005;11(9):920-922.

171. Gil J, Bernard D, Martinez D, et al. Polycomb CBX7 has a unifying role in cellular lifespan. Nat Cell Biol. Jan 2004;6(1):67-72.

172. Bracken $A P$, Kleine-Kohlbrecher $D$, Dietrich $N$, et al. The Polycomb group proteins bind throughout the INK4A-ARF locus and are disassociated in senescent cells. Genes Dev. Mar 1 2007;21(5):525-530.

173. Kotake $Y$, Cao $R$, Viatour $P$, et al. pRB family proteins are required for $H 3 K 27$ trimethylation and Polycomb repression complexes binding to and silencing p16INK4a tumor suppressor gene. Genes Dev. January 1, 2007 2007;21(1):49-54.

174. Dimri GP, Martinez JL, Jacobs JJ, et al. The Bmi-1 oncogene induces telomerase activity and immortalizes human mammary epithelial cells. Cancer Res. Aug 15 2002;62(16):4736-4745.

175. Itahana K, Zou Y, Itahana $Y$, et al. Control of the replicative life span of human fibroblasts by $\mathrm{p} 16$ and the polycomb protein Bmi-1. Mol Cell Biol. Jan 2003;23(1):389-401.

176. Kim RH, Kang MK, Shin $\mathrm{KH}$, et al. Bmi-1 cooperates with human papillomavirus type 16 E6 to immortalize normal human oral keratinocytes. Exp Cell Res. Feb 1 2007;313(3):462-472.

177. Al-Hajj M, Clarke MF. Self-renewal and solid tumor stem cells. Oncogene. Sep 20 2004;23(43):7274-7282.

178. Liu L, Andrews LG, Tollefsbol TO. Loss of the human polycomb group protein BMI1 promotes cancer-specific cell death. Oncogene. Jul 20 2006;25(31):4370-4375. 

Chapter 3

\section{Talking to chromatin: post-translational modulation of Polycomb Group function}


Talking to chromatin: post-translational modulation of PcG function

\begin{abstract}
Polycomb Group proteins are important epigenetic regulators of gene expression. Epigenetic control by Polycomb Group proteins involves intrinsic as well as associated enzymatic activities. Polycomb target genes change with cellular context, among which lineage commitment and differentiation status, revealing dynamic regulation of Polycomb function. It is currently unclear how this dynamic modulation is controlled and how signaling affects Polycombmediated epigenetic processes at the molecular level. Experimental evidence on regulation of Polycomb function by post-translational mechanisms is steadily emerging: Polycomb Group proteins are targeted for ubiquitylation, sumoylation and phosphorylation. In addition, specific Polycomb Group proteins modify other (chromatin-) associated proteins via similar post-translational modifications. Such modifications affect protein function by affecting protein stability, protein-protein interactions and enzymatic activities. We here review current insights in covalent modification of Polycomb Group proteins in the context of protein function and present a tentative view of integrated signaling to chromatin in the context of phosphorylation. Clearly, available literature reveals the tip of the iceberg, and exact molecular mechanisms in, and biological relevance of post-translational regulation of Polycomb function await further elucidation. Our understanding of causes and consequences of posttranslational modification of Polycomb proteins will gain significantly from in vivo validation experiments. Impaired Polycomb function has important repercussions for stem cell function, development and disease. Ultimately, increased understanding of signaling to chromatin and mechanisms involved in epigenetic remodeling will contribute to development of therapeutic intervention in cell fate decisions in development and disease.
\end{abstract}




\section{Introduction}

Polycomb Group (PcG) proteins preserve transcriptionally silenced states through epigenetic marking of target genes in higher eukaryotes. Currently at least two biochemically and functionally distinct Polycomb Repressive Complexes (PRC) are recognized, PRC2 and PRC1, which contribute to establishment and maintenance of gene repression profiles (Fig. 3.1A $)^{1-3}$. As such PcG function equips the cell with a transcriptional memory throughout development and differentiation. It is becoming increasingly clear that PcGchromatin association is subject to dynamic regulation; PcG complex composition and chromatin association change throughout eukaryotic development $^{4,5}$. In a constantly changing environment (for example during differentiation) cells respond to a plethora of extracellular and intrinsic cues. Mechanistic insight in epigenetic regulation in response to signaling is essential to understand how cell fate, function and physiology are controlled. It is, however, still largely unknown how cells "talk" to chromatin to facilitate appropriate cellular responses. Physiological adaptation of cells is initially mediated by mostly transient and reversible covalent post-translational modifications (PTMs) at specific amino acid residues including ubiquitylation, sumoylation, and phosphorylation (see Box 3.1). Through altered proteinprotein interaction, subcellular localization, enzyme activity and protein stability, PTMs ultimately also affect gene expression. We review current established PTMs on PcG proteins and the effect they have on interaction and enzymatic activity in the paragraphs below. In addition, we extracted PcG specific PTM from published analyses and used these to predict upstream kinase pathways signaling to Polycomb. The final section presents a tentative integrated view on signaling to chromatin in the context of PcG PTM.

\section{Polycomb-mediated Ubiquitylation}

Ubiquitylation plays a central role in PRC-mediated silencing. Histone 2A ( $\mathrm{H} 2 \mathrm{~A})$ is one of the most abundant ubiquitylated nuclear proteins, and H2AK119ub1 is required for PcG-mediated gene repression ${ }^{6}$. Published data shows that the PRC1 protein RNF2 (RING1B) ubiquitylates H2A, as loss of RNF2 dramatically decreases global H2Aub levels and derepresses PcG-controlled genes. The RING1 (RING1A) RING domain substitute for that of RNF2 in vitro ${ }^{7}$. Consistently, H2AK119ub1 is maintained in RING1 or RNF2 single null cells, but not in double knockout cells, supporting functionally redundant roles for these proteins in certain biological contexts ${ }^{8}$. RNF2-mediated H2A ubiquitylation is important in X chromosome inactivation $^{8,9}$. The exact role of RNF2 and H2AK119Ub1 in Xinactivation is currently under debate, however, as recent studies suggest that H2AK119ub1 may not be sufficient for X-inactivation and conversely, Xist- 


\begin{abstract}
Box 3.1. Most common PTM in Polycomb biology
Ubiquitylation.

Besides in protein degradation ubiquitylation fulfills many non-proteolytic roles, such as in regulating DNA repair, transcription and signal transduction ${ }^{74}$. Ubiquitin (Ub) is a small ubiquitous 76 amino acid polypeptide which is covalently bound as a monomer (monoubiquitin) to proteins or as a Ub-polymer (polyubiquitin). In polyubiquitin, chains are linked by conjugation to one of seven lysines (Lys, K) of a pre-existing ubiquityl-moiety, e.g. Lys48 or Lys63. Polyubiquitylation via Lys48 linkage is mostly implicated in $26 \mathrm{~S}$ proteasomemediated protein degradation. Covalent linkage of ubiquitin to a substrate requires sequential action of activating (E1), conjugating (E2) and ligating (E3) enzymes ${ }^{75}$ : E1 activates ubiquitin in an ATP-dependent manner, which is then conjugated to the E2, that, assisted by an E3 ligase, transfers ubiquitin to a lysine residue onto the substrate protein ${ }^{74}$. The diversity and combination of these enzymes ultimately determines substrate specificity and biological responses. Two classes of E3 ligases are recognized: the HECT domain E3s and the RINGdomain E3s; RING-type E3 ligases are thought to function as bridging factors between the E2 and substrate ${ }^{75}$. Ub-protein substrates are de-ubiquitylated by DUBs (deubiquitylases). The large number of different E2 and E3 enzymes and DUBs identified to date and their involvement in a great variety of processes underscores the complexity of regulation by ubiquitylation ${ }^{75}$.
\end{abstract}

\title{
Sumoylation.
}

Small ubiquitin-related modifier (SUMO) proteins are approximately $10 \mathrm{kDa}$ in size ${ }^{76}$. Like ubiquitylation, sumoylation involves three distinct enzymatic activities: an E1 activating enzyme (AOS1/UBA2 heterodimer) an E2 conjugating enzyme (UBC9) and an E3 ligase. Currently three classes of SUMO E3 ligases are distinguished: SP-RING motif E3 ligases, such as PIAS (protein inhibitor of activated STAT), a second class containing RanBP2, and a third class with no apparent homology to either other class comprising CBX4 (HPC2). In contrast to ubiquitylation, sumoylation takes place at SUMO-acceptor sites: $\Psi$ KXE ( $\Psi$ and X represent hydrophobic and any amino acids).

Phosphorylation.

Phosphorylation is probably the most widespread and best studied PTM in cellular signaling. Protein kinases catalyze the transfer of $\psi$-phosphate from adenosine triphosphate (ATP) to a substrate protein, thereby generating $A D P^{77}$. Phosphorylation is reversible: phosphatases remove the attached phosphate moiety. An estimated $\sim 30 \%$ of all proteins are phosphorylated on at least one residue. Phosphate is most commonly linked to Ser (S), $\operatorname{Thr}(\mathrm{T})$ or $\operatorname{Tyr}(\mathrm{Y})$ ), but in addition occurs on His (H), Lys (K), Arg (R), Asp/Glu (D/E), and Cys (C) $)^{66}$.

initiated silencing occurs in the absence of RNF2 and H2AK119ub1 $1^{10,11}$. Also histone variant H2A.Z may be a target for RNF2-mediated ubiquitylation, as knockdown of RNF2 reduces $\mathrm{H} 2 \mathrm{Aub}$ and $\mathrm{H} 2 \mathrm{~A}$.Zub levels in vitro ${ }^{12}$.

Whereas in Drosophila melanogaster multiple E3-ligase complexes contribute to $\mathrm{H} 2 \mathrm{~A}$ ubiquitylation, the PRC1 protein RNF2 is currently considered the major E3 ligase for H2AK119 (Fig. 3.1B) ${ }^{13,14}$. Although within the PcG core complex, containing RING1, RNF2, BMI1 and PHC2, most in vitro H2A-E3 ligase activity is attributed to $\mathrm{RNF2}^{8}$, other PcG RING-type E3 ligases control H2A-directed 
A

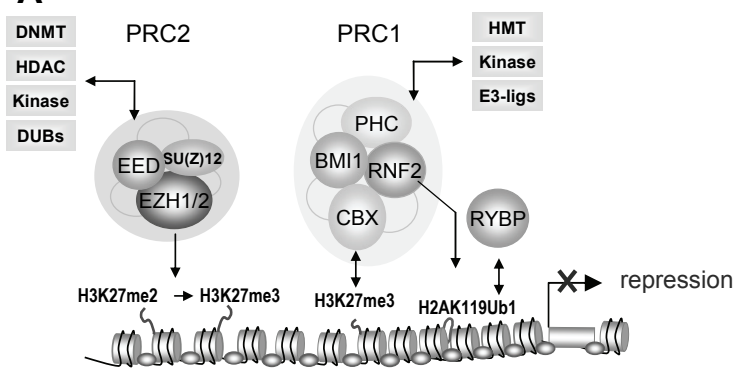

B

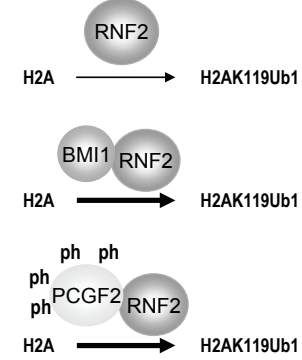

C

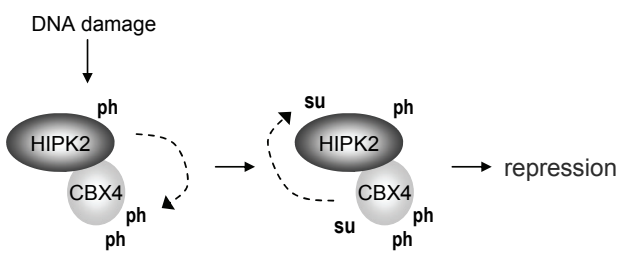

D

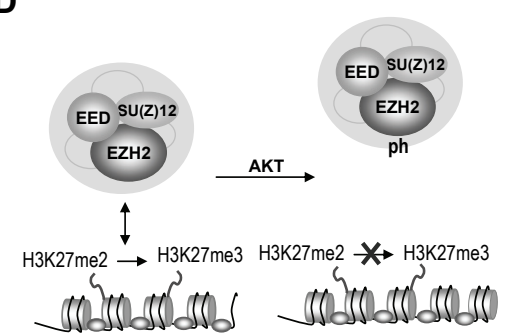

Figure 3.1. Examples of post-translational modulation of Polycomb Group and associated proteins.

(A) Simplified model of PcG-mediated repression. The histone methyltransferase EZH2 trimethylates histone $\mathrm{H} 3$ at lysine 27 , this mark is recognized by $\mathrm{CBX}$ proteins via the chromodomain. RNF2/RING1 homologs are E3 ubiquitin ligases for H2A; RYBP binds H2AK119Ub1. Combined these activities induce/maintain transcriptional repression. Gray boxes depict PRCassociated, epigenetically relevant enzymatic activities. (B) RNF2 E3-ligase activity is significantly enhanced in the presence of BMI1, or of phosphorylated PCGF2. (C) DNA damage-induced phosphorylation of HIPK2 leads to phosphorylation of CBX4. Phosphorylation of CBX4 at T495 in turn enhances the HIPK2 sumoylation. (D) AKT-induced phosphorylation of EZH2 on S21 impairs its binding to histone $\mathrm{H} 3$, thereby inhibiting $\mathrm{H} 3 \mathrm{~K} 27$ trimethylation. ph: phosphorylation, su: sumoylation; ub: ubiquitylation, me: methylation.

ubiquitylation and affect HOX gene silencing: BMI1 (PCGF4) homologues PCGF2 (MEL18) and PCGF1 (NSPC1) enhance H2A ubiquitin E3 ligase activity when complexed to RNF2 (Fig. 3.1B) ${ }^{15-18}$. In addition, PcG ubiquitin E3 ligase activity is enhanced within the molecular context of an intact PRC1 complex: fully reconstituted complexes containing RNF2, RING1, BMI1 and CBX8 show highest activity compared to RNF2 alone or subcomplete PRC1 complexes ${ }^{15}$. Crystal structure analyses of interacting RING domains of mammalian BMI1 and RNF2 reveals extensive contacts between the RNF2 and BMI1 RING domains: the Nterminal 'arm' of RNF2 embraces the BMI1 RING domain ${ }^{7}$, 19. RING-protein partnerships occur frequently in cell biology ${ }^{20}$; RING domain proteins function as adapters, bringing together E2 conjugases and their substrates (see Box 3.1) ${ }^{21}$. Based on structural analogy to a BRCA1-BARD1 complex, it was suggested that 
Talking to chromatin: post-translational modulation of PcG function

RNF2 contains an E2 binding site, whereas BMI1 is involved in substrate binding $^{19}$. E2 conjugase UbcH5 subtypes $a, b, c$ and $\mathrm{UbcH} 6$ promote H2A ubconjugation, although these Ubc's do not bind the RING RNF2/BMI1 complex ${ }^{7}$. Which E2 conjugases contribute to H2A ubiquitylation in vivo is currently not known. A summary of PcG-related PTMs and their functional relevance is provided in Table 3.1.

\section{Ubiquitylation of PcG proteins}

The above relatively simple picture is complicated by additional levels of PTM. Both RNF2 and BMI1 are ubiquitin-proteins and differential auto-ubiquitylation of RNF2 is required for H2AK119ub1, 22 . Poly-ubiquitylation of RNF2 requires Lys6, Lys27 and Lys48 linkage on the same ubiquitin molecule and RNF2 autoubiquitylation is promoted by Ubc5 in vitro ${ }^{22}$. Some of these K-residues are involved in epigenetic silencing, as RNF2s' ability to promote H2AK119ub1 relates to the availability of UbK6 and UbK27, not UbK48 ${ }^{22}$. Although inhibition of Ub-dependent degradation with proteasome inhibitor increases RNF2 levels, auto-ubiquitylation-mutant RNF2(I53S) proteins are still efficiently degraded, suggesting the involvement of other E3 ligase and/or Ub-site(s). BMI1 inhibits ubiquitylation of RNF2 and coexpression of RNF2 and BMI1 blocks its degradation in a RING domain dependent manner ${ }^{22}$. Unlike RNF2, BMI1 lacks auto-ubiquitylation activity. However, like RNF2, it is stabilized by proteasome inhibition. As for RNF2, the identity of the ubiquitin E3 ligase responsible for proteasomal degradation of BMI1 is not known. Whereas RNF2K112ub appears dispensable for H2A E3-ligase activity ${ }^{7}$, mutant RNF2 with an intact RING domain, however missing most ubiquitylation sites (K92-198R) still binds BMI1, but lacks E3 ligase activity ${ }^{22}$. Thus, seemingly at odds with each other: although RNF2 autoubiquitylation is required for $\mathrm{H} 2 \mathrm{~A}$ ubiquitylation, it is inhibited by BMI1, yet overall, BMI1 promotes RNF2 H2A-E3 ligase activity and blocks its proteolytic degradation ${ }^{22}$. A possible explanation for this discrepancy may involve number, length and linkage-type of ubiquitin chains, aside from molecular context.

A candidate E3 ubiquitin ligase for BMI1 is the CULLIN3/SPOP complex: in vitro and in vivo analyses confirmed that CULLIN3 and SPOP are required for BMI1ubiquitylation in cells. As RNAi-mediated knockdown of CULLIN3 or SPOP does not affect BMI1 protein levels, CULLIN3/SPOP mediated ubiquitylation of BMI1 most likely has no bearing on protein stability ${ }^{23}$. Interestingly, a human BMI1 polymorphism resulting in a C18Y substitution increases ubiquitylation and proteasomal degradation ${ }^{24}$. Whether or not this sorts any effect on human health is currently not clear. 
Table 3.1. PTMs in PcG biology

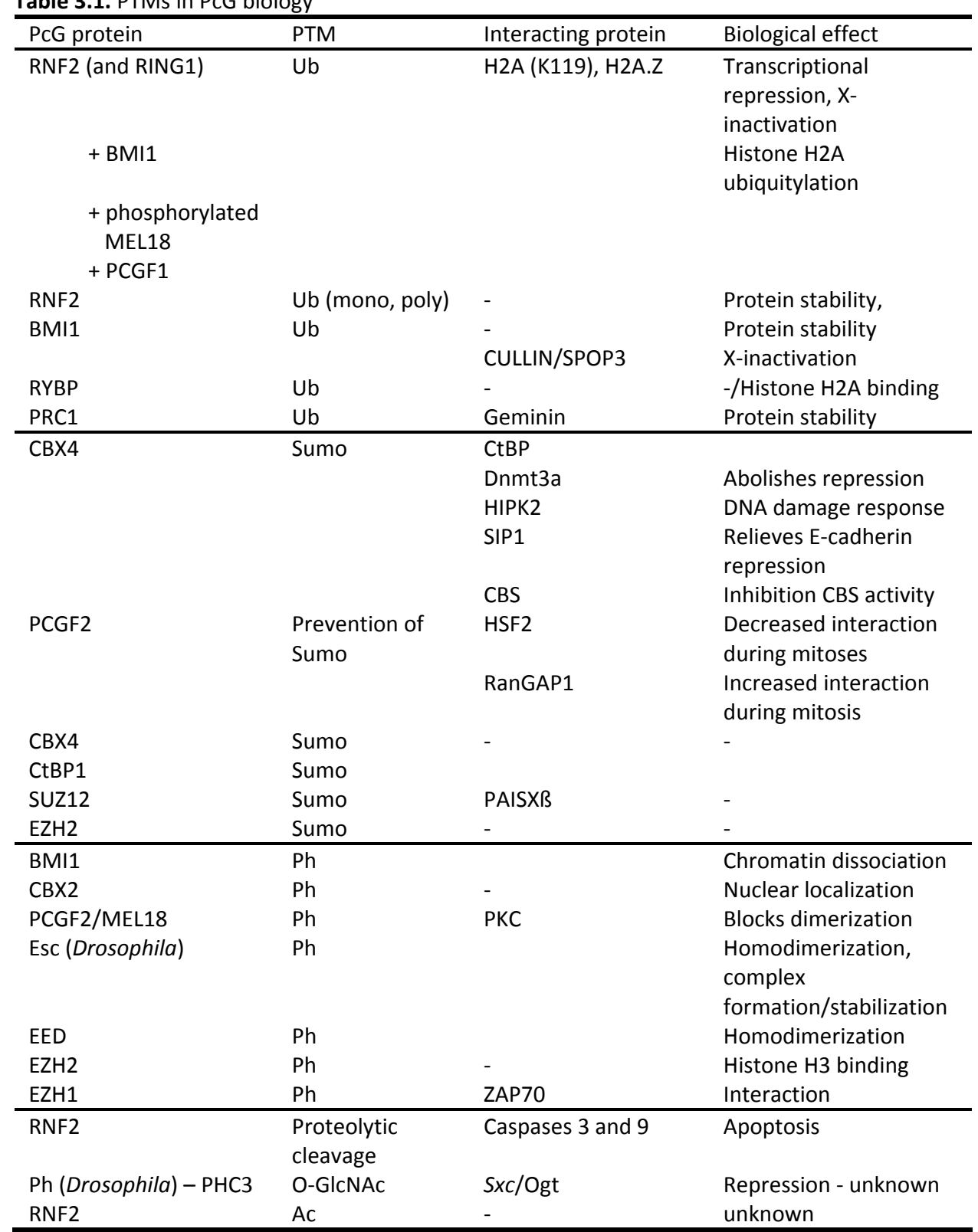

Listed are published biochemical connections between PcG and associated proteins; see main text for details on functional relationships.

The PcG protein RYBP (RING1 and YY1 binding protein) is mono-ubiquitylated by RING proteins, and binds H2AUb1, among other proteins, in vitro, through a zinc finger Ubiquitin binding domain (UBD) of the NZF type (Npl14 zinc finger). 
Talking to chromatin: post-translational modulation of PcG function

Although a UBD-NZF mutant still interacts with RING1 and RNF2, it prevents formation of Polycomb-bodies in osteosarcoma cells, suggesting a dominant negative role in PcG recruitment ${ }^{25}$. Thus, RYBP may play a role in engagement of specific transcription factors, and hence direction of PcG complexes to specific target genes ${ }^{17,26}$.

Combined, the above data shows that PRC proteins are engaged in numerous ubiquitin-dependent regulatory mechanisms, and that ubiquitylation is important for PcG-mediated silencing at multiple levels.

\section{Polycomb-mediated Sumoylation and Polycomb Sumoylation}

Although mechanistically not completely understood, one of the potential functional outcomes of PcG protein sumoylation is induction of transcriptional repression ${ }^{27}$. In support of a biologically relevant role in the context of transcriptional repression, sumoylation appears conserved throughout evolution. A genome-wide RNA interference screen in Drosophila cells identified proteins that, when absent, relieve sumo-dependent inactivation of the transcription factor $\mathrm{Sp}^{28}$. Among interactors identified were the PcG protein Sfmbt, the zinc-finger protein MEP-1 and $\mathrm{dMi}-2$, an ATP dependent chromatin remodeler which shows genetic interaction with $\mathrm{PcG}^{29}$; all three proteins bind Sp3-SUMO in vitro and all are recruited to promoters in a Sp3-sumoylation dependent manner ${ }^{28}$. Also in $C$. elegans a link was established between sumoylation and PCG proteins: the PcG-like protein SOP-2 interacts with UBC9 via its conserved SAM (sterile alpha motif/self association motif) ${ }^{30}$. SOP-2 sumoylated is required for in vivo localization to nuclear bodies and repression of Hox genes ${ }^{30}$.

The identification of CBX4 as a SUMO E3 ligase forged the first link between PcG function and SUMO. CtBP (carboxyl-terminus binding protein, an interaction partner of RING1 and other PCG proteins ${ }^{31}$ ) are sumoylated ${ }^{32,33}$. CBX4 interacts with E2 Ubc9 and CtBP and sequesters both proteins to PcG bodies. Multiple biological CBX4 targets have been identified which begin to link PCG-mediated sumoylation to relevant biological processes ${ }^{32,34-38}$. Among these targets is the de novo DNA methyltransferase (Dnmt3a). Despite its highly conserved nature among the PcG proteins $\mathrm{CBX} 2, \mathrm{CBX} 6, \mathrm{CBX} 7$ and $\mathrm{CBX} 8$, only the C-terminal $\mathrm{COOH}$ box of CBX4 interacts with Dnmt3a in a yeast two-hybrid setting. Dnmt3a is poly-sumoylated; sumoylation terminates the interaction of Dnmt3a with HDAC1/2 and completely abolishes its repressive ability in vitro, suggesting a role for PTMs in dynamic epigenetic regulation of gene expression ${ }^{35,36}$. DNA damage-induced homeodomain interacting protein kinase 2 (HIPK2) phosphorylates and activates CBX4 E3 sumo activity, whereas CBX4-mediated sumoylation of HIPK2 in turn enhances its ability to repress genes in response to 
Chapter 3

Table 3.2. Site-specific Polycomb sumoylation and ubiquitylation sites

\begin{tabular}{cccccccc}
\hline Complex & Name & $\begin{array}{c}\text { Alternative } \\
\text { symbol }\end{array}$ & $\begin{array}{c}\text { Accession } \\
\text { Number }\end{array}$ & $\begin{array}{c}\text { Total } \\
\text { nr AA }\end{array}$ & $\begin{array}{c}\text { Modification } \\
\text { Site }\end{array}$ & $\begin{array}{c}\text { Conservation } \\
\text { in Mouse }\end{array}$ & Ref \\
\hline PRC2 & SUZ12 & & Q15022 & 739 & K72 SUMO & K74 & 42 \\
& & & & & K73 SUMO & K75 & 42 \\
PRC1 & CBX4 & HPC2 & O00257 & 558 & K492 SUMO & K490 & $38,79,80$ \\
& Rnf2 & Ring1b & Q9CQJ4 & 336 & K112 Ub & K112* & 7 \\
PhoRC & YY1 & & P25490 & 414 & K288 SUMO & K288 & 81 \\
\hline
\end{tabular}

The table lists PTM confirmed by mass spectrometric and/or mutational analysis. AA: Amino Acid; SUMO: Sumoylation site; Ub: Ubiquitylation site.

DNA damage (Fig. 3.1C) ${ }^{38}$. This auto-regulatory feedback loop is likely relevant in the context of cellular DNA damage responses. Sumoylation of SIP1 (SMAD interacting protein 1) interferes with CtBP interaction and relieves repression of E-cadherin, an important regulator of EMT (epithelial mesenchymal transition) during development and tumorigenesis ${ }^{37}$. Furthermore $\mathrm{CBX} 4$ targets cystathionine beta-synthase (CBS), an enzyme involved in homocysteine to cysteine-conversion ${ }^{34}$. Sumoylation of CBS inhibited its enzymatic activity ${ }^{34}$. As homocysteine to cysteine conversion is an important step in the synthesis of SAdenosylmethionine (SAM), a major methyl-donor reagent for essential methylation reactions ${ }^{39}$, this may have obvious implications for local and global epigenetic regulation.

In the context of PRC1 function, the PCG protein PCGF2, appears to oppose sumoylation. PCGF2 binds, both in vitro and in vivo, heat shock factor 2 (HSF2), which is predominantly sumoylated during mitosis ${ }^{40}$. PCGF2 dissociates from HSF2 during mitosis and, conversely, recombinant PCGF2 inhibits in vitro sumoylation of HSF2. Thus PCGF2 may act as an anti-SUMO regulator ${ }^{40}$. PCGF2 also inhibits sumoylation of RanGAP1, which is independent of its RING domain ${ }^{41}$. Intriguingly, in contrast to HSF2, the interaction between PCGF2 and RanGAP1 increases during mitosis, suggesting a sumo-dependent switch of interaction partners of PCGF2 ${ }^{41}$.

PRC2 complex function is associated with sumoylation as well: SUZ12 and EZH2 (Fig. 3.1A) are both sumoylated; the E3 ligase for SUZ12 appears to be PAISXß, not CBX4. The exact biological role of SUZ12 sumoylation is not clear, as wild type or a non-sumoylatable SUZ12 3KR mutant both show similar H3K27me3 in a SUZ12 ${ }^{-/}$background, and 3KR co-localization with EZH2 and EED is not affected $^{42}$. An overview of experimentally confirmed site-specific sumoylation and ubiquitylation sites on PcG proteins is presented in Table 3.2.

In summary, sumoylation, like ubiquitylation emerges as a PTM relevant for regulation of gene expression. In contrast to ubiquityation, PcG-mediated 
Talking to chromatin: post-translational modulation of PcG function

sumoylation has not directly been linked to histone modifications yet. In stead, currently available data suggest a relevant role for sumoylation in dynamic interaction with non-PcG proteins in the context of cell physiology.

\section{Phosphorylation of PcG proteins}

Although thus far no kinases have been identified as PcG proteins, phosphorylation is a common PTM on PcG proteins. Recent observations begin to show that signaling, which triggers downstream phosphorylation events, affects subcellular localization, protein-interactions within complexes, enzymatic activity and chromatin-association of several PcG proteins and other factors. The first report of PcG protein phosphorylation suggested a meaningful regulatory role for PcG phosphorylation, as phosphorylated BMI1 dissociates from chromatin at late S-phase, when chromatin is assembled "de novo" ${ }^{\prime 43}$. Also MBLR (MEL18 and BMI1-Like RING finger protein; PCGF6) is predominantly phosphorylated in $\mathrm{G} 2 / \mathrm{M}^{44}$. In vitro kinase assays suggested PCGF6 as a substrate for $\mathrm{CDK} 7^{44}$. Interestingly, also Trithorax orthologs are phosphorylated in a cell cycle dependent manner ${ }^{45}$, suggesting phosphorylation as a common mechanism to temporarily relocate chromatin associated proteins. Phosphorylation may affect individual PCG proteins in other biologically relevant ways. CBX2/M33 phosphorylation affects nuclear localization: high-mobility (unmodified) CBX2 resides in the cytoplasm in mouse livers, whereas lowmobility isoforms localize to the nucleus ${ }^{46}$. Dimerization of PCGF2, is blocked in the presence of protein kinase C (PKC) ${ }^{47}$. Also NSPC1/ PCGF1 is functionally targeted by phosphorylation: a synthetic phospho-mutant GAL4-DBD-NSPc1 no longer transcriptionally represses a GAL4-LUC-reporter ${ }^{48}$.

Phosphorylated Drosophila PRC2 protein Extra sex combs (Esc) is preferentially found in a $600 \mathrm{kDa}$ complex with PcG protein enhancer of zeste (E(z)) and Esc phosphorylation is required for formation and stability of a larger $E s c / E(z)$ complex containing $\mathrm{PCL}$ and $\mathrm{RPD}^{49}{ }^{40}$. Both Esc and EED (its mammalian orthologue) are phosphorylated in a domain responsible for Esc/EED homodimerization $^{50}$. CK1 and CK2 may be the responsible kinases, as they phosphorylate Esc and EED in vitro and promote Esc/EED homodimerization. In addition, phosphorylation appears to regulate EZH2, a PRC2 histone methyl transferase (HMT) which trimethylates Lysine 27 on histone 3 (H3K27me3) ${ }^{51}$ : AKT (PKB)-induced EZH2 Ser21ph suppresses its methyltransferase activity by impeding EZH2 binding to histone H3 (Fig. 3.1D) ${ }^{52}$. In addition, phosphorylation affects self-recruitment of EZH2 to its own mark, which may have bearing on maintenance of repression throughout cell divisions ${ }^{53,54}$. Also the PcG EZH2 homologue EZH1 is phosphorylated: the tyrosine kinase $\mathrm{p} 56^{\text {lck }}$ is required for the phospho-dependent association between EZH1 and zeta associated protein-70 
(ZAP-70) in activated T cells ${ }^{55}$; whether phospho-residues within EZH1 and ZAP70 are directly involved in binding awaits experimental validation.
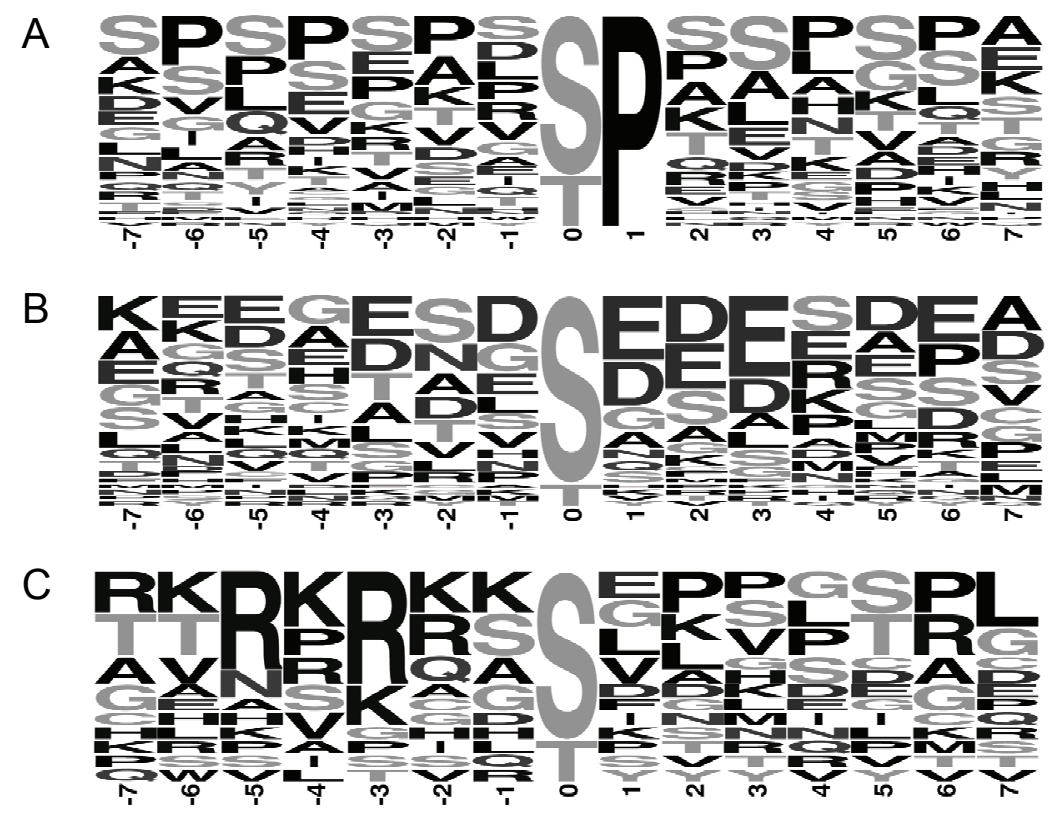

Figure 3.2. Classification of $S / T$ phosphorylation sites into general kinase recognition sequence categories.

At present, not all consensus phosphorylation motifs are known for all kinases. A number of general phospho-site classes have been annotated based on amino acid sequences surrounding S/T phosphorylation sites: proline-directed, acidic, basic and otherwise ${ }^{78}$. (A-C) Sequence logos for PcG phosphorylation motifs of Proline-directed $(A ; n=42)$ acidic $(B ; n=36)$ and basic $(C ; n=15)$ categories where the phosphorylated residue $(S / T)$ is centered were generated with Weblogo (http://weblogo.berkeley.edu). Only serine and threonine phosphorylation sites were taken into account when a full 15-mer sequence was available. To avoid sequence bias only non-overlapping human and mouse PcG phosphorylation sites were used. Centered 15-mer sequences were assigned to a motif class sequentially by following a binary decision tree as follows: $\mathrm{P}$ at +1 (Prodirected), 5 or more $E / D$ at +1 to +6 (acidic), R/K at -3 (basic), $D / E$ at $+1 /+2$ or +3 (acidic), 2 or more $\mathrm{R} / \mathrm{K}$ at -6 to -1 (basic), otherwise. (A) Although phospho-site numbers are low and thus no solid deductions are warranted, it is apparent for the proline-directed class (classified by a $\mathrm{P}$ in the +1 position), that prolines are not limited to +1 , but are abundant in various - and + positions. (B) In the acidic motif, characterized by the presence of the amino acids glutamic acid (E) and aspartic acid $(D)$ in the + residues, E/D's are present in the - positions. (C) In basic motifs, Arginine (R) is predominantly found in -3 positions, in addition to -5 .

\section{Classification of PcG-phospho-sites}

Most current published information on PcG phosphorylation neither unequivocally identifies responsible kinases nor targeted amino acid residues, and the majority of existing in vitro data will have to be confirmed and 
functionally tested in vivo. Over recent years several large-scale phosphoproteomic analyses were published. We have extracted PcG-related data from these and our own studies; this reveals numerous PcG phosphorylation sites: to date 118 human (Table 3.3) and 31 mouse (data not shown) PcG phosphorylation sites have been published; so far 14 of these phosphorylation events are shared by both species (Table 3.4). Amino acids surrounding phosphorylation sites direct kinase-binding and hence define kinase-substrate specificity. Classification of currently known PcG phosphorylation sites into predicted phospho-site categories shows that most sites group in the prolinedirected or acidic class (Table 3.5; Fig. 3.2A-C). Kinases that recognize/bind the proline-directed residues belong to the MAPkinase family; acidic motifs are phosphorylated by casein kinase II (CK2); kinases targeting basic motifs belong to the AKT/PKB and PKA types ${ }^{56}$. Consistent with our analysis. published PCGF2/6 (CK1/2) and EZH2 phospho-sites (AKT/PKB) classify in the acidic and basic target group, respectively.

Although it is not known at present whether PcG phosphorylation directly affects chromatin association, their correlation (i.e. signaling induced phosphorylation and chromatin dissociation) suggests cells use phosphorylation cascades to relay environment cues to chromatin, where reprogramming of gene activity includes epigenetic remodeling events ${ }^{57}$. Consistent with a functional link between MAPK signaling and PcG function, we recently showed that PRC1/chromatin association is disrupted downstream of MAPK activation ${ }^{57}$. In summary, it is clear that phosphorylation is a relevant part of PcG biology. Further characterization and functional validation of these phosphorylation sites will be pivotal for our understanding of the cellular conditions under which PcG phosphorylation take place, the regulatory pathways involved and how cells use these pathways to modulate chromatin structure to allow biologically appropriate responses.

\section{Other PTMs in PcG biology}

\section{GIcNAcylation}

Recently, the Drosophila PcG gene super sex combs (sxc) was reported to encode the enzyme O-linked $\mathrm{N}$-acetylglucosamine (O-GlcNAc) transferase $(\mathrm{Ogt})^{58}$. PRC1 protein Polyhomeotic (Ph), is GlcNAcylated by sxc/Ogt in vivo. PRC1-mediated repression is dependent on functional sxc/Ogt, possibly via GlcNAcylation of $\mathrm{Ph}^{58}$. Interestingly, the process appears conserved across species, as the mammalian orthologue PHC3 is O-GlcNAcylated as well ${ }^{59}$. Analogous to PcG, GlcNAcylation of the histone methyltransferase MLL5, a trithorax-like protein, generally assumed to counteract PcG function, regulates 
Chapter 3

Table 3.3. Human Polycomb phosphorylation sites

\begin{tabular}{|c|c|c|c|c|c|c|c|}
\hline Complex & Name & $\begin{array}{c}\text { Alternative } \\
\text { symbol }\end{array}$ & $\begin{array}{l}\text { Accession } \\
\text { Number }\end{array}$ & $\begin{array}{l}\text { Total } \\
\text { nr AA } \\
\end{array}$ & $\begin{array}{l}\text { Phospho- } \\
\text { site } \\
\end{array}$ & $\begin{array}{c}\text { Conservation } \\
\text { in Mouse } \\
\end{array}$ & Ref \\
\hline \multirow[t]{24}{*}{ PRC2 } & EZH1 & & Q92800 & 747 & - & - & - \\
\hline & EZH2 & & Q15910 & 746 & S21 & S21 & 52 \\
\hline & & & & & Т339 & T339 & 82 \\
\hline & & & & & S362 & S362 & 83 \\
\hline & & & & & S363 & S363 & 83 \\
\hline & & & & & S366 & S366 & 82,83 \\
\hline & & & & & T367 & T367 & 82,83 \\
\hline & & & & & S380 & S380 & 84 \\
\hline & & & & & T487 & T487* & $82,83,85-90$ \\
\hline & EED & & 075530 & 441 & S25 & S25 & $82 \wedge$ \\
\hline & & & & & S34 & S34 & 82 \\
\hline & & & & & S43 & S43 & $82 \wedge$ \\
\hline & & & & & S46 & S46 & $82 \wedge$ \\
\hline & & & & & T50 & T50 & $82 \wedge$ \\
\hline & & & & & T55 & T55 & 82 \\
\hline & & & & & T57 & T57 & 82 \\
\hline & SUZ12 & & Q15022 & 739 & S37 & S37 & 82 \\
\hline & & & & & T131 & T133 & 91 \\
\hline & & & & & S139 & S141 & 91 \\
\hline & & & & & S382 & S384 & 83 \\
\hline & & & & & T418 & NC & 92 \\
\hline & & & & & S541 & S543 & 82 \\
\hline & & & & & S546 & S548* & $82,83,85,87,90$ \\
\hline & & & & & S583 & S585* & 83,87 \\
\hline \multirow[t]{15}{*}{ PRC1 } & $\mathrm{CBX} 2$ & HPC1 & Q14781 & 532 & - & - & - \\
\hline & CBX4 & HPC2 & 000257 & 558 & Y205 & Y207 & 93 \\
\hline & & & & & S347 & S350 & $82 \wedge$ \\
\hline & & & & & T349 & T352 & $82 \wedge$ \\
\hline & & & & & S413 & S427 & 90 \\
\hline & & & & & T415 & T412 & 83 \\
\hline & & & & & S430 & S427 & 87 \\
\hline & & & & & T435 & T432 & 83 \\
\hline & & & & & T495 & NC & 38 \\
\hline & CBX6 & & 095503 & 412 & S107 & S107 & 83 \\
\hline & & & & & S301 & S302 & 87 \\
\hline & & & & & S303 & S304 & 87 \\
\hline & CBX7 & & 095931 & 251 & - & - & - \\
\hline & CBX8 & HPC3 & Q9HC52 & 389 & S110 & S110 & $82,88, \#$ \\
\hline & & & & & S130 & NC & 82 \\
\hline
\end{tabular}


Talking to chromatin: post-translational modulation of PcG function

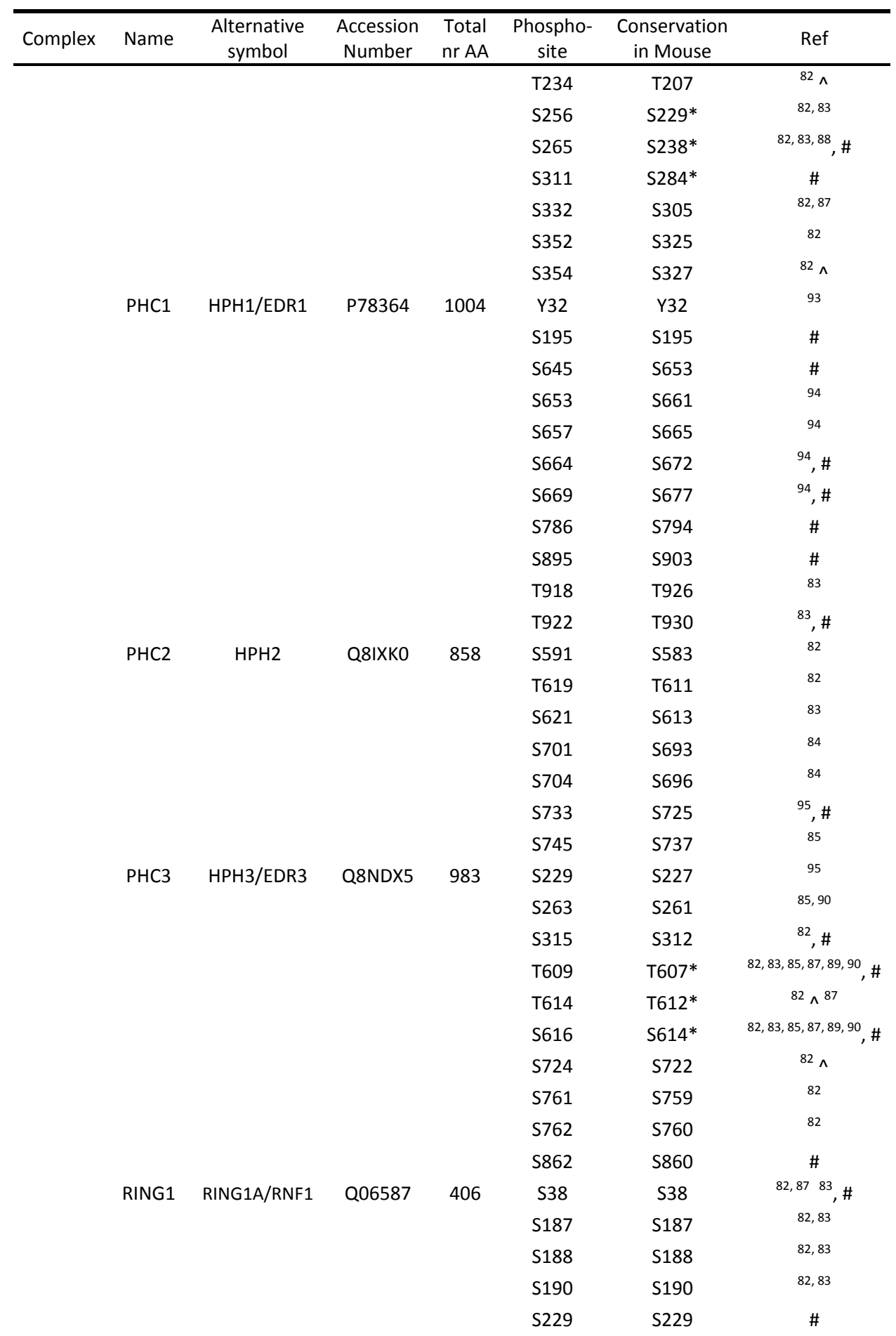


Chapter 3

\begin{tabular}{|c|c|c|c|c|c|c|c|}
\hline Complex & Name & $\begin{array}{c}\text { Alternative } \\
\text { symbol }\end{array}$ & $\begin{array}{c}\text { Accession } \\
\text { Number }\end{array}$ & $\begin{array}{l}\text { Total } \\
\text { nr AA }\end{array}$ & $\begin{array}{l}\text { Phospho- } \\
\text { site }\end{array}$ & $\begin{array}{l}\text { Conservation } \\
\text { in Mouse }\end{array}$ & Ref \\
\hline & \multirow[t]{2}{*}{ RNF2 } & \multirow[t]{2}{*}{ RING1B } & \multirow[t]{2}{*}{ Q99496 } & \multirow[t]{2}{*}{336} & S41 & S41 & 63 \\
\hline & & & & & S168 & S168 & 90 \\
\hline & \multirow[t]{3}{*}{ BMI1 } & \multirow[t]{3}{*}{ PCGF4 } & \multirow[t]{3}{*}{ P35226 } & \multirow[t]{3}{*}{326} & S251 & S249* & 90 \\
\hline & & & & & S253 & S251* & 90 \\
\hline & & & & & S255 & S253* & 90 \\
\hline & \multirow[t]{4}{*}{ PCGF2 } & \multirow[t]{4}{*}{ MEL18 } & \multirow[t]{4}{*}{ P35227 } & \multirow[t]{4}{*}{344} & Y197 & Y197 & 93 \\
\hline & & & & & Y205 & Y205 & 93 \\
\hline & & & & & Y206 & Y206 & 93 \\
\hline & & & & & T344 & gap & 82 \\
\hline \multirow[t]{6}{*}{ PhoRC } & \multirow[t]{6}{*}{ YY1 } & & \multirow[t]{6}{*}{ P25490 } & \multirow[t]{6}{*}{414} & S118 & S120* & 89 \\
\hline & & & & & S184 & S184 & 84 \\
\hline & & & & & S247 & S247* & $82,83,85,88,89$ \\
\hline & & & & & Y251 & Y251 & 82 \\
\hline & & & & & T348 & T348 & 82,96 \\
\hline & & & & & T378 & T378 & 82,83 \\
\hline \multirow[t]{25}{*}{ Other } & PCGF1 & NSPc1 & Q9BSM1 & 259 & - & - & - \\
\hline & PCGF6 & MBLR & Q9BYE7 & 350 & $\mathrm{~S} 30^{\$}$ & S34 & 44 \\
\hline & SCMH1 & & Q96GD3 & 660 & S649 & S653 & 90,94 \\
\hline & \multirow[t]{3}{*}{ SCML1 } & & \multirow[t]{3}{*}{ Q9UN30 } & \multirow[t]{3}{*}{208} & S15 & N.A. & $82 \wedge$ \\
\hline & & & & & S17 & N.A. & 82 \\
\hline & & & & & S117 & N.A. & 88 \\
\hline & \multirow[t]{18}{*}{ SCML2 } & & \multirow[t]{18}{*}{ Q9UQR0 } & \multirow[t]{18}{*}{700} & S255 & N.A. & $82 \wedge$ \\
\hline & & & & & S256 & N.A. & 82 \\
\hline & & & & & S258 & N.A. & 82 \\
\hline & & & & & S267 & N.A. & 82 \\
\hline & & & & & S299 & N.A. & 82 \\
\hline & & & & & S300 & N.A. & 82 \\
\hline & & & & & T305 & N.A. & 82 \\
\hline & & & & & S495 & N.A. & $82 \wedge$ \\
\hline & & & & & S499 & N.A. & $82,83,85,86$ \\
\hline & & & & & T503 & N.A. & 82 \\
\hline & & & & & S511 & N.A. & $82,83,85,86$ \\
\hline & & & & & S570 & N.A. & 95 \\
\hline & & & & & S576 & N.A. & 82 \\
\hline & & & & & T581 & N.A. & $82 \wedge$ \\
\hline & & & & & S583 & N.A. & 82 \\
\hline & & & & & S590 & N.A. & 82,83 \\
\hline & & & & & S594 & N.A. & 82,83 \\
\hline & & & & & S606 & N.A. & 82 \\
\hline & RYBP & & Q8N488 & 228 & S127 & S127 & 82 \\
\hline
\end{tabular}


Talking to chromatin: post-translational modulation of PcG function

\begin{tabular}{|c|c|c|c|c|c|c|c|}
\hline Complex & Name & $\begin{array}{c}\text { Alternative } \\
\text { symbol }\end{array}$ & $\begin{array}{l}\text { Accession } \\
\text { Number }\end{array}$ & $\begin{array}{l}\text { Total } \\
\text { nr AA }\end{array}$ & $\begin{array}{l}\text { Phospho- } \\
\text { site }\end{array}$ & $\begin{array}{c}\text { Conservation } \\
\text { in Mouse }\end{array}$ & Ref \\
\hline & & & & & S130 & $\mathrm{S} 130$ & 82 \\
\hline & & & & & S203 & S203 & $82 \wedge$ \\
\hline & & & & & T215 & T215 & $82 \wedge$ \\
\hline
\end{tabular}

Asterix $\left({ }^{*}\right)$ indicates sites that were detected as phosphorylation sites in mouse cells as well; $\mathrm{AA}$ : Amino Acid; NC: non-conserved; N.A.: Not available; \# marks unpublished results (HN,JD,JWV); $\$$ Site was referred to as S32 in original article; ${ }^{\wedge}$ : These putative phosphorylation sites do not reach a sufficiently high probability based on prediction algorithms used.

methylation of $\mathrm{H} 3 \mathrm{~K}^{60}{ }^{60}$. These findings begin to show that GlcNAcylation of chromatin factors, such as PcG proteins, is relevant for epigenetic regulation and provide important leads for future study.

\section{Proteolytic cleavage}

Other than ubiquitin-26S proteasome dependent protein degradation, as holds for PCG proteins RNF2 and BMI1 ${ }^{22}$, proteolytic cleavage may also occur via activated caspases ${ }^{61}$. Caspase substrates include i.a. structural proteins, such as actin, vimentin and nuclear lamins and proteins involved in transcription and translation, such as NFkB and translation initiation factors ${ }^{61}$. Recently RNF2 was identified as a direct substrate of caspases-3 and 9 in apoptotic cells ${ }^{62}$. The exact function of RNF2 cleavage during apoptosis remains illusive, but it is possibly a prerequisite for nuclear condensation and DNA fragmentation to occur. Whether PcG protein cleavage is relevant outside the context of apoptosis is currently unclear.

\section{Acetylation}

Currently acetylation of only one PcG protein has been reported: RNF2 is acetylated at $\mathrm{S} 2$, which is accompanied by a $\mathrm{N}$-terminal methionine excision ${ }^{63}$. The significance of this modification in relation to PcG function is not known.

Table 3.4. Summary of PcG phosphorylation sites

\begin{tabular}{lllll}
\hline residue & Human & Mouse & $\begin{array}{l}\text { Human + Mouse non- } \\
\text { overlapping }\end{array}$ & $\begin{array}{l}\text { Human + Mouse } \\
\text { overlapping }\end{array}$ \\
\hline Serine & $87(74 \%)$ & $26(83 \%)$ & $101(75 \%)$ & $12(86 \%)$ \\
Threonine & $25(20 \%)$ & $5(16 \%)$ & $28(21 \%)$ & $2(14 \%)$ \\
Tyrosine & $6(6 \%)$ & - & $6(4 \%)$ & - \\
Total & $118(100 \%)$ & $31(100 \%)$ & $135(100 \%)$ & $14(100 \%)$ \\
\hline
\end{tabular}

Classification of PcG phospho-sites based on common phospho-amino acids. 


\section{Signaling to Chromatin: Post-translational Cross-talk to Polycomb}

It is evident that PcG proteins are subject to numerous different PTM (i.a. ubiquitylation, sumoylation, phosphorylation and GlcNAcylation) and, besides, harbor intrinsic enzymatic modifying activities themselves (HMT, ubiquitin and SUMO E3 ligase, O-GICNAc transferase). How these PTM relate to each other is currently far from clear, however, several studies begin to unveil an intricate interplay between different PTMs, their effect at the molecular level and their biological relevance (Fig. 3.1). Complex formation between PCGFs and RNF2 regulates $\mathrm{H} 2 \mathrm{~A}$ ubiquitin E3 ligase activity ${ }^{16}$. PCGF2 phosphorylation is required for substrate recognition in a relevant chromatin context, as dephosphorylated RNF2/PCGF2 complexes no longer efficiently ubiquitylate nucleosomes ${ }^{16}$. Similar regulation likely holds true for its close relatives BMI1 and PCGF1. Phosphorylated EZH2 has reduced methyltransferase activity toward histone $\mathrm{H} 3$, as a result of reduced substrate binding ${ }^{52}$. Phosphorylation and sumoylation mediated auto-regulatory feedback between CBX4 and HIPK2 has obvious relevance for DNA damage responses ${ }^{38}$. Recently the PRC1 complex was identified as the E3 ubiquitin ligase for Geminin, an inhibitor of replication licensing factor Cdt1. PHC1 (Rae28) deficiency in mice impairs ubiquitin/S26proteasome mediated degradation of Geminin and has direct consequences for cell cycle progression in the haematopoietic lineage ${ }^{64}$.

In keeping with differential chromatin association of $\mathrm{Ph}$ as compared to other PRC1 proteins, GlcNAcylated Ph does not co-purify with other PRC1 components in larval extracts, whereas it does in embryonic nuclear extracts ${ }^{58}$. Phosphorylation and GlcNAcylation mostly affect the same amino acids $(\mathrm{S} / \mathrm{T})$, hence an intricate interplay between these modifications may be predicted, either via competitive occupancy at the same site or alternative occupancy at adjacent sites ${ }^{65}$.

Although clearly numerous PTM affect PcG biology, molecular mechanisms in signaling to chromatin, down-stream modulation of epigenetic marking and the establishment and transfer of heritable epigenetic states remain largely elusive. Specific consensus/motif based kinase-substrate interactions most likely define and direct signaling-induced remodeling and/or other epigenetically relevant events at the chromatin level. In contrast, context-dependent variation in sumoylation sites is less well-defined and the role of select consensus motifs in ubiquitylation is largely unknown. Although speculative, this may suggest that once signaling is triggered, a hierarchical sequence of PTMs is initiated, the target-specificity (i.e. networks, pathways, complexes) of which is defined by phosphorylation events, whereas down-stream effects (i.a. altered protein interactions, activity or stability) are 'merely' consequential, and controlled by numerous other PTM. Indeed ubiquitylation, sumoylation, GlyNAcylation and 
phosphorylation are probably functionally linked in PcG biology, as important cross talk between these PTMs exists in many ways in other systems ${ }^{66}$. In this context important open issues are for instance how exactly PCG PTMs functionally relate to each other, i.e. whether PTM act separately, processively or combinatorially. Signaling-induced PTMs are generally reversible, proteolytic cleavage excluded, hence many chromatin-associated, epigenetic regulators are presumably rapidly converted to their initial post-translational status upon signal recession. However, at the receiving end, stable, heritable covalent histone modifications appear somehow exempt from such regulation. Notions like these should provide important basis for future hypothesis-driven research.

Table 3.5. Classification of PcG S/T phosphorylation sites

\begin{tabular}{ll}
\hline class & Human + Mouse non-overlapping \\
\hline Pro-directed & $42(37 \%)$ \\
Acidic & $36(32 \%)$ \\
Basic & $15(13 \%)$ \\
Other & $20(18 \%)$ \\
Total & $113(100 \%)$ \\
\hline
\end{tabular}

Classification of PcG phosphorylation sites in relation to amino acid context. Only putative Ser and Thr phosphorylation sites were taken into account when a full 15-mer sequence was available and a sufficiently high phosphorylation probability was predicted

\section{Conclusions}

It is evident that chromatin-associated protein complexes, like PcG proteins, are targets for cell signaling. These signaling events lead to PTMs that may affect chromatin binding, complex composition and catalytic activity. We and others found that multiple kinases target PcG proteins. In addition, PcG proteins are subject to ubiquitylation, sumoylation and additional PTM. Studies recapitulated in this Chapter have only just begun to unravel the complexity and multiple layers of regulation of PcG function. PcG-mediated transcriptional silencing already appears a much more complex process than the antiquated view that PRCs physically obstruct transcription factor binding to DNA, and ongoing studies refine positioning of PcG-function in the proper cellular context. Current conservative estimates predict the existence of anywhere between 60-100 or more mammalian PcG(-related) proteins, each likely with multiple phosphorylation and/or ubiquitylation, sumoylation and potentially numerous other PTM sites, including acetylation and methylation ${ }^{67,68}$. In stark contrast with this: at the moment only two PCG phospho-specific antisera exist ${ }^{44,52}$. Clearly there is a need for additional experimental tools and approaches.

Ultimately PTMs are aimed at concerted regulation of a number of chromatinbased processes in which PcG proteins play a role, including dynamic 
transcriptional regulation, long term silencing, DNA replication and DNA damage responses, to ensure proper regulation of cell fate and survival. Increased insight into mechanisms employed by cells to target chromatin and chromatinassociated factors, among which PcG, and their physiological consequences at the chromatin level will be important for further development and application of epigenetic strategies in for instance regenerative medicine. As many of the processes targeting and involving PcG function are etiologically linked to disease (e.g. overexpression in cancer, bypass of replicative senescence ${ }^{69-72}$ ), a better fundamental understanding of gene-environment interactions at the molecular level will eventually contribute to the development of therapeutic and preventive strategies relevant for western type diseases, including obesity, diabetes and cancer.

\section{Acknowledgements}

Collection of PcG annotations was based on www.uniprot.org and www.phosphosite.org. Cross-species sequence conservation was verified by aligning human and murine homologous sequences in Geneious software (Biomatters, Auckland New Zealand), using default settings. PTM-related protein nomenclature was based on published consensus ${ }^{73}$. The authors thank M. Vidal (Madrid, Spain) and R.Shiri-Sverdlov for critically reading the manuscript. 


\section{References}

1. Lewis EB. A gene complex controlling segmentation in Drosophila. Nature. Dec 7 1978;276(5688):565-570.

2. Orlando V. Polycomb, epigenomes, and control of cell identity. Cell. Mar 7 2003;112(5):599-606.

3. van Lohuizen M. Functional analysis of mouse Polycomb group genes. Cell Mol Life Sci. 1998;54(1):71-79.

4. Bracken AP, Dietrich N, Pasini D, et al. Genome-wide Mapping of Polycomb Target Genes Unravels Their Roles in Cell Fate Transitions. Genes and Development. May 1 2006;20(9):1123-1136.

5. Otte AP, Kwaks THJ. Gene repression by Polycomb group protein complexes: a distinct complex for every occasion? Current Opinion in Genetics \& Development. 2003;13(5):448-454.

6. Jason $\mathrm{L}$, Moore SC, Lewis JD, et al. Histone ubiquitination: a tagging tail unfolds? Bioessays. Feb 2002;24(2):166-174.

7. Buchwald G, van der Stoop P, Weichenrieder O, et al. Structure and E3-ligase activity of the Ring-Ring complex of polycomb proteins Bmi1 and Ring1b. Embo J. Jun 7 2006;25(11):2465-2474.

8. de Napoles M, Mermoud JE, Wakao R, et al. Polycomb group proteins Ring1A/B link ubiquitylation of histone $\mathrm{H} 2 \mathrm{~A}$ to heritable gene silencing and $\mathrm{X}$ inactivation. Dev Cell. Nov 2004;7(5):663-676.

9. Fang J, Chen T, Chadwick B, et al. Ring1b-mediated H2A ubiquitination associates with inactive $X$ chromosomes and is involved in initiation of $X$ inactivation. $J$ Biol Chem. Dec 17 2004;279(51):52812-52815.

10. Leeb M, Wutz A. Ring1B is crucial for the regulation of developmental control genes and PRC1 proteins but not X inactivation in embryonic cells. J Cell Biol. Jul 16 2007;178(2):219-229.

11. Schoeftner S, Sengupta AK, Kubicek S, et al. Recruitment of PRC1 function at the initiation of $X$ inactivation independent of PRC2 and silencing. Embo J. Jun 82006.

12. Sarcinella E, Zuzarte PC, Lau PN, et al. Monoubiquitylation of H2A.Z distinguishes its association with euchromatin or facultative heterochromatin. Mol Cell Biol. Sep 2007;27(18):6457-6468.

13. Wang $\mathrm{H}$, Wang L, Erdjument-Bromage $\mathrm{H}$, et al. Role of histone $\mathrm{H} 2 \mathrm{~A}$ ubiquitination in Polycomb silencing. Nature. Oct 14 2004;431(7010):873-878.

14. Lagarou A, Mohd-Sarip A, Moshkin YM, et al. dKDM2 couples histone H2A ubiquitylation to histone $\mathrm{H} 3$ demethylation during Polycomb group silencing. Genes Dev. Oct 15 2008;22(20):2799-2810.

15. Cao R, Tsukada $\mathrm{Y}$, Zhang Y. Role of Bmi-1 and Ring1A in H2A ubiquitylation and Hox gene silencing. Mol Cell. Dec 22 2005;20(6):845-854.

16. Elderkin S, Maertens GN, Endoh M, et al. A phosphorylated form of Mel-18 targets the Ring1B histone $\mathrm{H} 2 \mathrm{~A}$ ubiquitin ligase to chromatin. Mol Cell. Oct 12 2007;28(1):107-120.

17. Gearhart MD, Corcoran CM, Wamstad JA, et al. Polycomb group and SCF ubiquitin ligases are found in a novel BCOR complex that is recruited to BCL6 targets. Mol Cell Biol. Sep 2006;26(18):6880-6889. 
18. Wu X, Gong Y, Yue J, et al. Cooperation between EZH2, NSPc1-mediated histone $\mathrm{H} 2 \mathrm{~A}$ ubiquitination and Dnmt1 in HOX gene silencing. Nucleic Acids Res. Jun 2008;36(11):3590-3599.

19. Li Z, Cao R, Wang M, et al. Structure of a Bmi-1-Ring1B polycomb group ubiquitin ligase complex. J Biol Chem. Jul 21 2006;281(29):20643-20649.

20. Kentsis A, Borden KL. Construction of macromolecular assemblages in eukaryotic processes and their role in human disease: linking RINGs together. Curr Protein Pept Sci. Jul 2000;1(1):49-73.

21. Laney JD, Hochstrasser M. Substrate targeting in the ubiquitin system. Cell. May 14 1999;97(4):427-430.

22. Ben-Saadon $R$, Zaaroor $D$, Ziv $T$, et al. The polycomb protein Ring1B generates self atypical mixed ubiquitin chains required for its in vitro histone $\mathrm{H} 2 \mathrm{~A}$ ligase activity. Mol Cell. Dec 8 2006;24(5):701-711.

23. Hernandez-Munoz I, Lund AH, van der Stoop $\mathrm{P}$, et al. Stable X chromosome inactivation involves the PRC1 Polycomb complex and requires histone MACROH2A1 and the CULLIN3/SPOP ubiquitin E3 ligase. Proc Natl Acad Sci U S A. May 24 2005;102(21):7635-7640.

24. Zhang J, Sarge KD. Identification of a polymorphism in the RING finger of human Bmi-1 that causes its degradation by the ubiquitin-proteasome system. FEBS Lett. Feb 202009.

25. Arrigoni R, Alam SL, Wamstad JA, et al. The Polycomb-associated protein Rybp is a ubiquitin binding protein. FEBS Lett. Nov 13 2006;580(26):6233-6241.

26. Trimarchi JM, Fairchild B, Wen J, et al. The E2F6 transcription factor is a component of the mammalian Bmi1- containing polycomb complex. Proc Natl Acad Sci U S A. 2001;98(4):1519-1524.

27. Gill G. Something about SUMO inhibits transcription. Curr Opin Genet Dev. Oct 2005;15(5):536-541.

28. Stielow B, Sapetschnig A, Kruger I, et al. Identification of SUMO-dependent chromatin-associated transcriptional repression components by a genome-wide RNAi screen. Mol Cell. Mar 28 2008;29(6):742-754.

29. Kehle J, Beuchle D, Treuheit $S$, et al. dMi-2, a hunchback-interacting protein that functions in polycomb repression. Science. Dec 4 1998;282(5395):1897-1900.

30. Zhang $\mathrm{H}$, Smolen $\mathrm{GA}$, Palmer $\mathrm{R}$, et al. SUMO modification is required for in vivo Hox gene regulation by the Caenorhabditis elegans Polycomb group protein SOP-2. Nat Genet. May 2004;36(5):507-511.

31. Sewalt RG, Gunster MJ, van der Vlag J, et al. C-Terminal binding protein is a transcriptional repressor that interacts with a specific class of vertebrate Polycomb proteins. Mol Cell Biol. Jan 1999;19(1):777-787.

32. Kagey MH, Melhuish TA, Wotton D. The polycomb protein Pc2 is a SUMO E3. Cell. Apr 4 2003;113(1):127-137.

33. Wotton D, Merrill JC. Pc2 and SUMOylation. Biochem Soc Trans. Dec 2007;35(Pt 6):1401-1404.

34. Agrawal N, Banerjee R. Human polycomb 2 protein is a SUMO E3 ligase and alleviates substrate-induced inhibition of cystathionine beta-synthase sumoylation. PLOS ONE. 2008;3(12):e4032.

35. Li B, Zhou J, Liu $P$, et al. Polycomb protein $\mathrm{Cbx} 4$ promotes SUMO modification of de novo DNA methyltransferase Dnmt3a. Biochem J. Jul 15 2007;405(2):369-378. 
36. Ling $\mathrm{Y}$, Sankpal UT, Robertson AK, et al. Modification of de novo DNA methyltransferase 3a (Dnmt3a) by SUMO-1 modulates its interaction with histone deacetylases (HDACs) and its capacity to repress transcription. Nucl. Acids Res. January 29, 2004 2004;32(2):598-610.

37. Long J, Zuo D, Park M. Pc2-mediated sumoylation of Smad-interacting protein 1 attenuates transcriptional repression of E-cadherin. J Biol Chem. Oct 21 2005;280(42):35477-35489.

38. Roscic A, Moller A, Calzado MA, et al. Phosphorylation-dependent control of Pc2 SUMO E3 ligase activity by its substrate protein HIPK2. Mol Cell. Oct 6 2006;24(1):77-89.

39. Fontecave M, Atta M, Mulliez E. S-adenosylmethionine: nothing goes to waste. Trends Biochem Sci. May 2004;29(5):243-249.

40. Zhang J, Goodson ML, Hong Y, et al. MEL-18 Interacts with HSF2 and the SUMO E2 UBC9 to Inhibit HSF2 Sumoylation. J Biol Chem. Mar 21 2008;283(12):7464-7469.

41. Zhang J, Sarge KD. Mel-18 interacts with RanGAP1 and inhibits its sumoylation. Biochem Biophys Res Commun. Oct 17 2008;375(2):252-255.

42. Riising EM, Boggio R, Chiocca $S$, et al. The polycomb repressive complex 2 is a potential target of SUMO modifications. PLOS ONE. 2008;3(7):e2704.

43. Voncken JW, Schweizer D, Aagaard L, et al. Chromatin-association of the Polycomb group protein BMI1 is cell cycle-regulated and correlates with its phosphorylation status. J Cell Sci. Dec 1999;112 ( Pt 24):4627-4639.

44. Akasaka T, Takahashi N, Suzuki M, et al. MBLR, a new RING finger protein resembling mammalian Polycomb gene products, is regulated by cell cycledependent phosphorylation. Genes Cells. Aug 2002;7(8):835-850.

45. Muchardt C, Reyes JC, Bourachot B, et al. The hbrm and BRG-1 proteins, components of the human SNF/SWI complex, are phosphorylated and excluded from the condensed chromosomes during mitosis. Embo J. 1996;15(13):3394-3402.

46. Noguchi K, Shiurba R, Higashinakagawa T. Nuclear Translocation of Mouse Polycomb M33 Protein in Regenerating Liver. Biochemical and Biophysical Research Communications. 2002;291(3):508-515.

47. Fujisaki S, Ninomiya $\mathrm{Y}$, Ishihara $\mathrm{H}$, et al. Dimerization of the Polycomb-group protein Mel-18 is regulated by PKC phosphorylation. Biochem Biophys Res Commun. Jan 3 2003;300(1):135-140.

48. Gong Y, Wang X, Liu J, et al. NSPc1, a mainly nuclear localized protein of novel PcG family members, has a transcription repression activity related to its PKC phosphorylation site at S183. FEBS Lett. Jan 3 2005;579(1):115-121.

49. $\mathrm{Ng} \mathrm{J}$, Hart CM, Morgan $\mathrm{K}$, et al. A Drosophila ESC-E(Z) protein complex is distinct from other polycomb group complexes and contains covalently modified ESC. Mol Cell Biol. May 2000;20(9):3069-3078.

50. Tie F, Siebold AP, Harte PJ. The N-terminus of Drosophila ESC mediates its phosphorylation and dimerization. Biochem Biophys Res Commun. Jul 1 2005;332(2):622-632.

51. Kuzmichev A, Nishioka K, Erdjument-Bromage $\mathrm{H}$, et al. Histone methyltransferase activity associated with a human multiprotein complex containing the Enhancer of Zeste protein. Genes Dev. Nov 15 2002;16(22):2893-2905.

52. Cha TL, Zhou BP, Xia W, et al. Akt-mediated phosphorylation of EZH2 suppresses methylation of lysine 27 in histone H3. Science. Oct 14 2005;310(5746):306-310. 
53. Hansen KH, Bracken AP, Pasini D, et al. A model for transmission of the H3K27me3 epigenetic mark. Nat Cell Biol. Nov 2008;10(11):1291-1300.

54. Hansen $\mathrm{KH}$, Helin $\mathrm{K}$. Epigenetic inheritance through self-recruitment of the polycomb repressive complex 2. Epigenetics. Apr 18 2009;4(3).

55. Ogawa M, Hiraoka $\mathrm{Y}$, Aiso $\mathrm{S}$. The Polycomb-group protein ENX-2 interacts with ZAP70. Immunol Lett. Mar 3 2003;86(1):57-61.

56. Amanchy R, Periaswamy B, Mathivanan S, et al. A curated compendium of phosphorylation motifs. Nat Biotechnol. Mar 2007;25(3):285-286.

57. Voncken JW, Niessen $\mathrm{H}$, Neufeld B, et al. MAPKAP kinase 3pK phosphorylates and regulates chromatin association of the polycomb group protein Bmi1. J Biol Chem. Feb 18 2005;280(7):5178-5187.

58. Gambetta MC, Oktaba K, Muller J. Essential Role of the Glycosyltransferase Sxc/Ogt in Polycomb Repression. Science. May 282009.

59. Chalkley RJ, Thalhammer A, Schoepfer R, et al. Identification of protein OGlcNAcylation sites using electron transfer dissociation mass spectrometry on native peptides. Proc Natl Acad Sci U S A. Jun 2 2009;106(22):8894-8899.

60. Fujiki R, Chikanishi T, Hashiba W, et al. GlcNAcylation of a histone methyltransferase in retinoic-acid-induced granulopoiesis. Nature. May 21 2009;459(7245):455-459.

61. Taylor RC, Cullen SP, Martin SJ. Apoptosis: controlled demolition at the cellular level. Nat Rev Mol Cell Biol. Mar 2008;9(3):231-241.

62. Wong CK, Chen Z, So KL, et al. Polycomb group protein RING1B is a direct substrate of Caspases-3 and -9. Biochim Biophys Acta. Jun 2007;1773(6):844-852.

63. Rao PS, Satelli A, Zhang S, et al. RNF2 is the target for phosphorylation by the p38 MAPK and ERK signaling pathways. Proteomics. May 2009;9(10):2776-2787.

64. Ohtsubo M, Yasunaga S, Ohno $Y$, et al. Polycomb-group complex 1 acts as an E3 ubiquitin ligase for Geminin to sustain hematopoietic stem cell activity. Proc Natl Acad Sci U S A. Jul 29 2008;105(30):10396-10401.

65. Hart GW, Housley MP, Slawson C. Cycling of O-linked beta-N-acetylglucosamine on nucleocytoplasmic proteins. Nature. Apr 26 2007;446(7139):1017-1022.

66. Hunter T. The age of crosstalk: phosphorylation, ubiquitination, and beyond. $\mathrm{Mol}$ Cell. Dec 14 2007;28(5):730-738.

67. Spange $S$, Wagner $T$, Heinzel $T$, et al. Acetylation of non-histone proteins modulates cellular signalling at multiple levels. Int J Biochem Cell Biol. Jan 2009;41(1):185-198.

68. Huang J, Berger SL. The emerging field of dynamic lysine methylation of nonhistone proteins. Curr Opin Genet Dev. Apr 2008;18(2):152-158.

69. Dietrich N, Bracken AP, Trinh E, et al. Bypass of senescence by the polycomb group protein $\mathrm{CBX} 8$ through direct binding to the INK4A-ARF locus. Embo J. Mar 21 2007;26(6):1637-1648.

70. Bracken AP, Kleine-Kohlbrecher $\mathrm{D}$, Dietrich $\mathrm{N}$, et al. The Polycomb group proteins bind throughout the INK4A-ARF locus and are disassociated in senescent cells. Genes Dev. Mar 1 2007;21(5):525-530.

71. Sparmann A, van Lohuizen M. Polycomb silencers control cell fate, development and cancer. Nat Rev Cancer. Nov 2006;6(11):846-856.

72. Valk-Lingbeek ME, Bruggeman SW, van Lohuizen M. Stem cells and cancer; the polycomb connection. Cell. Aug 20 2004;118(4):409-418. 
73. Turner BM. Reading signals on the nucleosome with a new nomenclature for modified histones. Nat Struct Mol Biol. Feb 2005;12(2):110-112.

74. Welchman RL, Gordon C, Mayer RJ. Ubiquitin and ubiquitin-like proteins as multifunctional signals. Nat Rev Mol Cell Biol. Aug 2005;6(8):599-609.

75. Pickart CM. Back to the future with ubiquitin. Cell. Jan 23 2004;116(2):181-190.

76. Geiss-Friedlander R, Melchior F. Concepts in sumoylation: a decade on. Nat Rev Mol Cell Biol. Dec 2007;8(12):947-956.

77. Ubersax JA, Ferrell JE, Jr. Mechanisms of specificity in protein phosphorylation. Nat Rev Mol Cell Biol. Jul 2007;8(7):530-541.

78. Villen J, Beausoleil SA, Gerber SA, et al. Large-scale phosphorylation analysis of mouse liver. Proc Natl Acad Sci U S A. Jan 30 2007;104(5):1488-1493.

79. Kagey $\mathrm{MH}$, Melhuish TA, Powers SE, et al. Multiple activities contribute to Pc2 E3 function. Embo J. Jan 12 2005;24(1):108-119.

80. Vertegaal AC, Ogg SC, Jaffray E, et al. A proteomic study of SUMO-2 target proteins. $J$ Biol Chem. Aug 6 2004;279(32):33791-33798.

81. Deng Z, Wan M, Sui G. PIASy-mediated sumoylation of Yin Yang 1 depends on their interaction but not the RING finger. Mol Cell Biol. May 2007;27(10):3780-3792.

82. Dephoure N, Zhou C, Villen J, et al. A quantitative atlas of mitotic phosphorylation. Proc Natl Acad Sci U S A. Aug 5 2008;105(31):10762-10767.

83. Chen RQ, Yang QK, Lu BW, et al. CDC25B mediates rapamycin-induced oncogenic responses in cancer cells. Cancer Res. Mar 15 2009;69(6):2663-2668.

84. Molina H, Horn DM, Tang N, et al. Global proteomic profiling of phosphopeptides using electron transfer dissociation tandem mass spectrometry. Proc Natl Acad Sci U S A. Feb 13 2007;104(7):2199-2204.

85. Beausoleil SA, Jedrychowski M, Schwartz D, et al. Large-scale characterization of HeLa cell nuclear phosphoproteins. Proc Natl Acad Sci U S A. Aug 17 2004;101(33):12130-12135.

86. Beausoleil SA, Villen J, Gerber SA, et al. A probability-based approach for highthroughput protein phosphorylation analysis and site localization. Nat Biotechnol. Oct 2006;24(10):1285-1292.

87. Cantin GT, Yi W, Lu B, et al. Combining protein-based IMAC, peptide-based IMAC, and MudPIT for efficient phosphoproteomic analysis. J Proteome Res. Mar 2008;7(3):1346-1351.

88. Daub $H$, Olsen JV, Bairlein $M$, et al. Kinase-selective enrichment enables quantitative phosphoproteomics of the kinome across the cell cycle. Mol Cell. Aug 8 2008;31(3):438-448.

89. Nousiainen $M$, Sillje $H H$, Sauer $G$, et al. Phosphoproteome analysis of the human mitotic spindle. Proc Natl Acad Sci U S A. Apr 4 2006;103(14):5391-5396.

90. Olsen JV, Blagoev B, Gnad F, et al. Global, in vivo, and site-specific phosphorylation dynamics in signaling networks. Cell. Nov 3 2006;127(3):635-648.

91. Yang F, Stenoien DL, Strittmatter EF, et al. Phosphoproteome profiling of human skin fibroblast cells in response to low- and high-dose irradiation. J Proteome Res. May 2006;5(5):1252-1260.

92. Tang LY, Deng N, Wang LS, et al. Quantitative phosphoproteome profiling of Wnt3amediated signaling network: indicating the involvement of ribonucleosidediphosphate reductase $M 2$ subunit phosphorylation at residue serine 20 in canonical Wnt signal transduction. Mol Cell Proteomics. Nov 2007;6(11):1952-1967. 


\section{Chapter 3}

93. Rikova K, Guo A, Zeng Q, et al. Global survey of phosphotyrosine signaling identifies oncogenic kinases in lung cancer. Cell. Dec 14 2007;131(6):1190-1203.

94. Sui S, Wang J, Yang B, et al. Phosphoproteome analysis of the human Chang liver cells using SCX and a complementary mass spectrometric strategy. Proteomics. May 2008;8(10):2024-2034.

95. Matsuoka S, Ballif BA, Smogorzewska A, et al. ATM and ATR substrate analysis reveals extensive protein networks responsive to DNA damage. Science. May 25 2007;316(5828):1160-1166.

96. $\mathrm{Yu}$ LR, Zhu Z, Chan KC, et al. Improved titanium dioxide enrichment of phosphopeptides from HeLa cells and high confident phosphopeptide identification by cross-validation of $\mathrm{MS} / \mathrm{MS}$ and $\mathrm{MS} / \mathrm{MS} / \mathrm{MS}$ spectra. J Proteome Res. Nov 2007;6(11):4150-4162. 



\section{Chapter 4}

\section{Kinase 3pK phosphorylates and regulates chromatin association of the Polycomb Group protein Bmi1}

Voncken JW*, Niessen $\mathrm{H}^{*}$, Neufeld B*, Rennefahrt U, Dahlmans V, Kubben N, Holzer B, Ludwig S, Rapp UR. J Biol Chem. 2005;280(7):5178-5187.

*equal contribution 


\begin{abstract}
Polycomb group (PcG) proteins form chromatin-associated, transcriptionally repressive complexes, which are critically involved in the control of cell proliferation and differentiation. Although the mechanisms involved in PcGmediated repression are beginning to unravel, little is known about the regulation of PcG function. We showed previously that PcG complexes are phosphorylated in vivo, which regulates their association with chromatin. The nature of the responsible PcG kinases remained unknown. Here we present the novel finding that the PcG protein Bmi1 is phosphorylated by 3pK (MAPKAP kinase 3), a convergence point downstream of activated ERK and p38 signaling pathways and implicated in differentiation and developmental processes. We identified 3pK as an interaction partner of PcG proteins, in vitro and in vivo, by yeast two-hybrid interaction and co-immunoprecipitation, respectively. Activation or overexpression of $3 \mathrm{pK}$ resulted in phosphorylation of Bmi1 and other PcG members and their dissociation from chromatin. Phosphorylation and subsequent chromatin dissociation of PcG complexes were expected to result in de-repression of targets. One such reported Bmi1 target is the Cdkn2a/INK4A locus. Cells overexpressing $3 \mathrm{pK}$ showed PcG complex/chromatin dissociation and concomitant de-repression of $\mathrm{p} 14^{\mathrm{ARF}}$, which was encoded by the Cdkn2a/INK4A locus. Thus, $3 \mathrm{pK}$ is a candidate regulator of phosphorylationdependent $\mathrm{PcG} / \mathrm{ch}$ romatin interaction. We speculate that phosphorylation may not only affect chromatin association but, in addition, the function of individual complex members. Our findings linked for the first time MAPK signaling pathways to the Polycomb transcriptional memory system. This suggests a novel mechanism by which a silenced gene status can be modulated and implicates PcGmediated repression as a dynamically controlled process.
\end{abstract}




\section{Introduction}

Members of the mitogen-activated protein kinase (MAPK) family (ERK, JNK/SAPK, and p38 kinases) are implicated in many biological processes, such as adaptation to environmental changes, differentiation, immune activation, inflammatory responses, cell cycle modulation, transformation, and apoptosis ${ }^{1}$. These phosphorylation cascades may function as switching mechanisms that modulate gene activity ${ }^{2}$. $3 \mathrm{pK}$, also known as MAPK-activated protein kinase 3 (MAPKAPK3), belongs to a growing family of kinases that are activated by one or more members of the MAPK family ${ }^{3}$. To better understand processes regulated by $3 \mathrm{pK}$, we aimed to identify interactors and potential novel substrates of $3 \mathrm{pK}$.

Here, we report the finding of a group of novel interaction partners of $3 \mathrm{pK}$, the Polycomb group (PcG) proteins, including the mammalian PcG proteins HPH2 and $\mathrm{Bmi1}^{4,5}$. PcG protein complexes maintain a transcriptionally repressed gene status in dividing and differentiating cells throughout developing eukaryotes ${ }^{6-8}$. The mechanisms that contribute to PcG-mediated silencing are beginning to unravel. PcG proteins form large multimeric protein complexes that associate with chromatin (reviewed in Refs. ${ }^{9,}{ }^{10}$ ). The current view is that PcG-mediated silencing in mammals involves generation and recognition of histone modifications; a subset of PcG complexes, the EED/EZH complex (hPRC2 complex), associates with histone deacetylases, implicating histone tail deacetylation in PcG-mediated repression ${ }^{11}$. Within this complex, EZH2 was identified as a histone methyltransferase with preference for histone $\mathrm{H} 3$ lysine $27^{12}$. A biochemically distinct Polycomb-repressive complex (hPRC1 in human, PRC1 in Drosophila ${ }^{13,}{ }^{14}$ ) recognizes and binds the epigenetic trimethyl( $3 m$ )lysine 27 mark produced by the (h)PRC2 complex; recognition and maintenance of repressed chromatin may involve additional histone modifications, such as histone ubiquitination or methylation ${ }^{12,15-18}$. The current view is that PcG-mediated repressional maintenance involves a combination of (associated) catalytic activities responsible for posttranslational modifications on histone tails and extensive interactions among PcG members and other chromatin (-bound) factors, which generate a repressive higher order chromatin structure inaccessible to transcriptional activators and chromatin remodeling factors ${ }^{8,19-21}$.

Little is known about how chromatin association and, potentially, function of PcG complexes is controlled. In the present study, we identified Polycomb group $(\mathrm{PcG})$ proteins as in vivo interaction partners of the MAPKAP kinase $3 \mathrm{pK}$. We have provided evidence that MAPK signal transduction cascades target PcG protein complex/chromatin interaction through phosphorylation. 3pK acts as a Bmi1 kinase in vitro and in vivo. Of relevance, $3 \mathrm{pK}$ overexpression causes $\mathrm{PcG} /$ protein dissociation from chromatin and de-repression of the Cdkn2a/ 
INK4A locus. Our data support a model in which Polycombmediated repression is modulated by stress- and mitogenactivated protein kinase cascades. These findings point to a molecular mechanism by which a transcriptionally silenced gene status can be reprogrammed and implicates PcG-mediated repression as a dynamically controlled process. These observations are expected to have important implications in understanding epigenetic mechanisms in development and disease.

\section{Experimental procedures}

\section{Plasmid construction}

Eukaryotic expression vectors for untagged and tagged wild type or mutant 3pK have been described elsewhere ${ }^{3,22}$. The nucleus-retained $3 \mathrm{pK}$ mutant $3 \mathrm{pk} \Delta \mathrm{C}$ was created by deleting the C-terminal (aa 308-383) regulatory region from Gal4DB-3pK. pGAD10-HPH2 (C-298 aa) and pGAD10-HPH2 (432 aa) were described elsewhere ${ }^{4}$. HDII/SPM/SAM domain mutations within the C-198 HPH2 construct were generated by PCR-directed deletion of the $3^{\prime}$-most sequences or by site-directed mutagenesis (QuikChange; Stratagene Europe, Amsterdam, The Netherlands) within the fifth C-terminal-most $\alpha$-helix. MT2SM-HA-Bmi1 (mouse) was kindly provided by Dr. M. van Lohuizen ${ }^{5}$. Glutathione S-transferase (GST)tagged $3 \mathrm{pK}^{3,22}$ was recloned into $\mathrm{pBABE}$ - or LZRS-based retroviral expression vectors $^{23,24}$. The murine ecotropic receptor was recloned from an original construct by Dr. J. M. Cunningham (Harvard Medical School, Boston, MA) and shared by Dr. A. Lund (Netherlands Cancer Institute, Amsterdam, The Netherlands). RNA interfering 3pK sequences 5' - CGGCAAAGTGTCTGGAGTGC-3', 5'-GCAGCTGATCCGCCTCCTG- 3', and 5'-GGAGGAGATGACCAGTGCC-3' (Fig. 4.5C, respectively, lanes $1-3$ ) were cloned into stable hsRNA vectors described elsewhere ${ }^{25}$.

\section{Yeast two-hybrid system}

A kinase-inactive 3pK mutant (K73M) was used as bait in two-hybrid screens against a human heart MATCHMAKER CDNA library cloned into the pGAD10 vector (Clontech). Yeast strain CG-1945 (Clontech) was manipulated according the manufacturer's instructions. Positive clones were monitored by growth on $\mathrm{SD} /$-Trp/- Leu/-His plates and activity of the lacZ reporter gene in filter assays. In direct two-hybrid assays, reselected SD/-Trp/-Leu/-His filters were incubated for $12-24 \mathrm{~h}$ at $30^{\circ} \mathrm{C}$ before the $\beta$-Gal assay was performed. The liquid culture $\beta$-Gal assay with $o$-nitrophenyl- $\beta$-D-galactopyranoside (Sigma) as substrate was performed according to the manufacturer's instructions using the yeast strain Y190. 


\section{Cell culture and cell cycle synchronization}

Indicated cell lines were cultured at $37^{\circ} \mathrm{C}, 5 \% \mathrm{CO}, 100 \%$ humidity in Dulbecco's modified Eagle's medium supplemented with $10 \%$ fetal calf serum (FCS), antibiotics (100 units $/ \mathrm{ml}$ penicillin and $100 \mu \mathrm{g} / \mathrm{ml}$ streptomycin), $200 \mathrm{mM} \mathrm{L-}$ glutamine and $4.5 \mathrm{~g} /$ /iter L-glucose. The TIG3-Bmi1.2PY has been described elsewhere ${ }^{26}$. Human U2OS osteosarcoma cells and TIG3 primary human fibroblasts expressing the murine ecotropic receptor were provided by Dr. D. Shvarts (Utrecht Medical Center, Utrecht, The Netherlands) and Dr. D. Peeper (Netherlands Cancer Institute, Amsterdam, The Netherlands), respectively. Titers of LZRS-IRES-GFP (Bmi1, 3pK, or control) viral supernatants were sufficiently high to achieve near $100 \%$ infection; infection with pBABE-GST (3pK or control) virus was followed by selection with puromycin. G0/G1 arrest of cells was established by contact inhibition and/or a 48-h serum starvation period (in Dulbecco's modified Eagle's medium supplemented with $0.1 \%$ FCS). M phase enrichment was achieved by adding colcemid $(0.01 \mu \mathrm{g} / \mathrm{ml})$ to $\mathrm{S}$ phasesynchronized cells, acquired by a double thymidine block ( $2 \times 2 \mathrm{mM} ; 15-15 \mathrm{~h}$ ) essentially as published previously ${ }^{27}$. $\mathrm{M}$ phase enrichment was accomplished by mitotic shake-off.

\section{Immunofluorescence}

Immunofluorescence on methanol-fixed U2OS cells was carried out as described previously ${ }^{26}$. For immunocytochemical detection of cell cycle inhibitors, cells were infected on glass slides (Superfrost; Menzel GmbH \& Co. KG); fixation was accomplished by a $3-5-\mathrm{min}$ incubation in $100 \%$ methanol at $-20{ }^{\circ} \mathrm{C}$, or a $20-\mathrm{min}$ $3.7 \%$ formaldehyde fixation at ambient temperature, followed by a $7-\min 100 \%$ acetone treatment at $-20^{\circ} \mathrm{C}$, and subsequent washing and staining were carried out 3-5 days following infection. Polyclonal rabbit antiserum against recombinant $3 p K$ and GST antisera were obtained from rabbits immunized with purified GST. The anti-Bmi1 mAb F6 and anti-MPh 1 (HPH1) pAb 70092 were kindly provided by Dr. M. van Lohuizen. Other antisera used were anti-2Py mAb (MMS-115R; Babco, Richmond, CA); anti-Bmi1 mAb (6C9; Bmi10), anti-HPc2 mAb (M9), anti-Ring1A mAb (M3) kindly provided by Dr. A. Otte ${ }^{28}$; anti-Rnf2 (Ring1B) $\mathrm{mAb} \mathrm{b}^{29}$; anti-dinG (Ring1B) pAb (Dr. M. Dyer, University of Leicester, Leicester, UK); anti-HPH1 mAb (Dr. H. Koseki, RIKEN Yokohama Institute, Yokohama, Japan), anti-Gsk3 $\beta$ pAb (catalog number 9332; Cell Signaling), antiAKT pAb (catalog number 9272; Cell Signaling), anti-p14 ${ }^{A R F} / \mathrm{p} 16 \beta$ pAb (Ab-1; LabVision Corp., Fremont, CA), anti-pSer10 pAb (Upstate Biotechnology, Lake Placid, NY), and anti-pSer28 pAb (rat) kindly provided by Dr. M. Inagaki ${ }^{30}$. Monoclonal primary antibodies were detected with goat-anti-mouse Texas Red polyclonal primary antisera with goat-anti-rabbit fluorescein isothiocyanate. 


\section{Transfections and $3 p K$ activation}

HEK293 and U2OS cells were transfected at 10-30\% confluency. Transfections were done by standard calcium phosphate co-precipitation. Production of infectious viral particles was carried out as described previously ${ }^{31}$. Cells were starved in Dulbecco's modified Eagle's medium with $0.1 \%$ (U2OS) or $0.3 \%$ (HEK293) FCS for $48 \mathrm{~h}$. For activation of 3pK, the cells were stimulated with $0.2-$ $0.5 \mathrm{mM}$ sodium-meta-arsenite (Sigma) or with 5 or $10 \%$ FCS with or without 100 $\mathrm{ng} / \mathrm{ml}$ tetradecanoyl phorbol acetate (TPA) for $1 \mathrm{~h}$ before harvesting, unless indicated otherwise. Preincubation with kinase inhibitor $\mathrm{UO}^{2} 6^{32}$ or SB202190 33 was $20-30$ min before activation of the cells.

\section{Immunoprecipitation and differential extraction}

Cell lysates were prepared as described previously, ${ }^{3,5}$. For immunoprecipitation, cells were extracted with ELB buffer ${ }^{5,26}$; immune complexes were precipitated with protein A- or G-agarose. Differential extraction was carried out as described previously ${ }^{34}$. Briefly, the cells were washed twice in phosphatebuffered saline and carefully suspended in $200 \mu$ of phosphate-buffered saline supplemented with $1 \mathrm{mM} \mathrm{NaVO} 4$ and $50 \mathrm{mM} \mathrm{NaF}$ and extracted in IP0.1 buffer $(60 \mathrm{mM} \mathrm{KCl}, 15 \mathrm{mM} \mathrm{NaCl}, 5 \mathrm{mM} \mathrm{MgCl} 2,0.1 \mathrm{mM}$ EGTA, $15 \mathrm{mM}$ Tris- $\mathrm{HCl}, \mathrm{pH}$ 7.4, $300 \mathrm{mM}$ sucrose, $1 \mathrm{mM}$ NaVO4 and $50 \mathrm{mM} \mathrm{NaF}$ ) supplemented with $0.3 \%$ nonionic detergent Igepal (Nonidet P-40). The cells were incubated for $3 \mathrm{~min}$ at ambient temperature, gently pelleted, and the supernatant was collected (soluble fraction). The pellet was carefully washed once in nuclear buffer and extracted in IP0.1 buffer ( 20 mM HEPES, pH 7.6, 10\% glycerol, $25 \mathrm{mM} \mathrm{MgCl} 2,0.1$ mM EDTA, 0.2\% Nonidet P-40, 0.1 M Potassium acetate, $1 \mathrm{mM}$ NaVO4, $50 \mathrm{mM}$ $\mathrm{NaF}$; chromatin-bound fraction) as described previously ${ }^{34}$. Protein extracts were analyzed by standard Western blot technology.

\section{Immune complex kinase assay}

GST-3pK and HA-Bmi1 immune complexes were immunoprecipitated separately and combined and washed twice in high salt radioimmune precipitation assay buffer $(500 \mathrm{mM} \mathrm{NaCl})$ and kinase buffer $(10 \mathrm{mM} \mathrm{MgCl} 2,25 \mathrm{mM} \beta$ glycerophosphate, $25 \mathrm{mM}$ HEPES, $\mathrm{pH} 7.5,5 \mathrm{mM}$ benzamidine, $0.5 \mathrm{mM}$ dithiothreitol, $1 \mathrm{mM} \mathrm{NaVO} 4{ }^{3}{ }^{2}$. In control experiments, GST-3pK-containing immune complexes were incubated with $\mathrm{Hsp} 27$ as a substrate. The kinase assays were performed at $30^{\circ} \mathrm{C}$ for $30-120 \mathrm{~min}$ in kinase buffer supplemented with 3-5 $\mu \mathrm{Ci}[\gamma-32 \mathrm{P}] \mathrm{ATP}$ and $0.02-0.1 \mathrm{mM}$ cold ATP. In vitro kinase assays with recombinant protein utilized $1 \mu \mathrm{g}$ of kinase (3pK-EE) and $5 \mu \mathrm{g}$ of substrate (Hisor GST-tagged Bmi1). 
A

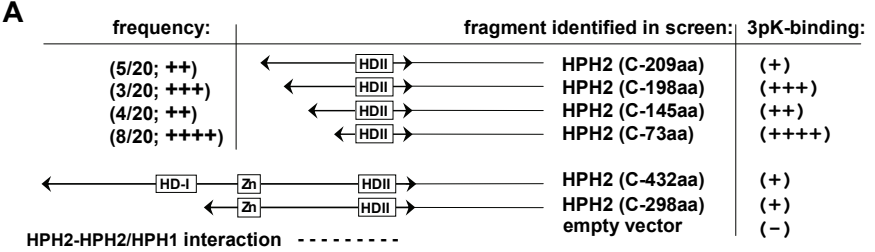

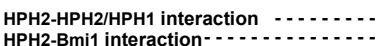

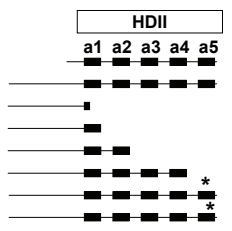

C

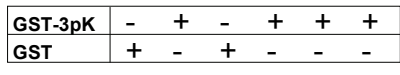

IP:

(input)

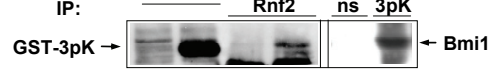

D

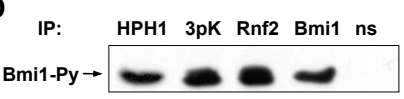

$E$

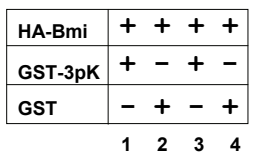

IP: GST HA

HA blot:

$\lg G \rightarrow$

HA-Bmi1-

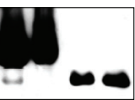

360-432 (C-73aa)

235-377

235-397

$235-415$

L417A

$(+++)$
$(-)$
$(-)$
$(-)$
$(-)$
$( \pm)$
$(-)$

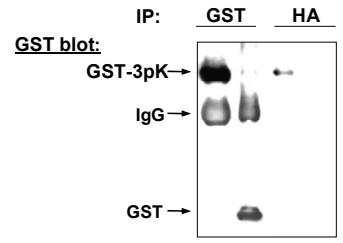

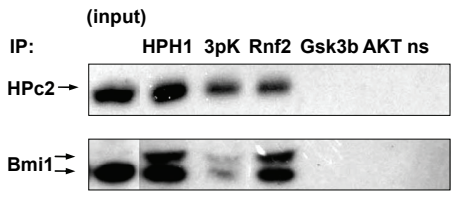

Figure 4.1. 3pK and PcG proteins associate in yeast and in mammalian cells.

(A) schematic depiction of the HPH2 clones interacting with $3 \mathrm{pK}$ (hit-frequency, left; arbitrary staining intensity, right). Homology domains (HD-I and HDIl boxes) and the zinc finger $(\mathrm{Zn})$ and interaction domains required for homo- and heterotypic interactions (---) are shown. Arrows demarcate the coding sequences. Direct two-hybrid binding assay between $3 p K(K 73 M)$ and the various GAL4-AD-HPH2 fusion constructs are identified in the figure. The relative binding strength (3pK-binding), as determined by liquid culture $\beta$-gal assay, is depicted $( \pm)$. Empty control vectors were negative in all experiments. Mutational analysis of the HDII/SPM/SAM domain in the C-198 aa construct shows that the $\alpha 5$ motif is crucial for $\mathrm{HPH} 2 / 3 \mathrm{pK}$ interaction. Quantitation is as follows: ++++, $30 \mathrm{~min}$ (C-73 aa); +++, 60-150 min (C-198 aa);, $\pm 150-360 \mathrm{~min}$ (C-198 aa, L417A). (B) HA-tagged full-length Bmi1 co-immunoprecipitates with GST-3pK (lane 1) and vice versa (lane 3) from HEK293 (human embryonic kidney) cell extracts; no interaction is observed in control samples (lanes 2 and 4). (C) endogenous PcG complexes from U2OS (osteosarcoma) cell extracts co-precipitate GST-3pK (left panel); Bmi1 is co-precipitated with 3pK (right panel); overexpression of GST-3pK (GST-3pK-IRES-GFP retroviral vector) is indicated (+). (D) 3pK associates with PcG proteins in HeLa (cervical carcinoma) cells overexpressing Bmi1-PY; Bmi1 precipitates with its binding partners hRnf2 and HPH1. (E) co-immunoprecipitation of endogenous proteins, only, from HeLa cell extracts. Antisera used for immunoprecipitation (IP) are indicated. ns, normal serum. Two unrelated kinases, AKT and GSK3 $\beta$, were used in control immunoprecipitations. Immunoprecipitation was confirmed by reduced detection in the depleted extract. Antisera used in Western detection are as indicated (arrows): anti-GST (for GST-3pK) and anti-Bmi1 (F6; for either endogenous or overexpressed Bmi1). 


\section{Results}

\section{$3 p K$ binds the $C$ terminus of $H P H 2$ in vitro}

In two independent yeast two-hybrid screens using an inactive 3pK (K73M) variant as bait, 20 overlapping clones containing CDNA of the human Polyhomeotic protein (HPH2) were isolated (Fig. 4.1A). These clones represented 73, 145, 198, or 209 C-terminal amino acid fragments of HPH2 (Fig. 4.1A). In a direct yeast two-hybrid test, $3 \mathrm{pK}$ also interacted with a larger HPH2 Cterminal fragment of 298 aa and the putative full-length HPH2 (432 aa) (Fig. 4.1, A and B). The C-terminal 3pK interaction domain of HPH2 (Fig. 4.1A) overlaps with the $\alpha$-helical HDII/ SPM/SAM domain involved in hetero- and homotypic interactions between several Polycomb proteins ${ }^{4,5,35,36}$. Mutational analysis of the C-198 fragment was used to further investigate the role of the $\mathrm{HDIl}$ domain in the HPH2/3pK interaction. The HDII domain contains at least five distinct $\alpha$-helical $(\alpha 1-\alpha 5)$ structures ${ }^{37}$. C-terminal deletions removing these $\alpha$ helices prevent $\mathrm{HPH} 2 / 3 \mathrm{pK}$ interaction (Fig. 4.1A, lower inset). Removal of the Cterminal-most helix $(\alpha 5)$ is sufficient to completely abolish interaction. The requirement of an intact $\alpha 5$ was confirmed by the introduction of selected point mutations in $\alpha 5$ (Fig. 4.1A, asterisks on lower panel), which are predicted to be present on the surface of the protein and therefore may be required for the interaction with 3pK. Removing the basic side chain through exchange of K422A prevented interaction between HPH2 C-198 and 3pK completely, whereas exchange of L417A led to a reduction of protein association. 3pK (K73M) displays high affinity for the shorter $\mathrm{HPH} 2$ fragments, in particular for the Cterminal 73 fragment (Fig. 4.1A). This may relate to binding-site masking in fulllength $\mathrm{HPH} 2$. Interestingly, mutation of known phosphorylation sites on $3 \mathrm{pK}$ (e.g. T313E, T313A, T201E/T313E) does not alter binding affinity as compared with the wild type kinase (not shown), suggesting that HPH2 binding is independent of Thr201/Thr313 phosphorylation. Thus, the HDII/ SPM/SAM domain plays an important role in $\mathrm{HPH} 2 / 3 \mathrm{pK}$ interaction.

\section{3pK complexes with PcG proteins in vivo}

Interaction between $3 \mathrm{pK}$ and the individual $\mathrm{HPH} 2$ fragments in mammalian cells was confirmed by co-immunoprecipitation experiments (data not shown) with results consistent with the quantitative yeast two-hybrid data (Fig. 4.1A). The finding that $3 \mathrm{pK}$ is a binding partner of $\mathrm{HPH} 2$ suggests that the kinase may be part of a PcG complex and may also be associated with other PcG proteins. Biochemical analysis indeed confirms that HA-tagged Bmi1, a direct binding partner of $\mathrm{HPH} 1 / 2^{4,5}$, is specifically co-immunoprecipitated with GST-3pK and vice versa (Fig. 4.1B). In vivo, GST-3pK co-precipitates with endogenous PcG 
proteins, such as (h)Rnf2 (Fig. 4.1C), which is part of the hPRC1 complex ${ }^{38,39}$. Exposure of cells to a 3pK-activating agent, the stress-inducer arsenite ${ }^{3}$, does not alter the interaction quantitatively in these cells (not shown), again suggesting that phosphorylation of $3 p \mathrm{KK}$ does not affect PcG association. This is in line with the comparable interaction of $3 p K$ phosphorylation- site mutants with $\mathrm{HPH} 2$ described above. In a reciprocal experiment, Bmi1 was immunoprecipitated with an anti-3pK antiserum in both U2OS cell extracts (Fig. 4.1C) and HeLa cell extracts with high Bmi1 levels (Fig. 4.1D). Finally, we showed that endogenous proteins co-precipitate (Fig. 4.1E); this interaction was specific, because two unrelated kinases, AKT and Gsk3 $\beta$, did not co-precipitate hPRC1 core members (Fig. 4.1E). These biochemical data demonstrated association of $3 \mathrm{pK}$ with PcG proteins in vivo, without the need for overexpressed binding partners.

\section{Mitogen- and stress-induced phosphorylation of Bmi1 in vitro and in vivo}

$3 p K$ is a kinase activated by both stress stimuli and mitogenic signals. Activation by mitogens, such as serum and TPA, occurs almost exclusively via the ERK pathway, whereas stress stimulation with arsenite recruits the MAPKAPK to the p38 MAPK cascade ${ }^{3}$. Thus, we next examined whether PcG proteins may represent downstream targets of these MAP kinase cascades by applying the respective stimuli. We focused on Bmi1, because chromatin association of Bmi1 correlates with its phosphorylation status ${ }^{26}$. ERK activation, via mitogenic stimulation of serum-starved cells, leads to a rapid and readily detectable phosphorylation of Bmi1 in vivo; activation of $\mathrm{p} 38$, via arsenite, induces a much stronger hyperphosphorylation of Bmi1 as compared with mitogenic stimulation (Fig. 4.2A). Importantly, serum starvation prior to activation in these experiments precludes cell cycle-dependent phosphorylation ${ }^{26}$ from interfering with these assays. Phosphatase treatment of PcG proteins extracted from arseniteexposed cells establishes phosphorylation as the main posttranslational modification on PcG proteins in response to p38 activation (Fig. 4.2B). We then studied the effect of protein phosphorylation on PcG core complex/protein interaction. As indicated in Fig. 4.2C, interaction of known PcG core complex partners, such as $\mathrm{HPH} 1$ and $\mathrm{HPc}^{14}$, is at least in part preserved, as they still coimmunoprecipitate with Bmi1. Stress (Fig. 4.2D) or mitogenic (data not shown) stimulation result in Bmi1 phosphorylation in HeLa and 293T cells and, importantly, also in primary human TIG3 fibroblasts, showing that the observation is not cell-type restricted or linked to a specific cellular phenotype. Ground-state phosphorylation comparison in the different cell types also reveals that Bmi1 is already phosphorylated in some serum-starved established cell lines (Fig. 4.2, A and D). This would be consistent with a constitutive activation of MAP kinase signaling pathways in some cancer cell lines. Arsenite-induced 
Chapter 4

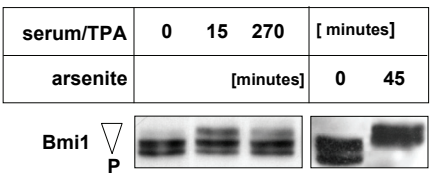

B

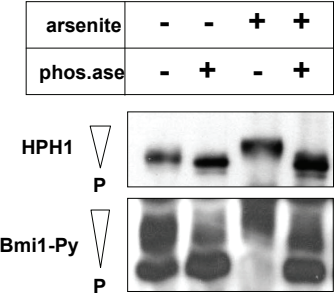

C

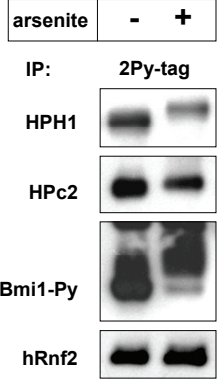

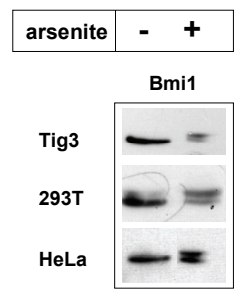

E

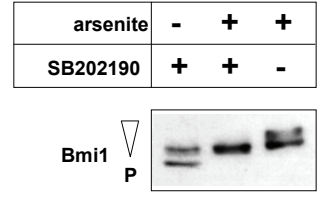

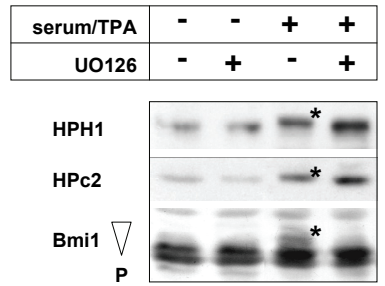

Figure 4.2. Mitogen-activated and stress-induced phosphorylation cascades target Bmi1.

(A) signaling through ERK1/2 or p38/SAPK, via serum/TPA or arsenite stimulation respectively, results in Bmi1 phosphorylation in vivo. U2OS cells were serum-starved prior to activation. (B) arsenite-induced phosphorylation of Bmi1 and HPH1 in U2OS cells. Immunoprecipitated protein complexes were subjected to phosphatase treatment and detected by Western blot. (C) PcG/protein interactions in response to p38 activation in U2OS cells. Co-precipitation of nonphosphorylated or phosphorylated core complex members from arsenite-stimulated cells shows the PcG core complexes remain largely intact. (D) phosphorylation of Bmi1 following arsenite exposure in 293T, HeLa, and TIG3 (human primary fibroblasts) cells; the latter two cell lines overexpress Bmi1. Western detection was done with anti-Bmi1 (F6). (E) the p38 inhibitor SB202190 partially blocks Bmi1 phosphorylation in U2OS cells. Stress kinase cascade was activated by $0.2 \mathrm{mM}$ sodium arsenite. (F) the ERK inhibitor UO126 blocks MAPK-mediated Bmi1, HPc2, and HPH1 phosphorylation. U2OS cells (E and F) were serum-starved ( $0.1 \%$ FCS) for 2 days prior to stimulation. The MAPK cascade was activated as indicated under "Experimental Procedures." *indicate phosphorylated proteins.

Bmi1 phosphorylation is reduced in the presence of the p38 inhibitor SB202190 (Fig. 4.2E), providing additional evidence for specific catalytic targeting of Bmi1 by the stressactivated phosphorylation cascade, which acts through p38/ SAPK. Arsenite also activates the JNK pathway upstream of $3 \mathrm{pK}^{40}$, which may explain the incomplete reduction of Bmi1 phosphorylation upon treatment with the p38 inhibitor. The mitogen-activated protein kinase/extracellular signal-regulated kinase kinase inhibitor U0126 reduces mitogen-induced phosphorylation of Bmi1 (Fig. 4.2F) and of HPH1 and HPc2, two known PcG core complex factors. Finally, the degree of Bmi1 phosphorylation downstream of mitogen- or stress- 
activated kinase signaling (Fig. 4.2, A, E, and F), correlates well with the reported difference in $3 p K$ activation by these respective stimuli ${ }^{40}$.

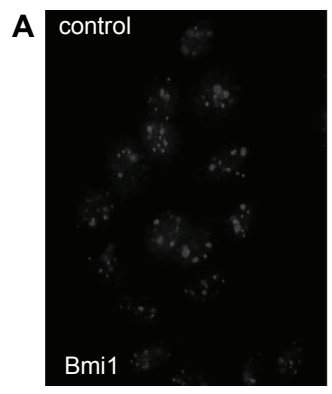

control
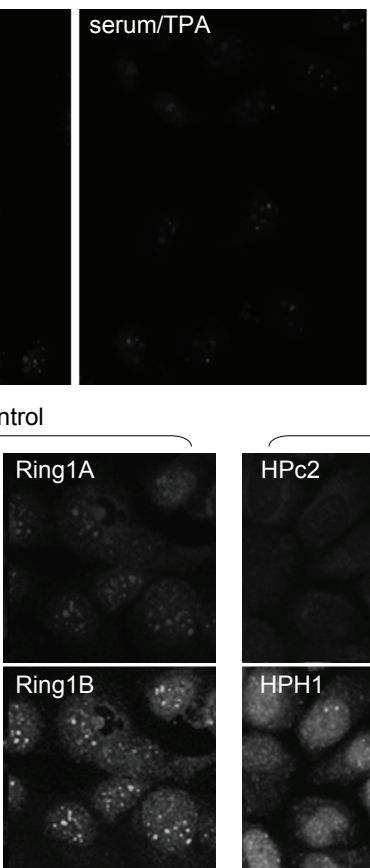

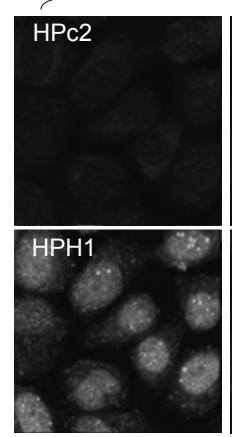

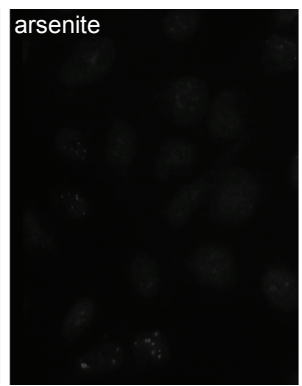

arsenite

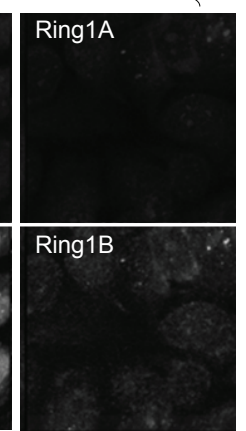

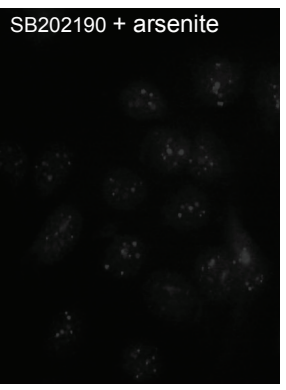

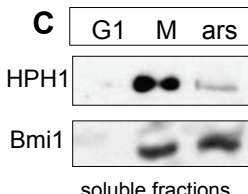

soluble fractions

Figure 4.3. Phosphorylation-dependent PcG/chromatin interaction.

(A) Bmi1 visibly dissociates from chromatin upon mitogenic or stress signaling. U2OS cells were serum-starved for $48 \mathrm{~h}$ prior to serum/TPA $(15 \mathrm{~min})$ or arsenite $(45 \mathrm{~min})$ treatment. $\mathrm{PcG} /$ chromatin release is partially inhibited by the p38 inhibitor SB202190 (far right; compare with Fig. 4.2E). (B) antibodies against a number of different PcG proteins show PcG/chromatin association under serum-starved conditions and $\mathrm{PcG} /$ chromatin dissociation following exposure to arsenite. Cells were fixed and permeabilized in $100 \%$ methanol, which allows for the detection of chromatin-bound PcG proteins ${ }^{26}$. (C) differential extraction (see "Experimental Procedures") of soluble fractions shows extensive chromatin dissociation of Bmi1 upon arsenite stimulation (ars), whereas HPH1 release is substantially less. Synchronized $\mathrm{G1}$ and M phase control cell extracts reveal the predicted chromatin association/dissociation, respectively ${ }^{26}$; loading was corrected for cell numbers. See page 198 for colour print.

\section{Signaling-induced phosphorylation abolishes Polycomb/chromatin association}

Next, the effect of MAPK signaling on PcG proteins/chromatin association was examined by immunocytochemistry. Serum-starved/refed cells (ERK1/2mediated signaling) show a clearly visible decrease of chromatin-associated nuclear Bmi1 domains (Fig. 4.3A) ${ }^{26,}{ }^{41}$. Likewise, arsenite exposure (p38mediated signaling) relieves $\mathrm{Bmi} 1 /$ chromatin association by a process that is partially inhibitable by blocking p38 activity (Fig. 4.3A, right panel). In addition to $B m i 1$, a number of other PcG proteins are released from chromatin. These 
include HPc2, hRing1, and hRnf2 (Fig. 4.3B). Diminished fluorescence can be explained in a number of ways. Proteolytic breakdown was excluded by comparing straight lysates in the presence or absence of proteasome inhibitors; detection was unaltered, independent of physiological condition or inhibition of proteolysis (data not shown). Epitope masking by phosphorylation is rather unlikely, because a number of PcG proteins were detected by multiple independent antisera (data not shown). Differential extraction of soluble and chromatin-bound PcG proteins confirms the above immunocytochemical findings. As in $M$ phase control extracts, which mainly contain soluble phosphorylated $\mathrm{Bmi1}^{26}$, upon p38 activation (arsenite), a substantial amount of phosphorylated Bmi1 is retrieved in the soluble fraction (Fig. 4.3C). Interestingly, $\mathrm{HPH} 1$ appears to undergo a nuclear redistribution upon exposure of cells to arsenite; consistently, less HPH1 is released from chromatin as compared with other PcG core proteins (Figs. 3B, 4A, and 5E). Also, less phosphorylated HPH1 is extractable as soluble protein from arsenite-stimulated cells, as compared with $\mathrm{M}$ phase cells (Fig. 4.3C). Despite this HPH1 "chromatin retention," a fraction of $\mathrm{HPH} 1$ interacts with Bmi1, even when phosphorylated (Fig. 4.2C). Multiple distinct interaction partners for HPH1 may indeed exist in various nuclear (sub)compartments; Drosophila polyhomeotic was found in multiple protein interactions, some of which were free from posterior sex combs and polycomb ${ }^{42}$.

p38/SAPK activation may affect chromatin remodeling more directly through phosphorylation of histones ${ }^{43}$. In analogy to the reported interference of $\mathrm{p}$ (phospho)Ser10 with heterochromatin protein (HP1)/3m(trimethyl)Lys9 interaction ${ }^{44}$, it is possible that simultaneous histone $\mathrm{H} 3$ phosphorylation and $\mathrm{PcG} /$ chromatin association are mutually exclusive. We therefore studied the dynamics of $\mathrm{PcG} /$ chromatin dissociation versus histone $\mathrm{H} 3$ Ser28/10 phosphorylation, as trimethylation at the adjacent lysine 27 residue is required for Polycomb complex/ histone H3 interaction ${ }^{12,15,16}$. Serum-starved U2OS cells showed very low histone H3 phospho-Ser (pSer28; Fig. 4.4A, and pSer10, not shown) levels (Fig. 4.4A and not shown); arsenite exposure led to the accumulation of both pSer10 and pSer28 (Fig. 4.4). There was a good correlation between histone $\mathrm{H} 3$ Ser28 phosphorylation and loss of $\mathrm{PcG} /$ chromatin association (Fig. 4.4A). Global histone H3 Ser28 phosphorylation varied significantly between cells, whereas individual PcG proteins dissociated or relocated uniformly (Fig. 4.4A). This suggests PcG/chromatin dissociation may occur relatively fast in response to direct phosphorylation by $3 \mathrm{pK}$ (or other arsenite-activated kinases) or in response to local histone H3 Ser28 phosphorylation. Kinase assays on $\mathrm{N}$-terminal peptides, however, suggest that $\mathrm{H} 3$ and $\mathrm{H} 4$ are not direct $3 \mathrm{pK}$ phosphorylation targets in vitro (HN, VD and JWV, unpublished data). In contrast, pSer10 and PcG/chromatin association are not 
mutually exclusive (Fig. 4.4B), consistent with the observation that histone $\mathrm{H} 3$ pSer10 phosphorylation is thought to interfere with recognition and binding of the $3 m$ Lys9 silencing mark by HP1 chromodomain proteins but not by HPc chromodomain proteins ${ }^{44}$.

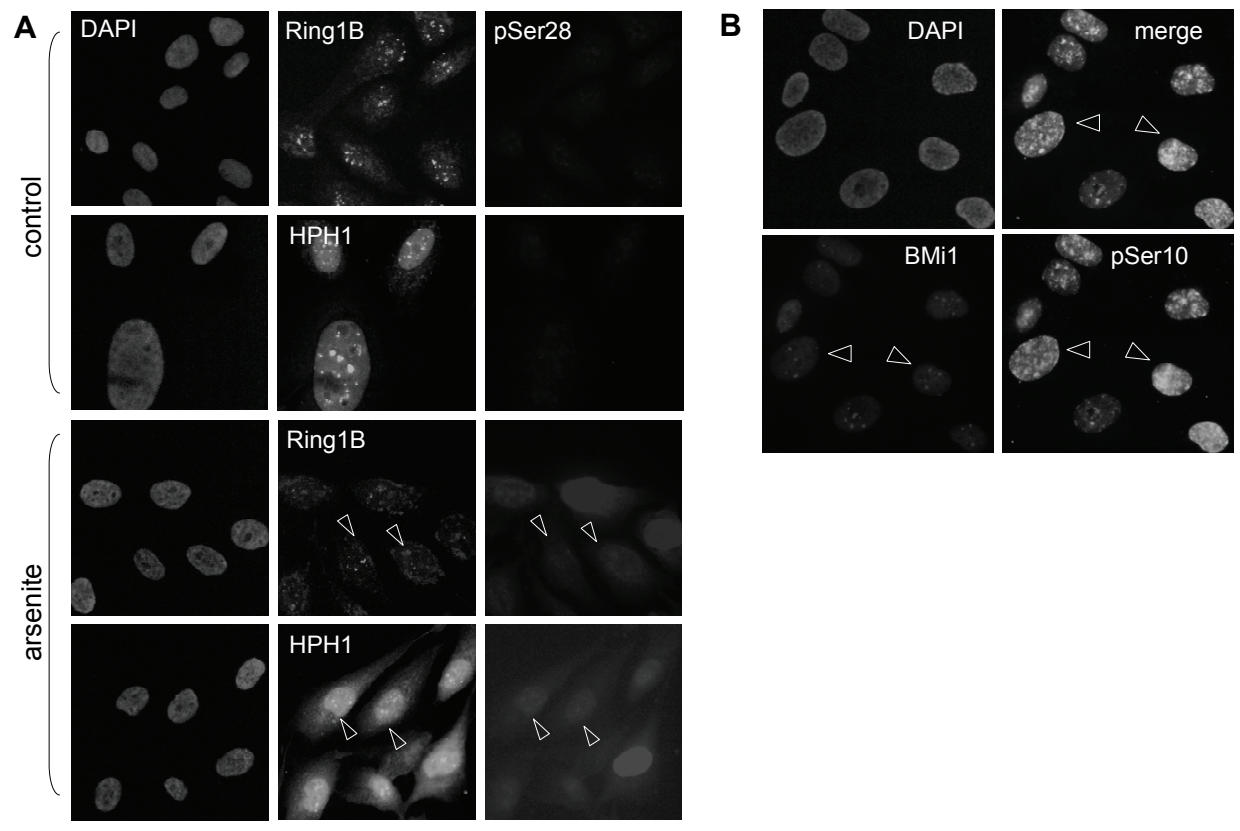

Figure 4.4. Post-translational histone $\mathrm{H} 3$-tail modifications during stress signaling.

(A) histone H3 Ser28 phosphorylation correlates with loss of PcG/chromatin association in U2OS cells. Arsenite-exposed cells show loss of Ring1B binding and the characteristic relocation of HPH1 (see also Fig. 4.3B). Phosphorylation of Histone H3 Ser28 is not detectable in serum-starved cells (control), whereas it clearly is upon arsenite exposure. (B) histone H3 Ser10 phosphorylation in cells does not correlate with PcG/chromatin dissociation in arsenite-exposed cells. Shown is an example of cells in which histone $\mathrm{H} 3$ Ser10 phosphorylation in response to arsenite, as well as the typical punctate nuclear PcG staining, is clearly visible. Histone H3 Ser10 phosphorylation in control cells (serum starved) is non-detectable (not shown). Arrows indicate cells positive for both pSer10 and chromatin-bound PcG complexes; cells were exposed to arsenite on glass slides and fixed in formaldehyde/acetone. DAPI, 4',6-diamidino- 2-phenylindole. See page 198 for colour.

\section{Identification of 3pK as a candidate Bmi1 kinase}

We studied 3pK as a candidate Bmi1 kinase by in vitro kinase assays and by stimulation of cells with altered $3 \mathrm{pK}$ expression levels. Using recombinant proteins, we showed that $\mathrm{Bmi1}$ is a direct phosphorylation target for $3 \mathrm{pK}$ in vitro (Fig. 4.5A). For additional in vitro kinase assays, active 3pK was obtained by mitogen or arsenite stimulation of cells ${ }^{3}$. Immunoprecipitated Bmi1 is strongly phosphorylated in the presence of the active kinase (Fig. 4.5B, lower panel), 
similar to levels obtained with the control substrate Hsp27 (Fig. 4.5B, lower panel). Preliminary data obtained with PcG complexes purified by immunoprecipitation suggest that other PcG complex members (HPH1, HPc2) are also directly phosphorylated in vitro by $3 \mathrm{pK}$ (BN and SL, unpublished data). To provide additional evidence for phosphorylation of Bmi1 by $3 \mathrm{pK}$ in vivo, genetically matched cells with increased or diminished 3pK expression were used in the phosphorylation assays. The expression of a nucleus-retained active $3 \mathrm{pK}$ mutant results in more intensive Bmi1 phosphorylation after serum stimulation compared with wild type cells (Fig. 4.5C). Serum stimulation reveals subtle but clear differences in phosphorylation between control and 3pKoverexpressing cells (Fig. 4.5D); Bmi1 is phosphorylated more rapidly and more intensely in $3 p K$-overexpressing cells. We were able to relate these findings to specific biological effects of $3 \mathrm{pK}$ overexpression (HN and JWV, manuscript in preparation). Conversely, in cells in which $3 \mathrm{pK}$ is knocked down by RNA interference $^{25}$ using two independent RNA interfering sequences (Fig. 4.5E, lanes 1 and 3), decreased phosphorylation of Bmi1 correlates nicely with decreased 3pK levels. These findings connect 3pK expression levels and Bmi1 phosphorylation in vivo. Cells knocked down for $3 \mathrm{pK}$ expression retain $\mathrm{Bmi} 1$ and $\mathrm{HPH} 1 /$ chromatin association upon arsenite stimulation (Fig. 4.5F), whereas cells overexpressing $3 \mathrm{pK}$ show a more rapid Bmi1 release (data not shown), again directly implicating $3 \mathrm{pK}$ in this process. Combined, these findings strongly suggest that PcG proteins are phosphorylated downstream of activated MAPK (ERK/p38) pathways and identify $3 \mathrm{pK}$ as a Bmi1 kinase.

\section{Overexpression of $3 p \mathrm{~K}$ reduces PcG complex/chromatin association}

To qualify as a PcG complex-associated Bmi-1 kinase, 3pK would be expected to associate with chromatin. Indeed, differential nuclear extraction of cells overexpressing human $3 \mathrm{pK}$ constructs shows, in line with the immunoprecipitation data presented above, that a fraction of the wild type 3pK protein is associated with chromatin (Fig. 4.6A). Neither constitutively active nor kinase-inactive mutants of $3 \mathrm{pK}$ associate with chromatin to the extent wild type $3 p K$ does (Fig. 4.6A), in concordance with observations that such mutants are mainly found in the cytoplasm ${ }^{45-48}$. Combined with the immunoprecipitation data, this demonstrates that at least a fraction of cellular MAPKAP kinase 3 is associated with PcG complexes at the chromatin level.

Because repressive PcG complexes are intimately associated with chromatin and MAPK-induced PcG phosphorylation results in chromatin dissociation, it would follow that $3 \mathrm{pK}$ activation or overexpression causes $\mathrm{PcG} / \mathrm{chromatin}$ dissociation, which would then result in de-repression of PcG target genes. To begin to understand the biological relevance of PcG complex phosphorylation by $3 p \mathrm{pK}$, we studied the cellular function of $3 \mathrm{pK} .3 \mathrm{pK}$ overexpression induces a profound 
A

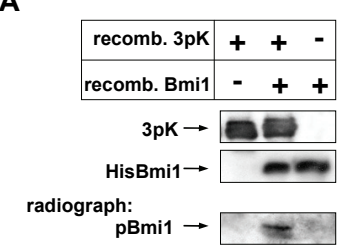

B

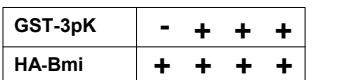

D

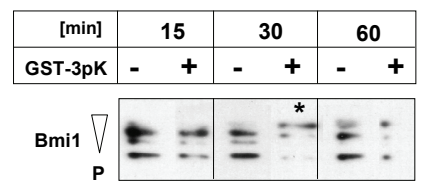

F

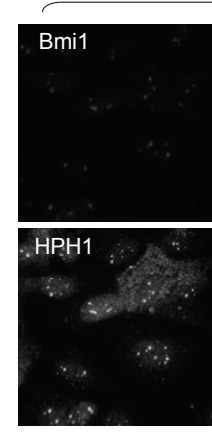

vector control control

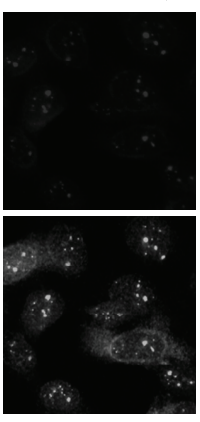

RNAi 3pK

E

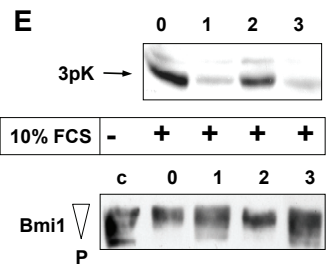

arsenite

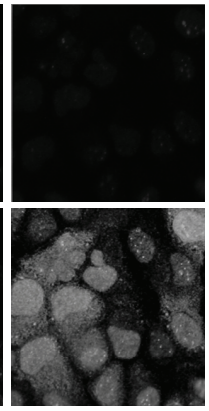

vector control

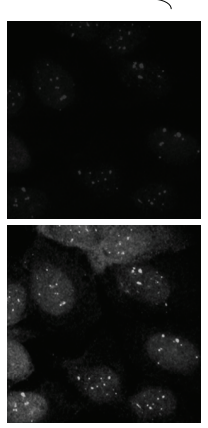

RNAi 3pK

Figure 4.5. Identification of $3 \mathrm{pK}$ as a candidate Bmi1 kinase.

(A) 3pK directly phosphorylates Bmi1. Recombinant GST-3pK (T201E/T313E) and recombinant Histagged Bmi1 protein were used in in vitro kinase assays. $(B)$ in vitro kinase assays show that immunoprecipitated Bmi1 is phosphorylated by 3pK. Active GST-3pK was obtained from HEK293 cells (arsenite- or serum/TPA-stimulated for $60 \mathrm{~min}$ ). HA-Bmi1 substrate and kinase were immunoprecipitated separately and then combined in kinase assays. Hsp27, a known 3pK substrate, was used in control reactions (lower panel). (C) increased in vivo phosphorylation of Bmi1 by a nucleus-retained (NR) 3pK mutant, which lacks the C-terminal (aa 308-383) regulatory region. Lane $c$, serum-starved cells; control cells or cell expressing NR-3pK were serum-stimulated (10\% FCS), following which Bmi1 was immunoprecipitated from cell extracts. P32 incorporation was determined by autoradiography. (D) exposure to serum (5\%) reveals differences in the kinetics of Bmi1 phosphorylation between control and 3pK overexpressing U2OS cells; time ( $\mathrm{min}$ ) between start of stimulation and harvest is indicated. (E) reduced Bmi1 phosphorylation in response to hsRNA-mediated 3pK reduction. Various stably expressed hsRNAs (Ianes 1-3; see "Experimental Procedures") reduce 3pK protein levels (upper panel); diminished Bmi1 phosphorylation upon mitogenic stimulation correlates well with lowered 3pK expression levels (lower panel). Lane $O$ is an empty vector control. U2OS cells were serum-starved prior to activation (lower panel, far left lane c). (F) reduced chromatin dissociation of PcG proteins Bmi1 and HPH1 upon arsenite stimulation of cells correlates with 3pK expression in U2OS cells. Cells were treated as described in the legend to Fig. 4.3A. RNA interfering sequence used: 1 (see Fig. 4.5C and "Experimental Procedures"). See page 195 for colour print.

effect on cell proliferation; cell cycling slows down significantly or arrests, depending on the cell type studied.4 We therefore asked whether overexpression of $3 \mathrm{pK}$ induces de-repression of the Cdkn2a/ INK4A locus, a well established Bmi-1 target $^{49,50}$ that is transcriptionally silent in U2OS cells ${ }^{51} .3 p K-$ 
overexpressing cells showed reduced (or loss of) nuclear PcG staining (Fig. 4.6C, middle panel). In agreement with this, in U2OS cells overexpressing $3 \mathrm{pK}$, less Bmi1 is present in the chromatin-bound fraction as compared with control cells (Fig. 4.6B), which supports the idea that $3 \mathrm{pK}$ overexpression results in chromatin release of Bmi1. Cells that have lost $\mathrm{PCG} /$ chromatin association show reexpression of $\mathrm{p} 14^{\mathrm{ARF}}$, one of the gene products of the Cdkn2a/INK4A locus (Fig. 4.6C). The above findings are consistent with the notion that PcG repression needs to be lost to de-repress a target gene.

\section{Discussion}

We here identify $3 \mathrm{pK}$ as a component of PcG complexes. Initially identified in a yeast two-hybrid screen as a binding partner of $\mathrm{HPH} 2,3 \mathrm{pK}$ was subsequently shown to associate with chromatin and PcG complexes by biochemical analysis. The region within HPH2 responsible for $3 p K$ binding is the HDII/SPM/SAM domain, which also mediates homo- and heterotypic interactions with other PcG proteins, such as SCM and $\mathrm{Bmi1}^{4,5,35,36}$. We established an intact $\alpha 5$ motif as a crucial structure for $\mathrm{HPH} 2 / 3 \mathrm{pK}$ interaction within the HDII domain. MAPKAP kinase 2, a close homolog of $3 \mathrm{pK}$, was recently found to bind $\mathrm{HPH} 2$ in a yeast two-hybrid screen $^{52}$. The interaction region was mapped to the C-terminally located HDII domain as well. In addition, full-length MPh1 (mouse Polyhomeotic) interacts with $3 \mathrm{pK}$ in direct interaction assays. 3 This combined information supports the notion that the HDII/ SPM/SAM domain plays an important role in $\mathrm{HPH} / 3 \mathrm{pK}$ interaction and suggests that complex composition may vary with cell type or physiology, or alternatively, that there may be ternary complex formation between $\mathrm{HPH} 1 / 2, \mathrm{Bmi} 1$, and $3 \mathrm{pK}$ or other binding partners in vivo.

3pK phosphorylates Bmi1 and possibly other PcG proteins in vitro, and 3pK overexpression or knockdown in genetically matched cell lines results in enhanced and reduced Bmi1 phosphorylation in vivo, respectively. In addition, we showed that the typical punctate nuclear PcG staining pattern is lost upon ERK or p38 activation. This implicates a connection between MAP kinase signaling and chromatin structure remodeling through modulation of PcG complex function. A simple mechanistic model proposes that PcG-associated $3 p K$ is an integral regulatory element within PcG complexes; $3 p K$ phosphorylation and activation by upstream nuclear shuttle kinases (ERK, p38 and possibly JNK) results in phosphorylation and subsequent chromatin dissociation of PcG complexes from known chromosomal binding sites ${ }^{26}$. Although chromatin dissociation is expected to result in reactivation of repressed genes, it is currently unknown what the molecular effect of protein phosphorylation is on PcG members. Phosphorylation is thought to affect 
A

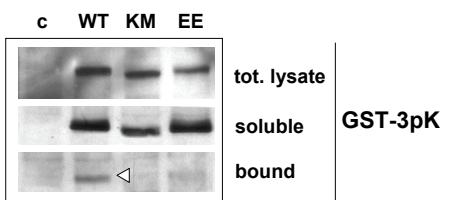

B
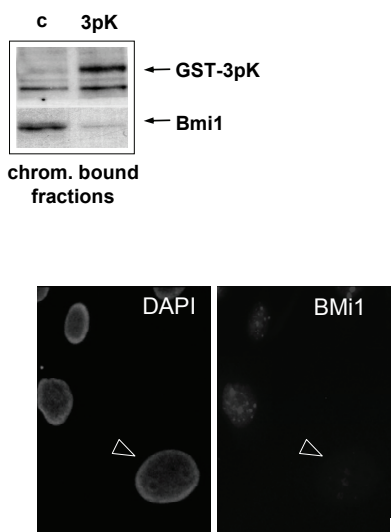

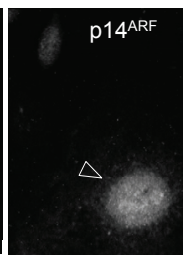

D

Extra-cellular signal (mitogen, stress)

Figure 4.6. Overexpression of $3 p \mathrm{~K}$ releases chromatin-associated Bmi1 and de-represses Cdkn2a/INK4A.

(A) GST-tagged wild type $3 \mathrm{pK}$ is chromatin-associated. Cells expressing wild type GST-3pK or mutant GST-3pK (K73M, TT201/313EE, respectively. KM and EE in figure) ${ }^{3}$ were differentially extracted. Shown are the chromatin-bound protein fractions. In concordance with published data $^{48}$, only wild type $3 \mathrm{pK}$ resides in the nucleus. (B) $3 \mathrm{pK}$ overexpression reduces chromatin association of Bmi1 (right panel). Shown is the chromatin-bound fraction of differential nuclear extracts. Cells were kept under high selection pressure (puromycin) for two passages. (C) reduced $\mathrm{PcG} /$ chromatin association (middle panel) and increased p14 ${ }^{\mathrm{ARF}}$ expression (right panel) in 3pKoverexpressing U2OS cells. U2OS cells were infected on glass slides with GST-3pK-IRES-GFP retrovirus; infection was confirmed by fluorescence. Under these conditions, $16-20 \%(n>150)$ of the cells have lost the typical nuclear PcG domains (arrowhead). The majority of these cells is positive for $\mathrm{p} 14^{\mathrm{ARF}}$ expression. Control cells, infected with empty vector, showed neither PcG dissociation nor $\mathrm{p} 14^{\mathrm{ARF}}$ expression $(n>250)$. (D) connection between cell signaling and epigenetic regulation of gene expression via chromatin remodeling factors. MAPK phosphorylation cascades are known to target transcription factors (TF, right) and chromatin (nucleosomes, left) directly. We propose that activated MAPK cascades (schematically depicted by circles on arrow) also target chromatin (beads) through modulation of chromatin remodeling complexes (gray structures), such as PcG complexes. Activation of 3pK leads to phosphorylation of PcG complexes; subsequent chromatin dissociation results in de-repression of silenced loci. See page 199 for colour print.

subcellular localization or homodimerization of some PcG proteins ${ }^{53,54}$. We find some relocation of PcG proteins to the cytoplasmic fraction (JWV, unpublished data). However, the fate of dissociated PcG complexes, as well as that of the activated MAPKAP kinase, is unclear, as studies with proteasome inhibitors do not show marked proteolytic breakdown. Given our observation that at least 
part of the mammalian PcG protein core complex ${ }^{14}$ remains intact upon phosphorylation, it is unlikely that Bmi1 phosphorylation directly causes chromatin dissociation. A more likely scenario is that $\mathrm{PcG} /$ chromatin binding is mediated by critical amino acid residues on a (limited number of) PcG complex member(s) in a phosphorylation-dependent manner. Potentially interesting candidates are the mammalian orthologs for $\mathrm{Pc}(\mathrm{HPc} 1 / 2 / 3)$, which may directly bind histone $\mathrm{H} 33 m$ (trimethyl) Lys27-silencing imprints through its chromodomain. It is possible that, besides chromatin association, protein/protein interaction and/or (associated) catalytic activity of individual PCG proteins is altered upon phosphorylation. In this light, the redistribution of $\mathrm{HPH} 1$ is interesting. Although the exact implications of this HPH1-redistribution are currently not clear, it may well serve to stall DNA replication and or gene expression upon activation of the stress kinase pathway through its interaction with DNA replication inhibitors ${ }^{55,56}$. Likewise, recently identified enzymatic activities of PcG proteins (i.e. histone methyltransferase activity of $\mathrm{EZH} 2$ ) $^{12}$, small ubiquitin- like modifier E3 ligase activity of HPc orthologs ${ }^{57}$, and ubiquitin E3 ligase activity for the Ring finger proteins (such as Ring $1 \mathrm{~B}^{58}$ and possibly Bmi1) are likely to be affected by phosphorylation. Clearly, identification of relevant cellular substrates of these enzymes and mutation analysis of relevant phosphorylation sites are essential to increasing our understanding of the exact role of phosphorylation in PcG-mediated silencing.

ERK and/or p38 and JNK MAP kinases and downstream MAPK effector kinases (one of which is $3 \mathrm{pK}$ ) are implicated in a variety of fundamental cellular processes, including proliferation, differentiation, and cell cycle regulation ${ }^{1}$. The involvement of PcG and trxG proteins in development and cancer is well documented (reviewed in Ref. ${ }^{7}$ ). Similar to $3 \mathrm{pK}$, we have also observed in vitro $\mathrm{HPH} 2$ binding (as previously reported ${ }^{52}$ ), Bmi1 phosphorylation by MAPKAP kinase 2, and reduced chromatin dissociation upon knockdown of MAPKAP kinase 2 protein levels (BN, SL, URR and JWV, unpublished data). These observations suggest that additional kinases may target PcG proteins downstream of active MAPK cascades. Interestingly, other kinases within the MAPKAP kinase family act on histones ${ }^{59}$, further supporting the idea that such kinases, besides directly activating transcription factors, also target chromatin components and chromatin remodeling factors (Fig. 4.6D). Phosphorylation of residues (e.g. histone $\mathrm{H} 3$ pSer10 or pSer28) adjacent to silencing marks (e.g. histone H3 $3 m$ Lys9 or $3 m$ Lys 27 ) could act as a (re-)activating event ${ }^{44}$ and serve to release repressive (HP1 or PcG, respectively) effector complexes and effectively de-repress target genes. In accordance with this "binary switch" model $^{44}$, our data suggest that $\mathrm{PcG} /$ chromatin dissociation is a relatively early event and may be directly connected to local phosphorylation of histone $\mathrm{H} 3$ Ser28; i.e. histone H3 Ser28 phosphorylation at target loci is sufficient to release 
PcG complexes from chromatin. The co-existence of pSer10 and Polycomb complexes in arsenite-stimulated cells, however, seems to rule out a major role for histone $\mathrm{H} 3 \mathrm{pSer} 10$ in $\mathrm{PcG} /$ chromatin dissociation, in line with a specific role for H3 $3 \mathrm{mLys} 9$ in HP1-mediated heterochromatin formation ${ }^{60}$. However, to formally exclude the possibility that these respective phosphorylation events are independent, detailed examination of the histone H3 Ser28 status at target genes in relation to $\mathrm{PcG} /$ chromatin association is required.

Bmi1 and its direct binding partners, Rnf2, MPh1 and M33, through transcriptional control of the Cdnk2a/INK4A locus, are involved in proliferative control during embryogenesis and postnatal life and in stem cell renewal in hematopoiesis and neurogenesis ${ }^{61-65}$. We have studied the effect of $3 p \mathrm{~K}$ on cell cycle progression and its genetic interaction with PcG proteins in detail.4 Relevantly, overexpression of 3pK de-represses the Cdnk2a/INK4A locus, further supporting the interaction of MAPK signaling and PcG-dependent chromatin remodeling. Both mitogenic as well as stress activation lead to PcG/chromatin dissociation. Clearly, different target genes are predicted to be (de)activated in response to these different physiological stimuli. Recent findings indicate that $3 \mathrm{pK}$ activation and translocation kinetics are dependent on the pathway through which it is activated ${ }^{3,48}$; this is expected to influence the type of substrates and genes targeted by activated kinases downstream of mitogens or cellular stressors.

In summary, we have described a novel link between signaling through MAP kinase cascades and an epigenetic transcription regulatory system. We propose this as a molecular mechanism by which cells modulate gene expression profiles to adequately respond to changes in their microenvironment; consequentially, PcG-mediated silencing may be subject to dynamic modulation. Chromatin association of both trxG and PcG protein complexes has been reported to depend on their phosphorylation status ${ }^{26,34}$. We propose that MAPK signaling impinges on gene expression through functional regulation of chromatinmodifying complexes via PCG and trxG kinases and/or phosphatases (Fig. 4.6D). Unraveling the nature of kinase/PcG and PcG/chromatin association and the exact biological significance of phosphorylation for PcG function presents an exciting and relevant challenge for future research. It will be of particular interest to examine whether and how this molecular connection relates to the proposed role of MAPK pathways as switching mechanisms that modulate gene activity $^{2}$. PcG, trxG proteins, and MAPK signaling pathways are connected to tumorigenesis; the hereindescribed findings will improve our understanding of how cells modulate gene expression at the epigenetic level in response to extracellular cues and have the potential to yield therapeutic strategies to fight cancer. 


\section{Acknowledgments}

We are much indebted to R. Agami, T. Brummelkamp, M. Dyer, M. Inagaki, H. Koseki, A. Lund, A. Otte, D. Peeper, D. Shvarts, M. van Lohuizen, M. Vidal, and $M$. Ummelen for sharing reagents and $M$. van Lohuizen and B. Wouters for useful comments to the manuscript.

\section{References}

1. Tibbles LA, Woodgett JR. The stress-activated protein kinase pathways. Cell Mol Life Sci. 1999;55(10):1230-1254.

2. Hazzalin CA, Mahadevan LC. MAPK-regulated transcription: a continuously variable gene switch? Nat Rev Mol Cell Biol. 2002;3(1):30-40.

3. Ludwig S, Engel K, Hoffmeyer A, Sithanandam G, Neufeld B, Palm D, Gaestel M, Rapp UR. 3pK, a novel mitogen-activated protein (MAP) kinase-activated protein kinase, is targeted by three MAP kinase pathways. Mol Cell Biol. 1996;16(12):66876697.

4. Gunster MJ, Satijn DP, Hamer KM, den Blaauwen JL, de Bruijn D, Alkema MJ, van Lohuizen $M$, van Driel R, Otte AP. Identification and characterization of interactions between the vertebrate polycomb-group protein BMI1 and human homologs of polyhomeotic. Mol.Cell Biol. 1997;17(4):2326-2335.

5. Alkema MJ, Bronk M, Verhoeven E, Otte A, van't Veer L, Berns A, van Lohuizen M. Identification of Bmi1-interacting proteins as constituents of a multimeric mammalian polycomb complex. Genes Dev. 1997;11(2):226-240.

6. Paro R. Imprinting a determined state into the chromatin of Drosophila. Trends Genet. 1990;6(12):416-421.

7. van Lohuizen M. Functional analysis of mouse Polycomb group genes. Cell Mol Life Sci. 1998;54(1):71-79.

8. Simon JA, Tamkun JW. Programming off and on states in chromatin: mechanisms of Polycomb and trithorax group complexes. Curr Opin Genet Dev. 2002;12(2):210218.

9. Orlando V, Paro R. Chromatin multiprotein complexes involved in the maintenance of transcription patterns. Curr Opin Genet Dev. 1995;5(2):174-179.

10. Pirrotta V. PCG complexes and chromatin silencing. Curr Opin Genet Dev. $1997 ; 7(2): 249-258$.

11. van der Vlag J, Otte AP. Transcriptional repression mediated by the human polycomb-group protein EED involves histone deacetylation. Nat.Genet. 1999;23(4):474-478.

12. Cao R, Wang L, Wang $H$, Xia L, Erdjument-Bromage $H$, Tempst $P$, Jones RS, Zhang $Y$. Role of histone H3 lysine 27 methylation in Polycomb-group silencing. Science. 2002;298(5595):1039-1043.

13. Shao Z, Raible F, Mollaaghababa R, Guyon JR, Wu CT, Bender W, Kingston RE. Stabilization of chromatin structure by PRC1, a Polycomb complex. Cell. 1999;98(1):37-46. 
14. Levine SS, Weiss A, Erdjument-Bromage $H$, Shao Z, Tempst $P$, Kingston RE. The core of the polycomb repressive complex is compositionally and functionally conserved in flies and humans. Mol Cell Biol. 2002;22(17):6070-6078.

15. Fischle W, Wang Y, Jacobs SA, Kim Y, Allis CD, Khorasanizadeh S. Molecular basis for the discrimination of repressive methyl-lysine marks in histone $\mathrm{H} 3$ by Polycomb and HP1 chromodomains. Genes Dev. 2003;17(15):1870-1881.

16. Min J, Zhang $Y, X u$ RM. Structural basis for specific binding of Polycomb chromodomain to histone H3 methylated at Lys 27. Genes Dev. 2003;17(15):18231828.

17. Sewalt RG, Lachner M, Vargas M, Hamer KM, den Blaauwen JL, Hendrix T, Melcher $M$, Schweizer D, Jenuwein T, Otte AP. Selective interactions between vertebrate polycomb homologs and the SUV39H1 histone lysine methyltransferase suggest that histone H3-K9 methylation contributes to chromosomal targeting of Polycomb group proteins. Mol Cell Biol. 2002;22(15):5539-5553.

18. Wang $\mathrm{H}$, Wang $\mathrm{L}$, Erdjument-Bromage $\mathrm{H}$, Vidal $\mathrm{M}$, Tempst $\mathrm{P}$, Jones $\mathrm{RS}$, Zhang $\mathrm{Y}$. Role of histone H2A ubiquitination in Polycomb silencing. Nature. 2004;431(7010):873878.

19. Brock HW, van Lohuizen M. The Polycomb group--no longer an exclusive club? Curr Opin Genet Dev. 2001;11(2):175-181.

20. Lund $\mathrm{AH}$, Van Lohuizen M. Polycomb complexes and silencing mechanisms. Curr Opin Cell Biol. 2004;16(3):239-246.

21. Levine SS, King IF, Kingston RE. Division of labor in Polycomb group repression. Trends Biochem Sci. 2004;29(9):478-485.

22. Neufeld B, Grosse-Wilde A, Hoffmeyer A, Jordan BW, Chen P, Dinev D, Ludwig S, Rapp UR. Serine/Threonine kinases $3 p K$ and MAPK-activated protein kinase 2 interact with the basic helix-loop-helix transcription factor E47 and repress its transcriptional activity. J Biol Chem. 2000;275(27):20239-20242.

23. Kinsella TM, Nolan GP. Episomal vectors rapidly and stably produce high-titer recombinant retrovirus. Hum.Gene Ther. 1996;7(12):1405-1413.

24. Morgenstern JP, Land H. Advanced mammalian gene transfer: high titre retroviral vectors with multiple drug selection markers and a complementary helper-free packaging cell line. Nucleic Acids Res. 1990;18(12):3587-3596.

25. Brummelkamp TR, Bernards R, Agami R. A system for stable expression of short interfering RNAs in mammalian cells. Science. 2002;296(5567):550-553.

26. Voncken JW, Schweizer D, Aagaard L, Sattler L, Jantsch MF, van Lohuizen M. Chromatin-association of the Polycomb group protein BMI1 is cell cycle- regulated and correlates with its phosphorylation status. J Cell Sci. 1999;112(Pt 24):46274639.

27. Ishida R, Sato $M$, Narita $T$, Utsumi $K$, Nishimoto $T$, Morita $T$, Nagata $H$, Andoh T. Inhibition of DNA topoisomerase II by ICRF-193 induces polyploidization by uncoupling chromosome dynamics from other cell cycle events. J. Cell Biol. 1994;126(6):1341-1351.

28. Hamer KM, Sewalt RG, den Blaauwen JL, Hendrix T, Satijn DP, Otte AP. A panel of monoclonal antibodies against human polycomb group proteins. Hybrid Hybridomics. 2002;21(4):245-252. 
29. Atsuta T, Fujimura S, Moriya H, Vidal M, Akasaka T, Koseki H. Production of monoclonal antibodies against mammalian Ring1B proteins. Hybridoma. 2001;20(1):43-46.

30. Goto H, Tomono Y, Ajiro K, Kosako H, Fujita M, Sakurai M, Okawa K, Iwamatsu A, Okigaki T, Takahashi T, Inagaki M. Identification of a novel phosphorylation site on histone H3 coupled with mitotic chromosome condensation. J Biol Chem. 1999;274(36):25543-25549.

31. Serrano $M$, Lin AW, McCurrach ME, Beach D, Lowe SW. Oncogenic ras provokes premature cell senescence associated with accumulation of p53 and p16INK4a. Cell. 1997;88(5):593-602.

32. Favata MF, Horiuchi KY, Manos EJ, Daulerio AJ, Stradley DA, Feeser WS, Van Dyk DE, Pitts WJ, Earl RA, Hobbs F, Copeland RA, Magolda RL, Scherle PA, Trzaskos JM. Identification of a novel inhibitor of mitogen-activated protein kinase kinase. J Biol Chem. 1998;273(29):18623-18632.

33. Lee JC, Laydon JT, McDonnell PC, Gallagher TF, Kumar S, Green D, McNulty D, Blumenthal MJ, Heys JR, Landvatter SW, et al. A protein kinase involved in the regulation of inflammatory cytokine biosynthesis. Nature. 1994;372(6508):739-746.

34. Muchardt C, Reyes JC, Bourachot B, Leguoy E, Yaniv M. The hbrm and BRG-1 proteins, components of the human SNF/SWI complex, are phosphorylated and excluded from the condensed chromosomes during mitosis. Embo $\mathrm{J}$. 1996;15(13):3394-3402.

35. Peterson AJ, Kyba M, Bornemann D, Morgan K, Brock HW, Simon J. A domain shared by the Polycomb group proteins $\mathrm{Scm}$ and ph mediates heterotypic and homotypic interactions. Mol Cell Biol. 1997;17(11):6683-6692.

36. Kyba M, Brock HW. The SAM domain of polyhomeotic, RAE28, and scm mediates specific interactions through conserved residues. Dev Genet. 1998;22(1):74-84.

37. Kim CA, Gingery M, Pilpa RM, Bowie JU. The SAM domain of polyhomeotic forms a helical polymer. Nat Struct Biol. 2002;9(6):453-457.

38. Hemenway CS, Halligan BW, Levy LS. The Bmi-1 oncoprotein interacts with dinG and MPh2: the role of RING finger domains. Oncogene. 1998;16(19):2541-2547.

39. Suzuki $M$, Mizutani-Koseki $Y$, Fujimura $Y$, Miyagishima $H$, Kaneko T, Takada $Y$, Akasaka T, Tanzawa H, Takihara $Y$, Nakano M, Masumoto H, Vidal M, Isono K, Koseki $\mathrm{H}$. Involvement of the Polycomb-group gene Ring1B in the specification of the anterior-posterior axis in mice. Development. 2002;129(18):4171-4183.

40. Ludwig S, Hoffmeyer A, Goebeler M, Kilian K, Hafner H, Neufeld B, Han J, Rapp UR. The Stress Inducer Arsenite Activates Mitogen-activated Protein Kinases Extracellular Signal-regulated Kinases 1 and 2 via a MAPK Kinase 6/p38-dependent Pathway. J. Biol. Chem. 1998;273(4):1917-1922.

41. Saurin AJ, Shiels C, Williamson J, Satijn DP, Otte AP, Sheer D, Freemont PS. The human polycomb group complex associates with pericentromeric heterochromatin to form a novel nuclear domain. J Cell Biol. 1998;142(4):887-898.

42. Hodgson JW, Argiropoulos B, Brock HW. Site-specific recognition of a 70-base-pair element containing $d(G A)(n)$ repeats mediates bithoraxoid polycomb group response element-dependent silencing. Mol Cell Biol. 2001;21(14):4528-4543.

43. Li J, Gorospe M, Hutter D, Barnes J, Keyse SM, Liu Y. Transcriptional induction of MKP-1 in response to stress is associated with histone H3 phosphorylationacetylation. Mol Cell Biol. 2001;21(23):8213-8224. 
44. Fischle $\mathrm{W}$, Wang $\mathrm{Y}$, Allis $\mathrm{CD}$. Binary switches and modification cassettes in histone biology and beyond. Nature. 2003;425(6957):475-479.

45. Engel K, Kotlyarov A, Gaestel M. Leptomycin B-sensitive nuclear export of MAPKAP kinase 2 is regulated by phosphorylation. Embo J. 1998;17(12):3363-3371.

46. New L, Jiang Y, Han J. Regulation of PRAK subcellular location by p38 MAP kinases. Mol Biol Cell. 2003;14(6):2603-2616.

47. Seternes OM, Johansen B, Hegge B, Johannessen M, Keyse SM, Moens U. Both binding and activation of p38 mitogen-activated protein kinase (MAPK) play essential roles in regulation of the nucleocytoplasmic distribution of MAPKactivated protein kinase 5 by cellular stress. Mol Cell Biol. 2002;22(20):6931-6945.

48. Zakowski V, Keramas G, Kilian K, Rapp UR, Ludwig S. Mitogen-activated 3p kinase is active in the nucleus. Exp Cell Res. 2004;299(1):101-109.

49. Jacobs JJ, Kieboom K, Marino S, DePinho RA, van Lohuizen M. The oncogene and Polycomb-group gene bmi-1 regulates cell proliferation and senescence through the ink4a locus. Nature. 1999;397(6715):164-168.

50. Jacobs JJ, Scheijen B, Voncken JW, Kieboom K, Berns A, van Lohuizen M. Bmi-1 collaborates with c-Myc in tumorigenesis by inhibiting c-Myc-induced apoptosis via INK4a/ARF. Genes Dev. 1999;13(20):2678-2690.

51. Park YB, Park MJ, Kimura K, Shimizu K, Lee SH, Yokota J. Alterations in the INK4a/ARF locus and their effects on the growth of human osteosarcoma cell lines. Cancer Genet Cytogenet. 2002;133(2):105-111.

52. Yannoni YM, Gaestel M, Lin LL. P66(ShCA) interacts with MAPKAP kinase 2 and regulates its activity. FEBS Lett. 2004;564(1-2):205-211.

53. Fujisaki S, Ninomiya $Y$, Ishihara H, Miyazaki M, Kanno R, Asahara T, Kanno M. Dimerization of the Polycomb-group protein Mel-18 is regulated by PKC phosphorylation. Biochem Biophys Res Commun. 2003;300(1):135-140.

54. Noguchi K, Shiurba R, Higashinakagawa T. Nuclear translocation of mouse polycomb $\mathrm{m} 33$ protein in regenerating liver. Biochem Biophys Res Commun. 2002;291(3):508-515.

55. Luo L, Yang $X$, Takihara $Y$, Knoetgen $H$, Kessel $M$. The cell-cycle regulator geminin inhibits Hox function through direct and polycomb-mediated interactions. Nature. 2004;427(6976):749-753.

56. Wohlschlegel JA, Dwyer BT, Dhar SK, Cvetic C, Walter JC, Dutta A. Inhibition of eukaryotic DNA replication by geminin binding to Cdt1. Science. 2000;290(5500):2309-2312.

57. Kagey MH, Melhuish TA, Wotton D. The polycomb protein Pc2 is a SUMO E3. Cell. 2003;113(1):127-137.

58. Lee SJ, Choi JY, Sung YM, Park H, Rhim H, Kang S. E3 ligase activity of RING finger proteins that interact with Hip-2, a human ubiquitin-conjugating enzyme. FEBS Lett. 2001;503(1):61-64.

59. Sassone-Corsi P, Mizzen CA, Cheung P, Crosio C, Monaco L, Jacquot S, Hanauer A, Allis $C D$. Requirement of Rsk-2 for epidermal growth factor-activated phosphorylation of histone H3. Science. 1999;285(5429):886-891.

60. Bannister AJ, Zegerman P, Partridge JF, Miska EA, Thomas JO, Allshire RC, Kouzarides T. Selective recognition of methylated lysine 9 on histone H3 by the HP1 chromo domain. Nature. 2001;410(6824):120-124. 
61. Core N, Joly F, Boned A, Djabali M. Disruption of E2F signaling suppresses the INK4a-induced proliferative defect in M33-deficient mice. Oncogene. 2004;23(46):7660-7668.

62. Lessard J, Sauvageau G. Polycomb group genes as epigenetic regulators of normal and leukemic hemopoiesis. Exp Hematol. 2003;31(7):567-585.

63. Molofsky AV, Pardal R, Iwashita T, Park IK, Clarke MF, Morrison SJ. Bmi-1 dependence distinguishes neural stem cell self-renewal from progenitor proliferation. Nature. 2003;425(6961):962-967.

64. Ohta H, Sawada A, Kim JY, Tokimasa S, Nishiguchi S, Humphries RK, Hara J, Takihara Y. Polycomb group gene rae28 is required for sustaining activity of hematopoietic stem cells. J Exp Med. 2002;195(6):759-770.

65. Voncken JW, Roelen BA, Roefs M, de Vries S, Verhoeven E, Marino S, Deschamps J, van Lohuizen M. Rnf2 (Ring1b) deficiency causes gastrulation arrest and cell cycle inhibition. Proc Natl Acad Sci U S A. 2003;100(5):2468-2473. 


\section{Chapter 5}

\section{MK3 controls proliferation by an epigenetic switch-mechanism involving Polycomb function}




\begin{abstract}
Polycomb (PcG)-chromatin association, although crucial for maintenance of gene repression profiles, is subject to dynamic regulation during development. Molecular insight in processes that control PcG-chromatin association is limited. We previously showed that activation of MAP/SAPK signaling triggers phosphorylation of PcG proteins through the kinase MK3. We report here that cells regulate proliferation and replicative life span through MK3. Importantly, MK3 alleviates PcG-chromatin binding at target loci without concomitant changes in H3K27 trimethylation. Our studies uncover a novel MK3-dependent epigenetic switching mechanism at PcG target loci in cell cycle control and support a role for MK3 in chromatin structure dynamics.
\end{abstract}


MK3 controls proliferation by an epigenetic switch mechanism involving PcG

\section{Introduction}

During its lifetime a cell integrates multiple signals, both internally and from its environment to generate appropriate biological responses. These responses are often initiated through changes in gene expression that arise as a result of changes in the rates of synthesis, activity, stability and sub-cellular localization of RNAs and proteins. At the chromatin level, gene-environment interactions are, besides activation and/or recruitment of transcription factors, determined by epigenetic control over chromatin structure and nucleosome movement.

Polycomb Group (PcG) repressive complexes (PRC) act as part of a cellular transcriptional maintenance system; as such they play an important role in cell fate determination. Recent genome-wide ChIP studies revealed that PcGchromatin association throughout development is subject to dynamic changes: lineage commitment of e.g. embryonal stem cells is accompanied by redistribution of PcG complexes across chromatin and establishment of novel lineage-relevant transcriptionally active domains ${ }^{1,2}$. The molecular mechanisms that underlie this dynamic relocation of repressive PcG complexes are currently unknown.

PcG proteins are functionally subdivided in two complexes. Polycomb repressive complex 2 (PRC2) contains SUZ12, EED and EZH2, the latter harbors histone lysine methyl transferase (HMT) activity toward histone 3 on lysine $27^{3}$. The PRC1 core consists of at least 4 PcG subclasses: BMI1/Mel18 (PCGF4/2), CBX2 (HPC1), CBX4 (HPC2), CBX6, CBX7 or CBX8, PHC1-3 (HPH1-3, EDR1-3) and RING1/RNF2 (Ring1A/1B), ${ }^{4}$. PRC1 and PRC2 function were shown to be linked in Drosophila melanogaster, in that the CBX homologue Pc binds to H3K27me ${ }^{6,7}$. Recently we demonstrated that mitogen-activated protein kinase-activated protein kinase 3 (MAPKAPK3; also known as MK3 or 3pK) phosphorylates PcG proteins ${ }^{8}$. Mitogenic signaling through GFRs (growth factor receptors) activates p21RAS. This subsequently triggers various downstream signaling cascades, among which MAPK/MAPKAPK pathways ${ }^{9}$, leading to changes in gene expression. Signaling to MK3 through SAPKs (JNK, p38) or MAPK (ERK) ${ }^{10}$ triggers distinct cellular responses (i.a. cell cycle arrest and proliferation). In cancer, oncogenic p21RASV12-signaling ultimately induces senescence as part of a failsafe mechanism to oncogenic transformation ${ }^{11}$. Both MAPK and SAPK signaling have been implicated in replicative life $\operatorname{span}^{12}$. Given its crucial positioning at convergent mitogenic and stress signaling, it is conceivable that MK3 fine tunes signaling in the context of cell cycle regulation.

Insight in signaling pathways that cells use to affect chromatin responses is limited. As PcG-phosphorylation correlates with dissociation from chromatin ${ }^{8,13}$, it is tempting to speculate on a function for MK3 in regulating PcG complexmediated transcriptional repression. Here we hypothesized that MK3 activity 
A

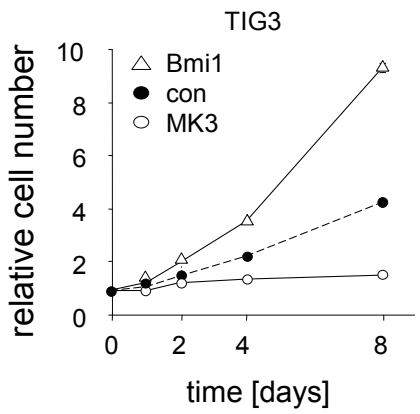

B

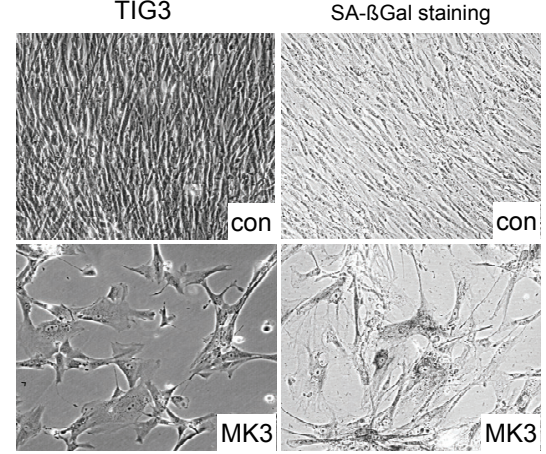

E

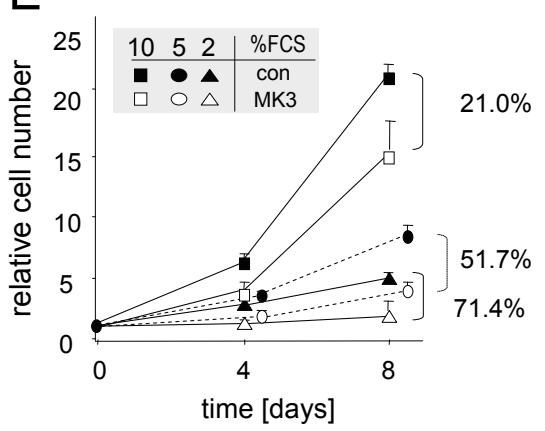

C

U2-OS

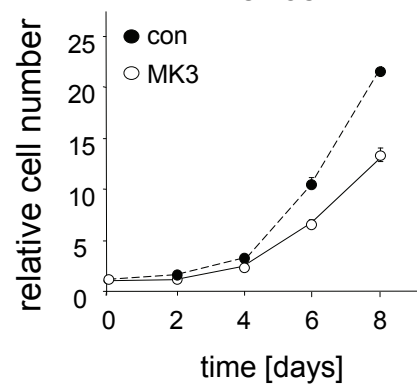

U2-OS

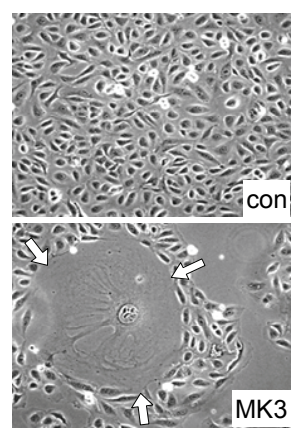

U2OS

$\mathrm{F}$

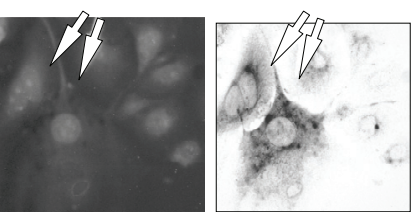

Figure 5.1. MK3 induces cell cycle arrest and a senescence-like state. $(A, C)$ Overexpression of MK3 reduces cell proliferation of primary human TIG3 fibroblasts (A) or osteosarcoma U2-OS cells (C) expressing murine Bmi1 (open triangles) or MK3 (open circles) or an empty vector control (filled circles). ( $B, D$ ) TIG3 (B) or U2-OS (D) cells overexpressing MK3 (MK3) display a replicative block and large flat cell phenotype. MK3 expressing large flat cells are positive for senescence-associated $\beta$ Galactosidase (SA-ßGal; $B$ : panel bottom right). Arrows (D) mark the outline a large flat cell. (E) The effect of MK3-OE is dependent on the intensity of mitogenic stimulation: decreased serum concentrations reduce proliferation in MK3 overexpressing U2-OS cells (squares: $10 \%$ FCS; circles: 5\% FCS; triangles: $2 \% \mathrm{FCS}$; filled symbols: con; open symbols: MK3). Indicated are percentages growth reduction relative to control cells. (F) MK3.ires.GFP-OE in U2-OS cells induces senescence. Arrows: large flat cells positive for GFP (left panel) and SA-ßGal (right panel). See page 199. 
MK3 controls proliferation by an epigenetic switch mechanism involving PcG

regulates PRC1-chromatin association, which results in derepression of PCG target genes. We show that overexpression of MK3 expression suppresses cell proliferation and induces a senescence-like state similar to loss of Polycomb function. We observe that MK3 binds to known PcG target gene promoters in human fibroblasts, and that activation of MK3 induces dissociation of the PRC1 protein complex, without the need for concomitant changes in local H3K27 methylation. Our data suggest a novel rapid epigenetic molecular switchingmechanism mediated by MK3 phosphorylation of PcG proteins leading to a dynamic regulation of relevant target genes in response to activated signaling cascades.

\section{Results \& Discussion}

MK3 overexpression reduces proliferation and induces a senescence-like arrest Overexpression of MK3 (MK3-OE) in primary human TIG3 fibroblasts significantly reduces proliferative capacity (Fig. 5.1A, 5.S1A,B). MK3-OE in TIG3 cells induces a large flat cell morphology that was accompanied by expression of the senescence-associated marker SA- $\beta$ Gal (SA- $\beta$-Galactosidase; Fig. 5.1B). Although MAPKs and SAPKs have been linked to regulation of hTERT-function ${ }^{14}$, 15, the observation that MK3-induces a similar morphology in hTERTimmortalized human fibroblasts cells (Fig. 5.S1C), suggests that MK3 acts either downstream or independent of hTERT. The human cancer cell lines U2-OS (Fig. 5.1C) and HeLa (data not shown) also show reduced proliferation following MK3-OE. Remarkably, also the U2-OS and HeLa cell lines show an enhanced flat cell phenotype (Fig. 5.1D, 5.S1D) upon MK3-OE and concomitant SA- $\beta$ Gal activity (Fig. 5.1F). Little to no apoptosis or cell death was observed in response to MK3-OE (Fig. 5.S1B). The MK3-OE phenotype resembles that of loss of PcG function: loss of PRC1 proteins such as Bmi1 or PHC2 induces a flat cell phenotype in U2-OS cells (Fig. 5.S1E,F) and has been associated with premature senescence in mouse fibroblasts ${ }^{16,17}$. Our observations suggest a potential role for MK3 in regulation of replicative life span.

Modulation of MK3 proteins levels is expected to result in a proliferativesignaling imbalance. Acute loss (stable short hairpin (sh)RNA-assisted knockdown) of MK3 function (MK3-KD) in primary human fibroblasts consistently results in a cell cycle arrest (Fig. 5.S2A,B,C). In addition to an expected mitogen concentration-dependent reduction in proliferation rate (Fig. 5.1E), serum reduction enhanced the large flat cell phenotype in both primary human fibroblasts as well as in U2-OS cells overexpressing MK3 (Fig. 5.S2D,E). Hence, mitogenic signaling appeared to balance-out a senescence program set-off by MK3-OE. 
A

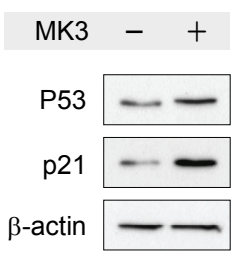

B

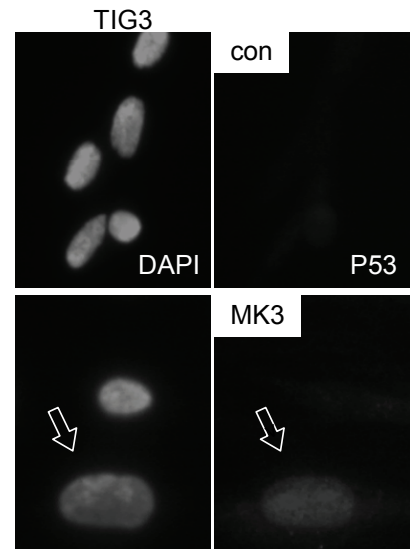

C

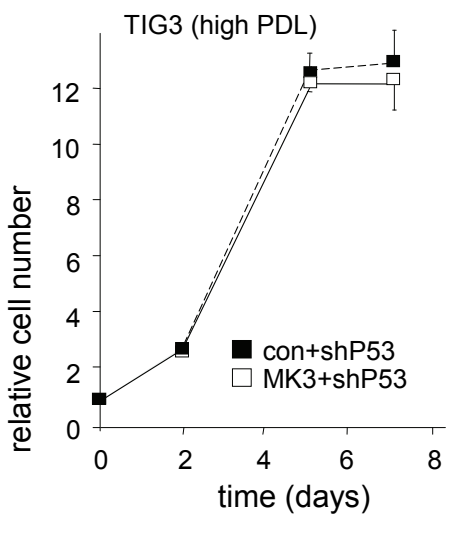

TIG3

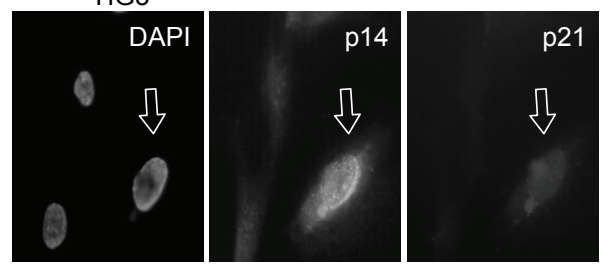

$E$
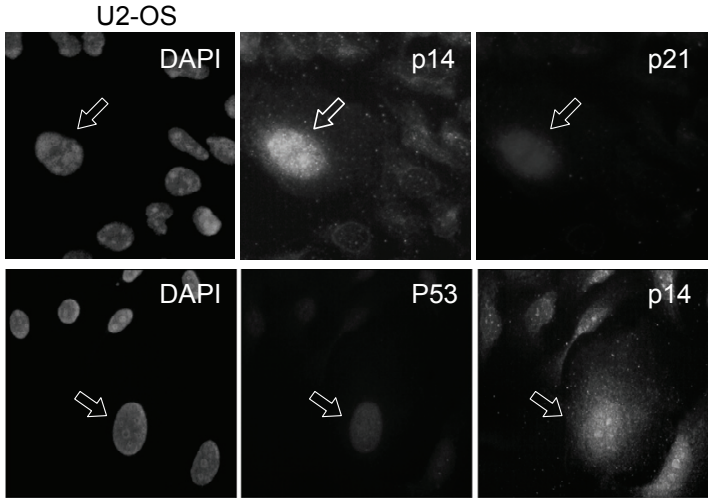

Figure 5.2. Expression analysis of cell cycle regulators in MK3-expressing senescent cells. (A) Upregulation of the check point regulator proteins $\mathrm{P} 53$ and $\mathrm{p} 21^{\mathrm{CIP1} 1 / \mathrm{WAF} 1}$ in response to MK3-OE in primary fibroblasts. $(B, D)$ Co-expression of P53 $(B), \mathrm{p} 21^{\mathrm{CP} 1 / \text { WAF1 }}$ and $\mathrm{p} 14^{\mathrm{ARF}}(D)$ in MK3 positive senescent TIG3 cells. (C) TIG3 fibroblasts deficient for P53 (shP53) are insensitive to the 3pKinduced cell cycle arrest (open squares: MK3-OE + shP53; closed squares (empty vector control + shP53). Compare proliferation profiles to those in Fig. 5.1a. (E) Co-expression of $\mathrm{p} 21^{\mathrm{CIP1} 1 \mathrm{WAF} 1}$ and $\mathrm{p} 14^{\mathrm{ARF}}$ and P53 and P14 ${ }^{\mathrm{ARF}}$ in MK3 positive senescent (arrow) U2-OS cells. See page 200 for colour.

\section{MK3 induced senescence is mediated by $p 53$ and the INK4A locus}

We studied the role of MK3 in RASV12-oncogene induced senescence (OIS), a known senescence program. Whereas either RASV12-OE or shMK3 induce replicative arrest in primary fibroblasts (Fig. 5.S3A), MK3-KD transiently prevents 
RASV12-induced proliferative arrest in a dosage-dependent manner, indicating that MK3 relays oncogenic signaling by RASV12. RASV12-induced senescence involves p53 signaling ${ }^{11}$. P53 expression is upregulated in MK3-OE cells (Fig. $5.2 \mathrm{~A}, \mathrm{~B}, 5 . \mathrm{S} 3 \mathrm{~B}$ ) and loss of $\mathrm{P} 53$ bypasses MK3-OE dependent proliferative arrest (Fig. 5.2C). P53 and $\mathrm{P} 21^{\mathrm{CP} 1 / \mathrm{WAF} 1}$ are both upregulated in MK3-OE cells (Fig. $5.2 A, D)$ in accordance with a P53/p21 $1^{\text {CP1/WAF1 }}$ dependency of early senescence ${ }^{18}$. Cells expressing nuclear P53 or p21 $1^{\text {CIP1/WAF1 }}$ are also positive for $\mathrm{p} 14^{\mathrm{ARF}}$ (Fig. $5.2 \mathrm{D}, \mathrm{E})$, which is, like $\mathrm{p} 16^{\mathrm{INK} 4 \mathrm{~A}}$, associated with replication check-points in human cells ${ }^{19}$. Although p14 ${ }^{\text {ARF }}$ may stabilize $\mathrm{P} 53^{20}$, we can not formally rule out possible independent roles for P53 and $\mathrm{p} 14^{\mathrm{ARF}}$ and $\mathrm{p} 21^{\mathrm{CIP1} / \mathrm{WAF} 1}$ in the MK3-OE induced replicative arrest ${ }^{21,22}$. Senescent fibroblasts show clear nuclear p16 ${ }^{\text {INK4A }}$ accumulation under these experimental conditions (Fig. 5.S3C); this was confirmed by immuno-blotting (Fig. 5.4C). The upregulated expression of p16 ${ }^{\text {INK4a }}$ upon prolonged MK3 overexpression is in good agreement with a crucial role for $\mathrm{p} 16^{\mathrm{INK} 4 \mathrm{~A}}$ in establishing irreversible senescence ${ }^{23-25}$.

We previously reported that MK3-OE reduces chromatin association of PRC1complex members Bmi1, CBX4 and RNF2 and induced re-expression of p14 ${ }^{\mathrm{ARF}}$, one of the gene products encoded by the CDKN2A/INK4A locus ${ }^{8}$ and a confirmed PcG-target ${ }^{26}$. We used chromatin immunopreciptation (ChIP) to prove a direct association of MK3 to CDKN2A/INK4A in primary human TIG3 fibroblasts. H3K27me3 and CBX8 enrichment at the p16 ${ }^{\text {INK4A }}$ promoter and at the p16-exon1 were confirmed: MK3 enrichment is observed at the CDKN2A/INK4A locus and increases when MK3 is overexpressed (Fig. 5.4A).

\section{Genetic interaction between MK3 and Polycomb function in senescence}

The PRC2 protein EZH2, generates the repression-associated H3K27me3 mark at target genes ${ }^{3}$. EZH2 levels are reduced in MK3-OE primary TIG3 cells (Fig. 5.4C, 5.S5A), in line with a previously reported senescence-associated decline in EZH2 levels ${ }^{26}$. In accordance with this, MK3-OE reproducibly decreases global H3K27me3 in HeLa cells (Fig. 5.3A). Bmi1-OE counters the global loss of H3K27me3 (Fig. 5.3B). We further explored a possible genetic interaction between PRC1 and MK3 in the context of cell cycle regulation. Co-expression of Bmi1 and MK3 in primary human fibroblasts cells restores proliferation rate (data not shown) and bypassed senescence-associated morphological changes induced by MK3-OE alone (Fig. 5.3C). In line with the above data simultaneous Bmi1-KD and MK3-OE in U2-OS cells causes a strong additive effect on induction of flat cell morphology (Fig. 5.S3D). Relevantly, serially transduced Bmi1+MK3 fibroblast cultures auto-select for increased Bmi1 levels over time (Fig. 5.3D), demonstrating that cells utilize Bmi1 to overcome the adverse effects of MK3$\mathrm{OE}$ on cell proliferation. Our findings support a strong genetic and biochemical interaction between MK3 and PRC1-function, with clear biological relevance to 
A

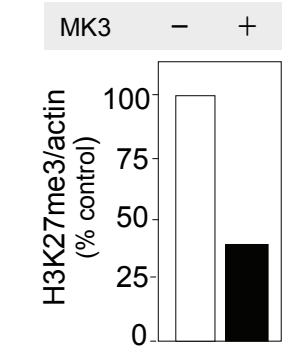

$\begin{aligned} \text { H3K27me3 } & - \\ \beta \text {-actin } & -\end{aligned}$

C
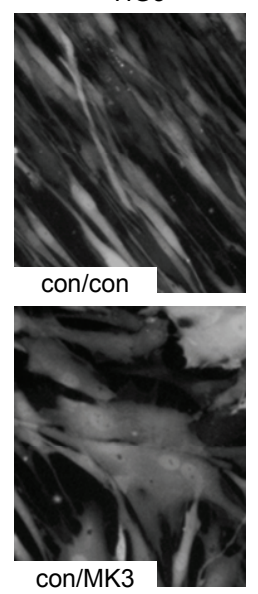

B

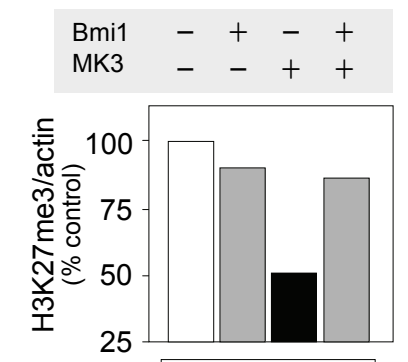

H3K27me3

$\beta$-actin

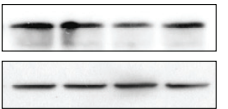

D
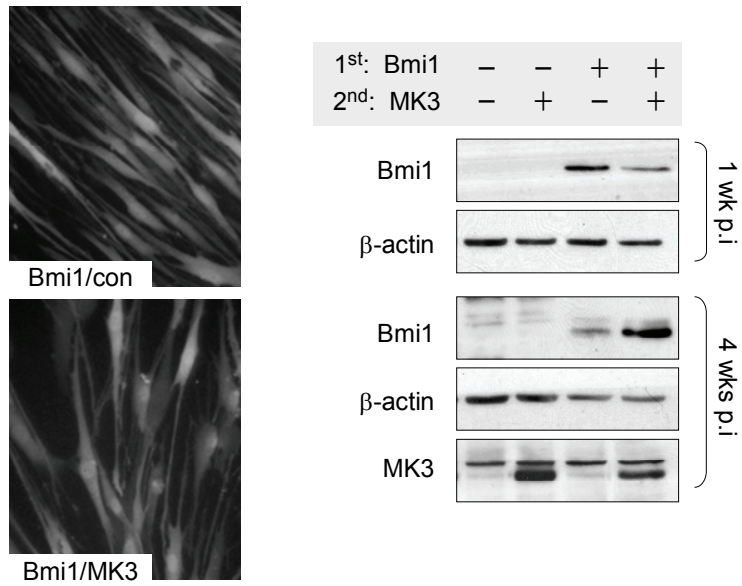

Figure 5.3. Genetic interaction between MK3 and Bmi1. (A) MK3-overexpressing HeLa cells show reduced global H3K27me3. Quantification of H3K27me3 was done by densitometry and normalized against ß-actin levels. (B) Overexpression of Bmi1 in MK3 transduced HeLa cells corrects H3K27me3 levels. (C) Reversal of MK3-induced proliferative and morphological alterations by overexpression of Bmi1 in primary human fibroblasts. Cells were sequentially transduced with either Bmi1.ires.GFP (Bmi1) or control (con) virus, and MK3 (MK3) or control virus (con) at 48 hour intervals. $(D)$ Serially transduced cultures (see $C$ ) were grown for 25 days and analyzed for MK3 and Bmi1 expression. See page 201 for colour print.

proliferative control. MK3 activates cell cycle checkpoints involving known tumorsuppressor pathways and counteracts the oncogenic effects of Bmi1. This is consistent with MK3 loss-of-function in several malignant cancers and hence a potential tumorsuppressive role ${ }^{27}$. However, our findings are also consistent with a pro-oncogenic role for MK3: MK3-OE induces similar cellular responses as RASV12, RASV12-induced OIS is dependent on MK3. A recent study on NMYC 
MK3 controls proliferation by an epigenetic switch mechanism involving PcG

suggested that the outcome of oncogenic signaling imbalance, i.e. proliferation (oncogenic) or apoptosis (anti-oncogenic), is dependent on critical threshold NMYC expression levels and, equally relevant, on the cells' intrinsic (i.a. genetic) state and its microenvironment ${ }^{28}$. In line with this notion, we show that changes in the mitogenic environment of MK3-OE cells significantly affects MK3 induced senescence. MK3 mutations were recently suggested to be potentially oncogenic, in contrast to MK2 mutations ${ }^{29}$. Although the exact role of these mutations in tumorigenesis awaits further analysis, our data support differential cellular functions for MK3 and MK2. This is corroborated by our finding that, in contrast to $M K 2^{30}, M K 3$ is not required for UV induced arrest (Fig. 5.S4A,B,C). Combined with the recent finding that MK5 (PRAK), although required for RASOIS, by itself is not capable of inducing senescence ${ }^{31}$, these data further support the idea that MAPKAP kinases although related, may have acquired divergent cellular context dependent functions.

\section{MK3-PRC1: an epigenomic dimmer switch}

We next studied regulatory protein occupation at known PcG-target loci using ChIP. Overexpression of MK3 only minimally affects H3K27me3 levels at the $p 16$ promoter, whereas $\mathrm{H} 3 \mathrm{~K} 27 \mathrm{me} 3$ is slightly reduced at $p 16$ exon 1 (Fig. 5.4A). Relevantly, the MK3-OE TIG3 cells used in this experiment express more p16 ${ }^{\text {INK4 }}$ and display the distinctive senescence phenotype (Fig. 5.4C, 5.S5A,B). Non-PcGtargets (i.a. p15exon1, CCNA2) show little to none CBX8 occupation (Fig. 5.4A, 5.S5D), in line with earlier reports ${ }^{26,32}$. Remarkably, although CBX8 and PHC1 are both part of the PRC1 complex, they show distinct chromatin association in response to MK3-OE: whereas local CBX8-chromatin occupation is substantially reduced, (e.g. ATF3, p16 exon1), PHC1 binding appears mostly increased (Fig. 5.4A, 5.S5D), indicating PHC1 occupation occurs without the need for simultaneous CBX occupation, and suggesting differential regulation between members of the same complex. This is consistent with our previous report that PHC behaves differently in response to MK3 activation compared to PRC1 proteins like BMI1, CBX4 and RNF2 ${ }^{8}$. In agreement with this, PHC-association to the PRC1 core complex was reported to be comparatively weak ${ }^{33}$ and purified PHC1 was shown to reside in multiple complexes, some of which are non-PRC complexes $^{34}$. Hence, nuclear PHC1 may fulfill multiple functions. Interestingly, MK3 and PHC1 show a very similar enrichment profile (Fig. 5.4A, 5.S5D), also at non-PcG targets (e.g. p15 and CCNA2). This is in good agreement with our previously reported direct interaction between MK3 and PHC proteins ${ }^{8}$. To obtain evidence for direct phosphorylation of PRC1 proteins by MK3, we performed an in vitro kinase assay using a PRC1 peptide spot array, covering potential phosphorylation sites in Bmi1, Cbx4, Phc2, Rnf2 and histone H3.3, that adhere to the common MK phosphorylation motif RxxS (Fig. 5.S6A). We 
A 0.15

$\square$ MK3

0.00

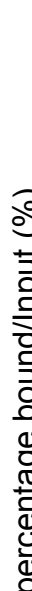
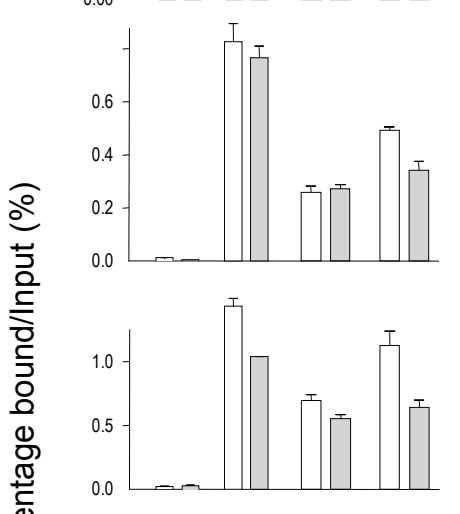

0.2

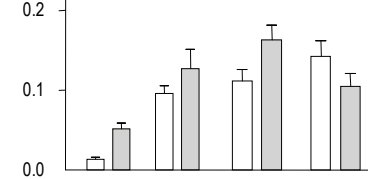

0.1

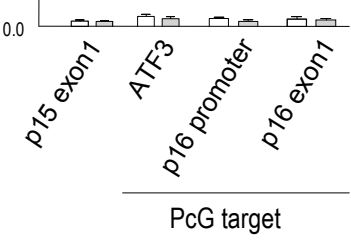

C

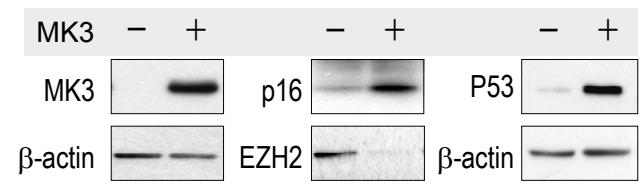

B $\quad \square$ starved

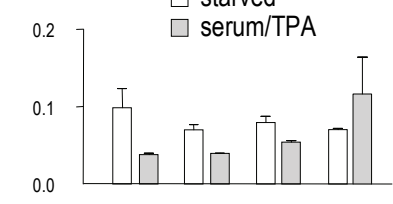

H3K27me3

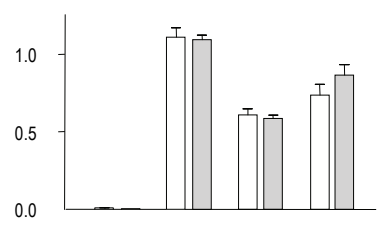

CBX8

PHC1

HA
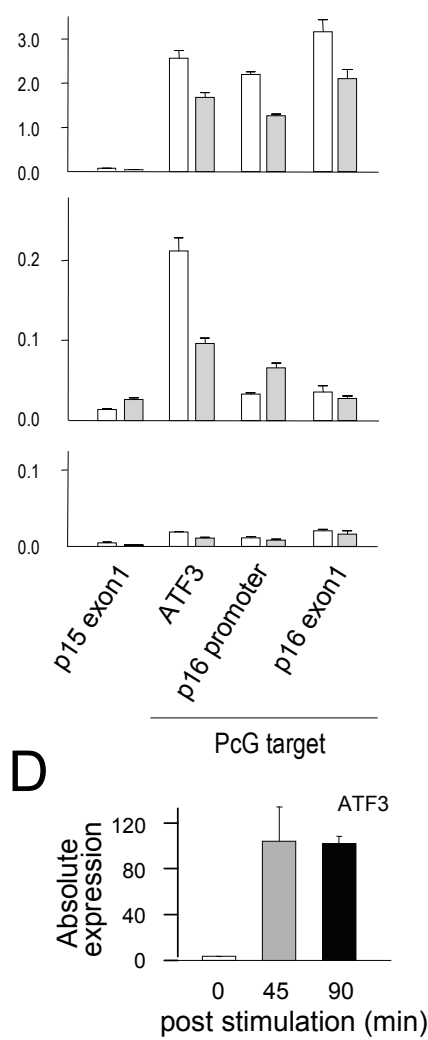

Figure 5.4. MK3-overexpression or activation regulates PRC1 chromatin association and gene activity. (A) ChIP analysis at known PcG target loci: CDKN2A/INK4A and ATF3 locus in MK3-OE (MK3) and control (con) TIG3 cells. p15 exon1 acts as a negative control. Enrichments are presented as percentages of total input. (B) ChIP analysis in TIG3 cells, after $48 \mathrm{hrs}$ of serum starvation with $0.1 \% \mathrm{FCS}$ followed by either no or $45 \mathrm{~min}$. stimulation with $15 \%$ serum and $100 \mathrm{ng} / \mathrm{ml} \mathrm{TPA}$. (C) Western analysis of cell lysates prepared from TIG3 cells expressing MK3 or control cells. P14 ${ }^{\mathrm{ARF}}$ was not detectable in either control or MK3 OE TIG3 cells. (D) real time quantitative ATF3 mRNA analysis upon 45 minutes and 90 minutes serum stimulation. 
MK3 controls proliferation by an epigenetic switch mechanism involving PcG

previously established that MK3 activation leads to PRC1 phosphorylation ${ }^{8}$. We now confirm that PRC1 peptides, in this specific assay are, targets for MK3 phosphorylation (Fig. 5.S6B). A much stronger MK3-induced phosphorylation is detected on $3 \mathrm{Phc} 2$ peptides and $1 \mathrm{Cbx} 4$ peptide. Peptides in which the $\mathrm{R}$ in the RxxS-motif is substituted by an A or synthetically pre-phosphorylated are not phosphorylated in the kinase assay (not shown), confirming the specificity of the assays and indicating that indeed the Serine residues within the RxxS MK3-motif are phosphorylated. Neither Rnf2 nor H3.3 peptides or full length H3.3 were phosphorylated by MK3 in vitro. These data show that MK3 targets multiple PRC1 proteins for phosphorylation. It is therefore tempting to speculate that MK3-OE affects PRC1-chromatin occupancy through phosphorylation and disruption of complexes.

As decreased EZH2 protein levels in MK3-OE TIG3 (Fig. 5.4C) may contribute to loss of global H3K27me3 and indirectly cause CBX8 displacement, we also studied PRC1-chromatin occupation in the context of a relevant physiological mitogenic stimulus. Bmi1 and CBX8 protein levels do not change under these conditions, and Bmi1-phosphorylation was confirmed upon mitogenic stimulation (Fig. 5.S5C). MK3-chromatin occupation is overall reduced in response to mitogenic stimulation (Fig. 5.4B, 5.S5E). Importantly, a relatively short mitogenic stimulus (45 minutes) does not change H3K27me3 levels at the CDKN2A/INK4A locus, but is sufficient to reduce CBX8 binding at all Polycomb targets (Fig. 5.4B). Changes in PHC1 occupation do not match that of CBX8: PHC1 increases at a number of loci ( $p 16$ promoter, $p 14^{A R F}$ exon1) (Fig. 5.4B, $\mathrm{S} 5 \mathrm{E})$. Conversely, chromatin at confirmed PRC1-targets (ATF3, distal promoters HOXA cluster; ${ }^{32}$ ) clearly reveals $\mathrm{CBX} 8$ displacement in response to stimulation, despite unchanged H3K27me3 levels (Fig. 5.4B, S5E). When combined with gene expression measurements, ChIP analysis revealed a clear correlation between loss of both $\mathrm{CBX} 8$ and PHC1 and activation of gene expression at the ATF3 locus (Fig. 5.4D). In contrast, loss of CBX8 only (PHC1 increased or unchanged) did not correlate with gene expression at other loci (Fig. 5.S5F). Hence, this data suggests that initial loss of PRC1-chromatin association but not removal of H3K27me3, correlates with gene expression activation and that all PRC1 core complex members may need to dissociate at crucial regulatory regions to allow for active transcription. We propose that signaling through MK3-PRC1 changes the local epigenomic state through progressive loss of PRC1 members from a repressed/poised state ${ }^{1,2}, 32$, to a 'de-repressed' and eventually fully transcriptionally active state (Fig. 5.5). Intergenic similarities in dynamic $\mathrm{PCG} /$ chromatin changes as well as intragenic variation in response to MK3-OE and serum stimulation, may point to global chromatin structure regulation in addition to complex local regulation, respectively. Genome-wide analysis of 


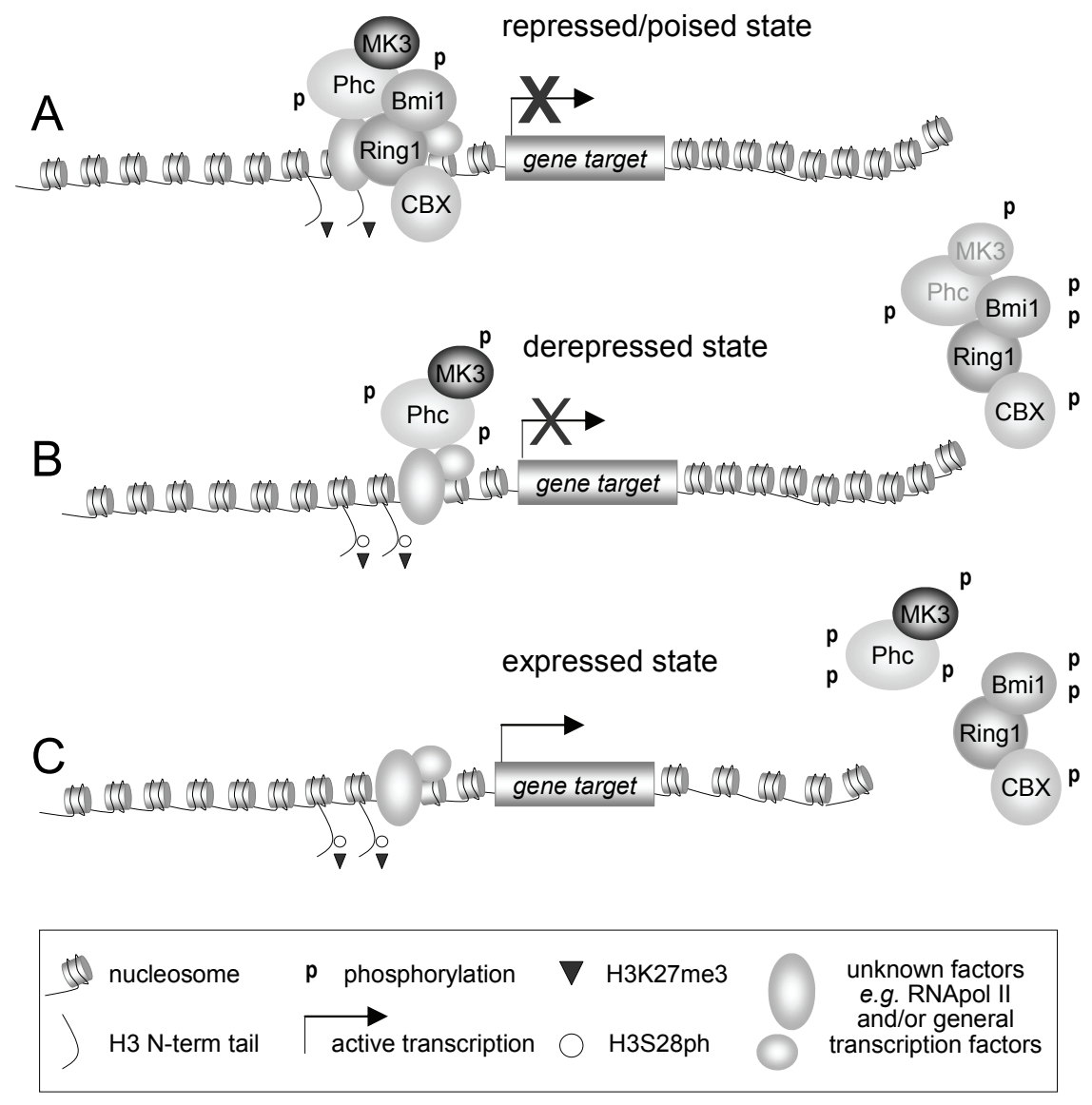

Figure 5.5. Hypothetical model for $M K 3 / P c G$ interaction at target genes. (A) Bmi1, Ring, $C B X$ and PHC proteins together form the PRC1 core complex, CBX proteins bind H3K27me3 marks at loci poised for transcriptional activation via the chromodomain. MK3 interacts with the PRC1 complex via $\mathrm{PHC}^{8}$. (B) Upon activation (e.g. by MAPK or SAPK activation) the PRC1 complex dissociates from chromatin. H3Ser28 phosphorylation is a very early event which correlates with PRC1-chromatin dissociation ${ }^{8}$. Part of the core-complex remains intact upon chromatin dissociation; in contrast, PHC partially dissociates from PRC1 but remains largely chromatin-associated. PHC1 may serve as an interface (e.g. epigenomic marking) for core-complex (re)binding or play an additional role. (C) Additional loss of PHC1 and acquisition of active epigenomic marks may be required for local gene expression. PRC1 protein phosphorylation $(p)$ is expected to affect protein-protein interaction and/or enzymatic activity of members within the complex.

MK3 occupation and chromatin-protein redistribution analyses are currently performed to explore these issues.

In summary, our findings suggest that signaling-imbalance is at the basis of cellular responses to MK3 and that an activated stress-program is responsible for the MK3-induced senescence-like replicative arrest. The data presented here 
MK3 controls proliferation by an epigenetic switch mechanism involving PcG

suggests that signaling upstream of MK3 disrupts PRC1-complexes, and consequently alleviates PRC1-repression which results in transcription of relevant target genes.

The observation that MK3 reactivates 'dormant' senescence checkpoints in cancer cells with compromised pRB and P53 function (i.e. CDKN2A/INK4A locus methylation in U2-OS cells $c q$. constitutive HPV-E6/E7 mediated inactivation of pRb and P53 in HeLa cells ${ }^{35,36}$ is quite remarkable and warrants further investigation into MK3-dependent epigenomic regulation of gene transcription in cancer.

We show here that MK3 activation releases PRC1-components from chromatin without changing the repressive PcG-associated histone H3K27me3 mark. Consistent with this, H3K4me3 does not change either (data not shown). MK3PRC1 may act as a molecular switch to allow for rapid dynamic regulation of gene activity. It is conceivable that disruption and/or dissociation of the PRC1 complex is dependent on post-translational modification, such as phosphorylation. In support of this notion, we obtained in vitro evidence that MK3 directly phosphorylates a number of PcG proteins. Global MK3-chromatin co-association analysis and PcG phospho-site mutation will help clarify the underlying molecular effects of MK3-to-Polycomb signaling.

\section{Materials and methods}

\section{Tissue culture and expression systems}

Indicated cell lines were cultured at $37^{\circ} \mathrm{C}, 5 \% \mathrm{CO}, 100 \%$ humidity in Dulbecco's modified Eagle's medium supplemented with $10 \%$ fetal calf serum (FCS). Tissue culture plastics were from Greiner Bio-One. Serum starvation was carried out at $0.05 \%$ FCS for cancer cell lines and at $0.1-0.5 \%$ for human fibroblasts. Retroviral expression vectors were used throughout these studies to maximize percentages of expressing cells and to minimize integration effects. Retroviral vectors ( $p B A B E-P U R O, p B M N-L Z R S$.ires.GFP, pBMN-LZRS.ires.NEO) expressing murine Bmi1 and human MK3 have been described elsewhere ${ }^{8}$. Criteria used for shRNA sequence design and the retroviral expression system were as described before $^{37}$. Targeting sequences are listed in Supplementary Table 5.1. Transduced cells were selected for 1 week on $4-16 \mu \mathrm{g} / \mathrm{ml}$ puromycin and then used in experiments. Growth curves were performed as described before ${ }^{11}$

\section{Immuno-histochemistry and cell staining}

Cell were seeded at $5-10 \%$ confluence on glass slides, infected at low MOI ( \pm 1:1) and subjected to a short, intense selection (i.e. 8 (Tig3) -16 $\mu \mathrm{g}$ (U2-OS) puromycin/ml) when applicable. Cells were fixed for 10 minutes at ambient 
temperature in $2 \%$ formaldehyde/PBS solution followed by permeabilization in $0,2 \%$ triton-X/PBS or directly fixed and permeabilized for 20 minutes in $100 \%$ methanol at $-20^{\circ} \mathrm{C}$. Antibody dilution was done in blocking buffer ( $5 \%$ normal goat serum, $5 \%$ fetal bovine serum, $0.02 \%$ triton $X$ in PBS). Polyclonal (Pab) rabbit antiserum glutathione S-transferase (GST) and monoclonal antiserum (Mab) against MK3 were kindly provided by $\mathrm{S}$. Ludwig (Münster, Germany). anti-2Py-tag Mab (MMS-115R; Babco, Richmond, California); anti-p14 ${ }^{\text {ARF }} / \mathrm{p} 16 ß$ Pab (Ab-1; LabVision corp., Fremont, California), Anti p16INKA mab (E6H4, MTM CINtec laboratories, Heidelberg, Germany), anti p21 Pab (C-19; Santa Cruz biotechnology), anti P53 Mab (DO-7; M7001; DAKO, Denmark). Primary Mabs were detected with goat-anti-mouse TexasRed, primary Pabs with goat-antirabbit FITC. SA-B-gal assays were performed as previously described ${ }^{38}$.

\section{ChIP assays}

ChIPs were performed and analyzed essentially as described ${ }^{39}$. The antibodies used were rabbit anti-H3K27me3 (07-449; Upstate Biotechnology), anti-HA (sc805; Santa Cruz Biotechnology), an equal mix of anti-CBX8 "LAST" and "GALD"32, anti-MK3 $3^{27}$, or anti-PHC1 ${ }^{40}$. The immunoprecipitated DNA was quantified by real-time qPCR. The sequences of the primers used are listed in Supplementary Table 5.1.

\section{Acknowledgments}

We are greatly indebted to a many colleagues for research materials and support of the study (please refer to Methods section). We thank Frédérique Peronnet, Ronit Sverdlov and Anders Lund for critically reading the manuscript and members of the MAASTRO and molecular genetics department for helpful discussions. These studies received financial support from the European Molecular Biology Organization (Germany) 186.00-06; the Dutch Science Organization (ZonMW-NWO): Research Support grant 908-02-040 to JWV and VIDI grant 016.046.362; the National Rheuma Foundation (Reumafonds) grant LLP14 to JWV and a Netherlands Genome Initiative (NGI) fellowship 050-72-422 to $\mathrm{HN}$. 


\section{References}

1. Boyer LA, Plath K, Zeitlinger J, Brambrink T, Medeiros LA, Lee TI, Levine SS, Wernig M, Tajonar A, Ray MK, Bell GW, Otte AP, Vidal M, Gifford DK, Young RA, Jaenisch R. Polycomb complexes repress developmental regulators in murine embryonic stem cells. Nature. 2006;441(7091):349-353.

2. Lee $\mathrm{TI}$, Jenner RG, Boyer LA, Guenther MG, Levine SS, Kumar RM, Chevalier B, Johnstone SE, Cole MF, Isono K, Koseki H, Fuchikami T, Abe K, Murray HL, Zucker JP, Yuan B, Bell GW, Herbolsheimer E, Hannett NM, Sun K, Odom DT, Otte AP, Volkert TL, Bartel DP, Melton DA, Gifford DK, Jaenisch R, Young RA. Control of developmental regulators by Polycomb in human embryonic stem cells. Cell. 2006;125(2):301-313.

3. Cao R, Zhang Y. The functions of $E(Z) / E Z H 2$-mediated methylation of lysine 27 in histone H3. Current Opinion in Genetics \& Development. 2004;14(2):155-164.

4. Levine SS, Weiss A, Erdjument-Bromage $H$, Shao Z, Tempst $P$, Kingston RE. The core of the polycomb repressive complex is compositionally and functionally conserved in flies and humans. Mol Cell Biol. 2002;22(17):6070-6078.

5. Otte AP, Kwaks TH. Gene repression by Polycomb group protein complexes: a distinct complex for every occasion? Curr Opin Genet Dev. 2003;13(5):448-454.

6. Min J, Zhang $\mathrm{Y}, \mathrm{Xu}$ RM. Structural basis for specific binding of Polycomb chromodomain to histone H3 methylated at Lys 27. Genes Dev. 2003;17(15):18231828.

7. Fischle W, Wang Y, Jacobs SA, Kim Y, Allis CD, Khorasanizadeh S. Molecular basis for the discrimination of repressive methyl-lysine marks in histone $\mathrm{H} 3$ by Polycomb and HP1 chromodomains. Genes Dev. 2003;17(15):1870-1881.

8. Voncken JW, Niessen H, Neufeld B, Rennefahrt U, Dahlmans V, Kubben N, Holzer B, Ludwig S, Rapp UR. MAPKAP kinase 3pK phosphorylates and regulates chromatin association of the polycomb group protein Bmi1. J Biol Chem. 2005;280(7):51785187.

9. Gaestel M. MAPKAP kinases - MKs - two's company, three's a crowd. Nat Rev Mol Cell Biol. 2006;7(2):120-130.

10. Ludwig S, Engel K, Hoffmeyer A, Sithanandam G, Neufeld B, Palm D, Gaestel M, Rapp UR. 3pK, a novel mitogen-activated protein (MAP) kinase-activated protein kinase, is targeted by three MAP kinase pathways. Mol Cell Biol. 1996;16(12):66876697.

11. Serrano $M$, Lin AW, McCurrach ME, Beach D, Lowe SW. Oncogenic ras provokes premature cell senescence associated with accumulation of p53 and p16INK4a. Cell. 1997;88(5):593-602.

12. Deng $\mathrm{Q}$, Liao $\mathrm{R}, \mathrm{Wu} B \mathrm{BL}$, Sun $\mathrm{P}$. High intensity ras signaling induces premature senescence by activating p38 pathway in primary human fibroblasts. $J$ Biol Chem. 2004;279(2):1050-1059.

13. Voncken JW, Schweizer D, Aagaard L, Sattler L, Jantsch MF, van Lohuizen M. Chromatin-association of the Polycomb group protein BMI1 is cell cycle- regulated and correlates with its phosphorylation status. J Cell Sci. 1999;112(Pt 24):46274639.

14. Ge Z, Liu C, Bjorkholm M, Gruber A, Xu D. Mitogen-activated protein kinase cascade-mediated histone $\mathrm{H} 3$ phosphorylation is critical for telomerase reverse 
transcriptase expression/telomerase activation induced by proliferation. Mol Cell Biol. 2006;26(1):230-237.

15. Bilsland AE, Stevenson $K$, Atkinson $S$, Kolch W, Keith WN. Transcriptional repression of telomerase RNA gene expression by c-Jun-NH2-kinase and Sp1/Sp3. Cancer Res. 2006;66(3):1363-1370.

16. Jacobs JJ, Kieboom K, Marino S, DePinho RA, van Lohuizen M. The oncogene and Polycomb-group gene bmi-1 regulates cell proliferation and senescence through the ink4a locus. Nature. 1999;397(6715):164-168.

17. Isono K, Fujimura Y, Shinga J, Yamaki M, J OW, Takihara Y, Murahashi Y, Takada Y, Mizutani-Koseki Y, Koseki H. Mammalian polyhomeotic homologues phc2 and phc1 act in synergy to mediate polycomb repression of hox genes. Mol Cell Biol. 2005;25(15):6694-6706.

18. Chen J, Huang X, Halicka D, Brodsky S, Avram A, Eskander J, Bloomgarden NA, Darzynkiewicz Z, Goligorsky MS. Contribution of p16INK4a and p21CIP1 pathways to induction of premature senescence of human endothelial cells: permissive role of p53. Am J Physiol Heart Circ Physiol. 2006;290(4):H1575-1586.

19. Sherr CJ. The INK4a/ARF network in tumour suppression. Nat Rev Mol Cell Biol. 2001;2(10):731-737.

20. Pomerantz J, Schreiber-Agus N, Liegeois NJ, Silverman A, Alland L, Chin L, Potes J, Chen K, Orlow I, Lee HW, Cordon-Cardo C, DePinho RA. The Ink4a tumor suppressor gene product, p19Arf, interacts with MDM2 and neutralizes MDM2's inhibition of p53. Cell. 1998;92(6):713-723.

21. Sherr CJ. Divorcing ARF and p53: an unsettled case. Nat Rev Cancer. 2006;6(9):663673.

22. Rowland BD, Peeper DS. KLF4, p21 and context-dependent opposing forces in cancer. Nat Rev Cancer. 2006;6(1):11-23.

23. Beausejour CM, Krtolica A, Galimi F, Narita M, Lowe SW, Yaswen P, Campisi J. Reversal of human cellular senescence: roles of the p53 and p16 pathways. Embo J. 2003;22(16):4212-4222.

24. Collado M, Blasco MA, Serrano M. Cellular senescence in cancer and aging. Cell. 2007;130(2):223-233.

25. Campisi J. Senescent cells, tumor suppression, and organismal aging: good citizens, bad neighbors. Cell. 2005;120(4):513-522.

26. Bracken AP, Kleine-Kohlbrecher D, Dietrich N, Pasini D, Gargiulo G, Beekman C, Theilgaard-Monch K, Minucci S, Porse BT, Marine JC, Hansen KH, Helin K. The Polycomb group proteins bind throughout the INK4A-ARF locus and are disassociated in senescent cells. Genes Dev. 2007;21(5):525-530.

27. Sithanandam G, Latif F, Duh FM, Bernal R, Smola U, Li H, Kuzmin I, Wixler V, Geil L, Shrestha S. 3pK, a new mitogen-activated protein kinase-activated protein kinase located in the small cell lung cancer tumor suppressor gene region. Mol Cell Biol. 1996;16(3):868-876.

28. Murphy DJ, Junttila MR, Pouyet L, Karnezis A, Shchors K, Bui DA, Brown-Swigart L, Johnson L, Evan Gl. Distinct Thresholds Govern Myc's Biological Output In Vivo. Cancer Cell. 2008;14(6):447-457.

29. Greenman C, Stephens P, Smith R, Dalgliesh GL, Hunter C, Bignell G, Davies H, Teague J, Butler A, Stevens C, Edkins S, O'Meara S, Vastrik I, Schmidt EE, Avis T, Barthorpe S, Bhamra G, Buck G, Choudhury B, Clements J, Cole J, Dicks E, Forbes S, 
Gray K, Halliday K, Harrison R, Hills K, Hinton J, Jenkinson A, Jones D, Menzies A, Mironenko T, Perry J, Raine K, Richardson D, Shepherd R, Small A, Tofts C, Varian J, Webb T, West S, Widaa S, Yates A, Cahill DP, Louis DN, Goldstraw P, Nicholson AG, Brasseur F, Looijenga L, Weber BL, Chiew YE, DeFazio A, Greaves MF, Green AR, Campbell P, Birney E, Easton DF, Chenevix-Trench G, Tan MH, Khoo SK, Teh BT, Yuen ST, Leung SY, Wooster R, Futreal PA, Stratton MR. Patterns of somatic mutation in human cancer genomes. Nature. 2007;446(7132):153-158.

30. Manke IA, Nguyen A, Lim D, Stewart MQ, Elia AE, Yaffe MB. MAPKAP kinase-2 is a cell cycle checkpoint kinase that regulates the $G 2 / M$ transition and $S$ phase progression in response to UV irradiation. Mol Cell. 2005;17(1):37-48.

31. Sun P, Yoshizuka N, New L, Moser BA, Li Y, Liao R, Xie C, Chen J, Deng Q, Yamout M, Dong MQ, Frangou CG, Yates JR, 3rd, Wright PE, Han J. PRAK is essential for rasinduced senescence and tumor suppression. Cell. 2007;128(2):295-308.

32. Bracken AP, Dietrich N, Pasini D, Hansen KH, Helin K. Genome-wide mapping of Polycomb target genes unravels their roles in cell fate transitions. Genes Dev. 2006;20(9):1123-1136.

33. Cao R, Tsukada YI, Zhang Y. Role of Bmi-1 and Ring1A in H2A Ubiquitylation and Hox Gene Silencing. Mol Cell. 2005;20(6):845-854.

34. Hodgson JW, Argiropoulos B, Brock HW. Site-specific recognition of a 70-base-pair element containing $d(G A)(n)$ repeats mediates bithoraxoid polycomb group response element-dependent silencing. Mol Cell Biol. 2001;21(14):4528-4543.

35. Park YB, Park MJ, Kimura K, Shimizu K, Lee SH, Yokota J. Alterations in the INK4a/ARF locus and their effects on the growth of human osteosarcoma cell lines. Cancer Genet Cytogenet. 2002;133(2):105-111.

36. Scheffner $M$, Whitaker NJ. Human papillomavirus-induced carcinogenesis and the ubiquitin-proteasome system. Seminars in Cancer Biology. 2003;13(1):59-67.

37. Brummelkamp TR, Bernards R, Agami R. A system for stable expression of short interfering RNAs in mammalian cells. Science. 2002;296(5567):550-553.

38. Narita M, Nunez S, Heard E, Lin AW, Hearn SA, Spector DL, Hannon GJ, Lowe SW. $\mathrm{Rb}$-mediated heterochromatin formation and silencing of E2F target genes during cellular senescence. Cell. 2003;113(6):703-716.

39. Bracken AP, Pasini D, Capra M, Prosperini E, Colli E, Helin K. EZH2 is downstream of the pRB-E2F pathway, essential for proliferation and amplified in cancer. Embo $\mathrm{J}$. 2003;22(20):5323-5335.

40. Takihara $Y$, Tomotsune D, Shirai M, Katoh-Fukui $Y$, Nishii K, Motaleb MA, Nomura M, Tsuchiya R, Fujita $Y$, Shibata $Y$, Higashinakagawa T, Shimada K. Targeted disruption of the mouse homologue of the Drosophila polyhomeotic gene leads to altered anteroposterior patterning and neural crest defects. Development. 1997;124(19):3673-3682. 


\section{Supplemental Materials and Methods}

\section{Cell lines}

Human U2-OS osteosarcoma cells were kindly provided by D. Shvarts (Utrecht Medical Center, Utrecht, The Netherlands); BJ-hTERT and primary human TIG3 fibroblasts expressing the murine ecotropic receptor were a courtesy of $D$. Peeper (Netherlands Cancer Institute, Amsterdam, The Netherlands). Expression vectors encoding the murine ecotropic receptor were kindly provided by $R$. Bernards, (Amsterdam, The Netherlands),

\section{ChIP assays}

MK3 overexpression: TIG3 cells were transduced with pBABE-puro GST or GST$3 \mathrm{pK}$ and initially selected with $4 \mu \mathrm{g} / \mathrm{ml}$ puromicyn. Cells were propagated without selection and finally plated with $16 \mu \mathrm{g} / \mathrm{ml}$ puromycin before fixation. 3pK activation: TIG3 cells were serum-starved for 48 hours in medium containing $0.1 \%$ FCS and subsequently stimulated or not for 45 min. with $15 \%$ FCS and $100 \mathrm{ng} / \mathrm{ml}$ tetradecanoyl phorbol acetate (TPA) before fixation. TIG3 cells were fixed in $1 \%$ formaldehyde. Cross-linking was allowed to proceed for $10 \mathrm{~min}$ at room temperature and stopped by addition of glycine at a final concentration of $0.125 \mathrm{M}$, followed by an additional incubation for $5 \mathrm{~min}$. Fixed cells were washed twice with PBS and harvested in SDS Buffer $(50 \mathrm{mM}$ Tris at $\mathrm{pH}$ 8.1, $0.5 \% \mathrm{SDS}, 100 \mathrm{mM} \mathrm{NaCl}, 5 \mathrm{mM}$ EDTA), supplemented with protease inhibitors (Aprotinin, Antipain and Leupeptin all at $5 \mu \mathrm{g} / \mathrm{mL}$ and $1 \mathrm{mM}$ PMSF). Cells were pelleted by centrifugation, and suspended in IP Buffer (100 mM Tris at $\mathrm{pH}$ 8.6, $100 \mathrm{mM} \mathrm{NaCl}, 0.3 \% \mathrm{SDS}, 1.7 \%$ Triton X-100, and $5 \mathrm{mM}$ EDTA), containing protease inhibitors. Cells were disrupted by sonication, yielding genomic DNA fragments with a bulk size of 200-500 bp. For each immunoprecipitation, $1 \mathrm{~mL}$ of lysate was precleared by addition of $35 \mu \mathrm{L}$ of blocked protein A beads ( $50 \%$ slurry protein A-Sepharose, Amersham; 0.5 $\mathrm{mg} / \mathrm{mL}$ fatty acid-free BSA, Sigma; and $0.2 \mathrm{mg} / \mathrm{mL}$ herring sperm DNA in TE), followed by clarification by centrifugation. $10 \mu \mathrm{l}$ aliquots of precleared suspension were reserved as input DNA and kept at $4^{\circ} \mathrm{C}$. Samples were immunoprecipitated overnight at $4^{\circ} \mathrm{C}$ with antibodies for either $\mathrm{HA}$ as a negative control (sc-805; Santa Cruz), H3K27me3 (07-449; Upstate), an equal mix of anti-CBX8 "LAST" and "GALD"32, anti-MK3 $3^{27}$, or anti-PHC1 ${ }^{40}$. Immune complexes were recovered by adding $40 \mu \mathrm{L}$ of blocked protein A beads and incubated for $4 \mathrm{~h}$ at $4^{\circ} \mathrm{C}$. Beads were washed three times in $1 \mathrm{~mL}$ of Mixed Micelle Buffer $(20 \mathrm{mM}$ Tris at $\mathrm{pH} 8.1,150 \mathrm{mM} \mathrm{NaCl}, 5 \mathrm{mM}$ EDTA, $5 \% \mathrm{w} / \mathrm{v}$ sucrose, $1 \%$ Triton $\mathrm{X}-100$, and $0.2 \%$ SDS), twice in $1 \mathrm{~mL}$ of Buffer 500 (50 mM HEPES at $\mathrm{pH} 7.5,0.1 \% \mathrm{w} / \mathrm{v}$ deoxycholic acid, $1 \%$ Triton $\mathrm{X}-100$, and $1 \mathrm{mM}$ EDTA), twice in $1 \mathrm{~mL}$ of $\mathrm{LiCl}$ Detergent Wash Buffer (10 mM Tris at pH 8.0, 0.5\% deoxycholic acid, 0.5\% NP- 
MK3 controls proliferation by an epigenetic switch mechanism involving PcG

40, $250 \mathrm{mM} \mathrm{LiCl}$, and $1 \mathrm{mM}$ EDTA), and once in $1 \mathrm{~mL}$ of TE. Immuno-complexes were eluted from beads in $250 \mu \mathrm{L}$ elution buffer (1\% SDS; and 0.1M NaHCO3) for $2 \mathrm{~h}$ at $65^{\circ} \mathrm{C}$ with continuous shaking at $1000 \mathrm{rpm}$, and after centrifugation supernatants were collected. $250 \mu \mathrm{L}$ elution buffer was added to input DNA samples and these were processed in parallel with eluted samples. Crosslinks were reversed overnight at $65^{\circ} \mathrm{C}$ followed by a $2 \mathrm{~h}$ digestion with RNAse $\mathrm{A}$ at $37^{\circ} \mathrm{C}$ and $2 \mathrm{~h}$ proteinase $\mathrm{K}(0.2 \mu \mathrm{g} / \mu \mathrm{L})$ at $55^{\circ} \mathrm{C}$. DNA fragments were recovered using QIAquick PCR purification columns, according to manufacturers' instructions. Samples were eluted in $75 \mu \mathrm{L}$ EB buffer and then further $1 / 5$ diluted in TE buffer. The immunoprecipitated DNA was quantified by real-time qPCR. The sequences of the primers used are listed in Supplementary Table 5.1. Each experiment was performed three times. Results of one representative experiment are shown.

\section{Western analysis}

Cells were lysed in RIPA buffer containing $5 \mathrm{mM}$ Benzamidine, $5 \mu \mathrm{g} / \mathrm{ml}$ Antipain, $5 \mu \mathrm{g} / \mathrm{ml}$ Leupeptin, $5 \mu \mathrm{g} / \mathrm{ml}$ Aprotinin, $1 \mathrm{mM}$ Sodium Vanadate, $10 \mathrm{mM}$ Sodium Fluoride, $10 \mathrm{mM}$ Pyrophosphate, $10 \mathrm{mM}$ ß-glycerophosphate, $0.5 \mathrm{mM}$ DTT and $1 \mathrm{mM}$ PMSF. After centrifugation for $10 \mathrm{~min}$ at $13.2 \mathrm{krpm}$, protein concentration was determined using a BCA protein assay kit (Pierce). Equal amounts of protein were boiled in Laemmli buffer and loaded on 9-15\% polyacrylamide gels. Proteins were transferred to polyvinylidene fluoride (PVDF) membranes. After blocking with $5 \%$ non-fat dry milk in PBS containing $0.1 \%$ Tween-20, membranes were incubated $\mathrm{o} / \mathrm{n}$ at $4^{\circ} \mathrm{C}$ with the following antibodies: anti ß-actin Mab (C4, 691001, MP Biomedicals), anti EZH2 Mab (BD43; courtesy D. Pasin; Copenhagen, Denmark), anti p16 Mab (DCS50), anti histone H3 Mab (Ab24824 Abcam), and anti P53 Mab, anti p21 Pab, anti CBX8 Pab, anti Bmi1 Mab (F6; courtesy M. van Lohuizen; Amsterdam, The Netherlands), anti MK3 Mab, anti MK3 Pab, anti H3K27me3 Pab and anti-2Py-tag Mab as described in the main text. After extensive washing, membranes were incubated with corresponding horseradish peroxidase conjugated secondary antibodies for $1 \mathrm{~h}$ at room temperature. Signals were detected using enhanced chemoluminescence.

\section{Quantification of mRNA levels by qPCR}

Total RNA was isolated using Tri-Reagent (Sigma). Quantity and quality of the RNA were checked on the nanodrop (Witec AG, Germany) according to the manufacturer's instructions. RNA (500ng) was converted into cDNA using the iScript ${ }^{\mathrm{TM}}$ cDNA synthesis kit (Bio-Rad) according to the manufacturer's protocol. MylQ analysis was performed on $10 \mathrm{ng}$ of cDNA using the $\mathrm{qPCR}^{\mathrm{i}} \mathrm{Q}^{\text {TM }}$ Custom SYBR $^{\circledast}$ Green Supermix (Bio-Rad) and 300nM primer. Analysis was performed on an iCycler ${ }^{\circledR}$ thermal cycler (Bio-Rad). Cyclophillin A was used as a control gene 
for normalization. The sequences of the primers used are listed in Supplementary Table 5.1.

\section{BrdUrd pulse labeling \& DNA profiling}

Tig3 cells were pulse labelled with $10 \mu M$ BrdUrd for $45 \mathrm{~min}$. Cells were fixed in cold methanol overnight at $-20^{\circ} \mathrm{C}$ immediately after labeling, DNA was denatured by incubation with $0.4 \mathrm{mg} / \mathrm{ml}$ pepsin in $0.1 \mathrm{~N} \mathrm{HCl}$ for $30 \mathrm{~min}$ followed by a 30 min incubation with $2 \mathrm{~N} \mathrm{HCl}$ at $37^{\circ} \mathrm{C}$, pH was readjusted to $7-8$ by addition of $0.1 \mathrm{M}$ sodium borate buffer $\mathrm{pH} 8.5$, subsequently cells were incubated with $5 \mu \mathrm{l}$ anti-BrdUrd IIB5 for 1-1.5 h at RT. Following washing, cells were incubated with $5 \mu \mathrm{l} \mathrm{FITC-conjugated} \mathrm{anti-mouse} \mathrm{lg} \mathrm{over} \mathrm{night} \mathrm{at} 4^{\circ} \mathrm{C}$, washed and resuspended in PBS containing $100 \mu \mathrm{g} / \mathrm{ml} \mathrm{RNAse}$ and $20 \mu \mathrm{g} / \mathrm{ml} \mathrm{PI}$ for 2-3 hours at RT in dark environment, immediately prior to FACS analysis. Analysis was performed using a Becton Dickinson FACS machine with CellQuest software.

After UV irradiation $\left(20 \mathrm{~J} / \mathrm{m}^{2}\right)$ U2OS cells were fixed in $70 \%$ ethanol overnight at $-20^{\circ} \mathrm{C}$, simultaneously permeabilized with PBS containing $0.2 \%$ Triton X-100 for 20 min at $4 \mathrm{C}$ and blocked with $2 \%$ FBS in PBS, incubated with anti-phosphohistone $\mathrm{H} 3$ for 60 min at RT. Following washing, cells were incubated with FITCconjugated goat anti-rabbit antibody (diluted 1:500) for $30 \mathrm{~min}$ at RT, washed, and resuspended in PBS containing $100 \mu \mathrm{g} / \mathrm{ml}$ RNAse and $20 \mu \mathrm{g} / \mathrm{ml}$ PI for 2-3 hours at RT in dark environment, immediately prior to FACS analysis. Analysis was performed using a Becton Dickinson FACS machine with CellQuest software.

\section{In vitro kinase assay on peptide arrays}

Custom arrays were produced by spotting peptides in triplicate on etched glass surface (PhosphoSiteDetector; Jerini peptide technology, Germany). Spotted 13mer peptides corresponded to $27 \mathrm{Bmi1}, 27 \mathrm{Cbx} 4,27 \mathrm{Phc} 2,10 \mathrm{Rnf} 2$ and 7 Histone H3.3 peptides. Positive control peptides of HSP27 and CREB were included. In vitro kinase assay was performed with constitutively active recombinant MK3-EE. The kinase was pre-incubated for 10 minutes at $30^{\circ} \mathrm{C}$ in kinase buffer $(10 \mathrm{mM} \mathrm{MgCl} 2,25 \mathrm{mM}$ ß-glycerophosphate, $25 \mathrm{mM}$ HEPES pH 7.5, $5 \mathrm{mM}$ benzamidine, $0.5 \mathrm{mM}$ DTT and $1 \mathrm{mM}$ sodiumvanadate) supplemented with $2 \mu \mathrm{M}$ ATP. Subsequently $45 \mu \mathrm{Ci}$ radioactively labeled gamma-ATP ${ }^{32}$ (Amersham $250 \mu \mathrm{Ci} / 25 \mu \mathrm{l} ; 3000 \mathrm{Ci} / \mathrm{mmol}$ ) was added; the reaction mix was wedged between one peptide array and one glass slide with the peptide spot surface facing each other and incubated for 2 hours at $30^{\circ} \mathrm{C}$. Slides were washed $5 \times 4$ min with $0.1 \mathrm{M}$ phosphoric acid and $5 \times 4 \mathrm{~min}$ with $\mathrm{MQ}$. Washing solutions were filtered through $0.4 \mu \mathrm{m}$ particle filters before use. The slide was rinsed in methanol and air dried. The slide was incubated overnight in a Phosphorlmager cassette and images were acquired with a Phosphorlmager. 


\section{Supplemental Figures}
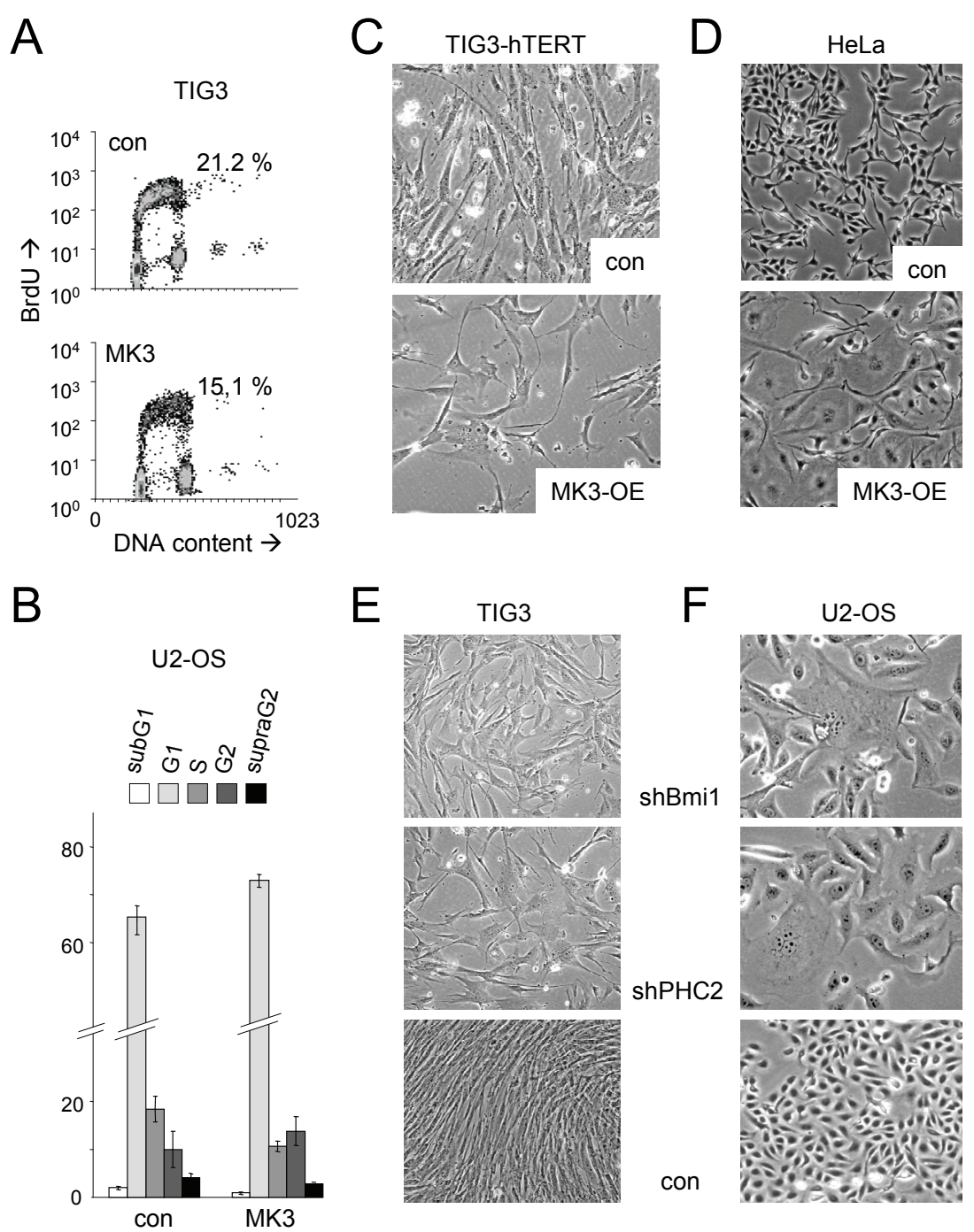

E
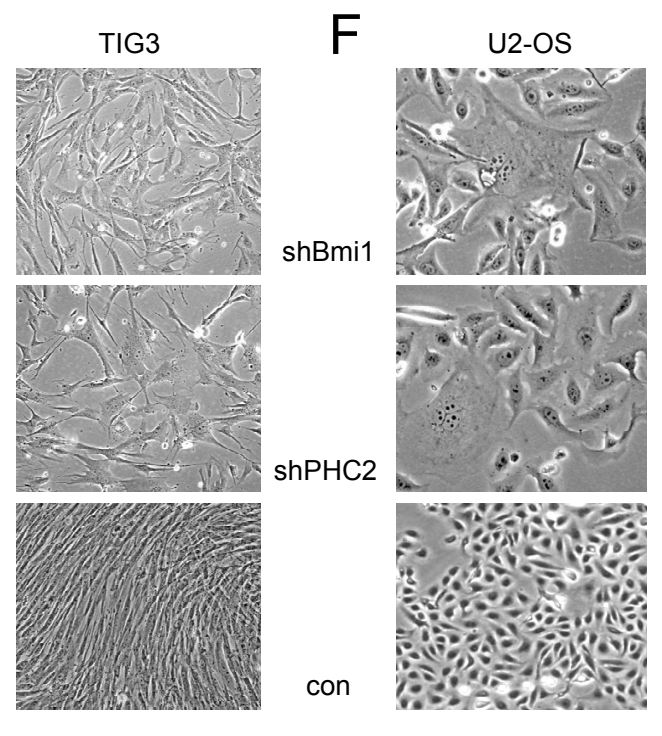

Figure 5.S1. MK3 offsets cell proliferation in different cell types. Representative DNA profiling $(A)$ and quantitative analysis ( $B$ ) shows $\mathrm{G1}$ accumulation and concomitantly reduced S-phase entry MK3 overexpressing low passage TIG3 cells. The effect of MK3-OE on primary cells positively correlated with MK3 expression levels and passage number (not shown). (C) MK3 overexpression induces a senescence-like phenotype in TIG3-hTERT (C) and hTERT-BJ fibroblasts (not shown). (D) Proliferative differences and morphological changes in MK3-overexpressing human cervical carcinoma HeLa cells. $(E, F)$ Induction of a senescent state in TIG3 (E) and U2-OS (F) cells via stable shRNA-mediated knock down of Bmi1 (upper panels) and HPC2 (middle panels). Large flat cells are positive for SA-BGAL (not shown). 
A
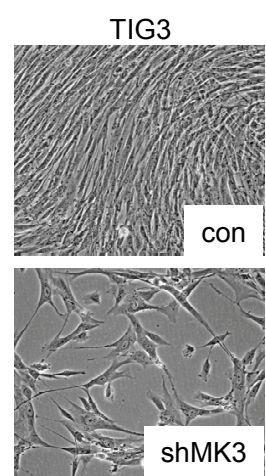

B

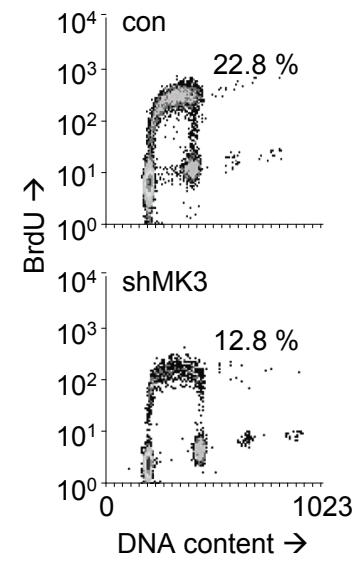

D
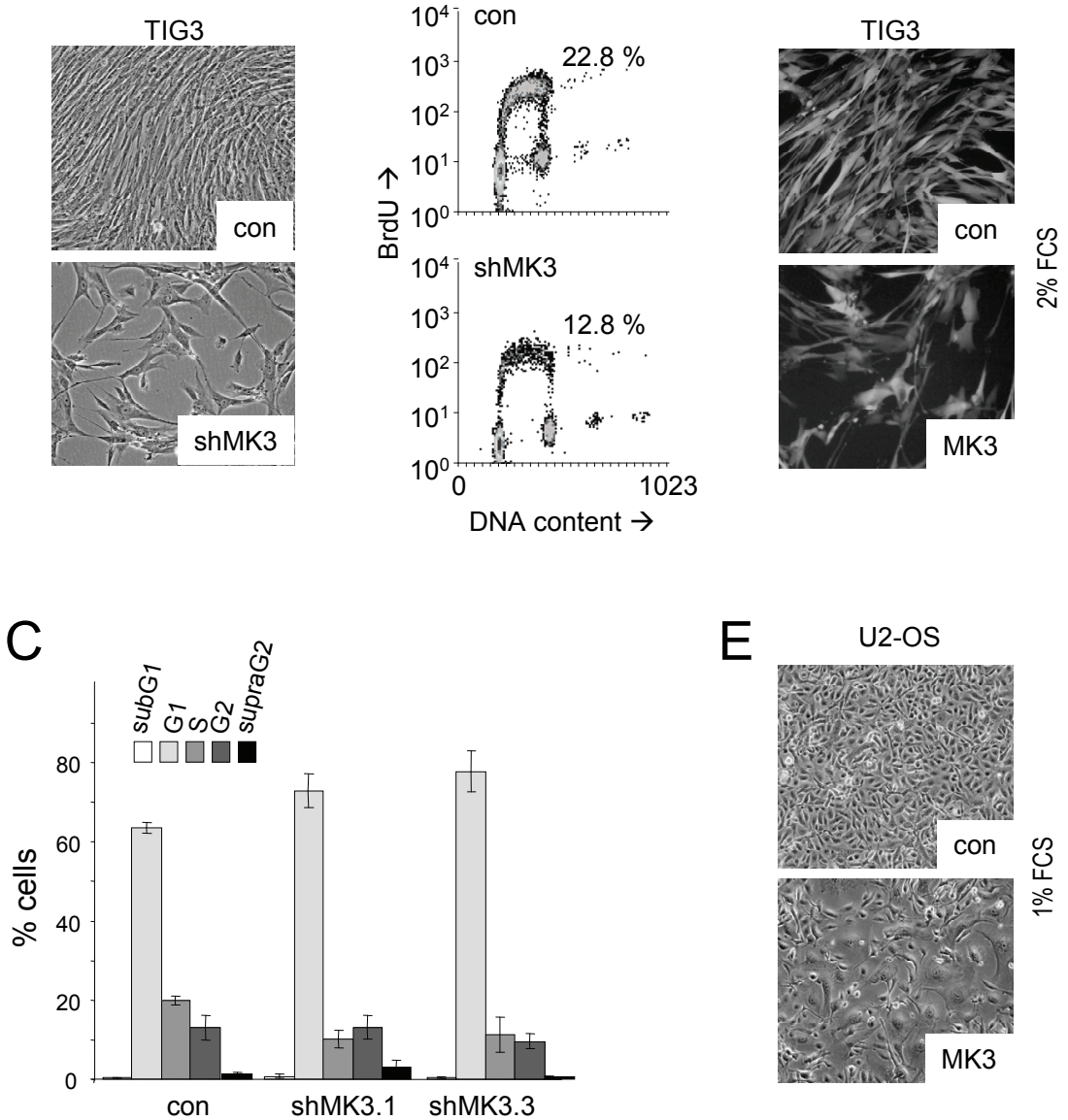

E

U2-OS

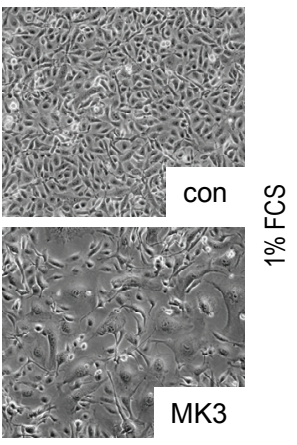

Figure 5.S2. MK3 expression level affects proliferation responses. (A) shRNA mediated knockdown of MK3 (shMK3) induces a replicative arrest in TIG3 cells. $(B, C)$ Corresponding representative DNA profile (B) and quantitative analysis (C) of shMK3 TIG3 cultures versus control. shMK3.1 and 3.3 represent two independent MK3 target sequences. (D) Low serum concentrations substantially increased the number of flat cells in low PDL (30-35) TIG3 MK3-OE cultures (D) and U2-OS cultures $(E) ;($ con = empty vector control cells). See page 201 for colour print. 


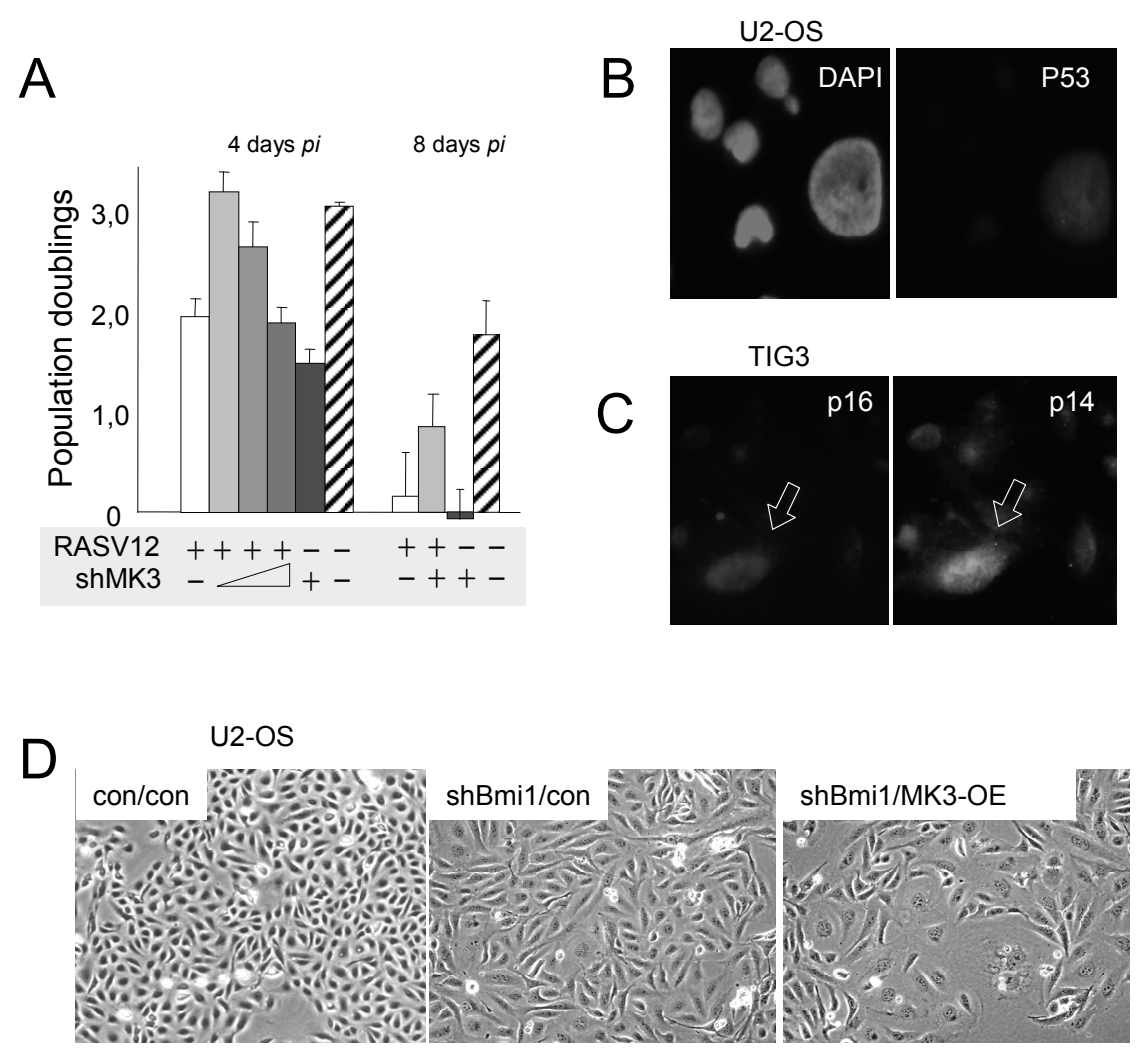

Figure 5.S3. Role of MK3 in senescence pathways. (A) shMK3 transiently reduced RASV12 provoked proliferative arrest. TIG3 cells were simultaneously transduced with a fixed $\mathrm{MOI}$ of RASV12-virus and increasing MOIs of shMK3 virus (gradient left to right: RASV12:MK3-KD 1:1, 1:3, 1:10). Population doubling was determined 4 days and 8 days post-infection (pi). The early and late effects of RASV12 oncogene induced senescence were reflected in cell death and strong vacuolization, respectively; both were less pronounced/absent in shMK3 cultures (not shown). Eventually RASV12 cells in culture senesced. (B) Expression of P53 in MK3 positive senescent (arrow) U2-OS cells. (C) Co-expression of $\mathrm{p} 16^{\mathrm{INK} 4 \mathrm{~A}}$ and $\mathrm{p} 14^{\mathrm{ARF}}$ in primary human TIG3 fibroblasts overexpressing MK3. Successful transduction was confirmed by GFP-fluorescence prior to methanol fixation; all large flat cells were GFP-positive; empty vector control TIG3 fibroblasts did not show the senescent phenotype. (D) Simultaneous knockdown of Bmi1 (shBmi1) and overexpression of MK3 (MK3) increases senescent phenotype in U2-OS cells. See page 201 for colour print. 
A

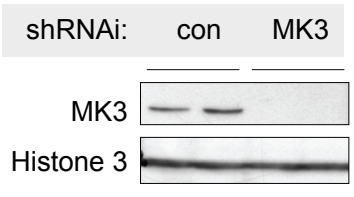

B

-UV
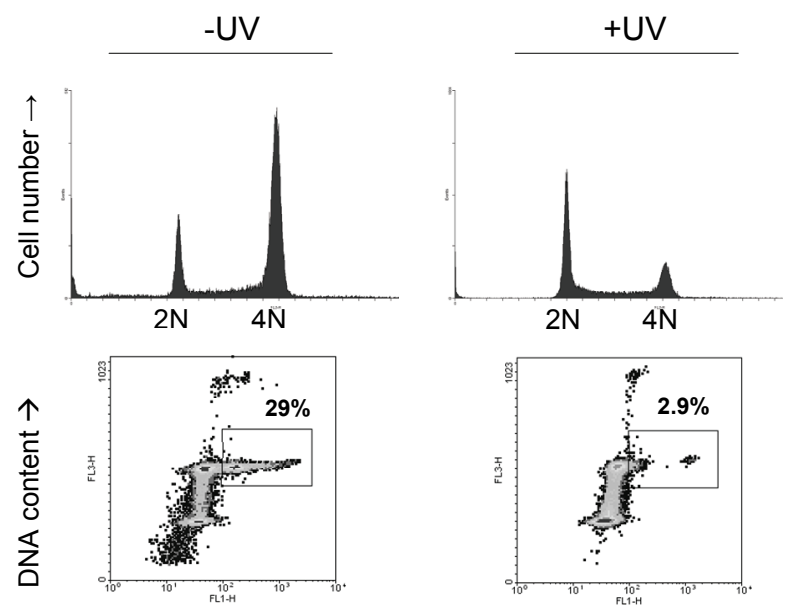

con

C

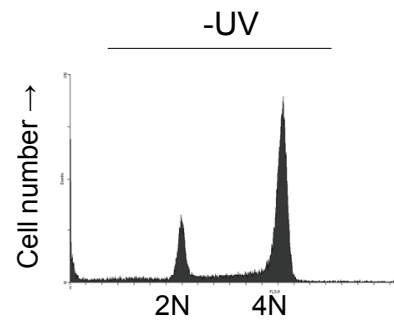

$\mathrm{H} 3 \mathrm{~S} 10 \mathrm{ph} \rightarrow$
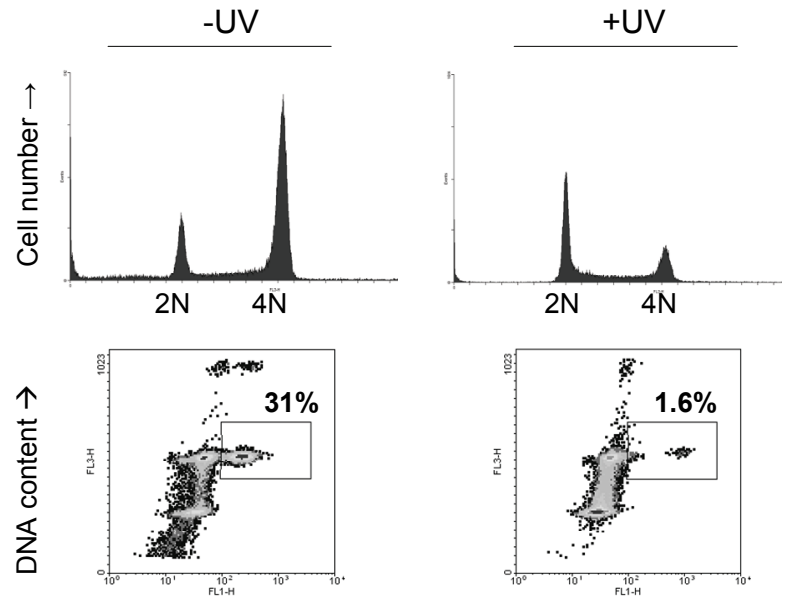

shMK3

H3S10ph $\rightarrow$

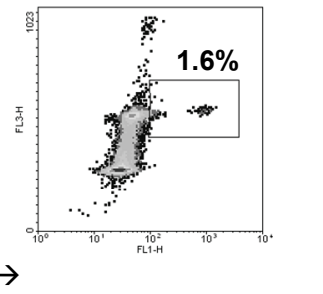

Figure 5.S4. MK3 is not required for G2/M arrest following UV-induced DNA damage. (A) Western blot analysis of cell lysates prepared from U2OS cells transduced with shMK3 or control shGFP. $(B, C)$ shGFP $(B)$ or shMK3 (C) expressing U2-OS cells were exposed to $20 \mathrm{~J} / \mathrm{m}^{2}$ UV (+UV) or sham treated (-UV) and then placed in $50 \mathrm{ng} / \mathrm{ml}$ nocodazole-containing media for an additional $16 \mathrm{hr}$. Cells were analyzed by flow cytometry for DNA content by PI staining and for H3S10p staining as a marker for mitotic entry. 
A
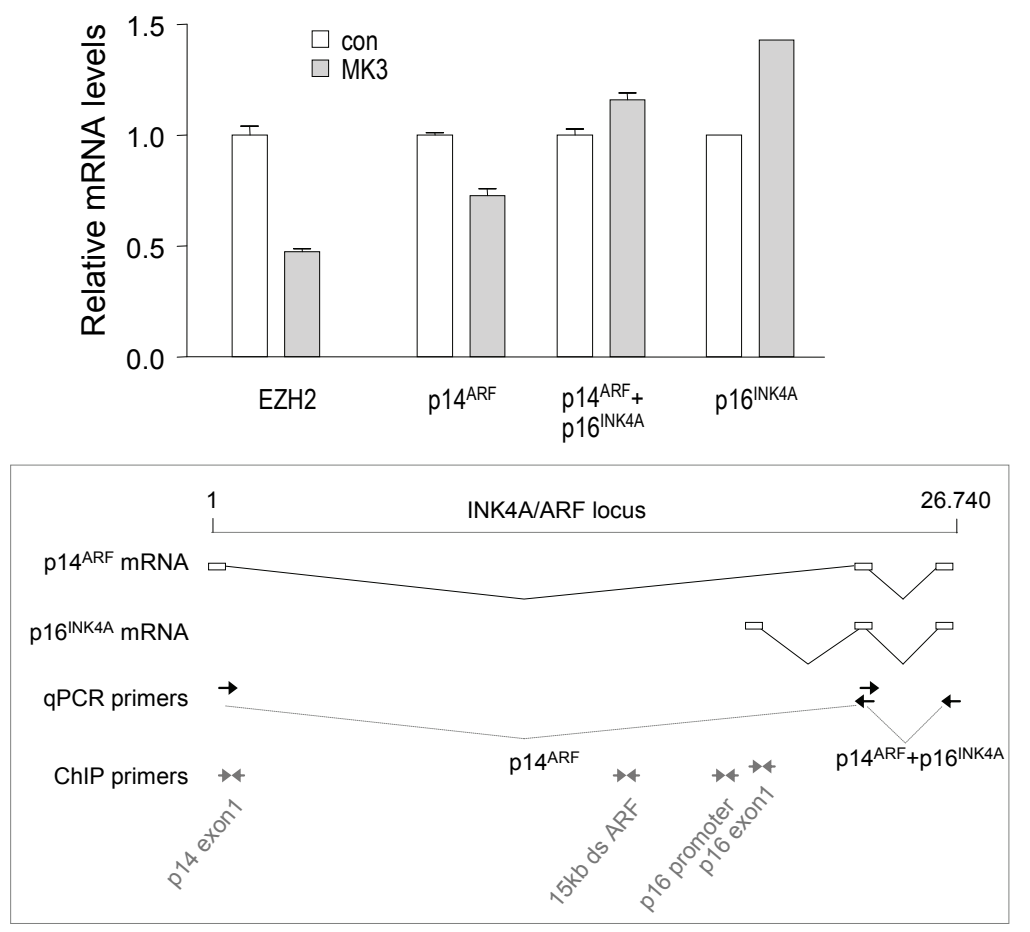

B

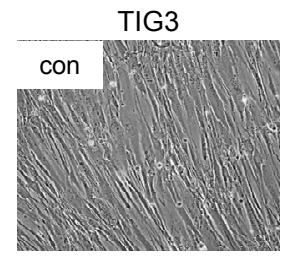

C
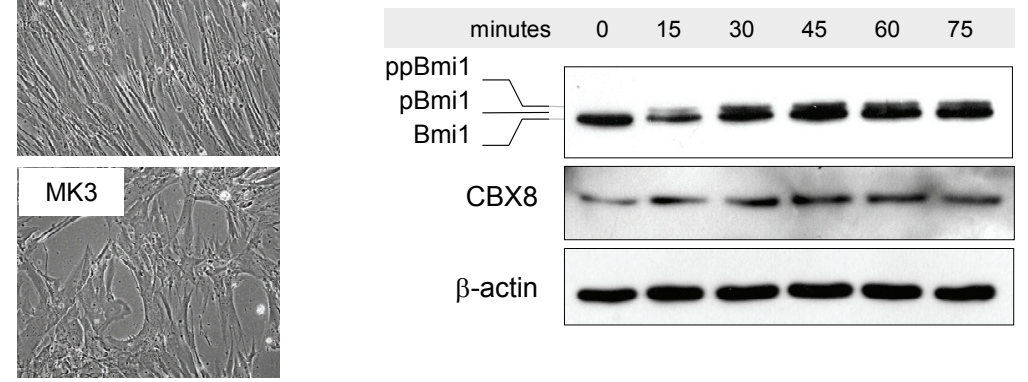

Figure 5.S5. MK3 overexpression or activation differentially affects PRC1 chromatin occupation and mRNA expression of target genes. (A) Top: qRT-rtPCR analysis of EZH2 and INK4A/ARF mRNA levels in MK3-OE and control TIG3 cells; bottom: schematic overview of human INK4A/ARF locus and primers used in this study. Due to overlap in mRNA sequences of P14 ${ }^{\mathrm{ARF}}$ and $\mathrm{p} 16^{\mathrm{INK} 4 \mathrm{~A}}$ detection of only $\mathrm{p} 16^{\mathrm{INK} 4 \mathrm{~A}}$ mRNA expression was not possible and was therefore calculated. (B) Microscopic morphology of cell cultures corresponding to experiments in $A$ and $C$. (C) Starvationserum restart induces Bmi1 phosphorylation ( $\mathrm{p} / \mathrm{ppBmi1}$ ); Western blot analysis of TIG3 cells expressing tagged Bmi1-2PY and CBX8 after 48hrs of serum starvation with $0.1 \%$ FCS followed by stimulation with $15 \%$ FCS and $100 \mathrm{ng} / \mathrm{ml}$ TPA for various amounts of time. Endogenous PHC1 was not detected. 
D
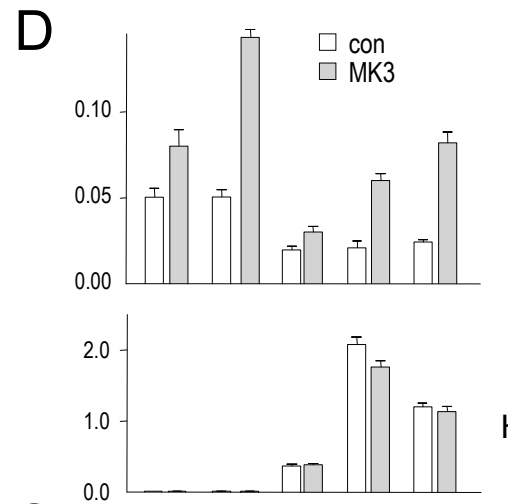

(a)

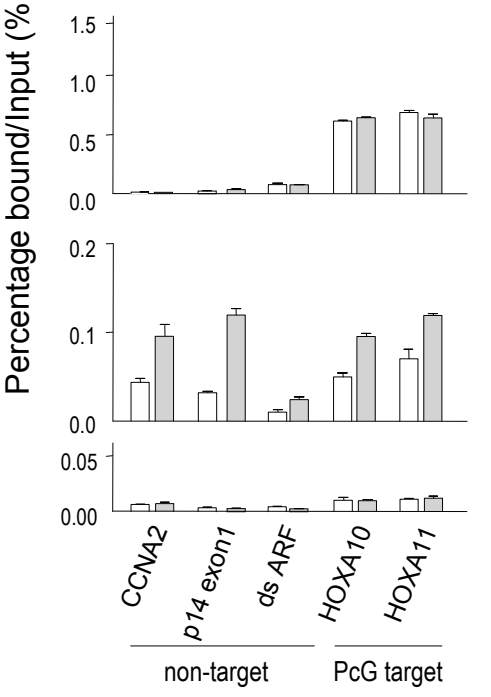

E

$\square$ starved
$\square$ serum/TPA

MK3

0.15

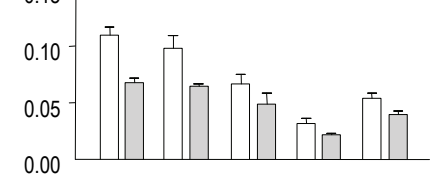

H3K27me3
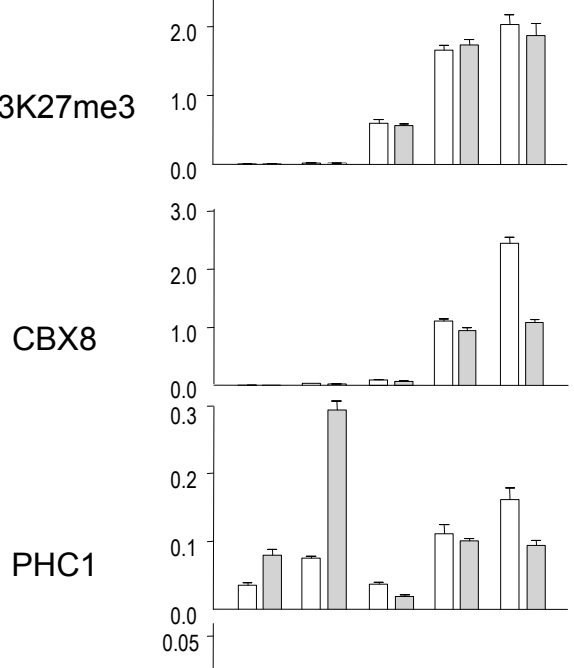

HA
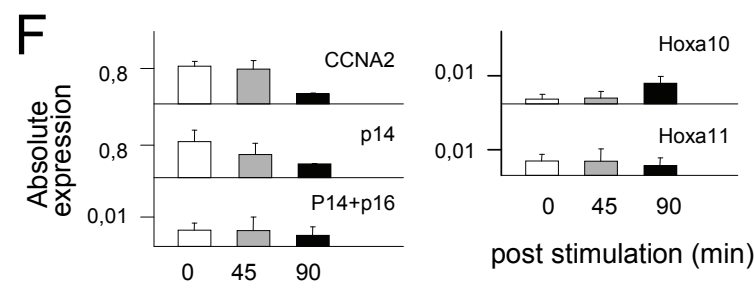

post stimulation (min)

Figure 5.S5. Continued

$(D, E)$ MK3-OE or activation regulates PRC1 chromatin association. (D) ChIP analysis in MK3-OE TIG3 cells of PCG target and non-target loci (as in Fig. 5.4A): CCNA2 and p14exon1 and a region 15 kilobases downstream of ARF (ds ARF) are not occupied by PRC1 complexes in TIG3 fibroblasts; HOXA10 and HOXA11 are PCG targets, as defined by H3K27me3 and CBX8 binding profiles. (E) ChIP analysis of PCG target and non-target loci in TIG3 cells after $48 \mathrm{hrs}$ of serum starvation with $0.1 \%$ FCS followed by either no or 45 min. stimulation with $15 \%$ serum and $100 \mathrm{ng} / \mathrm{ml}$ TPA (as in Fig. 5.4B). (F) real time quantitative mRNA measurements of (non) PcG-target genes upon 45 minutes and 90 minutes serum/TPA stimulation. 
A
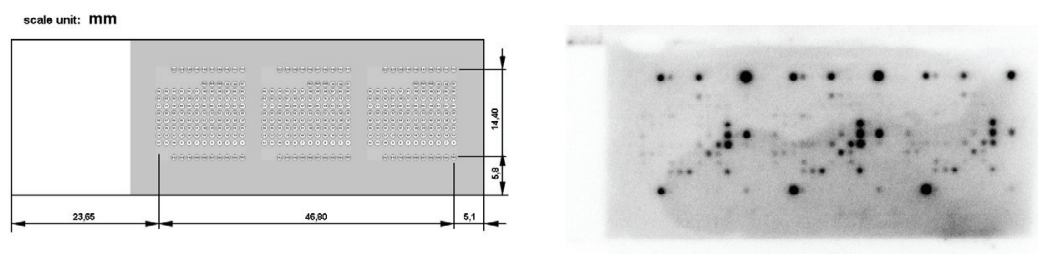

B
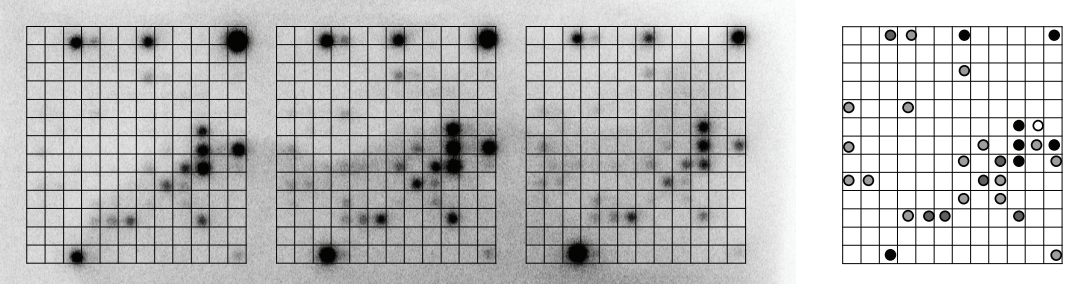

\begin{tabular}{lcccccc}
\hline Name & $\begin{array}{c}\text { Alternative } \\
\text { name }\end{array}$ & $\begin{array}{c}\text { Accession } \\
\text { number }\end{array}$ & $\begin{array}{c}\text { Total } \\
\text { nr AA }\end{array}$ & xxxxxRxxSxxxxxx & $\begin{array}{c}\text { Proposed } \\
\text { Phosphosite }\end{array}$ & $\begin{array}{c}\text { IVK } \\
\text { Classification }\end{array}$ \\
\hline Phc2 & mPh2/Edr2 & Q9QWH1 & 850 AA & QALHRQPSTAAQYL & S72 & strong \\
& & & & LVANRQGSTPGSSV & S124 & strong \\
& & & & LINRAQSVNSAAA & S158 & strong \\
\hline Cbx4 & MPC2 & 055187 & 551 AA & DLGSRKLSPTKEA & S350 & middle \\
& & & & LTARSISTPTCLG & S429 & strong \\
\hline Bmi1 & & P25916 & 324 AA & FASRPRKSSLNG & S314 & middle \\
\hline
\end{tabular}

Figure 5.S6. MK3 phosphorylates PRC1 proteins in vitro. (A) layout of peptide array (left) and phospholmager result (right). (B) Intensity analysis of phosphorylated peptides (top) and peptide sequence of corresponding peptides, centered around the RxxS motif (bottom) 
Chapter 5

Supplemental Table 5.1. Primers used for ChIP and mRNA expression analysis

\begin{tabular}{|c|c|c|}
\hline qPCR Primers for ChIP analysis & & sequence \\
\hline \multirow[t]{2}{*}{ p14ARF exon1 } & Forward & GTGGGTCCCAGTCTGCAGTTA \\
\hline & Reverse & CCTTTGGCACCAGAGGTGAG \\
\hline \multirow[t]{2}{*}{$15 \mathrm{~kb}$ downstream of ARFpromoter } & Forward & GCACTTGCCCTTCCAGGTATA \\
\hline & Reverse & TGATAGTTCAAGGCCCTATGCC \\
\hline \multirow[t]{2}{*}{ p16INK4A promoter } & Forward & ACCCCGATTCAATTTGGCAG \\
\hline & Reverse & AAAAAGAAATCCGCCCCCG \\
\hline \multirow[t]{2}{*}{ p16INK4A exon1 } & Forward & AGAGGGTCTGCAGCGG \\
\hline & Reverse & TCGAAGCGCTACCTGATTCC \\
\hline \multirow[t]{2}{*}{ CCNA2 } & Forward & TGACGTCATTCAAGGCGACAG \\
\hline & Reverse & GCTCAGTTTCCTTTGGTTTACCC \\
\hline \multirow[t]{2}{*}{ p15 exon1 } & Forward & GGAACCTAGATCGCCGATGTAG \\
\hline & Reverse & TGTTTTACGCGTGGAATGCAC \\
\hline \multirow[t]{2}{*}{ ATF3 } & Forward & TGTTTTTTTCTTTTGCGTTTGGC \\
\hline & Reverse & TCGTGGCAACCAAATCTAAACAG \\
\hline \multirow[t]{2}{*}{ HOXA10 } & Forward & CCCGAGCTGATGAGCGAGTC \\
\hline & Reverse & GCCAAATTATCCCACAACAATGTC \\
\hline \multirow[t]{2}{*}{ HOXA11 } & Forward & ААТСTATCCСCATCCTTAGCAGG \\
\hline & Reverse & TTGTCAATTTCAACATCGGGTC \\
\hline qPCR Primers for mRNA expression analysis & & sequence \\
\hline \multirow[t]{2}{*}{$\mathrm{EZH} 2$} & Forward & GGGACAGTAAAAATGTGTCCTGC \\
\hline & Reverse & TGCCAGCAATAGATGCTTTTTTG \\
\hline \multirow[t]{2}{*}{ p14ARF } & Forward & CCCTCGTGCTGCTGATGCTACTG \\
\hline & Reverse & CCCATCATCATGACCTGGTCTT \\
\hline \multirow[t]{2}{*}{ p14ARF+p16INK4A } & Forward & GAAGGTCCCTCAGACATCCCC \\
\hline & Reverse & CCCTGTAGGACCTTCGGTGAC \\
\hline \multirow[t]{2}{*}{ Cyclophillin A } & Forward & TTCCTGCTTTCACAGAATTATTCC \\
\hline & Reverse & GCCACCAGTGCCATTATGG \\
\hline \multirow[t]{2}{*}{ ATF3 } & Forward & TCACTGTCAGCGACAGACCC \\
\hline & Reverse & CTACCTCGGCTTTTGTGATGG \\
\hline \multirow[t]{2}{*}{ HOXA10 } & Forward & GCCCTTCCGAGAGCAGCAAAG \\
\hline & Reverse & AGGTGGACGCTGCGGCTAATCTCTA \\
\hline \multirow[t]{2}{*}{ HOXA11 } & Forward & TGCCAAGTTGTACTTACTACGTC \\
\hline & Reverse & GTTGGAGGAGTAGGAGTATGTCA \\
\hline \multirow[t]{2}{*}{ CCNA2 } & Forward & CGCTCCAAGAGGACCAGGA \\
\hline & Reverse & СCCTCCTGCAGATATCCCG \\
\hline shRNA Target sequences & & sequence \\
\hline $3 p K-1$ & & CGGCAAAGTGCTGGAGTGC \\
\hline $3 p K-3$ & & GGAGGAGATGACCAGTGCC \\
\hline BMI1 & & GAATGGTCCACTTCCATTG \\
\hline $\mathrm{PHC} 2$ & & GTTCAAGCGTCCAAGCGC \\
\hline p5 $3^{37}$ & & GACTCCAGTGGTAATCTAC \\
\hline
\end{tabular}


Chapter 6

\section{Cell stress-induced association of Polycomb Repressive Complex 1 with the chromatin factor KAP1}




\begin{abstract}
Polycomb Repressive Complex (PRC) proteins constitute a functional transcriptional memory during growth and development. We previously reported a correlation between phosphorylation of the PRC1 protein Bmi1 and its chromatin dissociation. Little is known about the molecular consequences of PRC-phosphorylation. Here we show that the cell stressors arsenite (As) and selenite (Se) induce phosphorylation of and association between Bmi1 and KAP1, a nuclear corepressor. Signaling pathways involved in As and Se-induced phosphorylation of Bmi1 and KAP1 include p38, ATM/ATR, PKC, JNK and GSK3ß pathways. As- or Se-induced Bmi1-KAP1 interaction requires kinase signaling, however, once established, it is no longer dependent on phosphorylation. The establishment of Bmi1-KAP1 association is enhanced by inhibition of PKC and JNK signaling and reduced by inhibition of GSK3ß signaling under cell stress; however, inhibition of p38 and ATM/ATR signaling reduces binding only in response to Se, not to As. This is the first report of a stress-specific interaction of Polycomb Repressive Complex 1 with the thus far unrelated chromatinassociated protein KAP1. Possible functional implications of the Bmi1-KAP1 interaction are discussed in the context of our findings.
\end{abstract}




\section{Introduction}

PcG proteins are part of an epigenetic memory system that contributes to maintenance of gene expression profiles in differentiation, development and stem cell self renewal ${ }^{1-3}$. PcG proteins act in two functionally distinct multiprotein complexes: Polycomb repressive complex 1 and 2 (PRC1; PRC2). The PRC2 complex, comprising EED, SUZ12 and EZH2, catalyzes trimethylation of histone 3 on lysine 27 (H3K27me3) ${ }^{4,5}$. PRC1 consists of BMI1, CBX2, CBX4, CBX6, CBX7, CBX8, PHC1-3, RING1 and RNF2 ${ }^{6}$. RNF2 and RING1 ubiquitinate H2A, which is enhanced by $\mathrm{Bmi1}^{7-10}$. In transcriptional regulation, PRC1 and PRC2 may, in part, act in succession in that CBX-chromo domain proteins are recruited to H3K27me3 marks. However, PRC1 can act independently of PRC2 as well ${ }^{11}$. Transcriptional repression by PcG proteins is currently viewed as a dynamic process. PRC complex composition and repressive activity are regulated throughout development and likely respond to specific stimuli. Cellular differentiation is accompanied by a redistribution of PcG binding patterns ${ }^{2}$. How this redistribution occurs is currently unknown. Several PcG proteins are regulated by post-translational modifications (PTMs). For instance, phosphorylation of EZH2 by AKT suppresses its methyltransferase activity by hindering binding to histone $3^{12}$. We recently identified the PRC1 complex as a target of canonical MAPK signaling pathways, and identified MAPKAPK3 (3pK, MK3) as an interaction partner of the PRC1 complex ${ }^{13}$. MK3 is activated downstream of mitogenic and stress response signaling ${ }^{14}$. Relevantly, phosphorylation of PRC1 correlates with chromatin dissociation, and activation of PcG-repressed tumor suppressors (Chapter 5 of this thesis).

To gain insight into regulation of Polycomb function, we set out to determine how PTMs regulate complex composition. To identify changes in PRC1 complex composition upon phosphorylation, immunoprecipitation and mass spectrometric analysis were combined. We report here an association between PRC1 and the transcriptional corepressor Krüppel-associated box (KRAB)associated protein1 KAP1 (TRIM28, TIF1ß, KRIP-1), a chromatin factor known to be involved in chromatin structure remodeling in transcriptional repression and DNA damage responses.

We show here that KAP1 associates with the PRC1 complex in the context of cellular stress. The induced interaction is stress stimulus-specific, and requires several signaling pathways. We show that both KAP1 and Bmi1 are phosphorylated in response to several stress stimuli. In addition, once established maintenance of PRC1-KAP1 interaction is not dependent on phosphorylation. This is the first report that links these thus far distinct chromatin associated proteins. 


\section{Results}

\section{Arsenite induces interaction of PRC1 and KAP1}

To induce PTMs on PcG proteins, cells were exposed to arsenite (As), a stimulus that induces phosphorylation of BMI 1 and other PcG proteins ${ }^{13}$. To identify phosphorylation events on PcG proteins, immunoprecipitations (IPs) of ectopically expressed Polyomavirus epitope-tagged Bmi1 (Bmi1-Py) in U2-OS cells were performed, and subjected to mass spectrometry. In keeping with published data most of the known mammalian PRC1 complex members, among which PHC, RING and CBX proteins ${ }^{6,15,16}$, are readily identifiable (Table 6.S1). We identified 9 previously described and 11 novel PcG phosphorylation sites on CBX8, PHC1, PHC2, PHC3, RING1 and Bmi1 (Table 6.S2). A number of additional phosphorylated peptides were detected, for which the exact phosphorylation sites could not be determined. As the used detection method is nonquantitative, we cannot formally exclude any relative changes in phosphorylation at these residues. In addition, many PRC1 members are relatively arginine $(R)$ and lysine $(K)$ rich around potential phosphorylation sites which interferes with detection of tryptic peptides. This data confirms that PRC1 members are phospho-proteins, and that a number of PRC proteins are polyphosphorylated.

Although detection of the PRC1 complex remained largely unchanged upon As treatment, KAP1 was consistently detected as a novel associated factor in stimulated extracts (Table 6.S1). The As-induced PRC1-KAP1 association was confirmed by IP and western blotting (Fig. 6.1A). Cells were serum-starved to prevent interference by cell cycle-dependent phosphorylation of PcG proteins ${ }^{17}$. Upon As treatment higher molecular weight forms of both Bmi1 and KAP1 appear, consistent with reduced electrophoretic migration as a result of phosphorylation (Fig. 6.1A). The novel interaction was validated by reciprocal IP against KAP1, which co-precipitates overexpressed Bmi1-Py (Fig. 6.1B). Asinduced phosphorylation as well as association of both Bmi1 and KAP1 increases over time and is dependent on the intensity of the stress stimulus. The association of Bmi1 with CBX4, however, is largely unaffected (Fig. 6.1C), which is in good agreement with the mass-spectrometric findings and our previous report $^{13}$. In keeping with our earlier findings that phosphorylated BMI1 dissociates from chromatin, immuno-fluorescence (IF) analysis of nuclear KAP1 and BMI1 in U2-OS cells reveals that KAP1 and BMI1 both dissociate from chromatin in response to As: cells in which the BMI1 containing PcG bodies disappear are the same cells that show a decreased nuclear staining of KAP1 (Fig. 6.1D). This suggests that mainly dissociated BMI1 engages KAP1. We observe co-localization of endogenous PRC1 complexes with KAP1 in U2-OS cultures upon shorter As exposure (Fig. 6.1E). Co-localization of PRC1 and KAP1 

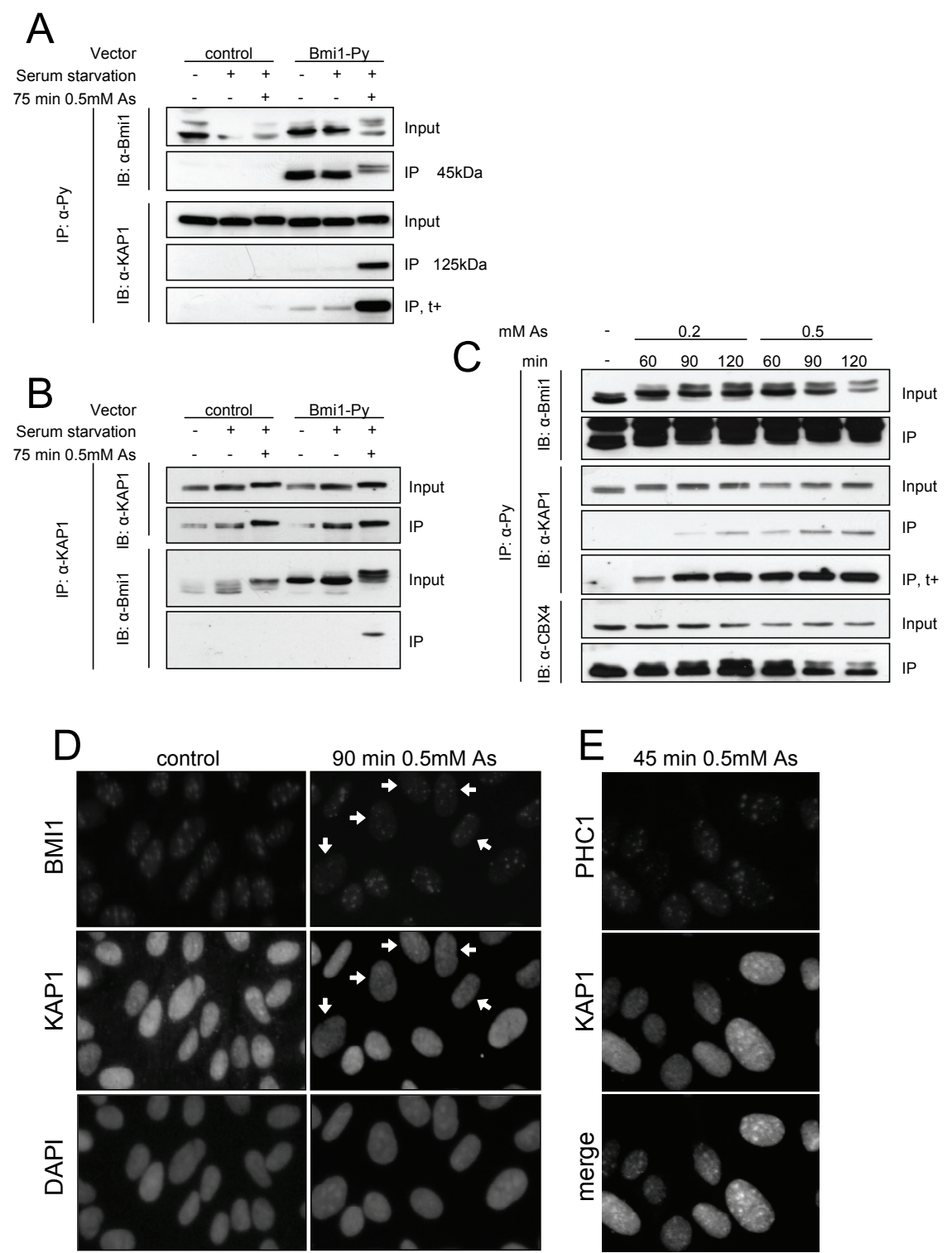

Figure 6.1. Bmi1-Py and KAP1 phosphorylation and association upon Arsenite exposure.

(A) Immunoprecipitation (IP) western analysis of U2-OS cells expressing Bmi1 with Py-tag (Bmi1Py) or not (control). Cells were serum-starved and subjected to Arsenite (As) stimulation as indicated. IPs were performed using an antibody against the Py epitope. Antibodies used for the immunoblotting are indicated by (IB). Longer exposure of film to the same western blot is indicated by $t+$. (B) Western analysis of IPs performed with an anti-KAP1 antibody. KAP1 was not fully immuno-depleted due to inferior IP-quality of the KAP1 immuno-serum (data not shown). (C) anti-Py IP western analysis of serum-starved U2-OS Bmi1-Py cells treated with indicated As concentrations for various amounts of time. (D-E) Immunofluorescence analysis of serum starved U2-OS cells treated with As for $90 \mathrm{~min}(D)$ or $45 \mathrm{~min}(E)$. See page 202 for colour print. 
occurs at the borders of nucleoli (Fig. 6.S1), perhaps suggesting a role in functional partitioning of the genome. At longer As exposures and higher concentrations, protein stability of Bmi1 and CBX4 appear compromised, we therefore used $75-90 \mathrm{~min} 0.2 \mathrm{mM}$ As exposure for most co-interaction studies. Collectively our data suggest that PRC1 and KAP1 associate upon As treatment and that this occurs when both Bmi1 and KAP1 are phosphorylated.

To further validate the PRC1-KAP1 interaction, we performed immunoprecipitations i) with endogenous proteins ii) in cell types other than U2-OS and iii) with other types of expression vectors. Although we were unable to detect association between endogenous proteins, most likely due to limiting availability of (free) binding partner and or the transient nature of the interaction (data not shown), the Bmi1-KAP1 association was reproduced in cervical carcinoma cells (HeLa) and primary human fibroblasts (Tig3) in support of a valid PRC1-KAP1 association (Fig. 6.S2A-C). Furthermore, the use of differently tagged PRC1-protein expression vectors confirmed the PRC1-KAP1 interaction and excluded potential interference by protein tags (Fig. 6.S3A-B). From these data we conclude that KAP1 is a valid interaction partner of PRC1 under certain stress-induced conditions.

\section{Dependence of arsenite-induced PRC1-KAP1 interaction on phosphorylation}

To gain further insight into the requirement of phosphorylation for PRC1-KAP1 interaction, co-IPs were subjected to phosphatase-treatment and vigorously washed. Migration of As-induced slower migrating forms of Bmi1, KAP1, CBX4 and PHC1 was largely restored by dephosphorylation (Fig. 6.2A), confirming phosphorylation as the main PTM under these conditions. Surprisingly, removal of phosphorylation does not affect interaction between Bmi1 and KAP1 or other PRC1 members (Fig. 6.2A). This suggests that the interaction between PRC1 and KAP1, once established, is not phosphorylation dependent.

To identify the kinase pathways involved in establishing the PRC1-KAP1 interaction, several kinase inhibitors were used in combination with stressors. We previously showed that the As-induced phosphorylation of Bmi1 is p38dependent ${ }^{13}$. KAP1 is known to be phosphorylated as part of a DNA damage response in an ATM-dependent manner ${ }^{18,19}$. Therefore kinase inhibitors of $p 38$ (SB202190) and ATM/ATR (caffeine) were used. As-induced phosphorylation of Bmi1 and KAP1 is dependent on both p38 and ATM/ATR signaling (Fig. 6.2B); a combined pretreatment with both inhibitors further reduces the migration of Bmi1 and KAP1 (Fig. 6.2B), indicating that these pathways function independently in Bmi1 and KAP1 phosphorylation. Use of inhibitors only marginally affects the Bmi1-KAP1 association (Fig. 6.2B). It is therefore unlikely that the interaction is dependent on p38 and ATM/ATR signaling. Employment of additional kinase inhibitors (NaSalicylate and Wortmannin) demonstrated 
A

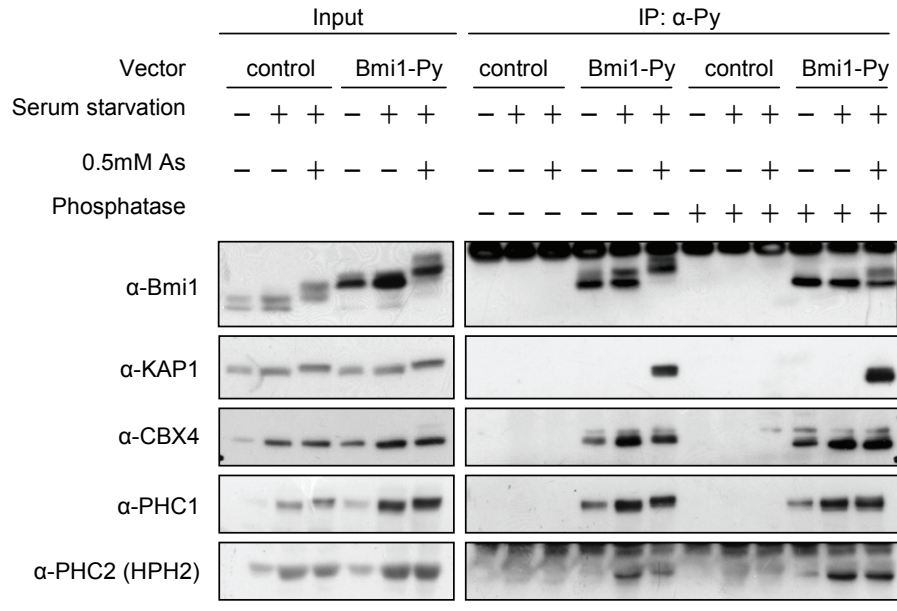

$45 \mathrm{kDa}$

$125 \mathrm{kDa}$

$72 \mathrm{kDa}$

$120 \mathrm{kDa}$

$36 \mathrm{kDa}$

B

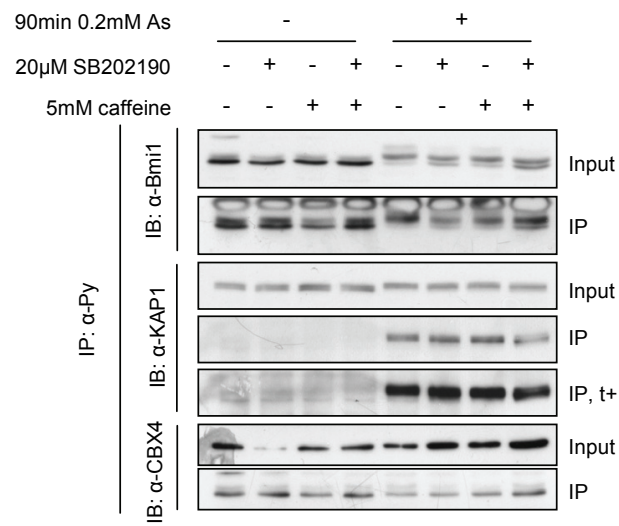

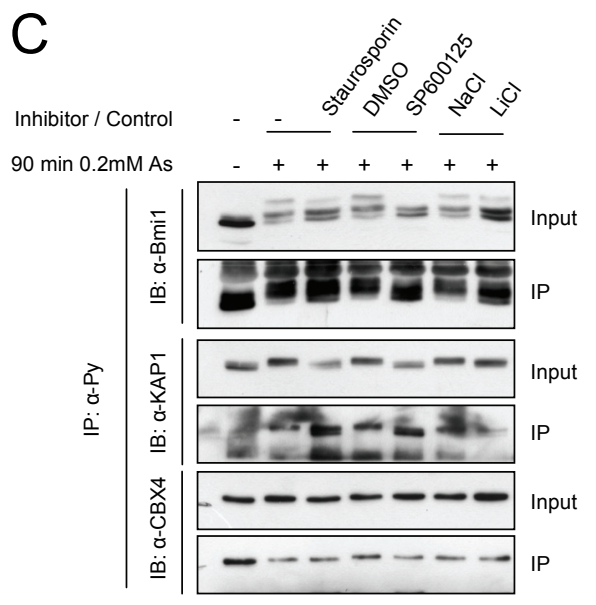

Figure 6.2. Kinase pathways involved in Arsenite-induced PRC1-KAP1 interaction.

(A) IP western analysis of U2-OS cells expressing Bmi1 with Py-tag (Bmi1-Py) or not (control). IPs were performed using an antibody against the Py epitope. Cells were serum-starved and subjected to Arsenic (As) stimulation as indicated. IPs were either subjected to phosphatase treatment or mock treated. (B) IP western analysis of serum-starved Bmi1-Py overexpressing U2OS cells pretreated with a p38 inhibitor (SB202190) and/or an ATM/ATR inhibitor (caffeine) before As application. Longer exposure of film to the same western blot is indicated by $t+$. (C) IP western analysis of serum-starved Bmi1-Py overexpressing U2-OS cells pretreated with a PKC inhibitor (staurosporin), a JNK inhibitor (SP600125) or a GSK3ß inhibitor (LiCl) or their corresponding controls before As exposure.

that NFkB and AKT/PKB do not affect Bmi1 or KAP1 phosphorylation (data not shown). In contrast, inhibitors of PKC (staurosporin), JNK (SP600125) and GSK3ß (LiCl) reduce Bmi1 and KAP1 phosphorylation (Fig. 6.2C). Remarkably, both 
treatment with Staurosporin and SP600125 enhance the association between Bmi1 and KAP1, whereas LiCl treatment has the opposite effect (Fig. 6.2C). Thus progressive phosphorylation of Bmi1 and KAP1 downstream of PKC and JNK signaling negatively interferes with their association, whereas GSK3ß signaling increases association, supporting a role of one or more PKC/JNK phospho-sites in regulating the Bmi1-KAP1 interaction. In remarkable contrast, interaction between PRC1 core members Bmi1 and CBX4 is not affected. To further address the role of Bmi1 phosphorylation in the interaction, Bmi1 mutants were implemented, in which 7 putative RXXS/T consensus phosphorylation sites were mutated to obtain less-phosphorylatable Bmi1 (Bmi7A) or a phospho-mimetic form of Bmi1 (Bmi7E). RXXS/T are potential consensus sites for a number of kinases, among which MAPKAPKs and PKCs. As Bmi7E does not bind to KAP1 under basal conditions, and Bmi7A still interacts with KAP1 upon As exposure (Fig. 6.S4A), it is unlikely that phosphorylation at these sites are instrumental in initiating the association. There may, however, be a role for these sites in combination with other PTMs in affecting Bmi1 function or interactions. Consistent with this, we find that the $7 \mathrm{E}$ mutant exhibits spontaneous additional changes, which apparently result in protein instability, as the 7E mutant is stabilized by proteasome inhibitors. In keeping with a role for RXXS/T phosphorylation in protein turn over, a 7A mutant does not display this instability (Fig. 6.S4B). Our findings demonstrate that As-induced activated p38, ATM/ATR, PKC, JNK and GSK3ß signaling cascades target Bmi1 and KAP1. Bmi1KAP1 association is differentially affected by signaling through these pathways: GSK3ß activity positively affects the association, whereas p38 and ATM/ATR have no effect, and PKC and JNK inhibit interaction. Collectively this data points to a specific involvement of signaling cascades and PTM-events in PRC1 protein biochemistry.

\section{Stimulus-specific phosphorylation of BMI1 and KAP1}

To chart physiological conditions that induce PRC1 and KAP1 phosphorylation, U2-OS cells were subjected to several stressors, including arsenite (As), selenite (Se), ionizing radiation (IR) or ultra violet (UV) treatment. As, Se and UV exposure phosphorylate BMI1, whereas IR does not (Fig. 6.3A-D). For Se and IR treatment, KAP1 phosphorylation was undetectable at the level of the total protein (Fig. 6.3B,C), whereas As exposure readily induces KAP1 phosphorylation (Fig. 6.3A). Upon UV exposure KAP1 is initially rapidly phosphorylated, after which it gradually declines over time (Fig. 6.3D). However, by using a phosphospecific antibody that recognizes KAP1 phosphorylation at S824, Se, IR and UV, but not As, are shown to specifically induce KAP1 phosphorylation at Ser824 (Fig. 6.3A-D), in line with ATM-dependent KAP1-phosphorylation in response to double strand DNA damage ${ }^{18-20}$. KAP1 phosphorylation at S473, which correlates 
with KAP1-HP1ß binding ${ }^{21}$, is potently induced by UV, and to a lesser extent by As, Se and IR (Fig. 6.S5 A-D). Thus, our data demonstrate that phosphorylation of BMI1 and KAP1 is stimulus-specific and confirm that both proteins are phosphorylated at multiple residues.

A

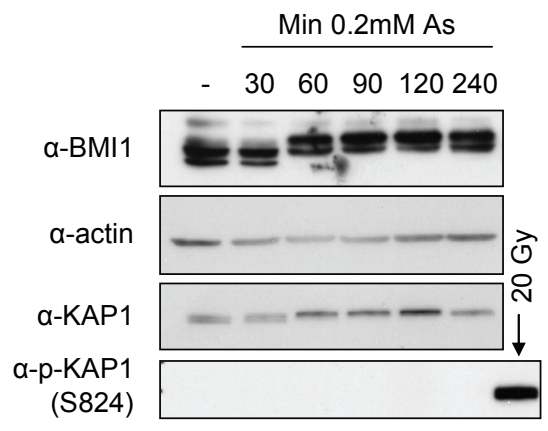

B

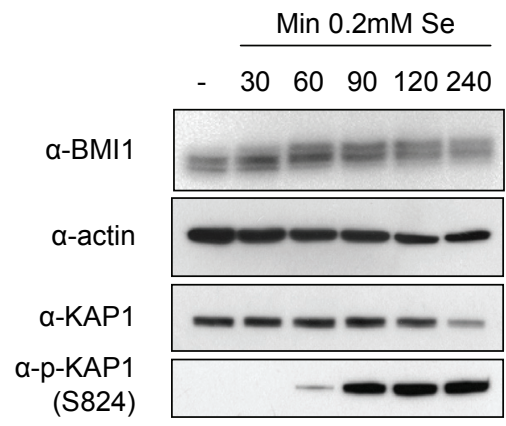

C Min after 20 Gy IR

- 10306090120240

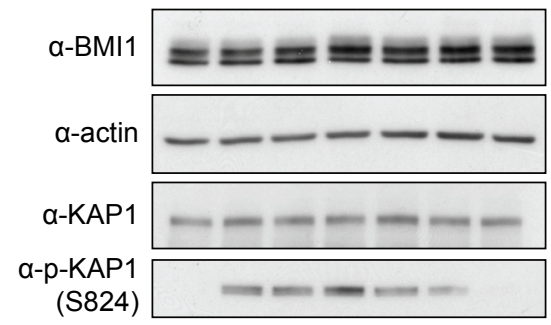

D

Min after $25 \mathrm{~J} / \mathrm{m}^{2} \mathrm{UV}$

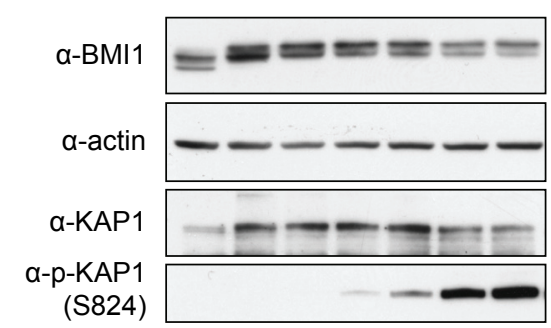

Figure 6.3. Stimulation specific phosphorylation of BMI1 and KAP1.

$(A-B)$ Western analysis of serum-starved U2-OS cells treated with $A s(A)$ and Se $(B)$ for indicated amounts of time. (C-D) Western analysis of confluent U2-OS cells treated with IR (C) and UV (D) where indicated minutes refer to the time-period between the stimulus and generation of protein extracts. Actin serves as loading control.

\section{Selenite induces interaction of PRC1 and KAP1}

We next investigated Bmi1-KAP1 association in response to various stressors. As KAP1 is phosphorylated upon DNA damage, we initially focused on DNA damage inducing treatments. Surprisingly, next to As, only Se appears a potent inducer of this interaction (Fig. 6.4A). IR, camptothecin and UV treatment did not elicit an interaction under the conditions tested (Fig. 6.S6A-C). Even though KAP1 is phosphorylated on S824 upon Se exposure, this modification is not readily detected in the IP (Fig. 6.4A), suggesting that this PTM is not required for the PRC1-KAP1 association and that pS824-KAP1 localizes to a different subcellular compartment (see below). 
A

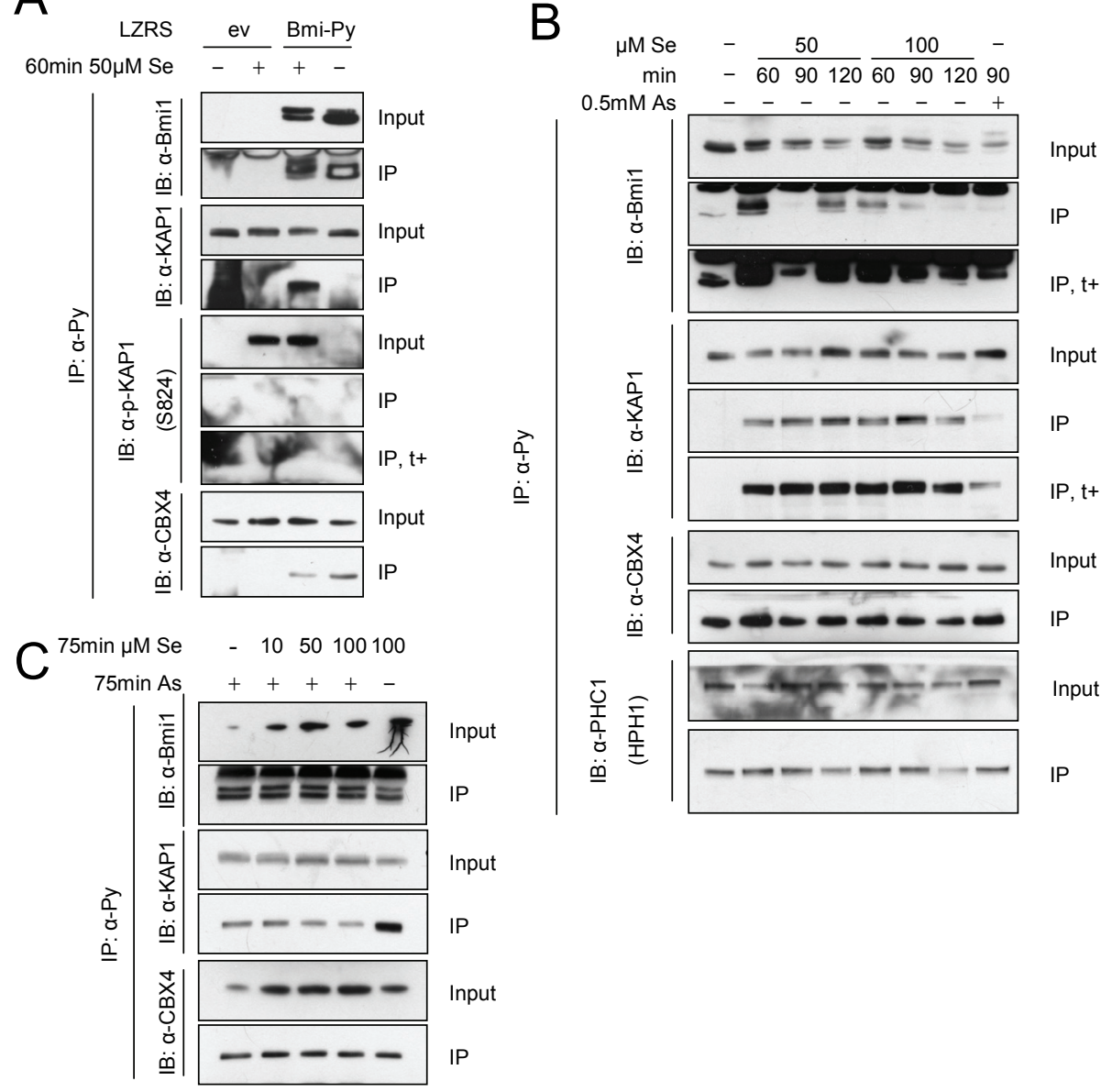

Figure 6.4. More potent association of Bmi1-Py and KAP1 after Selenite stimulation compared with Arsenite stimulation.

(A) IP western analysis of U2-OS cells expressing Bmi1 with Py-tag (Bmi1-Py) or empty vector (EV). Cells were serum-starved and subjected to Selenium (Se) stimulation as indicated. IPs were performed using an antibody against the Py epitope. Longer exposure of film to the same western blot is indicated by $\mathrm{t+}$. (B) anti-Py IP western analysis of serum-starved U2-OS Bmi1-Py cells treated with indicated Se concentrations for various amounts of time. (C) anti-Py IP western analysis of serum-starved U2-OS Bmi1-Py cells treated with As, Se or a combination of As and varying concentrations of Se as indicated.

The Se-induced association between Bmi1 and KAP1 is time-dependent and concentration-dependent (Fig. 6.4B). In comparison to As, Se evokes a more intense association between Bmi1 and KAP1 (Fig. 6.4B,C). As and Se have been reported to exert antagonistic effects on cellular signaling ${ }^{22}$. Remarkably, simultaneous exposure of As and Se reduces the association between Bmi1 and 
KAP1 as compared to Se only (Fig. 6.4C). Furthermore, KAP1 phosphorylation is consistently less profound with Se compared to As (Fig. 6.4B,3, S2), suggesting that As inhibits or overrules signaling by Se directly or indirectly.

\section{Dependence of selenite-induced PRC1-KAP1 interaction on phosphorylation}

Analogous to As, when IP's were phosphatase-treated the interaction between Bmi1 and KAP1 was not lost (Fig. 6.5A). Again, although a very weak band is seen for pS284-KAP1, it was by no means enriched in the co-IP experiment (Fig. 6.5A), further substantiating that it is not pS824 KAP1 that associates with PRC1. Pretreatment of cells with kinase inhibitors revealed a different pattern for Se than for As treatment. Whereas p38 and ATM/ATR inhibition did not affect Asinduced association (Fig. 6.2B), application of these kinase inhibitors prior to Se exposure completely prevented Bmi1-KAP1 association (Fig. 6.5B). Inhibition of PKC and JNK signaling reduces the Se-induced phosphorylation of KAP1, yet increases the association of KAP1 with Bmi1 (Fig. 6.5C). In addition, inhibition of GSK3ß signaling decreased binding (Fig. 6.5C). Therefore the Se-induced interaction between Bmi1 and KAP1 is negatively affected by phosphorylation downstream of PKC and JNK signaling and positively affected by p38, ATM/ATR and GSK3ß signaling.

Immuno-fluorescence analysis of KAP1 and BMI1 binding in U2-OS cells reveals that although KAP1 and BMI1 both dissociate from chromatin in response to As or Se (Fig. 6.1D; Fig. 6.S7), pS824-KAP1 is chromatin associated (Fig. 6.S7). Consistent with a separate task for pS824, IF on Se stimulated cells shows that PcG dissociation and pS824 inversely correlate: approximately half of nuclei positive for PcG bodies are pS824 negative or weak, whereas approximately half of KAP1-positive nuclei lack PcG bodies (Fig. 6.S8). In support of functionally separate KAP1 pools, phosphorylated S824 KAP1 was reported to associate with chromatin ${ }^{19}$.

Se-induced S824-KAP1 phosphorylation and H2AX phosphorylation ( $\mathrm{H} 2 \mathrm{AX})$, both known ATM-catalyzed events in response to DNA damage, are blocked by caffeine (Fig. 6.S9A,B). As predicted, p38 inhibition partially blocks PRC1 dissociation (Fig. 6.S7), but has no discernable effect on KAP1-S824 or H2AX phosphorylation. Interestingly, while As alone does not induce DNA damage under these conditions, simultaneous exposure of cells to As and Se blocks phosphorylation as efficiently as caffeine does, suggesting As counteracts Se at least in part through a mechanism involving ATM inhibition (Fig. 6.S9B). Conversely, KAP-1 dissociation appears not depend on either p38 or ATM activation alone; combined As and Se treatment, however, blocks KAP1 dissociation (Fig. 6.S9).

These immuno-histological data are therefore complementary to the interaction data and, combined, demonstrate that multiple kinase pathways differentially 
A

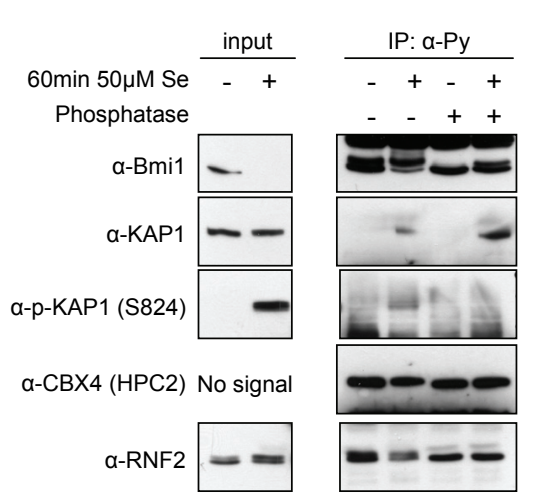

B

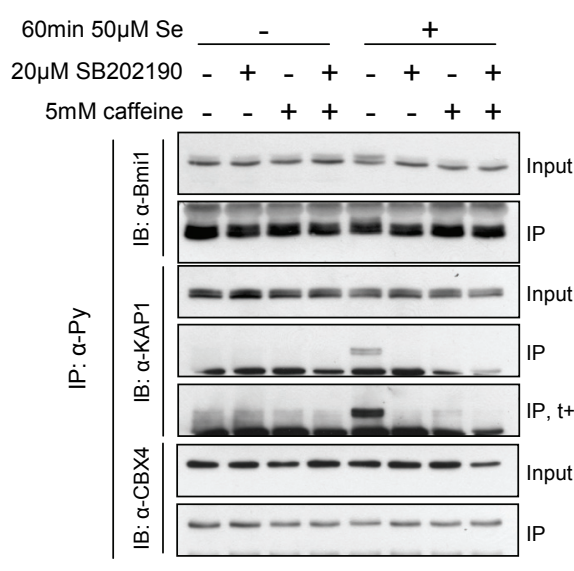

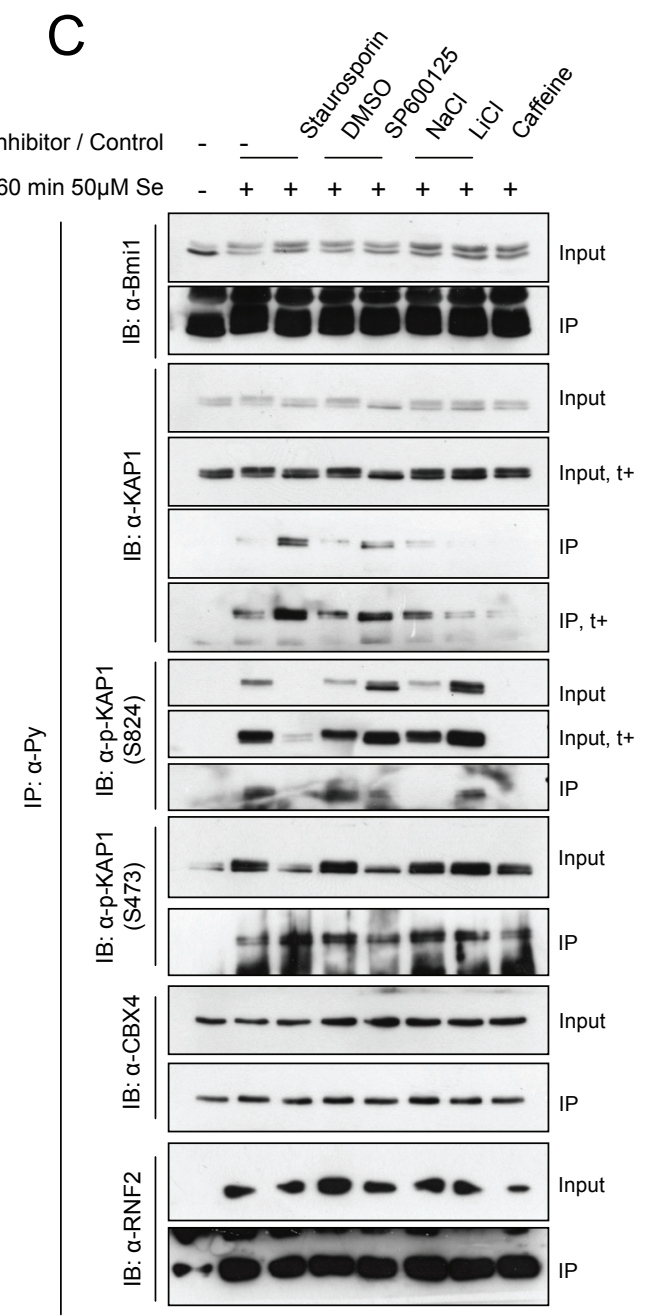

Figure 6.5. Kinase pathways involved in Selenite-induced PRC1-KAP1 interaction.

(A) IP western analysis of U2-OS cells expressing Bmi1 with Py-tag. IPs were performed using an antibody against the Py epitope. Cells were serum-starved and subjected to Se stimulation as indicated. IPs were either subjected to phosphatase or mock treatment. (B) IP western analysis of serum-starved Bmi1-Py overexpressing U2-OS cells pretreated with a p38 inhibitor (SB202190) and/or an ATM/ATR inhibitor (caffeine) before Se application. Longer exposure of film to the same western blot is indicated by $\mathrm{t}+$. (C) IP western analysis of serum-starved Bmi1-Py overexpressing U2-OS cells pretreated with a PKC inhibitor (staurosporin), a JNK inhibitor (SP600125) or a GSK3ß inhibitor (LiCl) or their corresponding controls before Se exposure.

affect PRC1 and KAP1. Even though both As and Se exposure induce phosphorylation and binding of Bmi1 and KAP1, the dependence of these two cellular stressors on signaling cascades is clearly different. Only Se signaling results in pS824-KAP1. Furthermore, the interaction between Bmi1 and KAP1 is 
dependent on p38 and ATM/ATR signaling only when induced by Se, and support the idea that these combined phosphorylation events are involved in chromatin dissociation of both interaction partners, rather than establishing the interaction.

\section{Biological relevance of PRC1-KAP interaction.}

To begin to understand the biological relevance of the PRC1-KAP1 interaction, we initiated a number of studies. As KAP1 acts as co-repressor, and through its interaction with HP1 proteins is part of the heterochromatic compartment in the nucleus, we investigated its potential role in PCG mediated repression. Mitogen-stimulated primary human TIG3 fibroblasts initiate a rapid increase in ATF3 mRNA (Fig. 6.6A); ATF3 was shown to be a genuine PRC-target in TIG3 cells $^{2}$; we have recently obtained experimental evidence for PRC1-chromatin dissociation at this locus in response to mitogenic signaling (Chapter 5 of this thesis). Consistent with its transcriptionally repressive properties, loss of KAP1 leads to an exaggerated transcriptional response (Fig. 6.6B). In good agreement with our finding that several kinase pathways converge on Bmi1 and KAP1 interaction, pretreatment of cells with p38 and/or ATM inhibitors increases basal ATF3 expression, whereas PKC inhibition reduces basal ATF3 levels (Fig. 6.6A). It is tempting to interpret these findings in the context of reduced and increased availability of PRC for local chromatin binding, respectively. Remarkably, staurosporin abolishes mitogen-induced ATF3 expression completely, whereas caffeine does not and p38 or MEK inhibition slightly, but substantially reduce ATF3 transcription. Without further insight into the contribution and interaction of individual phosphorylation events, it is impossible to pinpoint an exact mechanism. Combined these findings however indicate progressive and sequential phosphorylation events in PRC1/KAP1 regulation.

\section{Discussion}

In this study we demonstrate that multiple PRC1 proteins (Bmi1, CBX4 and PHC1) are phosphorylated upon induction of cell stress via As or Se stimulation. In addition we demonstrate for the first time that PRC1 complexes associate with KAP1 (alternative names TRIM28, TIF1ß, KRIP-1) upon induction of cell stress. PRC1 proteins are phosphorylated by various kinase pathways, including: p38, ATM/ATR, PKC, JNK and GSK3ß signaling. In addition, some PRC1 proteins, like Bmi1 and RNF2, appear phosphorylated under basal conditions, when cells are serum-starved, and arrested in G1 (Fig. 6.2A,5A). In total 20 PcG phosphorylation sites were identified by mass spectrometry, three of which were on CBX8, twelve on PHC proteins, two on RING1 and three on Bmi1. 
A

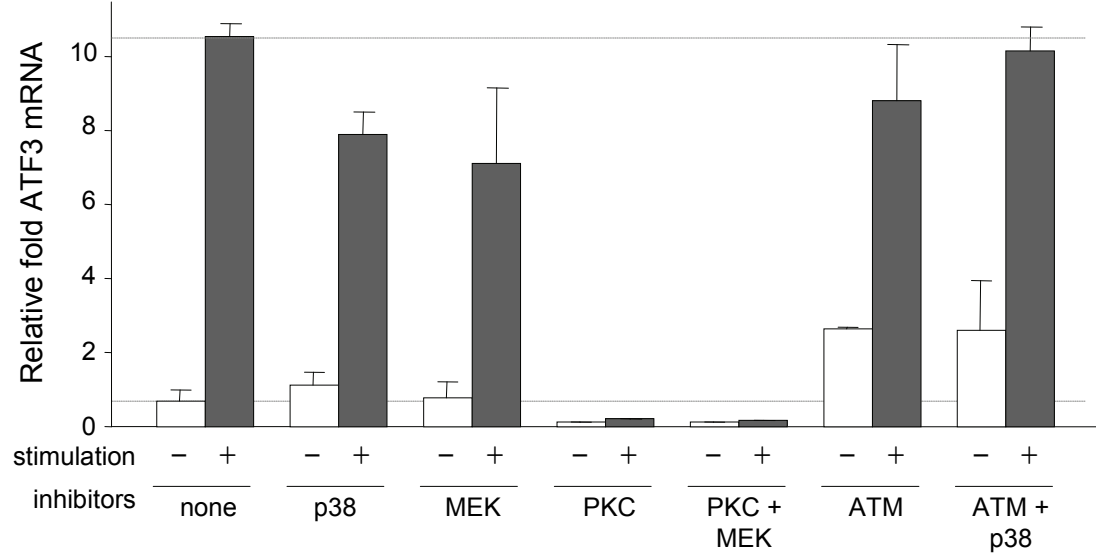

B

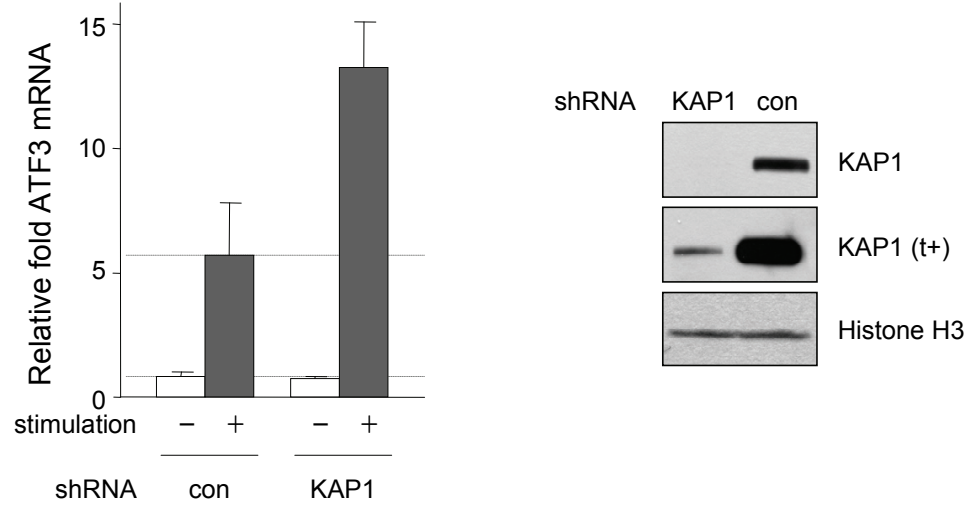

Figure 6.6. Mitogenic signaling-induced transcription of PcG target gene ATF3 is dependent on PKC and enhanced by KAP1 knockdown.

(A) Real time quantitative mRNA measurements of PcG target gene ATF3. Serum-starved TIG3 cells were incubated with indicated inhibitors prior to 45 minutes serum/TPA stimulation.

(B) Real time quantitative mRNA measurements of PcG target gene ATF3 expression in serumstarved TIG3 cells containing PRETROSUPER-based knockdown constructs of GFP (con) and KAP1. Cells were treated with serum/TPA stimulation as indicated (left). Western analysis confirming KAP1 knockdown (right).

We found that some, but not all DNA damage-inducing stimuli lead to Bmi1 phosphorylation. Previously phosphorylation of PHC2 on $\mathrm{S} 733$ and PHC3 on S227 was shown to result from DNA damage ${ }^{23}$. In addition, it was reported that DNA damage induction by adriamycin treatment induced CBX4 phosphorylation, which was dependent on HIPK2 kinase activity ${ }^{24}$. This suggests that the 
phosphorylation of PcG proteins is a common feature of DNA damage responses and suggests a role for PcG proteins in damage responses.

The association between Bmi1 and KAP1 appears to be direct, as high stringency washing $(1.5 \mathrm{M} \mathrm{NaCl})$ upon IP does not release the interaction. Phosphatase treatment of protein complexes once the interaction is established, does not affect Bmi1-KAP1 binding. Combined, our findings specify a role for phosphorylation events in initiation of PRC1-KAP1 association, whereas maintenance is no longer dependent on phosphorylation. In keeping with our earlier reports, this data supports functional compartmentalization of PRC1 proteins through phosphorylation-induced novel associations. The finding that PRC1 core complex members are quantitatively retrieved in IPs, suggests that either PCR1-core complex interactions are not compromised by KAP1 binding and/or Bmi1 is part of more than one complex. In some mass spectrometric analyses two other tripartite motif-containing proteins were detected, TRIM21/RO52 and TRIM25/Efp, suggesting the PRC1-association with this protein family is more widespread. The tripartite motif consists of a RING domain, one or two B-box motifs and a coiled-coil region, also known as the RBCC domain ${ }^{25}$. KAP1 carries C-terminal a PHD and a BROMO domain; both are also found in other TIF1 proteins (transcription intermediary factor). PHD and BROMO domains are often found in chromatin associated proteins and some have histone binding properties ${ }^{26}$. However, the PHD finger and bromodomain of KAP1 do not display methyllysine and acetyllysine binding properties, respectively ${ }^{27}$. Since the more C-terminally located domains in the three TRIM proteins are not similar, we speculate that the interaction between PRC1 and KAP1 is established via the RBCC domain of KAP1. An interaction between a PCG protein and a TRIM protein has been described before. RET finger protein (RFP; TRIM27) interacts via its coiled coil region with Enhancer of Polycomb (EPC) ${ }^{28}$. Efforts to identify the KAP1 region that is responsible for the PRC1-KAP1 interaction are underway. Initial attempts using C-terminally FLAG-tagged KAP1 deletion constructs failed due to inability of these constructs to localize to the nucleus and did not co-precipitate with Bmi1 (data not shown).

KAP1 binds to certain KRAB-containing zinc finger proteins ${ }^{29-31}$. It regulates transcriptional repression by interacting with several proteins and complexes including HP1 proteins ${ }^{32-34}$, a N-CoR-1 complex, containing the nuclear receptor corepressor (N-COR), HDAC3 and several members of the SWI/SNF protein family ${ }^{35}$, a NuRD complex containing a form of Mi-2 $\alpha, \mathrm{HDAC} 1$ and $\mathrm{RbAp} 48^{36}$, and SETDB1, a H3K9 methyltransferase ${ }^{37}$.

Sumoylation of KAP1 is essential for its transcriptional repressive properties ${ }^{38-40}$, and is necessary for HDAC, SETDB1 and CHD3/Mi2 recruitment ${ }^{39,40}$. DNA damage induces phosphorylation of KAP1 on S824, which is necessary for DSBinduced chromatin relaxation ${ }^{18,19}$. Furthermore ATM-induced KAP1 dissociation 
is specifically required for damage repair in heterochromatin ${ }^{20}$. Phosphorylation of KAP1 on S824 by ATM upon DOX treatment correlates with reduced sumoylation and an increased expression of several KAP1-repressed genes such as p21 and Gadd45 ${ }^{41}$. Whether S824 phosphorylation interferes with sumoylation is unclear as of yet. S473 phosphorylation, however, was shown to regulate KAP1 binding with $\mathrm{HP} 1^{21}$.

In an attempt to determine the biological relevance of KAP1-PRC1 interaction we looked at common targets of PRC1 and KAP1. Although our loss of KAP1 experiments indicate a potential role in PRC1 mediated repression, a comparative analysis of published ChIP-on-chip analysis of KAP1 and PRC1 binding in TIG3 cells ${ }^{1-3,42}$ revealed overlap between only few PRC1 and KAP1 sites (not shown). Of the top 2000 KAP1 targets approximately $11 \%$ were also bound by $\mathrm{H} 3 \mathrm{~K} 27 \mathrm{me} 3^{42}$. Our comparison did not identify ATF3 as a common PRC1/KAP1 target. This strongly suggests that the effect of KAP1 on PRC1 targets maybe indirect, via more global chromatin responses. Chromatin immunoprecipitation analysis will have to point out whether the dynamics of PRC1-chromatin dissociation is altered in the absence of KAP1. Clearly, whether and how KAP1-PRC1 interaction impinges on PcG-mediated repression should be the focus of future investigations.

Prolonged exposure to several stress stimuli seems to promote Bmi1 degradation. Previously it has been established that Rnf2 and Bmi1 are ubiquitylated and targeted for degradation by an as of yet unknown E3 ubiquitin ligase $^{43}$. Interestingly, some TRIM proteins are E3 ubiquitin ligases. TRIM25/Efp targets $14-3-3 \sigma$ for proteasomal degradation. The TRIM25 RING domain interacts with the E2 $\mathrm{UbcH} 8$, whereas the B-boxes and coiled-coil domain mediate substrate interaction ${ }^{44}$. Interestingly, the KAP1 PHD domain is a E3 sumo ligase for its adjacent bromodomain ${ }^{40}$. Based on this it is intriguing to speculate that KAP1 will function as an ubiquitin E3 ligase for Bmi1; this and the specific role of phosphorylation in protein stability warrant further research.

In conclusion, we have detected a novel interaction between PRC1 and KAP1, both involved in gene repression via epigenetic mechanisms. We here identify multiple phosphorylation events on PRC1 proteins, which illustrates the complexity of PcG regulation. Combined these findings indicate progressive and potentially sequentially hierarchical phosphorylation events in PRC1/KAP1 regulation. Further characterization of the circumstances under which novel associations occur, what the exact molecular nature of the interaction is, what phospo-residues are involved and what their biological significance is, is clearly needed. This will provide us with new insights in how regulation of PcG phosphorylation and chromatin dissociation contributes to processes such as development, differentiation and possibly tumorigenesis. 


\section{Materials and methods}

\section{Tissue culture and expression systems}

Human osteosarcoma cells (U2-OS), human cervix carcinoma cells (HeLa) and human primary fibroblasts (TIG3) were cultured at $37^{\circ} \mathrm{C}, 5 \% \mathrm{CO} 2,100 \%$ humidity in Dulbecco's modified Eagle's medium supplemented with $10 \%$ fetal calf serum (FCS), antibiotics (100 units $/ \mathrm{ml}$ penicillin and $100 \mu \mathrm{g} / \mathrm{ml}$ streptomycin), $200 \mathrm{mM}$ L-glutamine and $4.5 \mathrm{~g} /$ liter L-glucose. Serum starvation was carried out at $0.1 \%$ FCS for 48 hrs. Retroviral expression vectors were used throughout these studies to maximize percentages of expressing cells and to minimize integration effects. Expression constructs encoding murine Bmi1-2Py, MPH2-flag-TAP and Bmi1-TAP were constructed in pBABE-PURO, pBMNLZRS.ires.GFP or pBMN-LZRS.ires.NEO). The pRETRO-SUPER shRNA system used for KAP-1 (or GFP control) knockdown was obtained from A. Goodarzi ${ }^{20}$, with permission of Ziv et al. ${ }^{19}$. Phosphomutants of Bmi1 were made with the Quikchange $\mathrm{XL}$ site-directed mutagenesis kit according to manufacturers protocol (Stratagene). Primers are listed in Table 6.S3.

\section{Cell treatment}

Sodium (meta)arsenite (S7400, Sigma), sodium selenite (S5261, Sigma) and 15\% FCS and $100 \mathrm{ng} / \mathrm{ml}$ tetradecanoyl phorbol acetate (TPA) were used to stimulate cells. Pretreatment with kinase inhibitors prior to stimulation was performed as

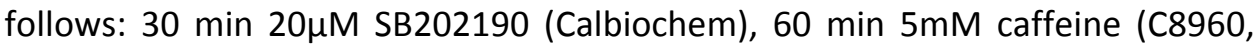
Sigma), $30 \mathrm{~min} 1 \mu \mathrm{M}$ Staurosporin (S4400, Sigma), $60 \mathrm{~min} 25 \mu \mathrm{M}$ SP600125 (Biomol), $30 \mathrm{~min} 20 \mathrm{mM} \mathrm{LiCl}$ (L9650, Sigma) or $30 \mathrm{~min} 10 \mu \mathrm{M}$ U0126. $20 \mu \mathrm{M}$ Proteasome inhibitor (539160, Calbiochem) or solvent (EtOH) was added 135 min prior to collection of cellular extracts.

\section{Cellular protein extracts}

Cells were lysed in RIPA buffer ( $150 \mathrm{mM} \mathrm{NaCl}, 1 \% \mathrm{NP}-40,0.5 \% \mathrm{DOC}, 0.1 \% \mathrm{SDS}$, $50 \mathrm{mM}$ Tris (pH 8), $5 \mathrm{mM}$ EDTA) supplemented with $5 \mathrm{mM}$ Benzamidine, $5 \mu \mathrm{g} / \mathrm{ml}$ Antipain, $5 \mu \mathrm{g} / \mathrm{ml}$ Leupeptin, $5 \mu \mathrm{g} / \mathrm{ml}$ Aprotinin, $1 \mathrm{mM}$ Sodium Vanadate, $10 \mathrm{mM}$ Sodium Fluoride, $10 \mathrm{mM}$ Pyrophosphate, $10 \mathrm{mM}$ B-glycerophosphate, $0.5 \mathrm{mM}$ DTT and 1mM PMSF. 10mM n-ethylmaleimide (NEM, E38760, Sigma Aldrich) or solvent $(\mathrm{EtOH})$ was added to the cell lysis buffer. Extracts were sonicated on ice and centrifuged for $10 \mathrm{~min}$ at $4^{\circ} \mathrm{C}$ at $13.2 \mathrm{Krpm}$.

\section{Immunoprecipitations}

Cells were lysed in ELB buffer ( $250 \mathrm{mM} \mathrm{NaCl}, 0.1 \%$ Igepal (NP40), 5mM EDTA, $50 \mathrm{mM}$ Hepes $\mathrm{pH} 7.0$ ) supplemented with $5 \mathrm{mM}$ Benzamidine, $5 \mu \mathrm{g} / \mathrm{ml}$ Antipain, $5 \mu \mathrm{g} / \mathrm{ml}$ Leupeptin, $5 \mu \mathrm{g} / \mathrm{ml}$ Aprotinin, $1 \mathrm{mM}$ Sodium Vanadate, $10 \mathrm{mM}$ Sodium 
Fluoride, $10 \mathrm{mM}$ Pyrophosphate, $10 \mathrm{mM}$ ß-glycerophosphate, $0.5 \mathrm{mM}$ DTT and $1 \mathrm{mM}$ PMSF. Extracts were sonicated on ice and centrifuged for $10 \mathrm{~min}$ at $4^{\circ} \mathrm{C}$ at $13.2 \mathrm{Krpm} .1 / 10^{\text {th }}$ of the supernatant was taken as input. Appropriate amount of antibody was added and incubated minimally $1 \mathrm{hr}$ at $4^{\circ} \mathrm{C}$ on a spinning wheel. Antibodies used are anti-2Py-tag Mab (MMS-115R; Babco), $\alpha$-KAP1 Pab (A300275A, Bethyl laboratories), $\alpha$-FLAG M2 (F3165, Sigma), $\alpha$-Bmi1 (F6) Mab (kind gift of M. van Lohuizen), $\alpha$-Bmi1 Mab $(\mathrm{AF} 27)^{45}$, or no antibody for TAP constructs. Appropriately washed beads were added (ProtA, ProtG or IgG beads) and incubated for minimally $4 \mathrm{hrs}$ at $4^{\circ} \mathrm{C}$ on a spinning wheel. The mixture was centrifuged $2 \mathrm{~min}, 4^{\circ} \mathrm{C}, 3000 \mathrm{rpm}$ and supernatant was collected as depleted fraction. Beads were washed $4 x$ in ELB buffer with supplements and stored in $80^{\circ} \mathrm{C}$ until analysis. For phosphatase treatment, IPs were washed an additional $2 \mathrm{x}$ in phosphatase buffer, phosphatase was added and IPs were incubated for $30 \mathrm{~min}$ at $37^{\circ} \mathrm{C}$. Afterwards beads were washed $4 x$ in ELB buffer with supplements and stored in $-80^{\circ} \mathrm{C}$ until analysis. IPs for mass spectrometry were performed differently. After taking input samples, cell lysates were precleared for $30 \mathrm{~min}$ at $4^{\circ} \mathrm{C}$ on a spinning wheel with an equal mix of ProtA and ProtG sepharose and subsequently incubated with $\alpha$-Py resin (affinity matrix AFC$115 \mathrm{P}$, Covance) for minimally $4 \mathrm{hrs}$ at $4^{\circ} \mathrm{C}$ on a spinning wheel. The mixture was centrifuged $2 \mathrm{~min}, 4^{\circ} \mathrm{C}, 3000 \mathrm{rpm}$ and supernatant was collected as depleted fraction. Beads were washed $4 x$ in ELB buffer with supplements and subsequently $4 \mathrm{x}$ washed in modified ELB buffer with supplements, containing $1.5 \mathrm{M} \mathrm{NaCl}$, and stored in $-80^{\circ} \mathrm{C}$ until analysis.

\section{Proteolytic digestion and mass spectrometric analysis}

Beads were washed three times with a $50 \mathrm{mM}$ Tris buffer ( $\mathrm{pH}$ 8.0). Trypsin was added to the beads suspension in a 1:20 ratio to the substrate and the suspension was then incubated $\mathrm{o} / \mathrm{n}$ at $37^{\circ} \mathrm{C}$ while shaking. Beads were spun down and the supernatant was used for mass spectrometry analysis. Phosphorylated peptides were selectively enriched for in an offline chromatographic manner using a titanium dioxide ( $\mathrm{TiO} 2$, Titansphere) packed fused silica capillary that is used as a trap and which acts as an first-dimension separation step in a two-dimensional chromatography system ${ }^{46}$. Phosphorylated peptides were separated from non-phosphorylated peptides by trapping them under acidic conditions on the $\mathrm{TiO} 2$ column and ultimately desorbed under alkaline conditions, dried and dissolved in $0.1 \mathrm{M}$ formic acid. Subsequently, nanoflow LC-MS/MS was performed on an 1100 series capillary LC system (Agilent Technologies) coupled to an LTQ-Orbitrap mass spectrometer (Thermo) operating in positive mode and equipped with a nanospray source. Peptide mixtures were trapped on a ReproSil C18 reversed phase column (Dr Maisch $\mathrm{GmbH}$; column dimensions $1.5 \mathrm{~cm} \times 100 \mu \mathrm{m}$, packed in-house) at a flow rate of 
$8 \mu \mathrm{l} / \mathrm{min}$. Peptide separation was performed on ReproSil C18 reversed phase column (Dr Maisch $\mathrm{GmbH}$; column dimensions $15 \mathrm{~cm} \times 50 \mu \mathrm{m}$, packed in-house) using a linear gradient from 0 to $80 \% B(A=0.1 \mathrm{M}$ formic acid; $B=80 \%(v / v)$ acetonitrile, $0.1 \mathrm{M}$ formic acid) in $70 \mathrm{~min}$ and at a constant flow rate of 200 $\mathrm{nl} / \mathrm{min}$ using a splitter. The column eluent was directly sprayed into the ESI source of the mass spectrometer. Mass spectra were acquired in continuum mode; fragmentation of the peptides was performed in data-dependent mode. Peak lists were automatically created from raw data files using the Mascot Distiller software (version 2.1; MatrixScience). The Mascot search algorithm (version 2.2, MatrixScience) was used for searching against the NCBInr database (release 20070617; taxonomy: Mus musculus and Homo sapiens). The peptide tolerance was set to $10 \mathrm{ppm}$ and the fragment ion tolerance to $0.8 \mathrm{Da}$. A maximum number of 2 missed cleavages by trypsin were allowed and carbamidomethylated cysteine and oxidized methionine were set as fixed and variable modifications, respectively. The Mascot score cut-off value for a positive protein hit was set to 60 . Individual peptide MS/MS spectra with Mowse scores below 40 were checked manually and either interpreted as valid identifications or discarded.

\section{Western blot analysis}

Immunoblotting was performed with the following antibodies: anti ß-actin Mab (C4, 691001, MP Biomedicals), anti-2Py-tag Mab (MMS-115R; Babco); $\alpha$-KAP1 Pab (A300-275A, Bethyl laboratories), $\alpha$-p-KAP1S824 pAb (A300-767A, Bethyl laboratories), $\alpha$-Bmi1 (F6); $\alpha$-CBX4 (HPC2 M9, A. Otte), $\alpha$-PHC1 Pab ( $\alpha$-HPH1, 70092, M. van Lohuizen) $\alpha-\mathrm{PHC2}$ Mab ( $\alpha-\mathrm{HPH} 2, \mathrm{H}$. Koseki, RIKEN Yokohama Institute, Yokohama, Japan) $\alpha$-Histone H3 (ab 1791-100, Abcam) and $\alpha$-RNF2 Pab (anti-dinG (Ring1B) pAb (Dr. M. Dyer, University of Leicester, Leicester, UK).

\section{Immunofluorescence and cell staining.}

Cell were grown on $6 \mathrm{~W}$ culture plates and either fixed for 10 minutes at ambient temperature in 1-2\% formaldehyde/PBS solution followed by permeabilization in $0,2 \%$ triton-X/PBS or directly fixed and permeabilized for 20 minutes in $100 \%$ methanol at $-20^{\circ} \mathrm{C}$. Antibody dilution was done in blocking buffer ( $5 \%$ normal goat serum, $5 \%$ fetal bovine serum, $0.02 \%$ tritonX in PBS). Antibodies used were: $\alpha$-gamma H2AX Mab JBW301, Upstate), $\alpha$-Bmi1 (F6) Mab; $\alpha$-KAP1 Pab (A300-275A, Bethyl laboratories), $\alpha-p-K A P 1 S 824$ pAb (A300767A, Bethyl laboratories). Primary Mabs were detected with goat-anti-mouse TexasRed, primary Pabs with goat-anti-rabbit FITC. 


\section{Quantification of mRNA levels by qPCR}

Total RNA was isolated using Tri-Reagent (Sigma). Quantity and quality of the RNA were checked on the nanodrop (Witec AG, Germany) according to the manufacturer's instructions. RNA (500ng) was converted into cDNA using the iScript $^{\text {TM }}$ cDNA synthesis kit (Bio-Rad) according to the manufacturer's protocol. MylQ analysis was performed on 10 ng of cDNA using the qPCR iQ ${ }^{\mathrm{TM}}$ Custom SYBR $^{\circledast}$ Green Supermix (Bio-Rad) and 300nM primer. Analysis was performed on an iCycler ${ }^{\circledR}$ thermal cycler (Bio-Rad). Cyclophillin A was used as a control gene for normalization. Primers sequences are: ATF3: Forward TCACTGTCAGCGACAGACCC; Reverse CTACCTCGGCTTTTGTGATGG; Cyclophillin A: Forward TTCCTGCTTTCACAGAATTATTCC; Reverse GCCACCAGTGCCATTATGG.

\section{Acknowledgments}

We thank members of the MAASTRO and molecular genetics department for helpful discussions. We thank C. Ramaekers, J. Luiken, R. Langen and N. Kubben for sharing materials. The authors received financial support from the European Molecular Biology Organization (Germany) 186.00-06; the Dutch Science Organization (ZonMW-NWO); Research Support grant 908-02-040 to JWV and VIDI grant 016.046.362. 


\section{References}

1. Boyer LA, Plath K, Zeitlinger J, et al. Polycomb complexes repress developmental regulators in murine embryonic stem cells. Nature. May 18 2006;441(7091):349353.

2. Bracken AP, Dietrich N, Pasini D, et al. Genome-wide mapping of Polycomb target genes unravels their roles in cell fate transitions. Genes Dev. May 1 2006;20(9):1123-1136.

3. Lee $\mathrm{TI}$, Jenner RG, Boyer LA, et al. Control of developmental regulators by Polycomb in human embryonic stem cells. Cell. Apr 21 2006;125(2):301-313.

4. Cao $\mathrm{R}$, Wang $\mathrm{L}$, Wang $\mathrm{H}$, et al. Role of histone $\mathrm{H} 3$ lysine 27 methylation in Polycomb-group silencing. Science. Nov 1 2002;298(5595):1039-1043.

5. Kuzmichev A, Nishioka $\mathrm{K}$, Erdjument-Bromage $\mathrm{H}$, et al. Histone methyltransferase activity associated with a human multiprotein complex containing the Enhancer of Zeste protein. Genes Dev. Nov 15 2002;16(22):2893-2905.

6. Levine SS, Weiss A, Erdjument-Bromage $\mathrm{H}$, et al. The core of the polycomb repressive complex is compositionally and functionally conserved in flies and humans. Mol Cell Biol. Sep 2002;22(17):6070-6078.

7. Cao R, Tsukada $\mathrm{Y}$, Zhang Y. Role of Bmi-1 and Ring1A in H2A ubiquitylation and Hox gene silencing. Mol Cell. Dec 22 2005;20(6):845-854.

8. de Napoles M, Mermoud JE, Wakao R, et al. Polycomb group proteins Ring1A/B link ubiquitylation of histone $\mathrm{H} 2 \mathrm{~A}$ to heritable gene silencing and $\mathrm{X}$ inactivation. Dev Cell. Nov 2004;7(5):663-676.

9. Buchwald $G$, van der Stoop $P$, Weichenrieder $O$, et al. Structure and E3-ligase activity of the Ring-Ring complex of polycomb proteins Bmi1 and Ring1b. Embo J. Jun 7 2006;25(11):2465-2474.

10. Wang $\mathrm{H}$, Wang L, Erdjument-Bromage $\mathrm{H}$, et al. Role of histone $\mathrm{H} 2 \mathrm{~A}$ ubiquitination in Polycomb silencing. Nature. Oct 14 2004;431(7010):873-878.

11. Schoeftner S, Sengupta AK, Kubicek $S$, et al. Recruitment of PRC1 function at the initiation of $X$ inactivation independent of PRC2 and silencing. Embo J. Jun 82006.

12. Cha TL, Zhou BP, Xia W, et al. Akt-mediated phosphorylation of EZH2 suppresses methylation of lysine 27 in histone H3. Science. Oct 14 2005;310(5746):306-310.

13. Voncken JW, Niessen $\mathrm{H}$, Neufeld B, et al. MAPKAP kinase 3pK phosphorylates and regulates chromatin association of the polycomb group protein Bmi1. J Biol Chem. Feb 18 2005;280(7):5178-5187.

14. Ludwig S, Engel K, Hoffmeyer A, et al. $3 p K$, a novel mitogen-activated protein (MAP) kinase-activated protein kinase, is targeted by three MAP kinase pathways. Mol Cell Biol. Dec 1996;16(12):6687-6697.

15. Otte AP, Kwaks THJ. Gene repression by Polycomb group protein complexes: a distinct complex for every occasion? Current Opinion in Genetics \& Development. 2003;13(5):448-454.

16. Sanchez C, Sanchez I, Demmers JA, et al. Proteomics analysis of Ring1B/Rnf2 interactors identifies a novel complex with the Fbxl10/Jhdm1B histone demethylase and the Bcl6 interacting corepressor. Mol Cell Proteomics. May 2007;6(5):820-834.

17. Voncken JW, Schweizer D, Aagaard L, et al. Chromatin-association of the Polycomb group protein BMI1 is cell cycle-regulated and correlates with its phosphorylation status. J Cell Sci. Dec 1999;112 ( Pt 24):4627-4639. 
18. White DE, Negorev D, Peng $H$, et al. KAP1, a novel substrate for PIKK family members, colocalizes with numerous damage response factors at DNA lesions. Cancer Res. Dec 15 2006;66(24):11594-11599.

19. Ziv $Y$, Bielopolski D, Galanty $Y$, et al. Chromatin relaxation in response to DNA double-strand breaks is modulated by a novel ATM- and KAP-1 dependent pathway. Nat Cell Biol. Aug 2006;8(8):870-876.

20. Goodarzi AA, Noon AT, Deckbar D, et al. ATM signaling facilitates repair of DNA double-strand breaks associated with heterochromatin. Mol Cell. Jul 25 2008;31(2):167-177.

21. Chang CW, Chou HY, Lin YS, et al. Phosphorylation at Ser473 regulates heterochromatin protein 1 binding and corepressor function of TIF1beta/KAP1. BMC Mol Biol. Jul 1 2008;9(1):61.

22. Zeng $\mathrm{H}$, Uthus EO, Combs GF, Jr. Mechanistic aspects of the interaction between selenium and arsenic. J Inorg Biochem. Jun 2005;99(6):1269-1274.

23. Matsuoka S, Ballif BA, Smogorzewska A, et al. ATM and ATR substrate analysis reveals extensive protein networks responsive to DNA damage. Science. May 25 2007;316(5828):1160-1166.

24. Roscic A, Moller A, Calzado MA, et al. Phosphorylation-dependent control of Pc2 SUMO E3 ligase activity by its substrate protein HIPK2. Mol Cell. Oct 6 2006;24(1):77-89.

25. Meroni G, Diez-Roux G. TRIM/RBCC, a novel class of 'single protein RING finger' E3 ubiquitin ligases. Bioessays. Nov 2005;27(11):1147-1157.

26. Peng J, Wysocka J. It takes a PHD to SUMO. Trends Biochem Sci. May 2008;33(5):191-194.

27. Zeng L, Yap KL, Ivanov AV, et al. Structural insights into human KAP1 PHD fingerbromodomain and its role in gene silencing. Nat Struct Mol Biol. Jun 2008;15(6):626-633.

28. Shimono $\mathrm{Y}$, Murakami $\mathrm{H}$, Hasegawa $\mathrm{Y}$, et al. RET finger protein is a transcriptional repressor and interacts with enhancer of polycomb that has dual transcriptional functions. J Biol Chem. Dec 15 2000;275(50):39411-39419.

29. Friedman JR, Fredericks WJ, Jensen DE, et al. KAP-1, a novel corepressor for the highly conserved KRAB repression domain. Genes Dev. Aug 15 1996;10(16):20672078.

30. Kim SS, Chen YM, O'Leary E, et al. A novel member of the RING finger family, KRIP1 , associates with the KRAB-A transcriptional repressor domain of zinc finger proteins. Proc Natl Acad Sci U S A. Dec 24 1996;93(26):15299-15304.

31. Moosmann $P$, Georgiev $O$, Le Douarin $B$, et al. Transcriptional repression by RING finger protein TIF1 beta that interacts with the KRAB repressor domain of KOX1. Nucleic Acids Res. Dec 15 1996;24(24):4859-4867.

32. Ryan RF, Schultz DC, Ayyanathan K, et al. KAP-1 corepressor protein interacts and colocalizes with heterochromatic and euchromatic HP1 proteins: a potential role for Kruppel-associated box-zinc finger proteins in heterochromatin-mediated gene silencing. Mol Cell Biol. Jun 1999;19(6):4366-4378.

33. Le Douarin B, Nielsen AL, Garnier JM, et al. A possible involvement of TIF1 alpha and TIF1 beta in the epigenetic control of transcription by nuclear receptors. Embo J. Dec 2 1996;15(23):6701-6715. 
34. Nielsen AL, Ortiz JA, You J, et al. Interaction with members of the heterochromatin protein 1 (HP1) family and histone deacetylation are differentially involved in transcriptional silencing by members of the TIF1 family. Embo J. Nov 15 1999;18(22):6385-6395.

35. Underhill C, Qutob MS, Yee SP, et al. A novel nuclear receptor corepressor complex, $\mathrm{N}-\mathrm{CoR}$, contains components of the mammalian SWI/SNF complex and the corepressor KAP-1. J Biol Chem. Dec 22 2000;275(51):40463-40470.

36. Schultz DC, Friedman JR, Rauscher FJ, 3rd. Targeting histone deacetylase complexes via KRAB-zinc finger proteins: the PHD and bromodomains of KAP-1 form a cooperative unit that recruits a novel isoform of the Mi-2alpha subunit of NuRD. Genes Dev. Feb 15 2001;15(4):428-443.

37. Schultz DC, Ayyanathan K, Negorev D, et al. SETDB1: a novel KAP-1-associated histone H3, lysine 9-specific methyltransferase that contributes to HP1-mediated silencing of euchromatic genes by KRAB zinc-finger proteins. Genes Dev. Apr 15 2002;16(8):919-932.

38. Lee YK, Thomas SN, Yang AJ, et al. Doxorubicin down-regulates Kruppel-associated box domain-associated protein 1 sumoylation that relieves its transcription repression on p21WAF1/CIP1 in breast cancer MCF-7 cells. J Biol Chem. Jan 19 2007;282(3):1595-1606.

39. Mascle $\mathrm{XH}$, Germain-Desprez $\mathrm{D}$, Huynh $\mathrm{P}$, et al. Sumoylation of the transcriptional intermediary factor 1 beta (TIF1beta), the Co-repressor of the KRAB Multifinger proteins, is required for its transcriptional activity and is modulated by the KRAB domain. J Biol Chem. Apr 2007;282(14):10190-10202.

40. Ivanov AV, Peng $H$, Yurchenko $V$, et al. PHD domain-mediated E3 ligase activity directs intramolecular sumoylation of an adjacent bromodomain required for gene silencing. Mol Cell. Dec 14 2007;28(5):823-837.

41. Li X, Lee YK, Jeng JC, et al. Role for KAP1 serine 824 phosphorylation and sumoylation/desumoylation switch in regulating KAP1-mediated transcriptional repression. J Biol Chem. Dec 14 2007;282(50):36177-36189.

42. O'Geen H, Squazzo SL, lyengar S, et al. Genome-wide analysis of KAP1 binding suggests autoregulation of KRAB-ZNFs. PLoS Genet. Jun 2007;3(6):e89.

43. Ben-Saadon $\mathrm{R}$, Zaaroor $\mathrm{D}$, Ziv $\mathrm{T}$, et al. The polycomb protein Ring1B generates self atypical mixed ubiquitin chains required for its in vitro histone $\mathrm{H} 2 \mathrm{~A}$ ligase activity. Mol Cell. Dec 8 2006;24(5):701-711.

44. Urano T, Saito T, Tsukui T, et al. Efp targets 14-3-3 sigma for proteolysis and promotes breast tumour growth. Nature. Jun 20 2002;417(6891):871-875.

45. Bracken AP, Kleine-Kohlbrecher $\mathrm{D}$, Dietrich $\mathrm{N}$, et al. The Polycomb group proteins bind throughout the INK4A-ARF locus and are disassociated in senescent cells. Genes Dev. Mar 1 2007;21(5):525-530.

46. Pinkse MW, Uitto PM, Hilhorst MJ, et al. Selective isolation at the femtomole level of phosphopeptides from proteolytic digests using 2D-NanoLC-ESI-MS/MS and titanium oxide precolumns. Anal Chem. Jul 15 2004;76(14):3935-3943.

47. Dephoure N, Zhou C, Villen J, et al. A quantitative atlas of mitotic phosphorylation. Proc Natl Acad Sci U S A. Aug 5 2008;105(31):10762-10767.

48. Sui S, Wang J, Yang B, et al. Phosphoproteome analysis of the human Chang liver cells using SCX and a complementary mass spectrometric strategy. Proteomics. May 2008;8(10):2024-2034. 


\section{Chapter 6}

49. Beausoleil SA, Jedrychowski M, Schwartz D, et al. Large-scale characterization of HeLa cell nuclear phosphoproteins. Proc Natl Acad Sci U S A. Aug 17 2004;101(33):12130-12135.

50. Cantin GT, Yi W, Lu B, et al. Combining protein-based IMAC, peptide-based IMAC, and MudPIT for efficient phosphoproteomic analysis. J Proteome Res. Mar 2008;7(3):1346-1351.

51. Nousiainen $M$, Sillje $H H$, Sauer $G$, et al. Phosphoproteome analysis of the human mitotic spindle. Proc Natl Acad Sci U S A. Apr 4 2006;103(14):5391-5396.

52. Olsen JV, Blagoev B, Gnad F, et al. Global, in vivo, and site-specific phosphorylation dynamics in signaling networks. Cell. Nov 3 2006;127(3):635-648.

\section{Supplemental figures}
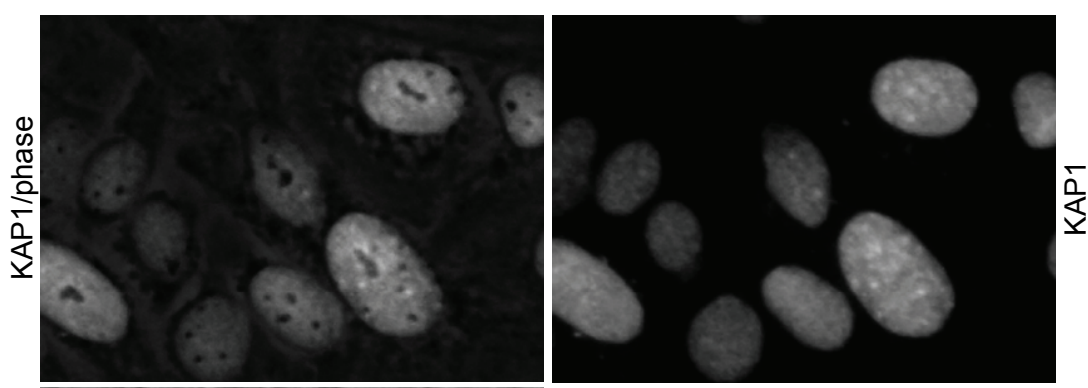

$\bar{Q}$
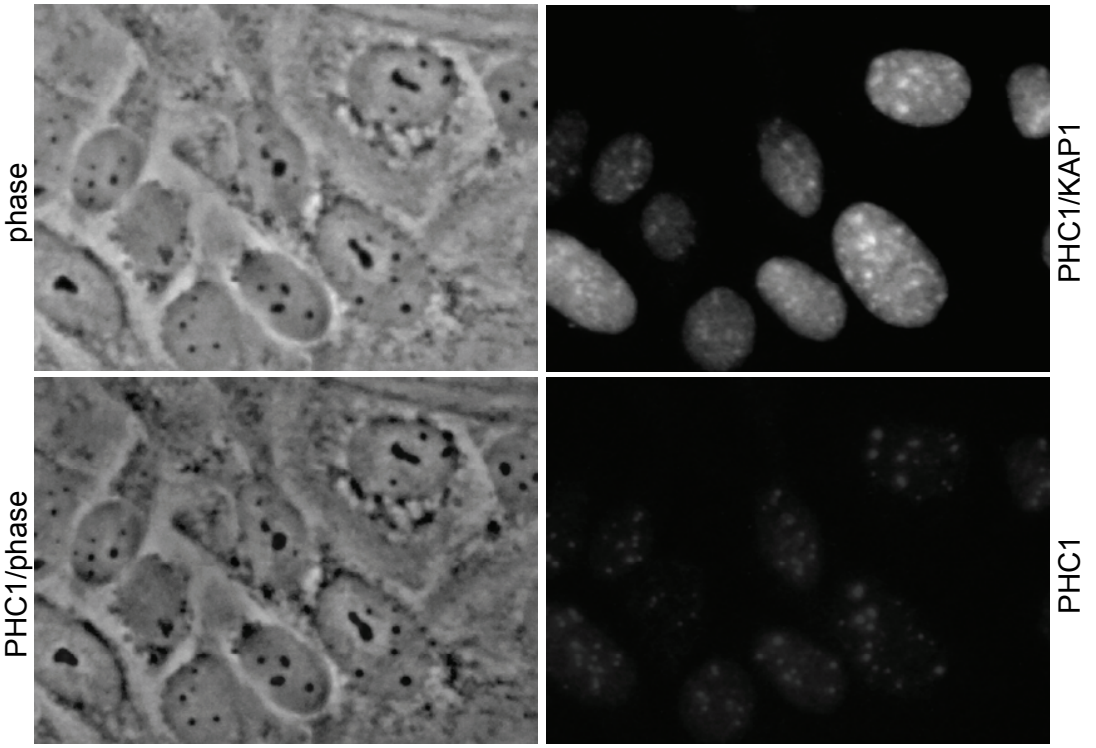

Figure 6.S1. PHC1 and KAP1 concentrate around nucleolar structures.

Immuno-fluorescence detects KAP1 and PHC1 compared to phase-contrast in serum-starved U2OS cells treated with As for $45 \mathrm{~min}$. Single colour photographs correspond to photographs in Fig. 6.1E. Photographs on the left show fluorescent images merged with phase-contrast images. See page 202 for colour print. 


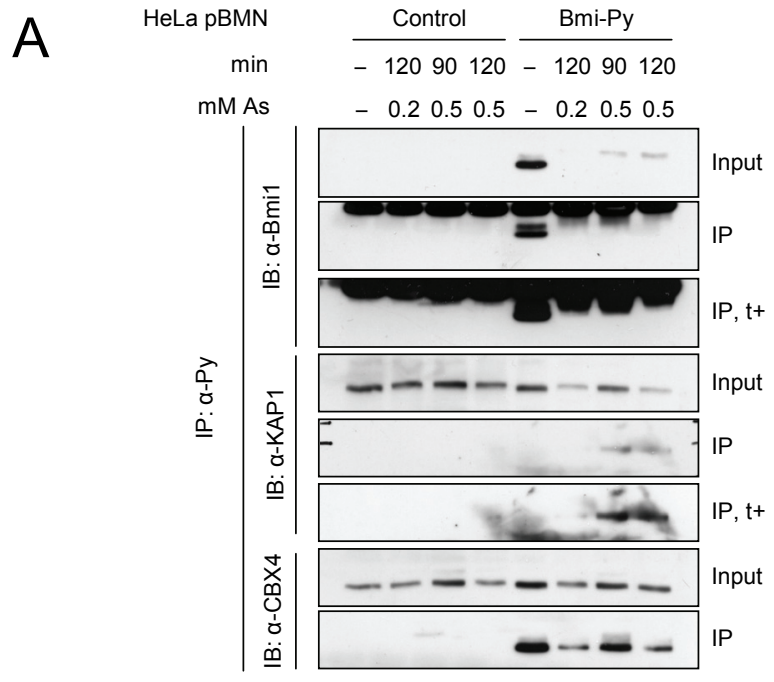

B
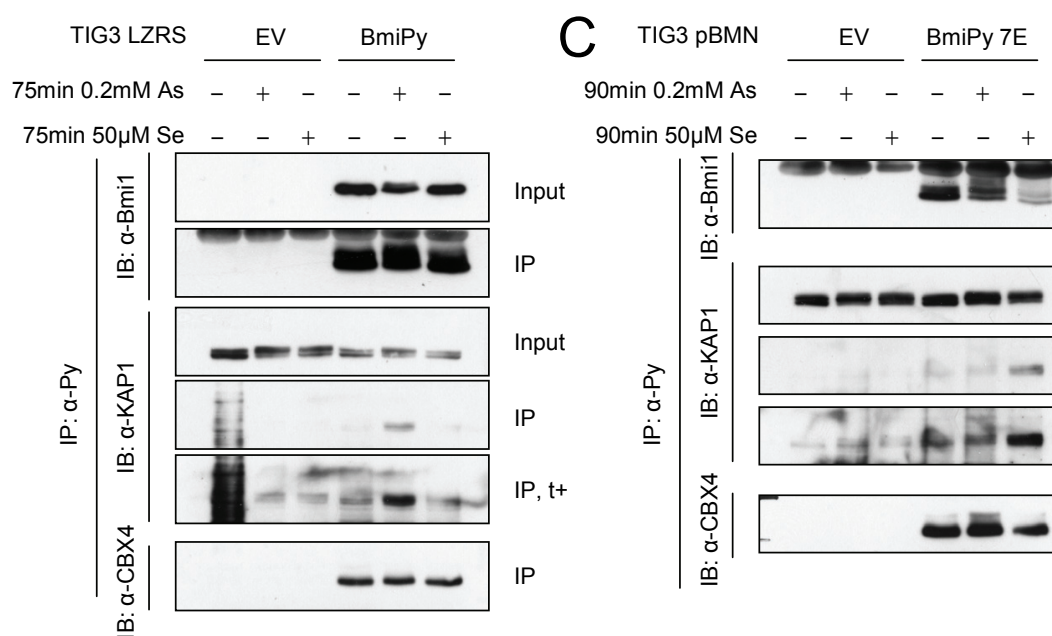

$90 \mathrm{~min} 50 \mu \mathrm{M}$ Se

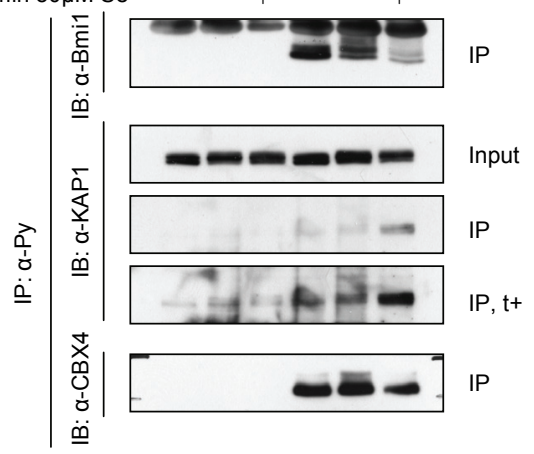

Figure 6.S2. Bmi1-Py-KAP1 association is not cell-type specific.

(A) IP western analysis of serum-starved HeLa cells expressing Bmi1 with Py-tag (Bmi1-Py) or empty vector (control). Cells were exposed to two As concentrations for various amounts of time as indicated. IPs were performed using an antibody against the Py epitope. Longer exposure of film to the same western blot is indicated by $t+$. (B-C) Anti-Py IP western analysis of serum-starved TIG3 cells transduced with either LZRS (B) or pBMN (C) based vectors; empty vector (EV), overexpression of Bmi1-Py or Bmi1-Py 7E. Cells were treated with As and Se as indicated. 


\section{Chapter 6}
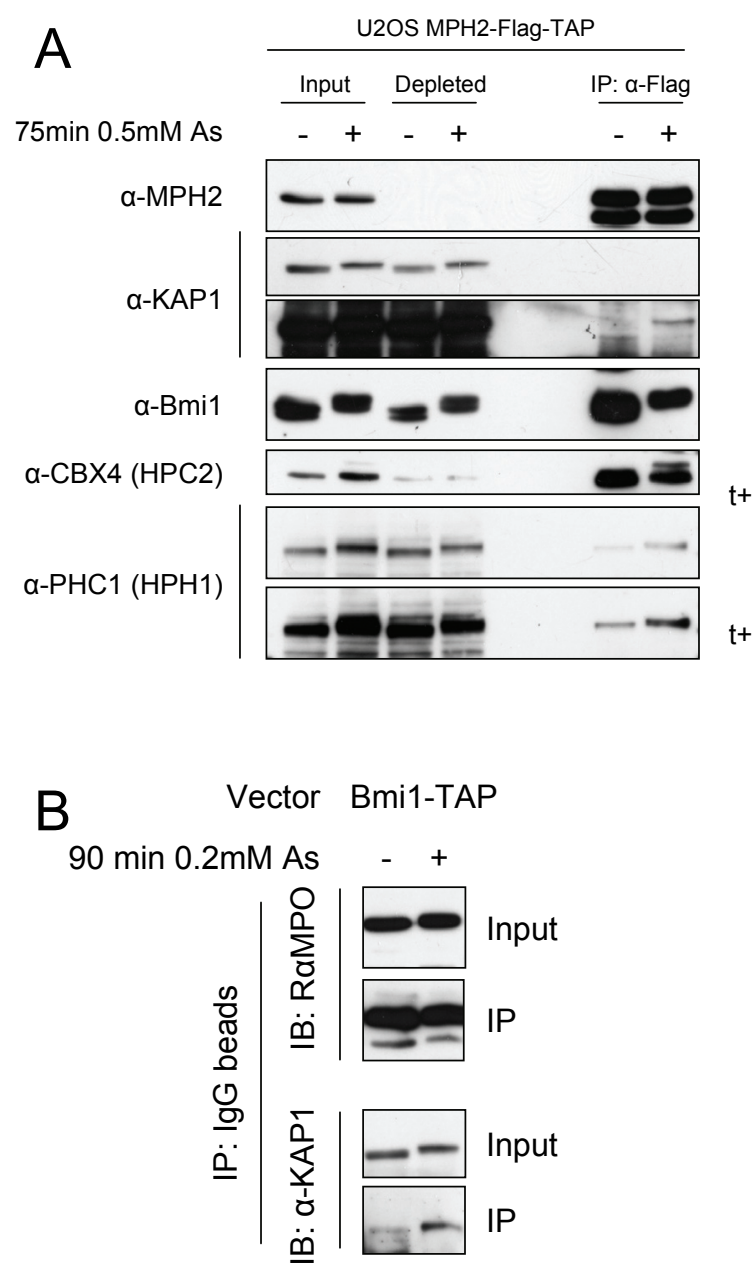

Figure 6.S3. PRC1-KAP1 association is not dependent on Bmi1 or Py-tag.

(A) IP western analysis of serum-starved U2-OS cells expressing MPH2 with a FLAG-TAP-tag exposed to As as indicated. IPs were performed using an antibody against the Flag epitope. Longer exposure of film to the same western blot is indicated by $t+$. (B) IP western analysis of serumstarved U2-OS cells expressing Bmi-TAP exposed to As as indicated. IPs were performed using IgG beads. The TAP-tag contains ProtA; therefore IP can be performed with IgG beads, and detection can be performed by using only secondary antibody (RaMPO). 


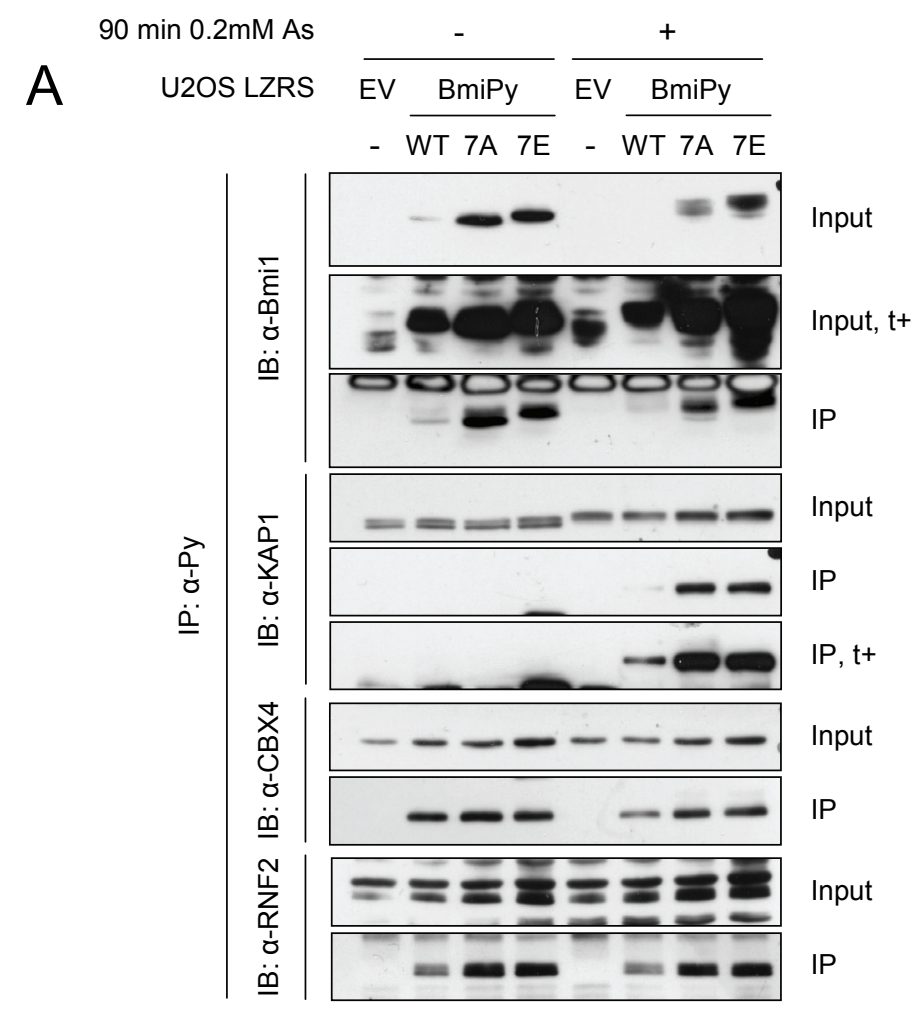

B

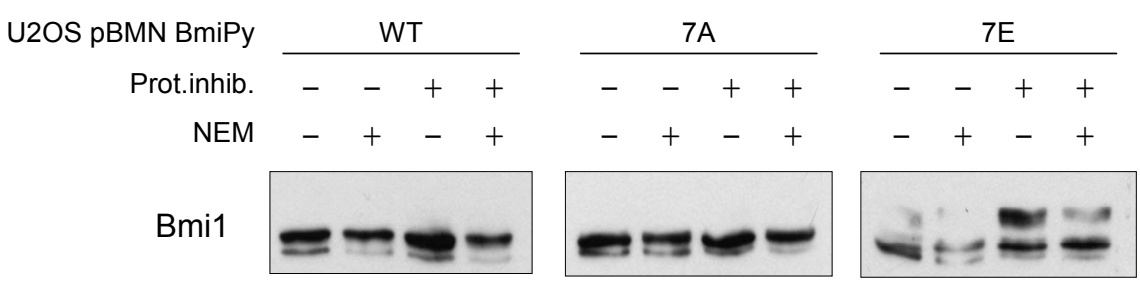

Figure 6.S4. KAP1 interaction and stability of phosphomutant forms of Bmi1.

(A) IP western analysis of U2-OS cells transduced with LZRS empty vector (EV) or vector containing Bmi1 with Py-tag (Bmi1-Py) in an unmutated, wildtype (WT) form, or with 7 possible phosphoacceptor sites mutated to either Alanine (7A) or glutamic acid (7E). Cells were serum-starved and subjected to Arsenic (As) stimulation as indicated. IPs were performed using an antibody against the Py epitope. Longer exposure of film to the same western blot is indicated by $t+$. (B) Western analysis of serum-starved U2-OS cells containing pBMN Bmi1-Py WT, 7A or 7E, treated with or without proteasome inhibitors. NEM was added to the lysisbuffer to prevent de-sumoylation or de-ubiquitylation. 


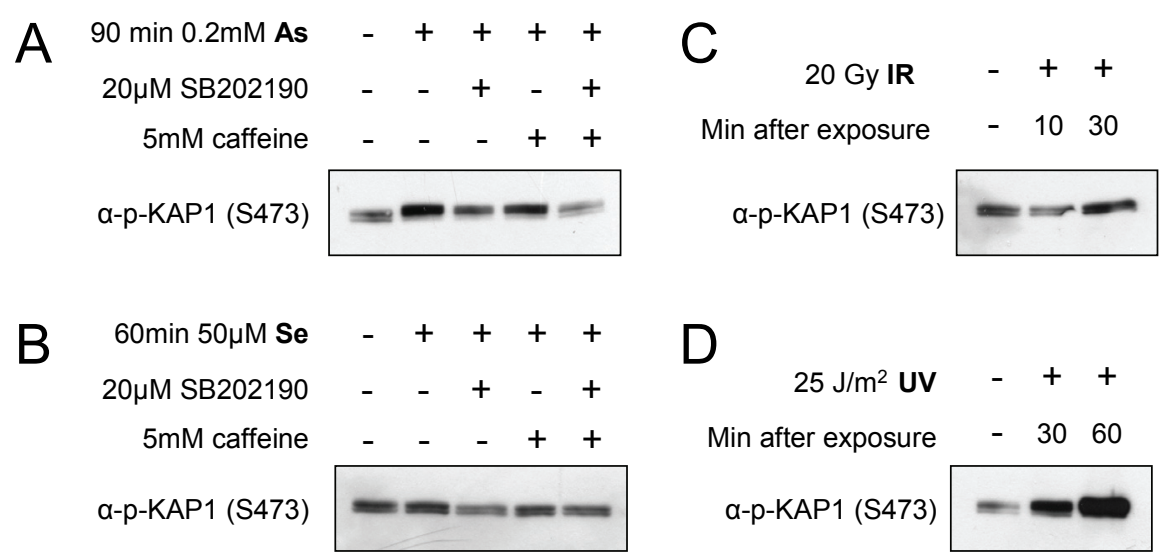

Figure 6.S5. Stimulation specific phosphorylation of KAP1 on S473.

$(A-B)$ Western analysis of serumstarved U2-OS (A) or U2-OS Bmi1-Py (B) cells pretreated with a p38 inhibitor (SB202190) and/or an ATM/ATR inhibitor (caffeine) before As (A) or Se (B) application. (C-D) Western analysis of confluent U2-OS cells treated with IR (C) and UV (D) where indicated minutes refer to the time-period between the stimulus and generation of protein extracts. Equal protein loading was validated by immunoblotting against actin (data not shown). 
A

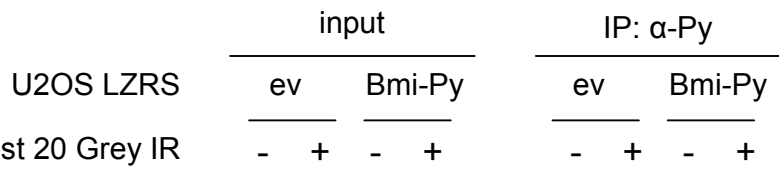

30 min post 20 Grey IR

IB: $\alpha-B m i$

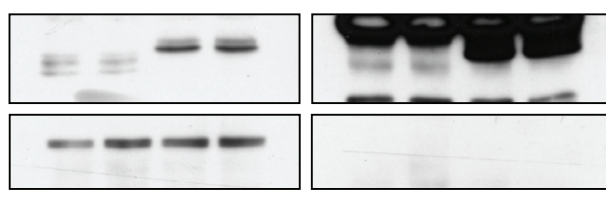

B

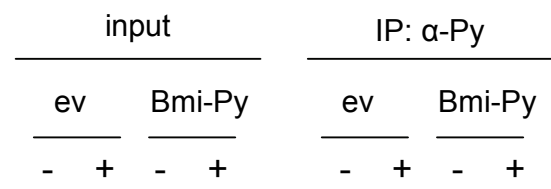

$60 \mathrm{~min} 100 \mathrm{mM}$ camptothecin

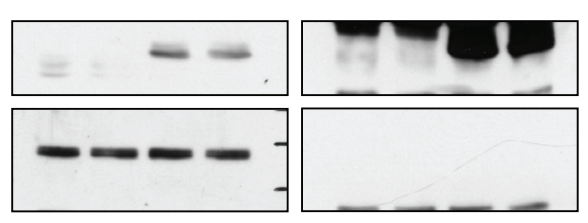

C

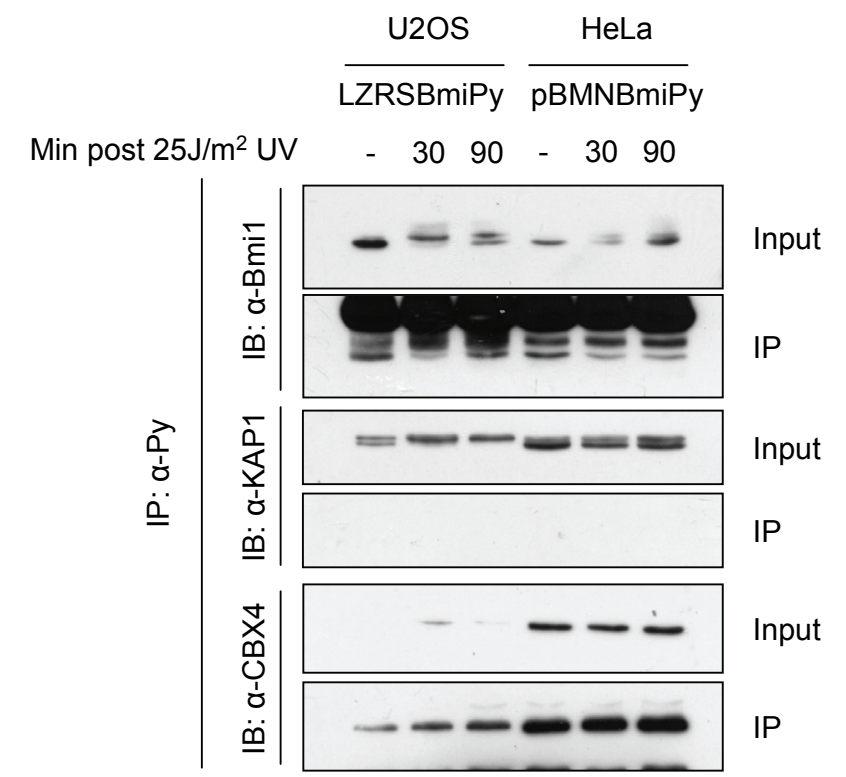

Figure 6.56. Double-strand DNA damage does not induce Bmi1-KAP1 association.

$(A-B)$ IP western analysis of U2-OS cells expressing Bmi1 with Py-tag (Bmi1-Py) or empty vector (EV). Confluent contact-inhibited cells were subjected to IR $(A)$ or camptothecin $(B)$ as indicated. IPs were performed using an antibody against the Py epitope. (C) Anti-Py IP western analysis of confluent U2-OS Bmi1-Py cells or HeLa Bmi1-Py cells treated with UV and harvested after various amounts of time. 


\section{Chapter 6}

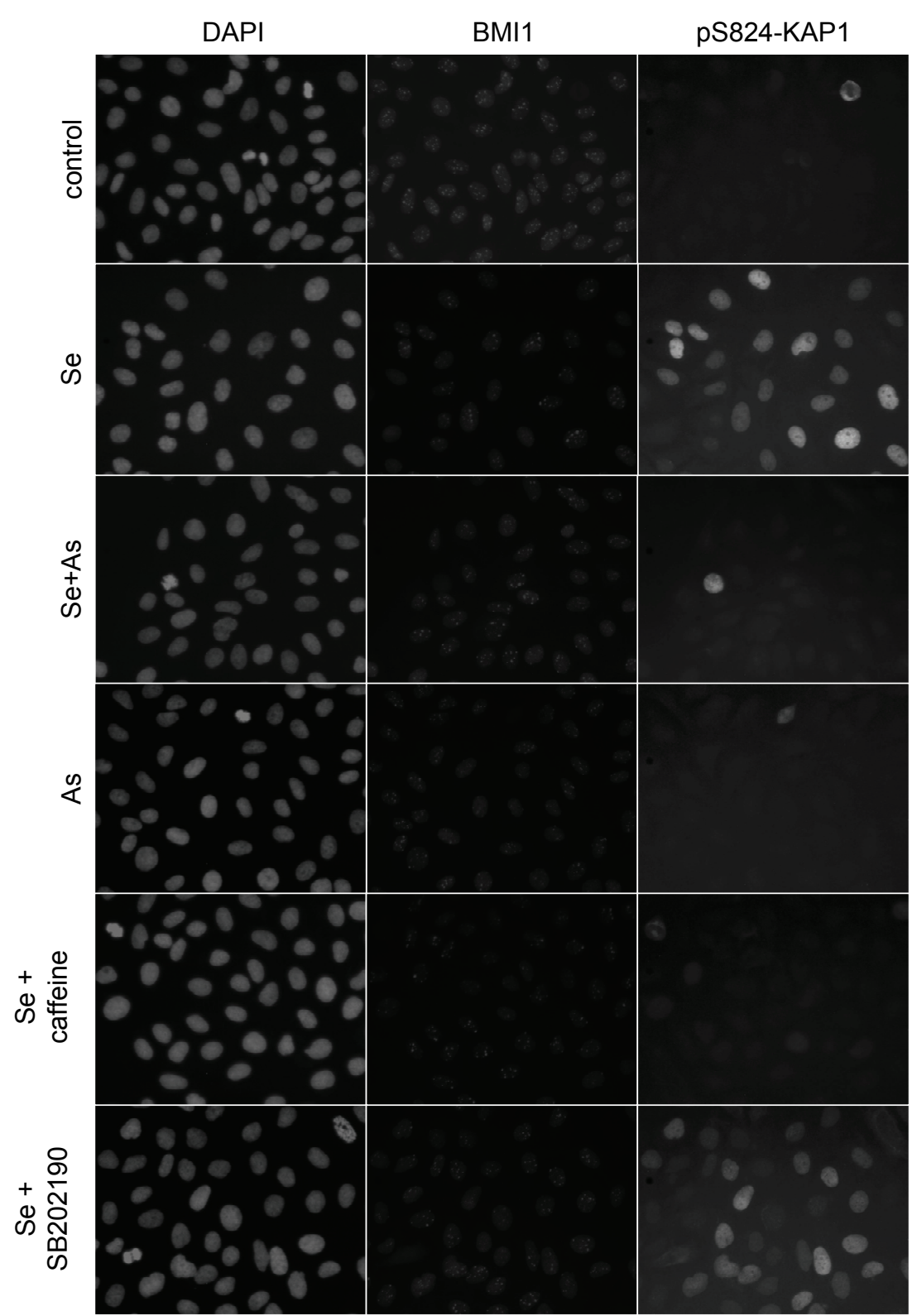

Figure 6.S7. Localization of BMI1 and KAP1 in stressed cells.

Immunofluorescence detecting BMI1 and PS824-KAP1 in serum-starved U2-OS cells incubated with indicated stimuli and inhibitors. See page 203 for colour print. 
A

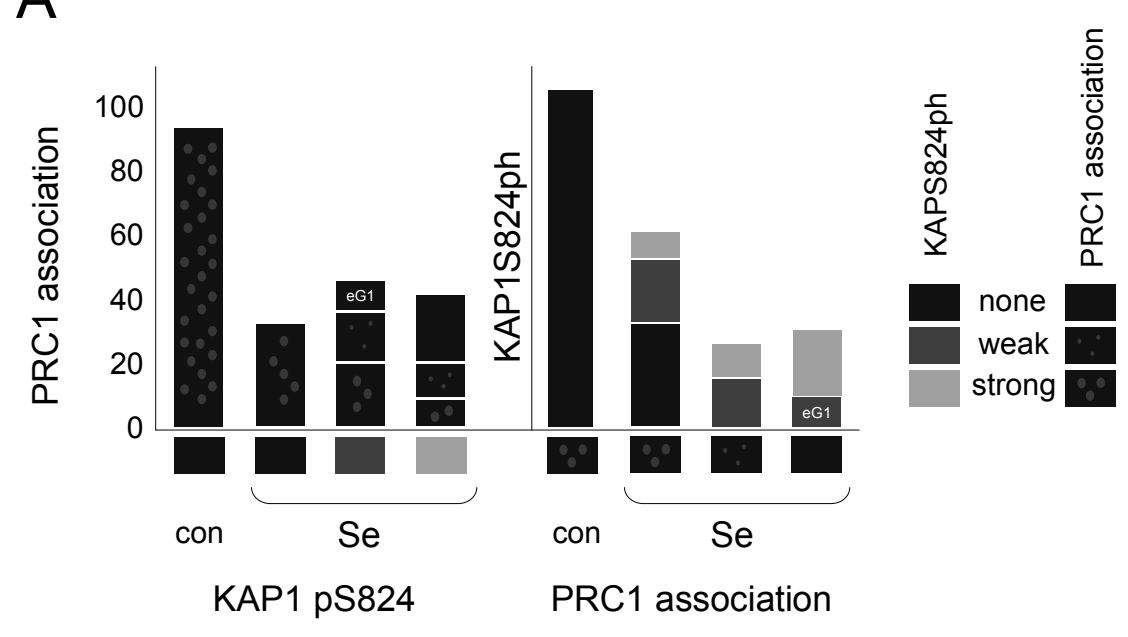

B

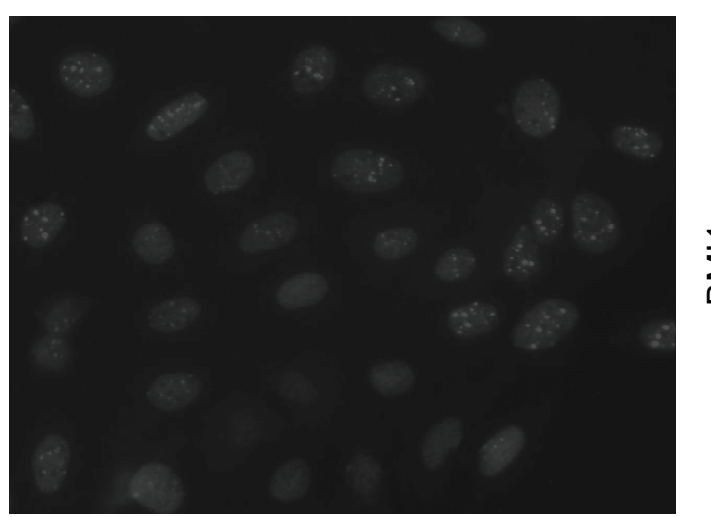

$\sum_{\infty}^{\doteqdot}$

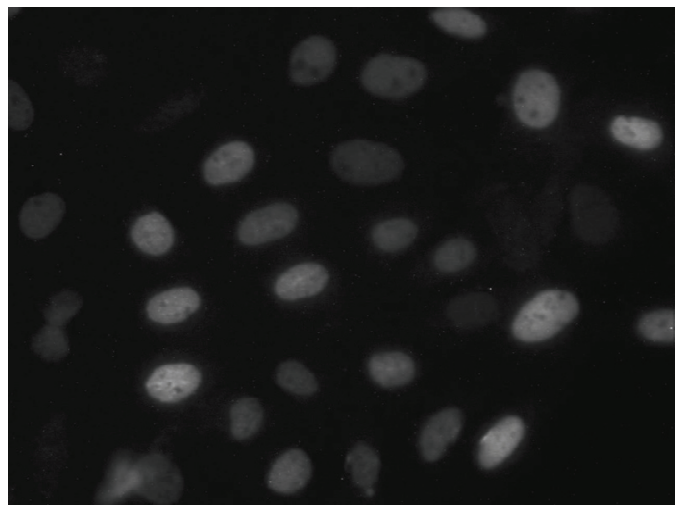

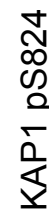

Figure 6.S8. BMI1 and pS824-KAP1 do not colocalize

(A) Scoring of PRC1 dotted staining pattern and pS824-KAP1 staining intensity in serum-starved U2-OS cells exposed as indicated to Se. A small number of small cells lacking PcG foci were probably in the early G1 phase of the cell-cycle (denoted as eG1). (B) Examples of scored fields. Immunofluorescence detection of Bmi1 and pS824-KAP1. See page 204 for colour print. 


\section{Chapter 6}

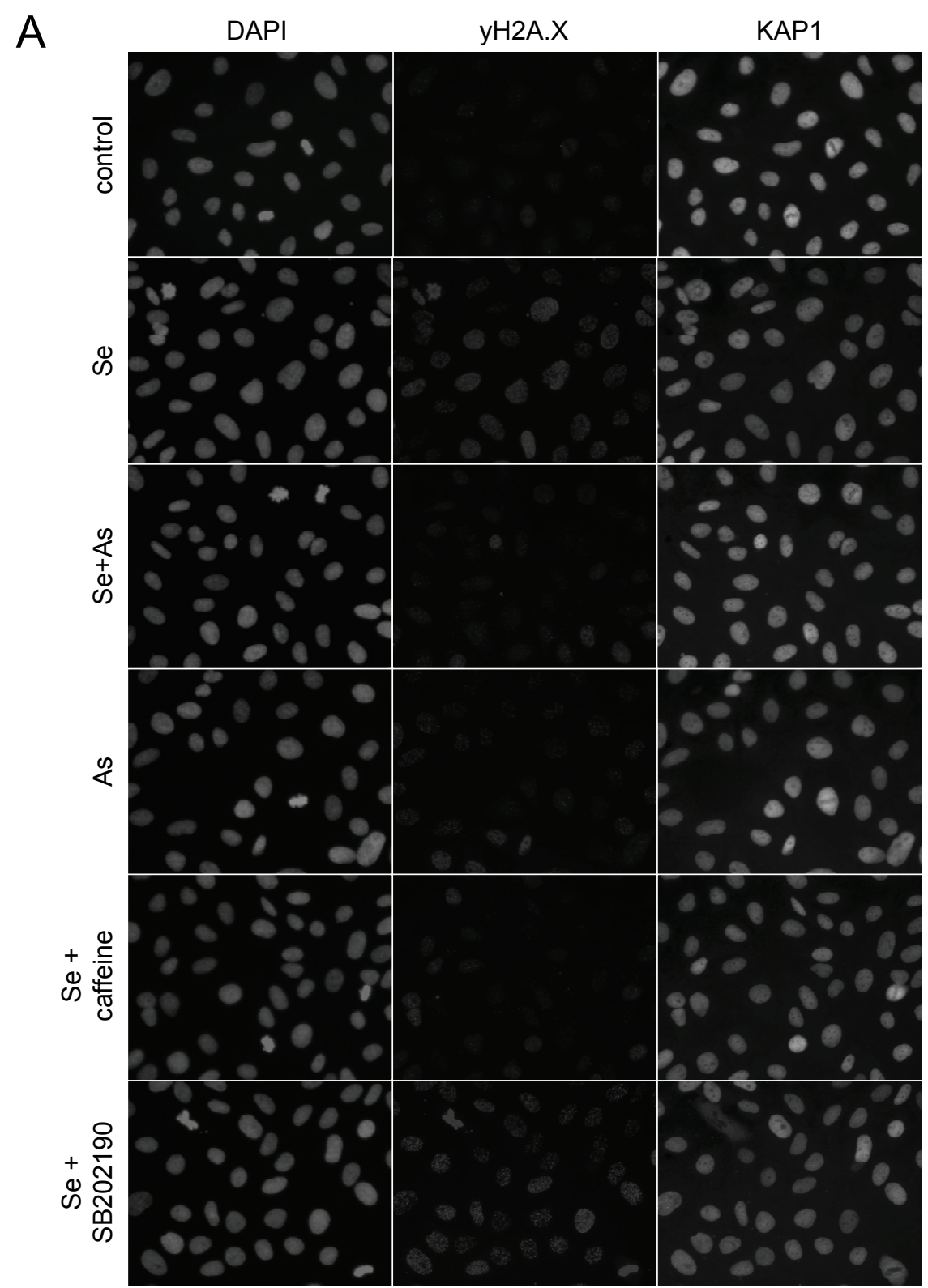

Figure 6.S9. Localization of DNA damage and KAP1 in stressed cells.

Immunofluorescence detecting (A) yH2A.X and KAP1 or (B) yH2A.X and pS824-KAP1 in serumstarved U2-OS cells incubated with indicated stimuli and inhibitors. See page 205 for colour print. 
B

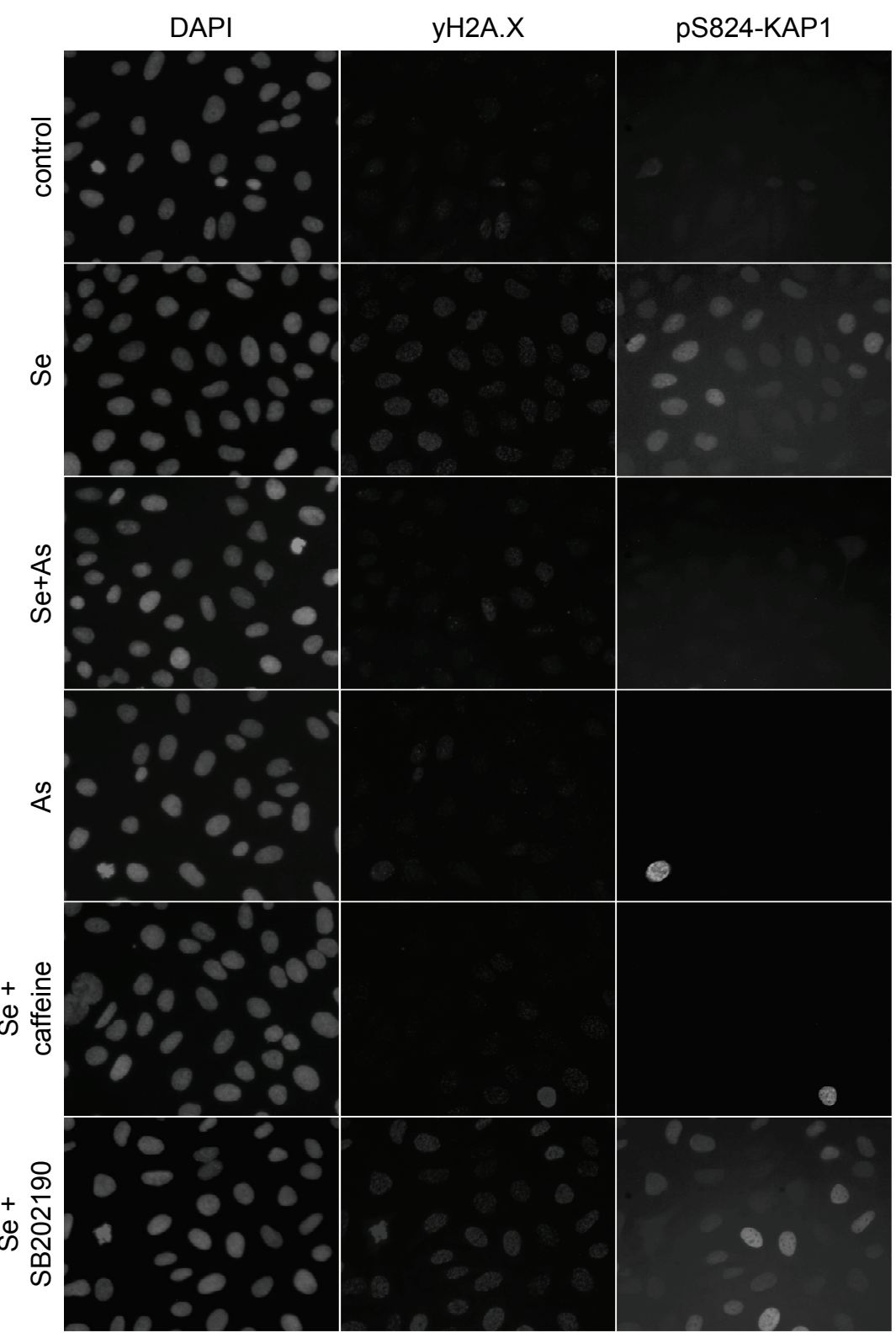

Figure 6.S9. Continued

See page 206 for colour print. 
Chapter 6

Table 6.S1. Mass spectrometric analysis of Bmi1-Py interacting proteins

\begin{tabular}{lllllll}
\hline \multirow{2}{*}{ Treatment } & Score & Protein & Da & cover (\%) & uniq pept. & total pept. \\
\hline - As & 547 & Bmi1 & 37254 & 22.2 & 6 & 9 \\
& 509 & PHC1 & 115996 & 9.9 & 6 & 6 \\
& 429 & RNF2 & 38088 & 24.1 & 6 & 9 \\
& 399 & RING1 & 42973 & 19.2 & 4 & 6 \\
& 368 & RYBP & 25065 & 22.8 & 3 & 3 \\
& 297 & PHC2 & 44862 & 11.9 & 4 & 5 \\
& 286 & CBX2 & 56388 & 11.1 & 4 & 4 \\
& 147 & CBX8 & 43483 & 10.3 & 3 & 3 \\
& 121 & PHC3 & 106910 & 2.5 & 2 & 2 \\
& 429 & KAP1 & 90247 & 12.3 & 6 & 6 \\
& 394 & RNF2 & 38088 & 19.9 & 5 & 6 \\
& 384 & PHC1 & 115996 & 8.6 & 5 & 5 \\
& 272 & CBX2 & 56388 & 11.1 & 4 & 4 \\
& 237 & Bmi1 & 37254 & 10.2 & 3 & 3 \\
& 237 & PHC2 & 44862 & 15.1 & 4 & 4 \\
& 201 & RYBP & 25065 & 18.9 & 2 & 3 \\
& 193 & CBX8 & 39893 & 14.1 & 4 & 4 \\
& 154 & RING1 & 42973 & 7.6 & 2 & 4 \\
\hline
\end{tabular}


Cell stress-induced association of PRC1 with KAP1

Table 6.S2. Identified PcG phosphorylation sites

\begin{tabular}{|c|c|c|c|c|c|}
\hline Organism & Protein & Accesion number & Total nr AA & Phospho-site & Described \\
\hline \multirow[t]{3}{*}{ Human } & CBX8 & Q9HC52 & $389 \mathrm{AA}$ & S110 & 47 \\
\hline & & & & S265 & 47 \\
\hline & & & & S311 & - \\
\hline \multirow[t]{7}{*}{ Human } & PHC1 & P78364 & $1004 \mathrm{AA}$ & S195 & - \\
\hline & & & & S645 & - \\
\hline & & & & S664 & 48 \\
\hline & & & & S669 & 48 \\
\hline & & & & S786 & - \\
\hline & & & & S895 & - \\
\hline & & & & T922 & - \\
\hline Human & $\mathrm{PHC2}$ & Q8IXKO & $858 \mathrm{AA}$ & S733 & 23 \\
\hline \multirow[t]{4}{*}{ Human } & $\mathrm{PHC3}$ & Q8NDX5 & $983 \mathrm{AA}$ & S315 & 47 \\
\hline & & & & T609 & $47,49-52$ \\
\hline & & & & S616 & $47,49-52$ \\
\hline & & & & S862 & - \\
\hline \multirow[t]{2}{*}{ Human } & RING1 & Q06587 & $406 \mathrm{AA}$ & S38 & 47,50 \\
\hline & & & & S229 & - \\
\hline \multirow[t]{3}{*}{ Mouse } & Bmi1 & P25916 & $324 \mathrm{AA}$ & S110 & - \\
\hline & & & & S251 & - \\
\hline & & & & S314 & - \\
\hline
\end{tabular}

Table 6.S3. Primer sequences for site-directed mutagenesis of Bmi1-Py

\begin{tabular}{lll}
\hline Mutation & Forward & Reverse \\
\hline T5A & GCATCGAACAGCCAGAATCAAGATC & GATCTTGATTCTGGCTGTTCGATGC \\
T5E & GCATCGAACAGAGAGAATCAAGATC & GATCTTGATTCTCTCTGTTCGATGC \\
T126A & GGAGAAGAGGATTATAGCTGATGATGAG & CTCATCATCAGCTATAATCCTCTTCTCC \\
T126E & GGAGAAGAGGATTATAGAGGATGATGAG & CTCATCATCCTCTATAATCCTCTTCTCC \\
T228A & GTTCGGCCAGCTTGCAAAAGAATG & CATTCTTTGCAAGCTGGCCGAAC \\
T228E & GTTCGGCCAGAGTGCAAAAGAATG & CATTCTTTGCACTCTGGCCGAAC \\
SS313314AA & GACCTCGAAAAGCAGCACTAAATGGGTCATC & GATGACCCATTTAGTGCTGCTTTTCGAGGTC \\
SS313314EE & GACCTCGAAAAGAAGAACTAAATGGGTCATC & GATGACCCATTTAGTTCTTCTTTTCGAGGTC \\
SS318319AA & ACTAAATGGGGCAGCAGCAACTTCATCTGGTGG & CCACCAGATGAAGTTGCTGCTGCCCCATTTAGT \\
SS318319EE & ACTAAATGGGGAAGAAGCAACTTCATCTGGTGG & CCACCAGATGAAGTTGCTTCTTCCCCATTTAGT \\
\hline
\end{tabular}



Chapter 7

General Discussion 
PcG proteins play a key role in repressing genes involved in development, differentiation and stem cell self renewal ${ }^{28-30}$. Little is known about the mechanism by which PcG/chromatin-binding is regulated. Based on earlier findings that PcG-phosphorylation correlates with chromatin-dissociation from late-S-phase throughout M-phase ${ }^{27}$, we hypothesized that phosphorylation of PcG proteins plays an important role in PcG dissociation from chromatin. We speculated that PcG-dissociation is required for cells to change their transcriptome and hence, cell fate. In this thesis various techniques have been implemented to determine phosphorylation sites on PcG proteins, the kinases responsible for PRC1 phosphorylation, potential changes of PRC1 complex composition upon phosphorylation and the biological relevance of PcG phosphorylation.

\section{Phosphorylation sites of PRC1 proteins}

Several approaches were taken to identify PRC1 protein phosphorylation. Experiments relying on a candidate approach, in which 7 potential phosphorylation sites of Bmi1 were mutated to alanine $(A)$ or glutamic acid $(E)$ residues, revealed that Bmi1 could still be phosphorylated, indicating that additional phosphorylation sites exist at other Bmi1 residues (Chapter 6). Another strategy we used was an in vitro kinase (IVK) assay with kinase MK3 on PRC1 peptides (Chapter 5). Several phosphorylation sites were detected on Phc2, Cbx4 and Bmi1 peptides. By combining immunoprecipitation (IP) experiments with mass spectrometry (MS) we have identified in total 20 phosphorylation sites on $\mathrm{CBX} 8, \mathrm{PHC1}, \mathrm{PHC} 2, \mathrm{PHC} 3, \mathrm{RING1}$ and Bmi1 proteins (Chapter 6). Of those 20, 9 had been previously described and 11 are newly identified. Until now in total 118 human and 31 murine PcG phosphorylation sites have been detected, including ours (Chapter 3). This indicates that PcG proteins are heavily phosphorylated. Since the majority of PcG phosphorylation sites has been identified in large-scale phospho-proteome analyses, not specifically aimed at PcG proteins, the biological relevance of those phosphosites has thus far not been addressed. Interestingly, we have detected Bmi1S314 phosphorylation independently by IVK and MS. Furthermore, the putative CBX4-S350 phospho-site, as detected by our IVK, is conserved on its human homologue CBX4 and a target of phosphorylation ${ }^{31}$ (S347; chapter 3). Thus, our findings confirm and extend the relevance of published data.

\section{Kinases involved in PcG phosphorylation}

Using a yeast-two hybrid assay we identified MK3 (MAPKAPK3, 3pK) as a direct interactor of $\mathrm{PHC} 2 / \mathrm{HPH} 2$ (Chapter 4). IPs confirmed MK3 as a genuine interactor of the PRC1 complex (Chapter 4). Recombinant MK3 phosphorylates PcG 
proteins in vitro (Chapter 5) and mass spectrometric analysis confirmed at least one of these phosphorylation sites in vivo (Chapter 6). Independently we established that MK3 is present at PcG target genes using Chromatin immunoprecipitation experiments (ChIP) and that part of the PRC1 complex dissociates from chromatin upon MAPK-signaling (Chapter 5). MK3 is not the only MAPKAPK that associates with PRC1 proteins. MAPKAPK2 (MK2) interacts with $\mathrm{HPH} 2$ in a yeast two-hybrid system ${ }^{32}$. Recently MK2 was also shown to maintain self-renewal capacity of hematopoietic stem cells, which was dependent on the binding of MK2 to $\mathrm{PHC} / \mathrm{HPH}^{33}$. Since MK2 and MK3 share most of their phosphorylation targets ${ }^{34,35}$, it is likely that MK2 is also a PRC1 kinase.

By using specific inhibitors we have established that P38, ATM/ATR, PKC, JNK, and GSK3ß signaling pathways all contribute to Bmi1 phosphorylation under certain conditions. PKC has already been described as a PcG related kinase ${ }^{36,37}$ (Chapter 3). Whether these kinases directly phosphorylate PRC1 proteins is currently not known. It does however substantiate the notion that multiple kinases are involved in PcG protein phosphorylation and that possibly sequential (i.e. progressive and interdependent) phosphorylation events takes place.

\section{PcG complex composition changes upon phosphorylation}

Phosphorylation of PCG proteins also appears to affect PRC1 complex composition and specific protein-protein interactions. Several observations underscore this hypothesis. First of all immuno-fluorescence studies showed different staining patterns for PHC1 compared to other PRC1 proteins upon arsenite treatment ${ }^{38}$ (Chapter 4). PcG-chromatin association, normally visible in G1-phase cells, is released upon arsenite treatment. In contrast to CBX4, RING1 and RNF2, whose chromatin association appears to be lost, PHC proteins appear to redistribute in the nucleus ${ }^{38}$ (Chapter 4). Although the involved posttranslational modifications (PTMs) are currently not fully mapped, the relocation is a phosphorylation-induced event. Secondly, PHC1/2 proteins are not stably associated to the PRC1 core complex as other PcG members under conditions of increased phosphorylation, whereas for instance levels of coprecipitated $\mathrm{CBX} 4$ are unchanged. Instead $\mathrm{PHC} 1 / 2$ proteins appear to show increased heterotypical interaction (Chapter 6). Thirdly, PHC and CBX show distinct chromatin enrichment/occupation profiles in response to physiological stimuli in ChIP studies (Chapter 5). Whereas CBX8 is mostly found on genes where also $\mathrm{H} 3 \mathrm{~K} 27 \mathrm{me} 3$ is present, $\mathrm{PHC1}$ enrichment profiles closely resemble those for the PHC1 interacting kinase MK3 (Chapter 5). Taken together, our own and other published observations clearly support differential regulation within the PRC1 complex upon activation of signaling cascades, implicitly suggesting 
differential roles for and/or regulation of PHC proteins and other members of the PRC1 complex in response to cellular signaling.

Importantly, we also identified a new interaction partner of the PRC1 complex, KAP1. The KAP1/PRC1 interaction is dependent on phosphorylation events, in our experimental systems, induced by the cell stressors arsenite and selenite (Chapter 6). Both stressors show an increased association of Bmi1-KAP1 by inhibition of PKC and JNK signaling and a reduced association by inhibition of GSK3ß signaling. However, inhibition of p38 and ATM/ATR signaling reduces binding only in response to Se, not to As. Our findings clearly demonstrate that multiple kinase pathways target PRC complexes and substantiate our previous findings. The biological relevance of the KAP1-PRC1 interaction is as of yet elusive. As both KAP1 and PcG proteins play a role in transcriptional repression, the interaction could have an effect on repression of certain genes. Indeed KAP1 knockdown enhances mitogen-induced expression of a PcG target gene, ATF3, suggestive of some form of co-repression. Surprisingly, ATF3 was not identified as a KAP1 target in promoter tiling array experiments ${ }^{39}$ (Chapter 6$)$. This could relate to limited analysis in the reported study (many regulatory elements can be found in intragenic regions and at locations more remote from the transcription start site). It is possible, however, that KAP1 fulfills a function in chromatin modulation at a level which is currently not understood. Cleary several functions converge in KAP1: it is a reported co-repressor, and has a distinct function in damaged heterochromatic DNA repair ${ }^{40}$. Likewise PRCs unite transcriptional regulation with DNA replication and perhaps also DNA damage responses ${ }^{41}$ 42. Furthermore, KAP1 could be involved in determining PRC1 protein stability: KAP1 is a sumo E3 ligase ${ }^{43}$, and has a RING finger, a domain which is often involved in ubiquitylation ${ }^{44}$. Our preliminary data indicate that Se and As induce proteolytic breakdown of some PRC1 proteins. Also, a phosphomimic form of Bmi1 appears instable; this is enhanced by Se exposure (Chapter 6 and unpublished observations). A possible link between KAP1 and destabilization of Bmi1 is therefore likely, although at this moment speculative.

\section{Control of chromatin association of PcG proteins}

The correlation between PCG phosphorylation and chromatin dissociation is currently widely accepted, both in a cell-cycle dependent and cell-cycle independent context ${ }^{27,38,45}$. The exact molecular mechanism underlying the effect of phosphorylation on PcG/chromatin binding is currently not known. However, several hypothetical mechanisms can be formulated by analogy to another histone binding protein family, HP1 (heterochromatin protein 1). Three HP1 isoforms exist (HP1 $\alpha, \beta$ and $\gamma$, respectively also referred to as CBX5, CBX1 and $(\mathrm{CBX} 3$ ), which associate with constitutive heterochromatin and regions of 
facultative heterochromatin ${ }^{46}$. HP1 and PcG CBX proteins share a chromodomain, which interacts with specific histone 3 trimethyl-marks. HP1 proteins specifically interact with $\mathrm{H} 3 \mathrm{~K}_{\mathrm{mme}}{ }^{47,}{ }^{48}$, whereas the PCG CBX homologues display differential binding to both H3K9me3 and H3K27me3 in vitro $^{49}$. Both chromodomain protein classes are released from chromatin during mitosis. HP1 dissociates from chromatin in M-phase, despite unchanged H3K9me3 levels. Phosphorylation on $\mathrm{H} 3 \mathrm{~S} 10$ adjacent to the K9me3 mark strongly reduces HP1 binding in vitro and releases HP1 from chromatin in vivo. The kinase responsible for the transient $\mathrm{M}$-phase related phosphorylation is Aurora kinase $\mathrm{B}^{50}$. As release of HP1 occurs without concomitant loss of H3K9 trimethylation, rather than de-methylation of the binding mark, phosphorylation was suggested to act as part of a "binary switch" mechanism of the "methyl/phos"-type: phosphorylation of a site adjacent to a methyl mark leads to induced loss of binding of a factor or complex, normally engaged by the methyl mark ${ }^{51,52}$. It has been suggested that this switching mechanism is not limited to the $\mathrm{K} 9 / \mathrm{S} 10$ region of $\mathrm{H} 3$, but may be more widespread: both $\mathrm{K} 9$ and K27 in histone 3 reside in very similar amino acid contexts (ARKS); hence this switching mechanism may be involved in controlling $\mathrm{CBX}$ binding to $\mathrm{H} 3$ as well (Fig. 7.1). Indeed, H3S28 is also phosphorylated in M-phase ${ }^{53,54}$. In addition we have reported a close correlation between PRC1 dissociation and H3S28ph, whereas this was not seen in relation to H3S10ph (Chapter 4) ${ }^{38}$. The dynamic control of protein binding by "methyl/phos" switching also provides a tentative explanation for how HP1 and CBX binding can be correctly re-established the end of mitosis. H3-(ARK)S-phosphorylation also occurs downstream of signaling, in a cell-cycle independent fashion. Physiological stimuli studied include arsenite, ultraviolet B, TPA and anisomycin. Arsenite induced H3S10ph is dependent on Akt1, extracellular signal-regulated kinase 2 (ERK2) and ribosomal S6 protein kinase 2 (RSK2), but not on mitogen and stress-activated protein kinase 1 (MSK1) $)^{55}$. Exposure of cells to ultraviolet $B(U V B)$ induces H3S10ph and $\mathrm{H} 3 \mathrm{~S} 28 \mathrm{ph}$, albeit with different kinetics. UVB induced phosphorylation of H3S10 is dependent on ERK and p38 MAP kinases ${ }^{56}$; H3S28 is targeted by ERK, p38, JNK1-MAPK signaling and by MSK1 ${ }^{57,}{ }^{58}$. Mitogenic signaling by TPA and stress signaling by anisomycin, via the ERK and p38 pathways respectively, lead to the phosphorylation of H3S10 and H3S28 by MSK2 and, to a lesser extent, MSK1 ${ }^{59}$. Hence, the larger family of MSK, ERK and RSK kinases appear to integrate regulation of gene expression at several functional levels by targeting transcription factors, chromatin binding complexes and nucleosomal components. Strikingly, the subnuclear distribution of H3S10ph is different from H3S28ph, they form distinct nuclear foci ${ }^{60,}{ }^{61}$. Even though MSK1 can phosphorylate $\mathrm{H} 3 \mathrm{~S} 10$ and $\mathrm{S} 28$ within the same peptide in vitro, this apparently does not happen in vivo ${ }^{61}$. The spatial distribution of these H3 PTMs is likely 
controlled by kinase recruitment (by e.g. HP1 or PcG complexes), substrate availability, and local regulation of kinase and phosphatase activity.

A combinatorial effect of PTMs on histone and non-histone proteins can be predicted. DNA damage induces HP1-ß T51 phosphorylation by casein kinase 2 (CK2), which mobilizes HP1- $B$, and facilitates H2AX phosphorylation ${ }^{62}$. The dissociation mechanism involves disruption of hydrogen bonds required for HP1- $B$ chromodomain folding around H3K9me3. Sequence alignment of HP1 and PCG CBX proteins reveals that T51 is conserved in human and mouse CBX1-8 proteins and in HP1 and Pc of the fruitfly (in human and murine CBX2 this amino acid is a serine). Although CBX protein phosphorylation at these conserved residues has not been reported yet, it is possible that, by analogy to HP1, these residues function in release of methyl-binding interfaces (Fig. 7.1). Interestingly, two recent studies identified subunits of CK2 as interactors of RNF2 and CBX8 ${ }^{63}$, ${ }^{64}$. It is currently unclear whether and how CK2 plays a role in complex dissociation. Likewise, determination of which (combinations of) phospho-sites within and outside chromo-boxes and other domains control PcG proteinprotein and PRC-chromatin interactions will be subject of future research.

Another level of regulation of PCG CBX chromatin binding occurs via the establishment and erasure of histone methylation. EZH2 of the PRC2 complex achieves H3K27 tri-methylation, to which PRC1 can bind. For a long time demethylating enzymes for this and every other histone methylation mark were unknown. Recently numerous histone demethylases have been identified, that display specificity for the position (e.g. H3K4 or H3K9) and the number of methyl groups (mono- di- or tri-methylation) ${ }^{65}$. UTX and JMJD3 have been identified as H3K27me2/3 demethylases ${ }^{66-70}$. Recruitment of UTX to promoters of the anterior genes of the HOXA and HOXB clusters during retinoic acid-induced differentiation of NT2/D1 cells leads to the loss of H3K27me3, SUZ12 and EZH2 from these promoters ${ }^{66,71}$. This indicates that a histone demethylase can regulate the chromatin association of PcG proteins. Finally, published data also suggest that the H3K27trimethyl mark per se is not sufficient for chomobox recruitment in situ, as in Drosophila cells loss of dRing and hence H2AK119Ub, also abolished Pc binding ${ }^{72}$. The PRC1 protein RNF2, in collaboration with Bmi1, acts as a ubiquitin E3-ligase for H2AK119 ${ }^{72-75}$; the H2AK119ub1 mark is closely associated with polycomb repressive action ${ }^{72-75}$.

Ultimately the binding of PRC1 to chromatin is determined by the interplay of multiple factors, including histone methylation, histone phosphorylation, PcG CBX protein phosphorylation and possibly other PRC1 phosphorylation. This in turn is controlled by signal transduction cascades influencing the expression, localization and activity of HMTs, HDMs, kinases and phosphatases. Future research will identify which enzymes are involved and which genes are then 
differentially regulated, depending on the biological context of the stimulus (e.g. stress or mitosis).

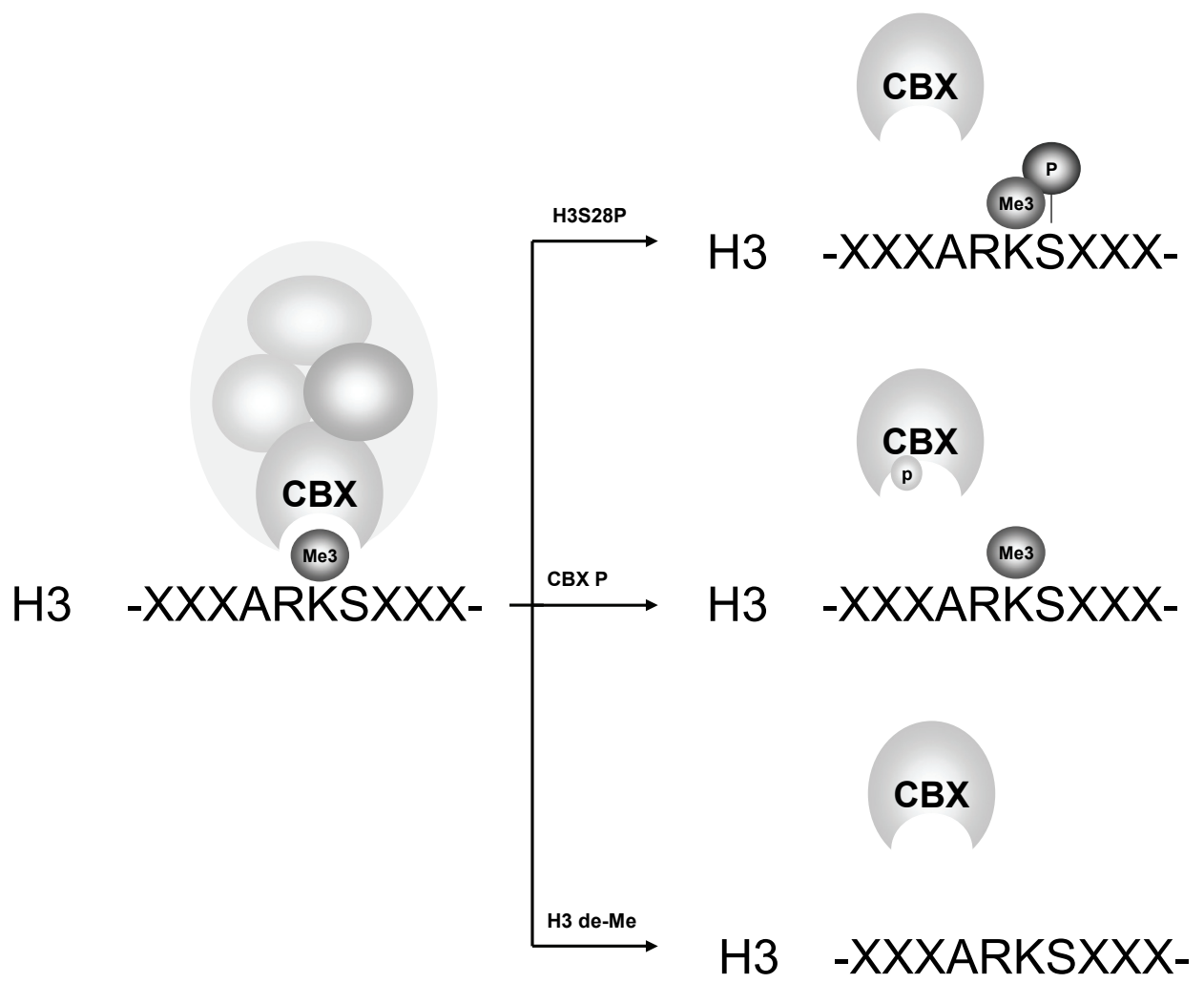

Figure 7.1. Proposed mechanisms for dissociation of PRC1 from chromatin.

The chromodomain of $\mathrm{CBX}$ interacts with $\mathrm{H} 3 \mathrm{~K} 27$ me3. Loss of $\mathrm{H} 3 \mathrm{~K} 27 \mathrm{me} 3$ or phosphorylation of H3S28 and/or conserved residue(s) within the chromodomain of CBX may contribute to chromatin dissociation.

\section{Future research directions}

Although we have identified phosphorylation sites on PcG proteins, the limitations of the used techniques are such that we are unable to exactly determine which phosphorylation event was induced by what stimulus or kinase. The development of antibodies, recognizing specific PcG phospho-sites would be of great help to clarify this. The proposed approach, however, will not be trivial, as there are more than 100 PcG-phosphorylation sites to start off with. By implementing quantitative methods, like stable isotope labeling by amino acids in cell culture (SILAC), a more detailed overview could be extracted of the PcG phospho-proteome ${ }^{76}$. MS, in combination with the use of specific kinase inhibitors could in principle help narrow down and identify the number 
of putatively involved kinases. If then these kinases and phosphorylation sites were further analyzed by the in vitro kinase strategy on peptide arrays, the PcG kinome-phosphoproteome could be further unraveled. Biochemical analysis, including ChIP assays in combination with transcriptional regulation of PcG gene targets and in vitro ubiquitylation assays will be pivotal in mapping the biological consequences of PRC-phosphorylation for transcriptional repression. Finally, functional assays involving (combinations of) phospho-mutant PRC proteins will ultimately help establish exact molecular mechanisms. To dissect these mechanisms it is important to map common targets of kinases and PcG proteins in a genome-wide approach, for instance by ChIP-on-chip or ChIP-seq analysis. Common targets would represent likely candidate genes for regulation by PcG phosphorylation by specific upstream kinase signaling pathways.

Many questions regarding the PRC1-KAP1 interaction still remain. It is not clear yet which region within KAP1 is responsible for the interaction and Bmi1 is not necessarily the PRC1 protein KAP1 interacts with. Immunoprecipitations performed with deletion mutants of KAP1 could solve this issue. The question whether KAP1 functions as a sumo or ubiquitin E3 ligase for PRC1 proteins is still unresolved, but should be addressed in future experiments.

\section{Conclusions}

The research in this thesis has started to unravel the dynamics of PcG phosphorylation. Combined, these recent observations begin to show that signaling, which triggers downstream phosphorylation events, affects subcellular localization, protein-interactions within complexes, enzymatic activity and chromatin-association of several PcG proteins. Further characterization and validation of these phosphorylation sites will increase our understanding of the cellular conditions under which PcG phosphorylation take place, which kinases and phosphatases are involved and how cells use these pathways to modulate chromatin structure to allow biologically appropriate responses.

PcG proteins are important for regulating embryonic development, cell proliferation and stem cell biology and PcG proteins are deregulated in many cancers (Chapter 2). Therefore regulation of PcG function by post-translational modification is likely to have an important impact on these processes. MK2 was recently reported to control self-renewal of hematopoietic stem cells; this is dependent on the interaction of MK2 and PRC1 ${ }^{33}$. This finding supports the notion that the interaction of a kinase with PcG proteins is a key determinant of stem cell biology. Whether MK3 is involved in stem cell self renewal needs to be addressed in future studies. Furthermore MK3 is involved in cancer development. The MK3 locus is often deleted in cancer and MK3 mutations 
have been reported to contribute to oncogenesis ${ }^{77,78}$. Although this would appear to qualify MK3 as a gene with potential tumor suppressive capacity, and we show that indeed MK3 has a negative effect on cell proliferation and proliferative life span, our studies suggest these adverse effects on cell proliferation may occur via processes akin to oncogenic signaling (Chapter 5). Recently, potential driver mutations in MK3 were identified, consistent with an oncogenic gain-of-function ${ }^{77}$. However the potential role in tumorigenesis of these mutations awaits functional validation. Interestingly, MK3 activation activates dormant check-points in cancer cells (i.a. cervical carcinoma, osteosarcoma). This suggests MK3 and efferent/afferent signaling modules could be targeted for therapeutic purposes. Loss of PRC1 members often correlates with reduced proliferative life span. Conversely, overexpression of PRC1 members is tumorigenic. We have shown that phosphorylation of PRC1 complexes and subsequent loss of chromatin-association, may be functionally equivalent to PRC1 loss-of-function. Arsenic and selenite both reduce PcG association via increased phosphorylation (Chapters 4 and 6). Arsenic has been applied as chemotherapy in diverse cancers ${ }^{79-81}$. We speculate that the antioncogenic properties of arsenite and possibly related non-metallic bivalent ions may in part mechanistically involve Polycomb Group proteins. This novel idea may open further avenues for development of anticancer therapies.

It is expected that regulation of PcG function by phosphorylation, which has been studied in this thesis on a cellular level, contributes to proper development on an organismal level. The relevance of post-translational modifications of PcG proteins and the effect of signaling to PcG proteins are relevant topics in the field of gene-environment interactions that in addition to normal embryogenesis will contribute to our understanding of cancer and other Western-type diseases. 


\section{References}

1. Kornberg RD, Lorch Y. Twenty-five years of the nucleosome, fundamental particle of the eukaryote chromosome. Cell. Aug 6 1999;98(3):285-294.

2. Luger K, Richmond TJ. The histone tails of the nucleosome. Curr Opin Genet Dev. Apr 1998;8(2):140-146.

3. Goldberg AD, Allis CD, Bernstein E. Epigenetics: a landscape takes shape. Cell. Feb 23 2007;128(4):635-638.

4. Avner P, Heard E. X-chromosome inactivation: counting, choice and initiation. Nat Rev Genet. Jan 2001;2(1):59-67.

5. Zaratiegui M, Irvine DV, Martienssen RA. Noncoding RNAs and gene silencing. Cell. Feb 23 2007;128(4):763-776.

6. Klose RJ, Bird AP. Genomic DNA methylation: the mark and its mediators. Trends Biochem Sci. Feb 2006;31(2):89-97.

7. Bernstein BE, Meissner A, Lander ES. The mammalian epigenome. Cell. Feb 23 2007;128(4):669-681.

8. Kouzarides T. Chromatin modifications and their function. Cell. Feb 23 2007;128(4):693-705.

9. Strahl BD, Allis CD. The language of covalent histone modifications. Nature. Jan 6 2000;403(6765):41-45.

10. van Lohuizen M. Functional analysis of mouse Polycomb group genes. Cell Mol Life Sci. Jan 1998;54(1):71-79.

11. Cao R, Wang L, Wang $\mathrm{H}$, et al. Role of Histone $\mathrm{H} 3$ Lysine 27 Methylation in Polycomb-Group Silencing. Science. 2002;26:1039-1043.

12. Muller J, Hart CM, Francis NJ, et al. Histone Methyltransferase Activity of a Drosophila Polycomb Group Repressor Complex. Cell. 2002;111(2):197-208.

13. Czermin B, Melfi R, McCabe D, et al. Drosophila Enhancer of Zeste/ESC Complexes Have a Histone H3 Methyltransferase Activity that Marks Chromosomal Polycomb Sites. Cell. 2002;111(2):185-196.

14. Kuzmichev A, Nishioka K, Erdjument-Bromage $H$, et al. Histone methyltransferase activity associated with a human multiprotein complex containing the Enhancer of Zeste protein. Genes Dev. Nov 15 2002;16(22):2893-2905.

15. Vire E, Brenner C, Deplus R, et al. The Polycomb group protein EZH2 directly controls DNA methylation. Nature. Feb 16 2006;439(7078):871-874.

16. van der Vlag J, Otte AP. Transcriptional repression mediated by the human polycomb-group protein EED involves histone deacetylation. Nat Genet. Dec 1999;23(4):474-478.

17. Cha TL, Zhou BP, Xia W, et al. Akt-mediated phosphorylation of EZH2 suppresses methylation of lysine 27 in histone H3. Science. Oct 14 2005;310(5746):306-310.

18. Higa LA, Wu M, Ye T, et al. CUL4-DDB1 ubiquitin ligase interacts with multiple WD40-repeat proteins and regulates histone methylation. Nat Cell Biol. Nov 2006;8(11):1277-1283.

19. Levine SS, Weiss A, Erdjument-Bromage $\mathrm{H}$, et al. The core of the polycomb repressive complex is compositionally and functionally conserved in flies and humans. Mol Cell Biol. Sep 2002;22(17):6070-6078. 
20. Alkema MJ, Bronk M, Verhoeven $\mathrm{E}$, et al. Identification of Bmi1-interacting proteins as constituents of a multimeric mammalian polycomb complex. Genes Dev. Jan 15 1997;11(2):226-240.

21. Min J, Zhang $Y, X u$ RM. Structural basis for specific binding of Polycomb chromodomain to histone $\mathrm{H} 3$ methylated at Lys 27. Genes Dev. Aug 1 2003;17(15):1823-1828.

22. Fischle $\mathrm{W}$, Wang $\mathrm{Y}$, Jacobs $\mathrm{SA}$, et al. Molecular basis for the discrimination of repressive methyl-lysine marks in histone $\mathrm{H} 3$ by Polycomb and HP1 chromodomains. Genes Dev. Aug 1 2003;17(15):1870-1881.

23. Cao R, Tsukada YI, Zhang Y. Role of Bmi-1 and Ring1A in H2A Ubiquitylation and Hox Gene Silencing. Mol Cell. Dec 22 2005;20(6):845-854.

24. de Napoles M, Mermoud JE, Wakao R, et al. Polycomb Group Proteins Ring1A/B Link Ubiquitylation of Histone $\mathrm{H} 2 \mathrm{~A}$ to Heritable Gene Silencing and X Inactivation. Developmental Cell. 2004/11 2004;7(5):663-676.

25. Wang $\mathrm{H}$, Wang $\mathrm{L}$, Erdjument-Bromage $\mathrm{H}$, et al. Role of histone $\mathrm{H} 2 \mathrm{~A}$ ubiquitination in Polycomb silencing. Nature. Sep 22 2004;431:873-878.

26. Sewalt RG, Lachner $M$, Vargas $M$, et al. Selective interactions between vertebrate polycomb homologs and the SUV39H1 histone lysine methyltransferase suggest that histone H3-K9 methylation contributes to chromosomal targeting of Polycomb group proteins. Mol Cell Biol. Aug 2002;22(15):5539-5553.

27. Voncken JW, Schweizer D, Aagaard L, et al. Chromatin-association of the Polycomb group protein BMI1 is cell cycle-regulated and correlates with its phosphorylation status. J Cell Sci. Dec 1999;112 ( Pt 24):4627-4639.

28. Boyer LA, Plath K, Zeitlinger J, et al. Polycomb complexes repress developmental regulators in murine embryonic stem cells. Nature. May 18 2006;441(7091):349353.

29. Bracken AP, Dietrich N, Pasini D, et al. Genome-wide mapping of Polycomb target genes unravels their roles in cell fate transitions. Genes Dev. May 1 2006;20(9):1123-1136.

30. Lee TI, Jenner RG, Boyer LA, et al. Control of developmental regulators by Polycomb in human embryonic stem cells. Cell. Apr 21 2006;125(2):301-313.

31. Dephoure N, Zhou C, Villen J, et al. A quantitative atlas of mitotic phosphorylation. Proc Natl Acad Sci U S A. Aug 5 2008;105(31):10762-10767.

32. Yannoni YM, Gaestel M, Lin LL. P66(ShCA) interacts with MAPKAP kinase 2 and regulates its activity. FEBS Lett. Apr 23 2004;564(1-2):205-211.

33. Schwermann J, Rathinam C, Schubert M, et al. MAPKAP kinase MK2 maintains selfrenewal capacity of haematopoietic stem cells. Embo J. Apr 162009.

34. Gaestel M. MAPKAP kinases - MKs - two's company, three's a crowd. Nat Rev Mol Cell Biol. Feb 2006;7(2):120-130.

35. Ronkina N, Kotlyarov A, Gaestel M. MK2 and MK3--a pair of isoenzymes? Front Biosci. 2008;13:5511-5521.

36. Fujisaki S, Ninomiya $\mathrm{Y}$, Ishihara $\mathrm{H}$, et al. Dimerization of the Polycomb-group protein Mel-18 is regulated by PKC phosphorylation. Biochem Biophys Res Commun. Jan 3 2003;300(1):135-140.

37. Gong Y, Wang X, Liu J, et al. NSPc1, a mainly nuclear localized protein of novel PcG family members, has a transcription repression activity related to its PKC phosphorylation site at S183. FEBS Lett. Jan 3 2005;579(1):115-121. 
38. Voncken JW, Niessen $\mathrm{H}$, Neufeld B, et al. MAPKAP kinase 3pK phosphorylates and regulates chromatin association of the polycomb group protein Bmi1. J Biol Chem. Feb 18 2005;280(7):5178-5187.

39. O'Geen H, Squazzo SL, lyengar S, et al. Genome-wide analysis of KAP1 binding suggests autoregulation of KRAB-ZNFs. PLoS Genet. Jun 2007;3(6):e89.

40. Goodarzi AA, Noon AT, Deckbar D, et al. ATM signaling facilitates repair of DNA double-strand breaks associated with heterochromatin. Mol Cell. Jul 25 2008;31(2):167-177.

41. Liu J, Cao L, Chen J, et al. Bmi1 regulates mitochondrial function and the DNA damage response pathway. Nature. Apr 292009.

42. O'Dor E, Beck SA, Brock HW. Polycomb group mutants exhibit mitotic defects in syncytial cell cycles of Drosophila embryos. Dev Biol. Feb 15 2006;290(2):312-322.

43. Ivanov AV, Peng $\mathrm{H}$, Yurchenko $\mathrm{V}$, et al. PHD domain-mediated E3 ligase activity directs intramolecular sumoylation of an adjacent bromodomain required for gene silencing. Mol Cell. Dec 14 2007;28(5):823-837.

44. Pickart CM. Back to the future with ubiquitin. Cell. Jan 23 2004;116(2):181-190.

45. Akasaka $T$, Takahashi $N$, Suzuki $M$, et al. MBLR, a new RING finger protein resembling mammalian Polycomb gene products, is regulated by cell cycledependent phosphorylation. Genes Cells. Aug 2002;7(8):835-850.

46. Li Y, Kirschmann DA, Wallrath LL. Does heterochromatin protein 1 always follow code? Proc Natl Acad Sci U S A. Dec 10 2002;99 Suppl 4:16462-16469.

47. Bannister AJ, Zegerman $P$, Partridge JF, et al. Selective recognition of methylated lysine 9 on histone $\mathrm{H} 3$ by the HP1 chromo domain. Nature. Mar 1 2001;410(6824):120-124.

48. Lachner $M, O^{\prime}$ Carroll $D$, Rea $S$, et al. Methylation of histone H3 lysine 9 creates a binding site for HP1 proteins. Nature. Mar 1 2001;410(6824):116-120.

49. Bernstein E, Duncan EM, Masui O, et al. Mouse polycomb proteins bind differentially to methylated histone $\mathrm{H3}$ and RNA and are enriched in facultative heterochromatin. Mol Cell Biol. Apr 2006;26(7):2560-2569.

50. Fischle W, Tseng BS, Dormann HL, et al. Regulation of HP1-chromatin binding by histone H3 methylation and phosphorylation. Nature. Dec 22 2005;438(7071):11161122.

51. Dormann HL, Tseng BS, Allis CD, et al. Dynamic regulation of effector protein binding to histone modifications: the biology of HP1 switching. Cell Cycle. Dec 2006;5(24):2842-2851.

52. Fischle $\mathrm{W}$, Wang $\mathrm{Y}$, Allis $\mathrm{CD}$. Binary switches and modification cassettes in histone biology and beyond. Nature. Oct 2 2003;425(6957):475-479.

53. Goto $\mathrm{H}$, Tomono $\mathrm{Y}$, Ajiro $\mathrm{K}$, et al. Identification of a novel phosphorylation site on histone H3 coupled with mitotic chromosome condensation. J Biol Chem. Sep 3 1999;274(36):25543-25549.

54. Goto $H$, Yasui $Y$, Nigg EA, et al. Aurora-B phosphorylates Histone H3 at serine28 with regard to the mitotic chromosome condensation. Genes Cells. Jan 2002;7(1):11-17.

55. He Z, Ma WY, Liu G, et al. Arsenite-induced phosphorylation of histone H3 at serine 10 is mediated by Akt1, extracellular signal-regulated kinase 2, and p90 ribosomal S6 kinase 2 but not mitogen- and stress-activated protein kinase 1. J Biol Chem. Mar 21 2003;278(12):10588-10593. 
56. Zhong SP, Ma WY, Dong Z. ERKs and p38 kinases mediate ultraviolet B-induced phosphorylation of histone H3 at serine 10. J Biol Chem. Jul 14 2000;275(28):2098020984.

57. Zhong $\mathrm{S}$, Jansen $\mathrm{C}$, She $\mathrm{QB}$, et al. Ultraviolet B-induced phosphorylation of histone H3 at serine 28 is mediated by MSK1. J Biol Chem. Aug 31 2001;276(35):3321333219.

58. Zhong $\mathrm{S}$, Zhang $\mathrm{Y}$, Jansen $\mathrm{C}$, et al. MAP kinases mediate UVB-induced phosphorylation of histone $\mathrm{H} 3$ at serine 28. J Biol Chem. Apr 20 2001;276(16):12932-12937.

59. Soloaga A, Thomson S, Wiggin GR, et al. MSK2 and MSK1 mediate the mitogen- and stress-induced phosphorylation of histone $\mathrm{H} 3$ and HMG-14. Embo J. Jun 2 2003;22(11):2788-2797.

60. Dunn KL, Davie JR. Stimulation of the Ras-MAPK pathway leads to independent phosphorylation of histone $\mathrm{H} 3$ on serine 10 and 28. Oncogene. May 12 2005;24(21):3492-3502.

61. Dyson $\mathrm{MH}$, Thomson $\mathrm{S}$, Inagaki $\mathrm{M}$, et al. MAP kinase-mediated phosphorylation of distinct pools of histone $\mathrm{H} 3$ at S10 or S28 via mitogen- and stress-activated kinase 1/2. J Cell Sci. May 15 2005;118(Pt 10):2247-2259.

62. Ayoub $\mathrm{N}$, Jeyasekharan $\mathrm{AD}$, Bernal JA, et al. HP1-beta mobilization promotes chromatin changes that initiate the DNA damage response. Nature. May 29 2008;453(7195):682-686.

63. Dietrich N, Bracken AP, Trinh E, et al. Bypass of senescence by the polycomb group protein $\mathrm{CBX} 8$ through direct binding to the INK4A-ARF locus. Embo J. Mar 21 2007;26(6):1637-1648.

64. Sanchez C, Sanchez I, Demmers JA, et al. Proteomics analysis of Ring1B/Rnf2 interactors identifies a novel complex with the Fbxl10/Jhdm1B histone demethylase and the Bcl6 interacting corepressor. Mol Cell Proteomics. May 2007;6(5):820-834.

65. Cloos PA, Christensen J, Agger K, et al. Erasing the methyl mark: histone demethylases at the center of cellular differentiation and disease. Genes Dev. May 1 2008;22(9):1115-1140.

66. Agger K, Cloos PA, Christensen J, et al. UTX and JMJD3 are histone H3K27 demethylases involved in HOX gene regulation and development. Nature. Oct 11 2007;449(7163):731-734.

67. De Santa F, Totaro MG, Prosperini E, et al. The histone H3 lysine-27 demethylase Jmjd3 links inflammation to inhibition of polycomb-mediated gene silencing. Cell. Sep 21 2007;130(6):1083-1094.

68. Hong S, Cho YW, Yu LR, et al. Identification of JmjC domain-containing UTX and JMJD3 as histone H3 lysine 27 demethylases. Proc Natl Acad Sci U S A. Nov 20 2007;104(47):18439-18444.

69. Lan F, Bayliss PE, Rinn JL, et al. A histone H3 lysine 27 demethylase regulates animal posterior development. Nature. Oct 11 2007;449(7163):689-694.

70. Xiang Y, Zhu Z, Han G, et al. JMJD3 is a histone H3K27 demethylase. Cell Res. Oct 2007;17(10):850-857.

71. Lee MG, Villa $R$, Trojer $P$, et al. Demethylation of $H 3 K 27$ regulates polycomb recruitment and H2A ubiquitination. Science. Oct 19 2007;318(5849):447-450.

72. Wang $\mathrm{H}$, Wang $\mathrm{L}$, Erdjument-Bromage $\mathrm{H}$, et al. Role of histone $\mathrm{H} 2 \mathrm{~A}$ ubiquitination in Polycomb silencing. Nature. Oct 14 2004;431(7010):873-878. 


\section{Chapter 7}

73. Buchwald G, van der Stoop $P$, Weichenrieder $O$, et al. Structure and E3-ligase activity of the Ring-Ring complex of polycomb proteins Bmi1 and Ring1b. Embo J. Jun 7 2006;25(11):2465-2474.

74. Cao R, Tsukada $\mathrm{Y}$, Zhang Y. Role of Bmi-1 and Ring1A in H2A ubiquitylation and Hox gene silencing. Mol Cell. Dec 22 2005;20(6):845-854.

75. Li Z, Cao R, Wang M, et al. Structure of a Bmi-1-Ring1B polycomb group ubiquitin ligase complex. J Biol Chem. Jul 21 2006;281(29):20643-20649.

76. Collins MO, Yu L, Choudhary JS. Analysis of protein phosphorylation on a proteomescale. Proteomics. Aug 2007;7(16):2751-2768.

77. Greenman C, Stephens $P$, Smith R, et al. Patterns of somatic mutation in human cancer genomes. Nature. Mar 8 2007;446(7132):153-158.

78. Sithanandam G, Latif F, Duh FM, et al. $3 p K$, a new mitogen-activated protein kinaseactivated protein kinase located in the small cell lung cancer tumor suppressor gene region. Mol Cell Biol. Mar 1996;16(3):868-876.

79. Tallman MS. The expanding role of arsenic in acute promyelocytic leukemia. Semin Hematol. Jul 2008;45(3 Suppl 2):S25-29.

80. Berenson JR, Yellin O. New drugs in multiple myeloma. Curr Opin Support Palliat Care. Sep 2008;2(3):204-210.

81. Amadori $\mathrm{S}$, Fenaux $\mathrm{P}$, Ludwig $\mathrm{H}$, et al. Use of arsenic trioxide in haematological malignancies: insight into the clinical development of a novel agent. Curr Med Res Opin. Mar 2005;21(3):403-411. 
Summary 
The specific function of a cell is mostly determined by the genes and proteins it expresses. The information required to make a protein is stored in DNA and is called a gene. Through transcription and translation of genes proteins are produced. As cell types with different functions express different sets of proteins, it is important to regulate which genes are transcribed, and equally important, which genes are not. The latter is in part controlled by Polycomb Group (PcG) proteins, which are an important part of the transcriptional memory system of a cell: they mark certain genes with repressive signals during developmental and differentiation processes. The repressive marking includes post-translational modifications (PTMs) on histone proteins, such as trimethylation of Lysine 27 on histone 3 (H3K27me3) and ubiquitylation of Lysine 119 on histone 2A (H2AK119ub1). Two main Polycomb Repressive Complexes are recognized, namely PRC1 and PRC2. The histone methyltransferase activity of PRC2 member EZH2 is responsible for the H3K27me3 mark, to which CBX proteins of the PRC1 complex can bind. Other PRC1 proteins, such as RNF2 ubiquitylate H2A. Together this, in general, maintains transcriptional repression. The basic biological concepts that are used in PcG biology, such as histones, chromatin and epigenetics, are described in Chapter 1.

Although the mechanisms that contribute to PcG-mediated silencing, as described above, are relatively well-known, there are still many aspects of PcG biology that are not understood. One important question formed the basis of the research described in this thesis: how is Polycomb Group function regulated? Answering this question is important, as PcG proteins control several biological processes. PcG proteins are essential for embryonic development and stem cell renewal. Among the genes that are targeted by PcG proteins are transcription factors, components of signalling pathways and tumor suppressor genes. Since PcG proteins control epigenetic silencing of many genes involved in cell fate decisions, it is not surprising that deregulated expression of PcG proteins is frequently found in cancer. The role for PcG proteins in the development of cancer is discussed in Chapter 2. Putative mechanisms of how PcG proteins contribute to tumorigenesis are bypass of senescence and maintenance of cancer stem cells.

PcG proteins are not only involved in post-translational modification of chromatin-associated proteins, they are targeted for PTMs, such as ubiquitylation, sumoylation and phosphorylation themselves (Chapter 3). These modifications affect protein function by affecting protein stability, proteinprotein interactions and enzymatic activities. The exact molecular mechanisms in, and biological relevance of the majority of PTMs on Polycomb function are 
not known. The research described in this thesis aimed to identify PcG phosphorylation sites, involved kinases and the relevance of PcG phosphorylation in terms of complex composition, chromatin association and gene repression.

At the beginning of this project it was known that at least some PcG proteins are phosphorylated and that this phosphorylation correlates with chromatin dissociation in a cell cycle-dependent fashion. The identification of MAPKAPK3 (MK3) as an interaction partner of the PRC1 complex member PHC2 provided an interesting lead to further elucidate the functional relevance of PcG phosphorylation (Chapter 4). Stimulation of the ERK and p38 MAPK cascades, of which MK3 is a downstream target, leads to the phosphorylation of the PRC1 members $\mathrm{PHC1}$ and $\mathrm{BMI} 1$. In vitro data establish that MK3 can directly phosphorylate BMI1. The induced phosphorylation of most PRC1 proteins correlates with both dissociation from chromatin and appearance of H3S28 phosphorylation. PHC1 staining, however, is not lost upon phosphorylation but is redistributed within the nucleus. This indicates a differential response of PRC1 complex members to phosphorylation. Manipulation of MK3 levels in cells confirms that Bmi1 phosphorylation is, at least in part, dependent on MK3. Furthermore the overexpression of MK3 results in expression of $\mathrm{p} 14^{\mathrm{ARF}}$, a cellcycle inhibitor, indicating derepression of the PcG target gene CDKN2A. These results are in line with the hypothesis that activation of MAPK signalling cascades lead to phosphorylation and chromatin dissociation of PcG proteins, thereby relieving transcriptional repression and allowing for gene activation.

This hypothesis was further tested in Chapter 5 in which MK3 overexpression was studied in the context of cell cycle regulation. Overexpression of MK3 reduces cell proliferation and induces a senescence-like state. This is accompanied by upregulation of several cell cycle regulatory proteins, such as $\mathrm{p} 16, \mathrm{p} 14^{\mathrm{ARF}}, \mathrm{p} 21$ and $\mathrm{p} 53$. Knockdown of relevant PcG proteins also induces senescent-like states, indicating that MK3 overexpression and PcG knockdown have the same functional implication. Concomitant overexpression of BMI1 with MK3 reverses the MK3-induced cell-morphological changes. Combined with the observation that BMI1 and MK3 overexpressing cells select for high BMI1 expression this indicates a genetic interaction between BMI1 and MK3. Chromatin Immunoprecipitations (ChIP) further demonstrated that MK3 binds to the promoters of several PcG target genes, including the CDKN2A locus. Activation of MK3 is sufficient for a partial release of PRC1 proteins CBX8 and PHC1 from certain genes and transcriptional activation of these genes. Surprisingly this occurs despite an unchanged H3K27me3 mark. The MK3-PRC1 
interaction may act as a molecular switch, allowing the cell to regulate PcGmediated gene expression and rapidly respond to changes in its environment.

Chromatin association of PHC1 in ChIP does not mirror CBX8 enrichment, but closely resembles the MK3 occupation dynamics. This observation supported the atypical behaviour of PHC1 compared to other PRC1 proteins. To study direct phosphorylation of PRC1 proteins by MK3 in vitro phosphorylation studies were conducted on spotted PRC1 peptides. The strongest in vitro MK3 phosphorylation occurs on PHC2 peptides. The signaling-induced differences in PHC chromatin binding compared to other PRC1 proteins might be explained by (1) the direct binding of MK3 to PHC proteins and (2) the direct phosphorylation of PHC proteins by MK3.

To gain insight into regulation of Polycomb function PRC1 complex composition was studied in the context of stress-signaling (Chapter 6). Next to the identification of several PcG phosphorylation sites, a new PRC1 interacting protein, KAP1, was identified, which only binds to PRC1 under certain stress conditions. Although phosphorylation occurs on both Bmi1 and KAP1 when this interaction occurs, the phosphorylation itself is not necessary for the established interaction. Signaling pathways involved in arsenite (As) and selenite (Se) -induced phosphorylation of BMI1 and KAP1 include p38, ATM/ATR, PKC, JNK and GSK3ß pathways. The establishment of Bmi1-KAP1 association is enhanced by inhibition of PKC and JNK signalling, yet is reduced by inhibition of GSK3ß signaling under cell stress; however, inhibition of p38 and ATM/ATR signaling reduces binding only in response to Se, not to As. PcG mediated transcriptional repression is potentially regulated by this interaction. Mitogenic signalling leads to a higher mRNA expression of PcG target gene ATF3, which is potentiated by concomitant knockdown of KAP1. This might, however, occur via more global chromatin responses. The biological relevance of this interaction is therefore currently not clear.

The significance of the results and their interrelationship are discussed in Chapter 7. The research described in this thesis begins to show how activation of signaling cascades leads to phosphorylation of PcG proteins and affects their subcellular localization, protein interactions within the PRC1 complex and their binding to certain target genes, whose expression is thus regulated. Future studies on the regulation of PcG proteins by phosphorylation and other posttranslational modifications will determine which impact it has on both physiological processes, such as embryonic development and stem cell renewal, and pathological processes like cancer. 
Samenvatting 
De specifieke functie van een cel wordt grotendeels bepaald door expressie van genen en eiwitten. De informatie die nodig is om een eiwit te maken, ligt opgeslagen in het DNA en wordt een gen genoemd: de DNA code van genen wordt overgeschreven tot een RNA code (transcriptie) en vertaald in een eiwit code (translatie). Verschillen in celtype worden bepaald door welke eiwitten tot expressie worden gebracht en welke niet. Dit laatste wordt gedeeltelijk bepaald door Polycomb Groep (PcG) eiwitten; PcG eiwitten vormen een belangrijk transcriptioneel geheugensysteem: ze markeren bepaalde genen met epigenetisch repressieve signalen tijdens ontwikkeling en differentiatieprocessen. Dergelijke repressieve markering bestaat deels uit posttranslationele modificaties (PTMs) op histon eiwitten, waaronder trimethylering van Lysine 27 op histon 3 (H3K27me3) en ubiquitylering van Lysine 119 op histon 2A (H2AK119ub1). Er bestaan twee belangrijke Polycomb Repressieve Complexen: PRC1 en PRC2. De histon methyltransferase activiteit van het PRC2eiwit EZH2 is verantwoordelijk voor de H3K27me3 markering, waaraan CBX eiwitten van het PRC1 complex kunnen binden. Andere PRC1 eiwitten, waaronder RNF2, ubiquityleren H2A. In het algemeen leidt dit tot behoud van transcriptionele repressie. De algemene biologische concepten die gebruikt worden in de PcG biologie, zoals histonen, chromatine en epigenetica, worden uitgelegd in hoofdstuk 1.

Ofschoon een aantal mechanismen, dat betrokken is bij PcG-afhankelijke repressie, zoals hierboven beschreven, ontrafeld is, blijven er nog steeds veel aspecten van PcG biologie onbegrepen. Ondermeer de vraag hoe PcG-functie gereguleerd wordt, stond aan de basis van het onderzoek beschreven in dit proefschrift. Het beantwoorden van deze vraag is relevant, omdat PcG eiwitten belangrijke fundamentele biologische processen reguleren. PcG eiwitten zijn essentieel voor embryonale ontwikkeling en stamcel-vernieuwing. Onder de genen die gereguleerd worden door PcG eiwitten zijn transcriptiefactoren, onderdelen van singnaaltransductie cascades en tumor suppressor genen. Aangezien veel van dergelijke genen betrokken zijn bij het differentiatie en celdeling, is het niet verrassend dat ontregeling van PcG-eiwitten vaak voorkomt in kanker. De rol van PcG eiwitten bij het ontstaan van kanker wordt belicht in hoofdstuk 2. Mechanismen die bijdragen aan kankerontwikkeling zijn het voorkomen van een verouderingsrespons (senescentie) en de instandhouding van kanker stamcellen.

PcG eiwitten zijn niet alleen betrokken bij het aanbrengen van posttranslationele modificaties op chromatine-geassocieerde eiwitten, maar worden zelf ook post-translationeel gemodificeerd, ondermeer door ubiquitylering, sumoylering en fosforylering (hoofdstuk 3). Deze modificaties beïnvloeden de 
functie van eiwitten door aan te grijpen op eiwitstabiliteit, eiwit-eiwit interacties en enzymatische activiteit. De exacte gevolgen van PTMs op PcG functie op moleculair nivo en hun biologische relevantie zijn niet bekend. Het onderzoek beschreven in dit proefschrift had o.m. tot doel PcG specifieke gefosforyleerde aminozuren en betrokken kinases te identficeren en de gevolgen van PcG fosforylering in termen van complex compositie, chromatine associatie en gen repressie te bepalen.

Bij aanvang van dit project was het bekend dat op zijn minst enkele PcG eiwitten gefosforyleerd worden en dat deze fosforylatie op een cel-cyclus-afhankelijke manier correleerde met een PcG-dissociatie van chromatine. De identificatie van MAPKAPK3 (MK3) als interactie partner van PHC2, dat deel uitmaakt van PRC1, zorgde voor een aanknopingspunt om de functionele relevantie van PcG fosforylatie te bestuderen (hoofdstuk 4). Stimulatie van ERK en p38 MAPK cascades, van welke MK3 een target is, leidt tot de fosforylatie van PRC1 leden PHC1 en BMI1. In vitro data bevestigen dat MK3 direct BMI1 kan fosforyleren. De geïnduceerde fosforylatie van de meeste PRC1 eiwitten correleert met zowel de dissociatie van chromatine als de verschijning van H3S28 fosforylatie. Chromatine associatie van PHC1 gaat daarentegen niet verloren na fosforylering, maar vertoont een redistributie in de nucleus. Deze observatie correleert met een differentiële respons van PRC1 eiwitten na fosforylatie. Manipulatie van MK3 eiwit niveaus in cellen bevestigt dat BMI1 fosforylatie, op zijn minst gedeeltelijk, afhankelijk is van MK3. Verder resulteert de overexpressie van MK3 in de expressie van p14 ${ }^{A R F}$, een celcyclus remmer, wat een derepressie van het PcG target gen CDKN2A aangeeft. Deze resultaten zijn in overeenstemming met de hypothese dat activering van MAPK-signalering leidt tot fosforylatie en chromatine dissociatie van PcG eiwitten, waardoor transcriptionele repressie wordt opgeheven en de mogelijkheid tot genactivatie ontstaat.

Deze hypothese werd verder getoetst in hoofdstuk 5 waarin MK3 overexpressie bestudeerd werd in de context van celcyclus regulatie. Overexpressie van MK3 vermindert celdeling en induceert een op celveroudering lijkende status: cellen worden groot en plat en delen niet meer. Deze verandering gaat gepaard met activering van verschillende celdelings remmers, waaronder p16, p14 ${ }^{\mathrm{ARF}}$, p21 en p53. Experimenteel geïnduceerd verlies van relevante PcG eiwitten resulteert eveneens in een verouderingsrespons. Dit geeft aan dat MK3 overexpressie en PcG verlies vergelijkbare functionele gevolgen hebben. Gelijktijdige overexpressie van BMI1 en MK3 draait de MK3-geïnduceerde celmorfologische veranderingen terug. Samen met de waarneming dat BMI1 en MK3 overexpresserende cellen selecteren voor een hoge BMI1 expressie, duidt dit op 
een genetische interactie tussen BMI1 en MK3. Chromatine Immunoprecipitaties (ChIP) demonstreerden dat MK3 bindt aan promotoren van PcG doelwitgenen, waaronder de CDKN2A locus. Activering van MK3 is voldoende voor een gedeeltelijk verlies van chromatine-associatie van de PRC1 eiwitten CBX8 en PHC1 op bepaalde genen; dit gaat gepaard met een verhoogde transcriptie van deze genen. Opmerkelijk is dat dit gebeurt met behoud van de epigenetisch repressieve H3K27me3 markering. Onze bevindingen suggereren dat MK3-PRC1 als een moleculair schakelmechanisme werken, waardoor een cel PcG-gemedieerde gen repressie snel kan aanpassen en daarmee kan reageren op veranderingen uit de cellulaire omgeving. Chromatine-associatie veranderingen van $\mathrm{PHC1}$, bepaald met behulp van ChIP, volgen niet de CBX8associatie profielen, maar lijken eerder op die van MK3. Deze waarneming ondersteunt het eerder gevonden atypische gedrag van PHC1 in vergelijking tot andere PRC1 eiwitten. Om fosforylering van PRC1 eiwitten door MK3 te bestuderen hebben we in vitro fosforylerings studies gedaan op geïmmobiliseerde PRC1 peptiden. De duidelijkste in vitro MK3 fosforylering blijkt plaats te vinden op PHC peptiden. De signalerings-geïnduceerde verschillen in PHC-chromatine binding in vergelijking tot andere PRC1 eiwitten worden mogelijk verklaard door (1) de directe binding van MK3 aan PHC eiwitten en (2) de directe fosforylering van PHC eiwitten door MK3.

Om inzicht te krijgen in de regulering van Polycomb functie werd de complex samenstelling van PRC1 bestudeerd in de context van stress-signalering (hoofdstuk 6). Naast identificatie van verschillende PcG fosforyl-aminozuren ontdekten we een nieuw PRC1-bindend eiwit, KAP1, dat alleen aan PRC1 bindt onder stress condities. Ofschoon fosforylering plaatsvindt op zowel Bmi1 als KAP1 wanneer deze interactie plaatsvindt, blijkt fosforylering niet noodzakelijk om de interactie in stand te houden. Signaleringscascades die betrokken zijn bij Arseen (As) en Seleen (Se)-geïnduceerde fosforylering van BMI1 en KAP1 zijn onder andere P38, ATM/ATR, PKC, JNK en GSK3ß cascades. De totstandkoming van BMI1-KAP1 binding onder cel-stress condities, wordt gestimuleerd door remming van PKC en JNK signalering, en verhinderd door remming van GSK3ß. Echter, blokkering van p38 en ATM/ATR signalering vermindert de binding alleen als gevolg van Se, en niet As. Polycomb gemedieerde transcriptionele repressie wordt mogelijk beïnvloed door deze interactie. Mitogene signalering leidt tot hogere mRNA expressie van PcG target gen ATF3, die bovendien versterkt wordt door verlies van KAP1. Ofschoon de biologische relevantie van deze interactie nog niet duidelijk is, is het mogelijk dat hierbij een meer globale chromatine structuurverandering betrokken is. 
De betekenis van de resultaten en hun onderlinge verband worden bediscussieerd in hoofdstuk 7. Het onderzoek beschreven in dit proefschrift laat zien hoe activering van signaaltransductie cascades leidt tot fosforylering van PcG eiwitten en daardoor hun subcellulaire locatie, eiwit interacties binnen het PRC1 complex en binding aan bepaalde target genen beïnvloed wordt, waardoor de expressie van deze genen wordt gereguleerd. Verder onderzoek naar de regulering van PcG eiwitten door fosforylering en andere posttranslationele modificaties zijn nodig om de invloed van dergelijke veranderingen op zowel normale fysiologische processen, waaronder embryonale ontwikkeling en stamcel vernieuwing, als pathologische processen zoals kanker, te bepalen. 

Dankwoord 
$\mathrm{Na}$ de afgelopen jaren hard gewerkt te hebben om mijn promotieonderzoek af te ronden, ben ik toegekomen aan het schrijven van dit dankwoord. Aan iedereen die van plan is om alleen dit gedeelte te lezen wil ik toch even zeggen dat de rest ook best de moeite waard is. Er zijn veel mensen die mij de afgelopen jaren geholpen hebben, en die ik wil bedanken voor hun steun (en ook ik hoop dat ik niemand vergeet).

Ten eerste mijn co-promotor en promotores.

Beste Willem, jouw enthousiasme voor de wetenschap is de grote drijfveer achter het Polycomb Groep-groepje. Tijdens werkbesprekingen werden alle foto's, grafieken, staaf-diagrammen (waar zijn de blips?) en vooral blotjes (nee, ik heb niets omgewisseld) tot in detail besproken, en leverden een stortvloed aan nieuwe ideeën op. Je hoge standaard heeft, buiten wat frustraties hier en daar, het beste uit me naar boven gehaald. Bedankt voor alles wat ik van je heb geleerd.

Beste Joep en Marten, bedankt voor de begeleiding, vooral tijdens de laatste fase.

Vivian, ik weet niet wat er van mijn promotie terecht was gekomen zonder jou. Je hebt niet alleen bergen werk verzet, maar je stond ook altijd klaar met een goed advies of luisterend oor als het wetenschappelijk gezien even tegenzat. Jouw efficiëntie en nauwkeurigheid op het lab zijn ongeëvenaard, en altijd een voorbeeld voor mij geweest. Buiten dat vond ik je altijd een gezellige collega. Ik ben blij dat ik jou straks als paranimf achter me heb staan. Ik vraag me trouwens af hoe lang het nog duurt, voordat we onafhankelijk van elkaar exact dezelfde schoenen kopen.

De rest van het VWO groepje (Claudia, Céline, Frank, Peggy, Nard, Iris, Elena, Raymond en Juliette) wil ik bedanken voor de goede sfeer op het lab (en dat jullie me nooit verboden hebben om met de radio mee te zingen). Claudia, jij hebt zonder morren altijd de meest vreselijke klusjes uitgevoerd (cellen tellen, mutanten maken, virussen maken etc). De uren in de celkweek vlogen met jou erbij om! Céline, I enjoyed having you as a colleague. I admire your ability to stay strong, even though your research-life was tough on you. Frank (Frenkieee!), onze eeuwige optimist (wat goed van pas komt in de wetenschap en als Ajax-fan). Met jou als labbuurman wist ik dat ik mijn spullen nooit meer dan een halve labtafel verderop moest zoeken. Ondanks dat het je niet gelukt is om mijn muzieksmaak te beïnvloeden, kon ik je muzikale heropvoedingspogingen wel waarderen. Succes met de laatste loodjes! Peggy, ook met jou heb ik altijd een gezellige tijd gehad. Met jou erbij valt er nooit een pijnlijke stilte. Ik ben blij dat je verder gaat met waar ik gebleven was. Met jouw perfectionisme moet het wel goed komen. Mocht je nog wat adviezen kunnen gebruiken van je 
AlO-mamma, dan hoor ik het wel! Nard, je behoort misschien niet tot het core complex, maar je bent zeker een geassocieerde factor. Ik vind het leuk om op de hoogte te blijven van je avonturen in Washington. Succes met afronden.

Verder kwamen er elk jaar een heleboel studenten voorbij die ons groepje hebben versterkt. Zonder volledig te zijn (onmogelijke taak) wil ik Caroline, Chantal, Guus, Joyce, Marjolein, Martin, Martijn, Merel, Petra H., Rene, Sjoerd, Yvette en in het bijzonder Petra C. en Stefanie bedanken voor de gezelligheid en (in meer of mindere mate) voor de hulp bij het totstandkomen van dit proefschrift.

De soms lange dagen op het lab vlogen voorbij dankzij de gemoedelijke sfeer op het lab en tijdens de koffiepauzes. Aangezien ik best wel lang bij moleculaire genetica heb gewerkt, heb ik veel collega's zien komen en gaan. Groot was mijn verbazing toen bleek dat mijn voormalige stageplaats verhuisde naar moleculaire genetica, en we ineens collega's werden. ledereen bedankt! In willekeurige volgorde: Veerle B., Veerle C., Wilma, Will (ho, ho), Daniëlle C., Ellen L. (denk eraan, alles komt goed), Ellen D., Guillaume (ik kon het niet meer verplaatsen), Marjon (jouw onbezonnen uitspraken zijn vaak hilarisch), Jan, Pieter, Patrick (altijd netjes; ondanks mijn $116^{\mathrm{e}}$ vraag), Daphna, Daniëlle vd V., Nicole, Petra, Joost, Chantal, Robert, Inge, Arjen, Laura, Sander, Le (how could every song somehow be related to Burt Bacharach?), Ronit, Monique (wie is hier blauw?), Wino (wat kan cellen kweken toch frustrerend zijn!), Menno, Sofia (Hey Sofiaaaa!), Kristiaan, Mathijs (wanneer zorgen we nu eens voor die integratie?), Stijn, Jana, Olivier, Debby, Roy, Susan, Remco, Maurice en Mohammed.

Dan zijn er nog de mensen buiten de afdeling die hun steentje hebben bijgedragen.

Dear Adrian, thanks for showing me how to perform a decent ChIP experiment. It was a crucial part of my PhD studies. Even though it was a short stay, I learned a lot from the meaningful discussions.

Ik wil iedereen van de Maastro besprekingen bedanken voor hun bijdrage aan mijn "oncologische-ontwikkeling". Door deze samenwerking heb ik geleerd verder te kijken dan mijn Polycomb-neus lang is. Dus bedankt Brad, Marianne, Jan, Roland, Ludwig, Michael, Maud, Younan, Asferd, Sherry, Barry, Kim, Kim, Natasja, Chantal (voor je DNA schade expertise), Kasper (dat er ge-ChIP'ed moest worden), Twan (dat jij daar ook nog wat aan had), Ramon en Jos.

Natuurlijk mag ik mijn nieuwe collega's niet vergeten. Alle "Angels" (man/vrouw) bedankt voor jullie oprechte interesse en bemoedigende woorden bij het afronden van dit boekje. In het bijzonder Manon (bedankt dat ik bij je aan de slag mocht en voor het duwen richting de streep), Sarah (al aan het 
samenwerken voordat we collega's werden), Kim en Veerle (mijn huidige roomies; hoe goed kan het klikken tussen collega's?).

Natuurlijk is het belangrijk om naast het werk nog een sociaal leven te hebben. Saskia, of eigenlijk Sas. Onze vriendschap bestaat al zo lang, dat we het begin niet eens kunnen herinneren. Van peuterspeelzaal tot promoveren, samen stonden we sterk. De bezoekjes over en weer zijn de laatste tijd wat sporadisch geworden, maar ik hoop dat nu weer wat meer op te kunnen pakken. Wat denk je, Utrecht, Maastricht of Roermond?

Susan, lieve Suus, van stagiaire naar collega's naar vriendinnen. Ik heb er bewondering voor hoe jij altijd het positieve in mensen kunt zien. Hopelijk kunnen we nog lang samen lunchen.

Mijn sportvriendinnen. Inge, wat een geduld had jij toen mijn conditie nog nietbestaand was. Zonder jou als stok achter de deur had ik het hardlopen nooit volgehouden. Bedankt ook voor je feilloze tips qua muziek. Imke, met jou erbij is rennen nooit saai. Simultaan rennen en praten is voor jou een makkie. Ik hoop dat we snel weer kunnen beginnen (en anders slaan we dat rennen over en gaan we meteen door met eten en bijkletsen). Anouk, onze wekelijkse tennis of badminton avonden waren altijd erg gezellig (vooral het naborrelen). Met je nuchtere blik kun je de af en toe rare randvoorwaarden van het onderzoekswereldje in het juiste perspectief plaatsten. Nu kan ik je eindelijk ook eens uitnodigen voor een feestje!

Waar zou je zijn, zonder je familie? Lieve pap en mam (Jeanneke en ziene Jan), jullie liefde voor ons vind je terug in al jullie woorden en daden. Ik voel me gezegend met jullie als ouders. Bedankt voor alles!

Petra, lieve Peetje, van jongs af aan kunnen wij het altijd goed met elkaar vinden. Je bent een schat! Waar anderen zich niet konden voorstellen om ooit met hun broer/zus te moeten samenwerken, was dat voor ons totaal geen probleem. Bedankt voor al je kalmerende woorden wanneer de proefschriftstress weer eens in volle hevigheid toesloeg. Ik ben blij dat ik zo'n lieve zus, en paranimf, heb. Sander, tijdens mijn promotie ging jij van collega naar schoonbroer. Ik had me geen betere kunnen wensen. Wat wordt het volgende concert?

Al zijn ze tegenwoordig qua opzet veranderd, de zondagmiddagen staan in mijn geheugen gegrift. Opa en oma, Frank, Marion, Dennis, Frits, Margriet, Wouter, Marjolein en Ewout, bedankt voor al het heerlijke gebak en eten, het ongezouten voetbalcommentaar, de ongeordende discussies, maar vooral voor de gezelligheid.

Hanneke 
Curriculum Vitae 
Hanneke Niessen werd geboren op 10 juni 1980 in Roermond. In 1992 begon zij aan de gymnasium opleiding van het Bisschoppelijk College Broekhin te Roermond. Net als haar zus ontwikkelde ze een gezonde belangstelling voor het vak biologie. Aangezien ze niet nog een opleiding wilde doorlopen waar de docenten haar betitelden als "het zusje van" besloot ze in 1998 Biomedische Gezondheidswetenschappen te studeren in Nijmegen. Later koos ze voor pathobiologie als hoofdvak en moleculaire levenswetenschappen als bijvak. Tijdens haar stages bij de vakgroepen Matrix Biochemie (Nijmegen Centre for Molecular Life Sciencese, UMC St Radboud) en Fysiologie (Universiteit Maastricht) bleek haar voorkeur uit te gaan naar de moleculaire biologie. Deze interesse kwam goed van pas tijdens haar promotie-onderzoek op het redelijk ambitieuze project "the identification and characterization of Polycombassociated kinase activity" dat ze eind 2002 onder supervisie van Dr. J.W. Voncken startte bij de vakgroep Moleculaire Genetica in Maastricht, niet geheel toevallig de afdeling waar haar zus al werkzaam was. Door de toekenning van een NGI en een short-term EMBO fellowship kon ze in 2006 naar het Biotech Research \& Innovation Centre in Kopenhagen, waar zij de chromatine immunoprecipitatie techniek leerde van Dr. A. Bracken.

Sinds augustus 2008 is ze als postdoc werkzaam bij de vakgroep Pathologie, waar ze onder begeleiding van Dr. M. van Engeland onderzoek doet naar de relevantie van GATA4 en GATA5 promotermethylering in darmtumoren. 
List of publications 


\section{Papers}

Niessen HEC, Prickaerts P*, Salvaing J*, Spaapen F*, Dahlmans V, Geijselaers C, Bartels S, Takihara Y, Hansen K, Wouters B, Bracken A, Rapp U, Voncken JW. MK3 controls proliferation by an epigenetic switch-mechanism involving Polycomb function. Submitted

Rouschop KMA, van den Beucken T, Dubois L, Niessen H, Bussink J, Savelkouls K, Keulers T, Mujcic H, Landuyt W, Voncken JW, Lambin P, van der Kogel AJ, Koritzinsky M, Wouters BG. The unfolded protein response protects cells during hypoxia through regulation of the autophagy genes LC3b and ATG5. Submitted

Niessen HEC, Dahlmans V, Prickaerts P, Spaapen F, Geijselaers C, Lee S-C, Wouters BG, Demmers J and Voncken JW. Cell stress-induced association of Polycomb Repressive Complex 1 with the chromatin factor KAP1. In preparation

Spaapen F, van den Akker G, Caron M, Prickaerts P, Niessen H, Dahlmans V, Surtel D, Paulis $Y$, Schweizer F, Rofel C, Welting T, Eijssen L, Voncken JW. The immediate early gene EGR1 controls epigenetic reprogramming through Polycomb Group proteins during chondrogenesis. In preparation

Niessen HE, Demmers JA, Voncken JW. Talking to chromatin: post-translational modulation of polycomb group function. Epigenetics Chromatin. 2009;2(1):10.

van den Beucken T, Koritzinsky M, Niessen $H$, Dubois L, Savelkouls K, Mujcic $H$, Jutten B, Kopacek J, Pastorekova S, van der Kogel AJ, Lambin P, Voncken W, Rouschop KM, Wouters BG. Hypoxia-induced Expression of Carbonic Anhydrase 9 Is Dependent on the Unfolded Protein Response. I Biol Chem. 2009;284(36):24204-24212.

Derks S, Bosch LJ, Niessen HE, Moerkerk PT, van den Bosch SM, Carvalho B, Mongera S, Voncken JW, Meijer GA, de Bruine AP, Herman JG, van Engeland M. Promoter $\mathrm{CpG}$ island hypermethylation- and H3K9me3 and H3K27me3mediated epigenetic silencing targets the deleted in colon cancer (DCC) gene in colorectal carcinogenesis without affecting neighboring genes on chromosomal region 18q21. Carcinogenesis. 2009;30(6):1041-1048. 
Luiken JJ, Niessen HE, Coort SL, Hoebers N, Coumans WA, Schwenk RW, Bonen A, Glatz JF. Etomoxir-induced partial carnitine palmitoyltransferase-I (CPT-I) inhibition in vivo does not alter cardiac long-chain fatty acid uptake and oxidation rates. Biochem J. 2009;419(2):447-455.

Voncken JW*, Niessen $\mathrm{H}^{*}$, Neufeld $\mathrm{B}^{*}$, Rennefahrt U, Dahlmans $\mathrm{V}$, Kubben $\mathrm{N}$, Holzer B, Ludwig S, Rapp UR. MAPKAP kinase 3pK phosphorylates and regulates chromatin association of the polycomb group protein Bmi1. J Biol Chem. 2005;280(7):5178-5187.

(*equal contribution)

\section{Book contribution}

Niessen H, Voncken JW. Polycomb Group Proteins in Tumorigenesis. In: Tollefsbol T, ed. Cancer Epigenetics. Boca Raton: CRC Press; 2008:281-302. 

Abbreviations 


\section{Abbreviations}

\begin{tabular}{|c|c|}
\hline $3 p K$ & MAPK-activated protein kinase 3 \\
\hline A & Alanine \\
\hline AA & Amino acid; \\
\hline AML & Acute myeloid leukemia \\
\hline A-P & Anteroposterior \\
\hline As/Ars & Arsenite \\
\hline ATM & Ataxia telangiectasia mutated \\
\hline ATP & Adenosine triphosphate \\
\hline ATR & Ataxia telangiectasia mutated-and Rad3-related \\
\hline BMI1 & B-cell-specific Moloney murine leukemia virus integration site 1 \\
\hline CBX & Chromobox homologue \\
\hline ChIP & Chromatin Immunoprecipitation \\
\hline CK2 & Casein kinase 2 \\
\hline CKI & Cyclin-dependent kinase inhibitor \\
\hline CSC & Cancer stem cells \\
\hline CtBP & Carboxyl-terminus binding protein \\
\hline DAPI & 4',6-diamidino- 2-phenylindole \\
\hline DNMTs & DNA methyltransferases \\
\hline DUBs & De-ubiquitinating enzymes \\
\hline$E$ & Glutamic acid \\
\hline EDR & Early development regulator \\
\hline EED & Embryonic ectoderm development \\
\hline e.g. & Exempli gratia \\
\hline EMT & Epithelial mesenchymal transition \\
\hline ERK & Extracellular signal-regulated kinase \\
\hline ES & Embryonic stem \\
\hline ESC & Extra sex combs \\
\hline EV & Empty vector \\
\hline$E(z)$ & Enhancer of zeste \\
\hline FCS & Fetal calf serum \\
\hline GFP & Green fluorescent protein \\
\hline GFRs & Growth factor receptors \\
\hline GSK3ß & Glycogen synthase kinase- $3 ß$ \\
\hline GST & Glutathione $S$-transferase \\
\hline $\mathrm{H} 2 \mathrm{~A}$ & Histone 2A \\
\hline H2AK119ub1 & Histone $\mathrm{H} 2 \mathrm{~A}$ monoubiquitylation of $\mathrm{K} 119$ \\
\hline $\mathrm{H} 2 \mathrm{~B}$ & Histone 2B \\
\hline $\mathrm{H} 3$ & Histone 3 \\
\hline $\mathrm{H} 4$ & Histone 4 \\
\hline H3K27me3 & Trimethylation on lysine 27 of histone 3 \\
\hline $\mathrm{HA}$ & Hemagglutinin \\
\hline HATs & Histone acetyl transferases \\
\hline HCNE & Highly conserved noncoding elements \\
\hline HDII/SPM/SAM & $\begin{array}{l}\text { Homology domain } 11 / \mathrm{sex} \text { combs on midleg, polyhomeotic, } \mathrm{I}(3) \mathrm{mbt} / \mathrm{self} \text { - } \\
\text { association motif }\end{array}$ \\
\hline HDACs & Histone deacetylases \\
\hline HIPK2 & Homeodomain interacting protein kinase 2 \\
\hline HMECS & Human mammary epithelial cells \\
\hline HMTs & Histone methyl transferases \\
\hline HOX & homeobox \\
\hline
\end{tabular}




\section{List of publications}

\begin{tabular}{|c|c|}
\hline HP1 & Heterochromatin protein 1 \\
\hline HPC & Homolog of polycomb \\
\hline $\mathrm{HPH}$ & Homolog of polyhomeotic \\
\hline HSC & Hematopoietic stem cell \\
\hline HSF & Heat shock factor \\
\hline hTERT & Human telomerase reverse transcriptase \\
\hline i. $a$ & Inter alia \\
\hline i.e. & Id est \\
\hline IF & Immuno-fluorescence \\
\hline IP & Immunoprecipitation \\
\hline IR & ionizing radiation \\
\hline IRES & Internal ribosomal entry site \\
\hline IVK & In vitro kinase \\
\hline JNK & c-Jun NH2-terminal kinase \\
\hline K & Lysine \\
\hline KAP1 & KRAB-associated protein 1 \\
\hline KD & Knock down \\
\hline KRAB & Krüppel-associated box \\
\hline $\mathrm{mAb}$ & Monoclonal antibody \\
\hline MAPK & Mitogen-activated protein kinase \\
\hline MAPKAP & Mitogen activated protein kinase activated protein \\
\hline MBLR & MEL18 and BMI1-Like RING finger protein \\
\hline MEL18 & Melanoma nuclear protein 18 \\
\hline MK2 & MAPKAP kinase 2 \\
\hline MK3 & MAPKAP kinase 3 \\
\hline MS & Mass spectrometry \\
\hline MSK1 & Mitogen and stress-activated protein kinase 1 \\
\hline $\mathrm{OE}$ & Overexpression \\
\hline O-GIcNAc & O-linked $\mathrm{N}$-acetylglucosamine \\
\hline Ogt & O-GIcNAc transferase \\
\hline OIS & Oncogene induced senescence \\
\hline pAb & Polyclonal antibody \\
\hline Pc & Polycomb \\
\hline PcG & Polycomb Group \\
\hline PCGF & Polycomb group ring finger \\
\hline $\mathrm{Ph}$ & Polyhomeotic \\
\hline PHC & Polyhomeotic-like \\
\hline Pho & Pleiohomeotic \\
\hline Phol & Pleiohomeotic-like \\
\hline PhoRC & Pho repressive complex \\
\hline PKC & Protein kinase $\mathrm{C}$ \\
\hline PRC1 & Polycomb Repressive Complex 1 \\
\hline PRC2 & Polycomb Repressive Complex 2 \\
\hline Psc & Posterior sex combs \\
\hline PTM & Post-translational modification \\
\hline RING & Really interesting new gene \\
\hline RNF & Ring finger protein \\
\hline RSK2 & Ribosomal S6 protein kinase 2 \\
\hline RYBP & RING1 and YY1 binding protein \\
\hline S & Serine \\
\hline
\end{tabular}




\section{Abbreviations}

$\begin{array}{ll}\text { SA-BGal } & \text { Senescence-associated B-Galactosidase } \\ \text { SAM } & \text { Self association motif } \\ \text { SAPK } & \text { Stress-activated protein kinase } \\ \text { Sce } & \text { Sex combs extra } \\ \text { Se } & \text { Selenite } \\ \text { SILAC } & \text { Stable isotope labeling by amino acids in cell culture } \\ \text { SIP1 } & \text { SMAD interacting protein } \\ \text { SUMO } & \text { Small ubiquitin-related modifier } \\ \text { Su(z) } & \text { Suppressor of zeste } \\ \text { SxC } & \text { Super sex combs } \\ \text { T } & \text { Threonine } \\ \text { TPA } & \text { 12-O-tetradecanoylphorbol-13-acetate } \\ \text { TRIM28 } & \text { Tripartite motif-containing 28 } \\ \text { TrXG } & \text { Trithorax Group } \\ \text { Ub } & \text { Ubiquitin } \\ \text { UBD } & \text { Ubiquitin binding domain } \\ \text { UVB } & \text { Ultraviolet B } \\ \text { Y } & \text { Tyrosine } \\ \text { YY } & \text { Yin-yang transcription factor } \\ \text { ZAP-70 } & \text { Zeta associated protein-70 }\end{array}$


Colour figures 


\section{Colour figures}

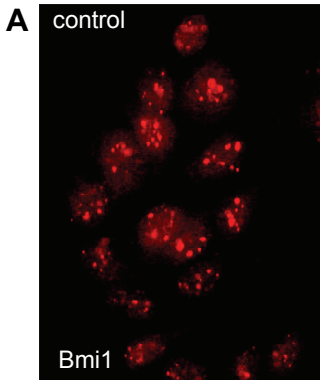

control
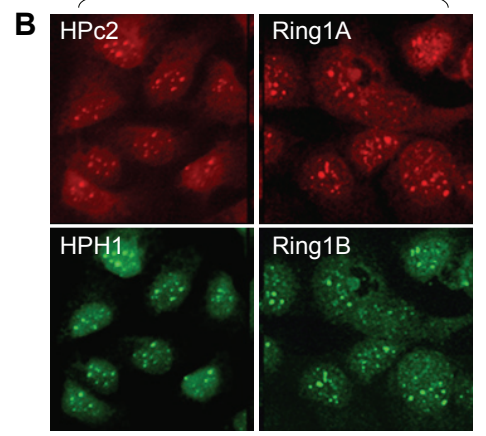
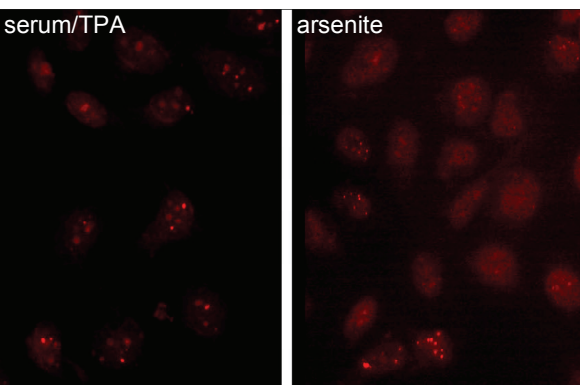

arsenite

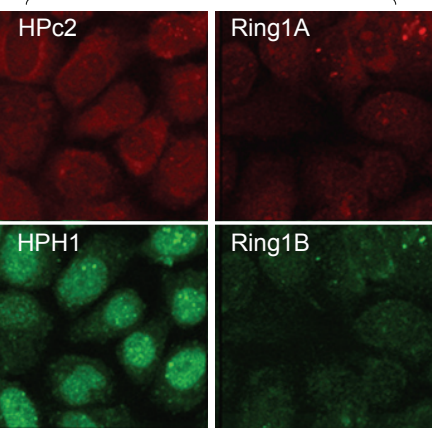

Figure 4.3. Phosphorylation-dependent PcG/chromatin interaction.
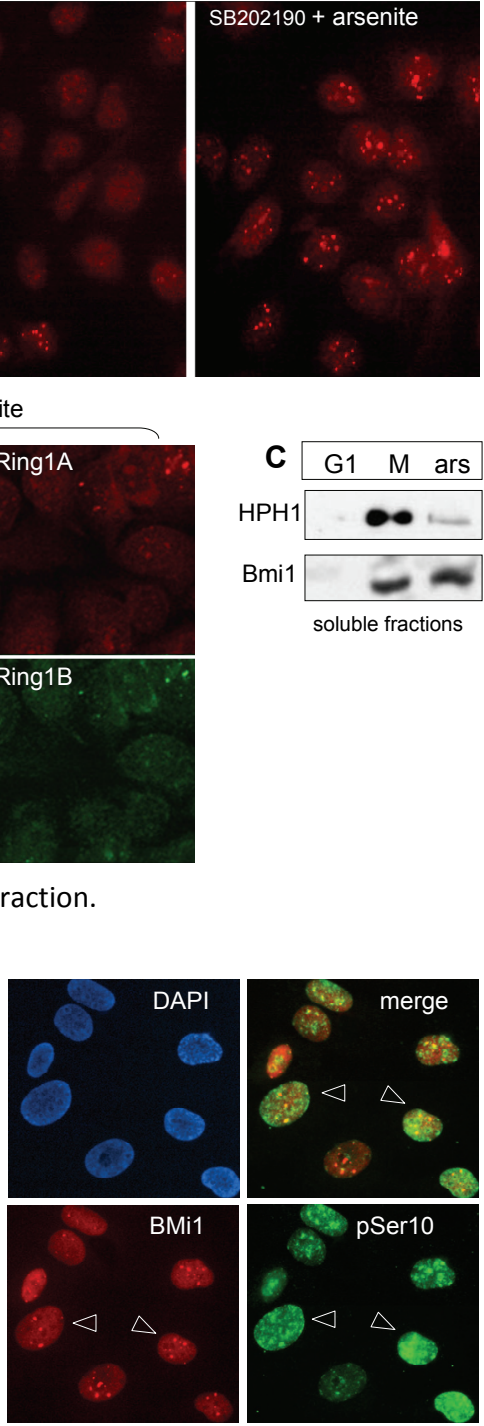

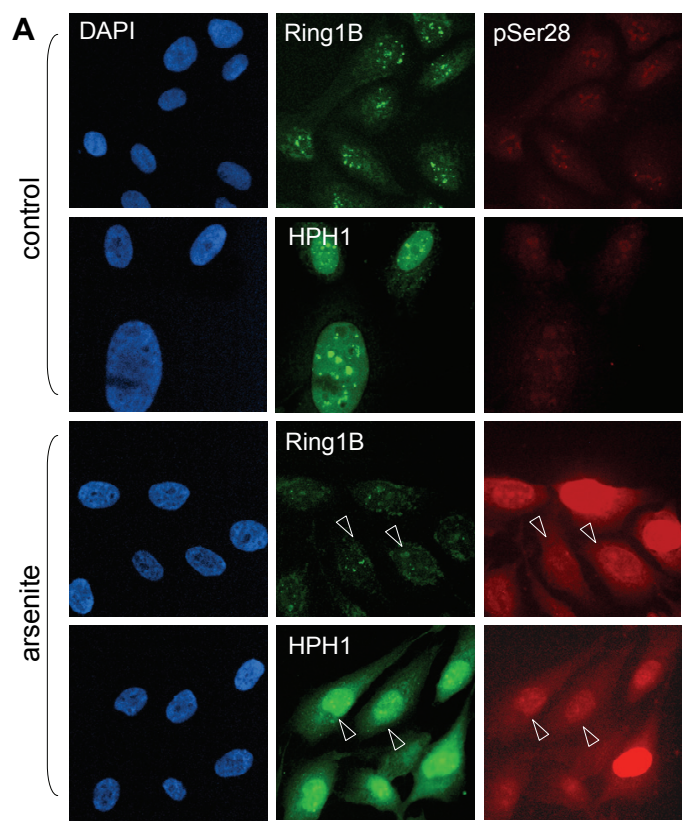

Figure 4.4. Post-translational histone H3-tail modifications during stress signaling. 


\section{Colour figures}

$\mathbf{F}$

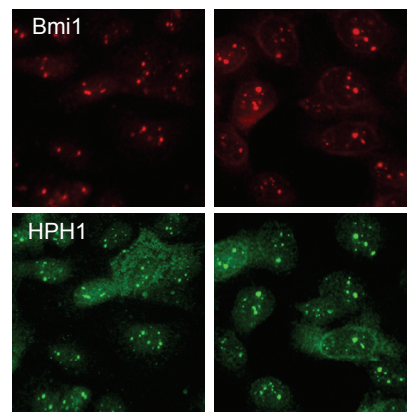

vector control

RNAi 3pK

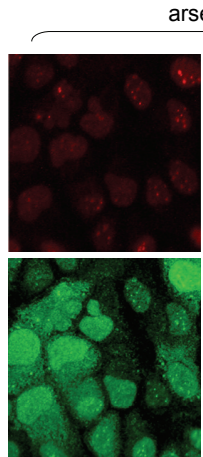

vector control arsenite

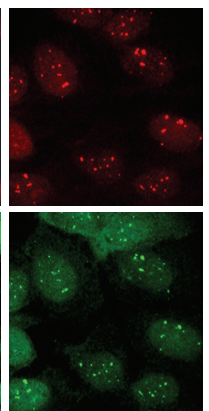

RNAi 3pK

Figure 4.5.F Identification of $3 p K$ as a candidate Bmi1 kinase.

C

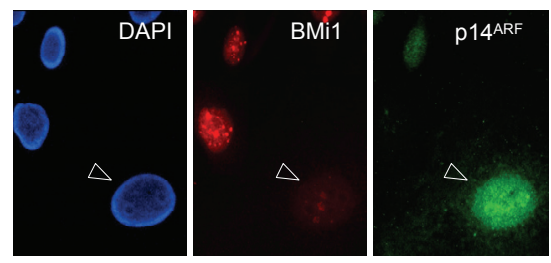

Figure 4.6.C Overexpression of 3pK releases chromatin-associated Bmi1 and derepresses Cdkn2aINK4A.

B

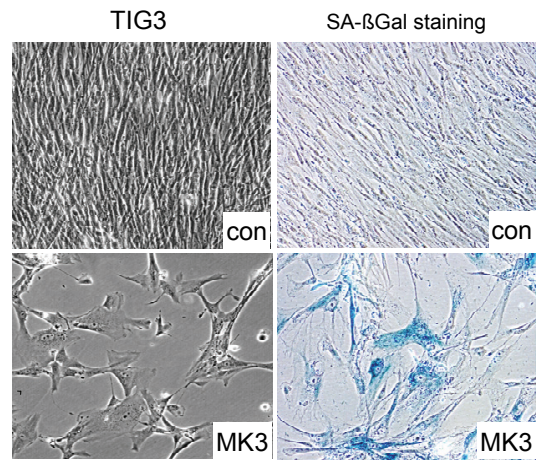

\section{$\mathrm{F}$}

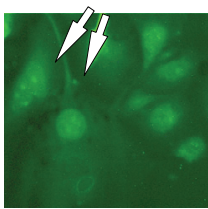

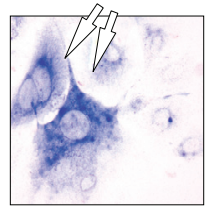

Figure 5.1.B+F MK3 induces cell cycle arrest and a senescence-like state. 


\section{Colour figures}

A

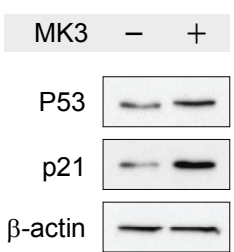

B

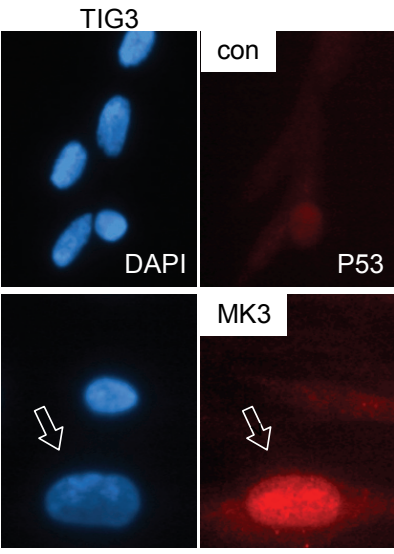

C

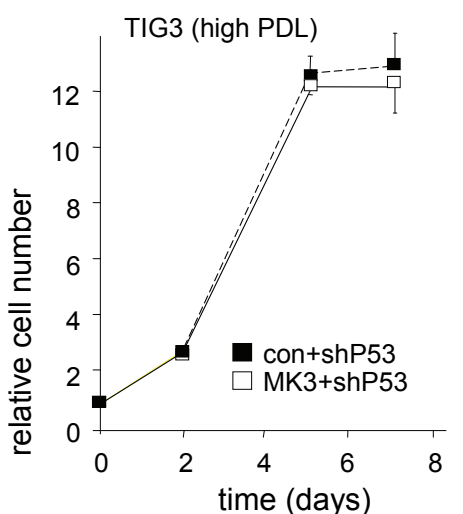

$\mathrm{D}$

TIG3

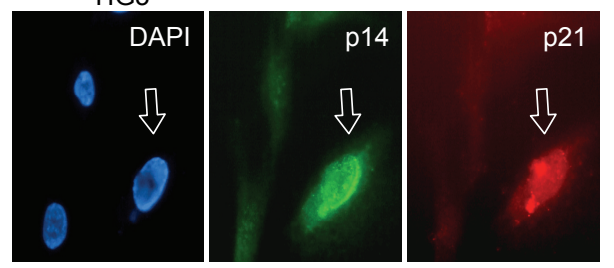

E

U2-OS

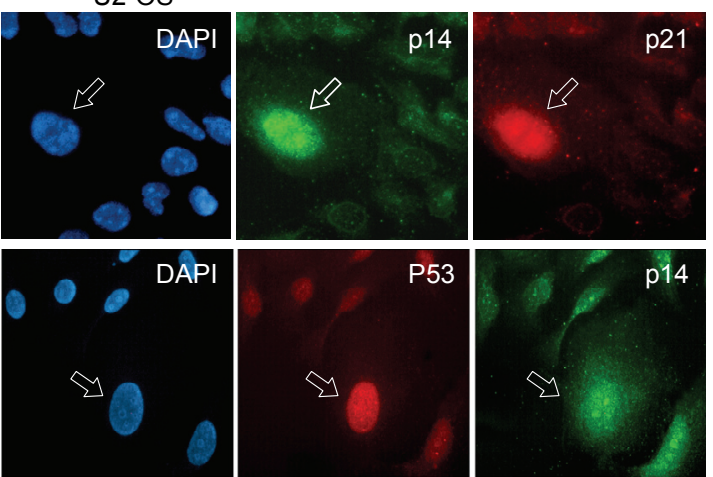

Figure 5.2. Expression analysis of cell cycle regulators in MK3-expressing senescent cells. 


\section{Colour figures}

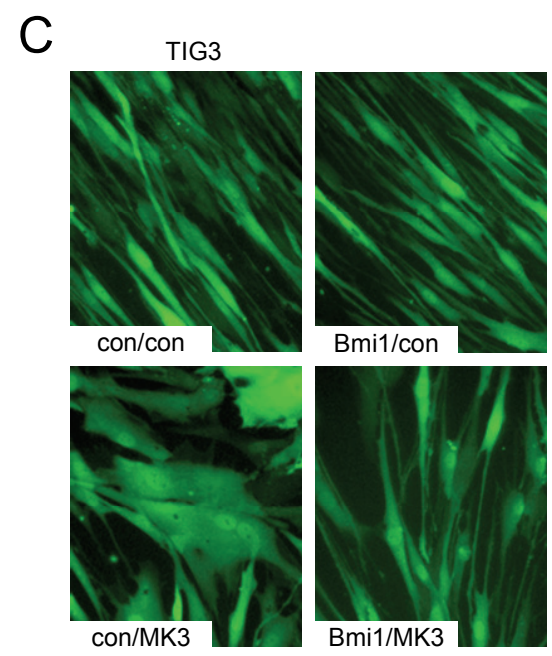

Figure 5.3.C Genetic interaction between MK3 and Bmi1.
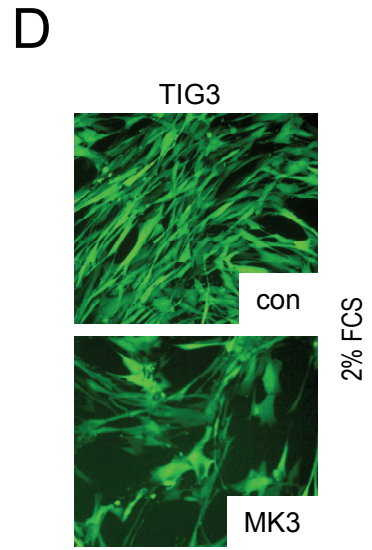

Figure 5.S2.D MK3 expression level affects proliferation responses.

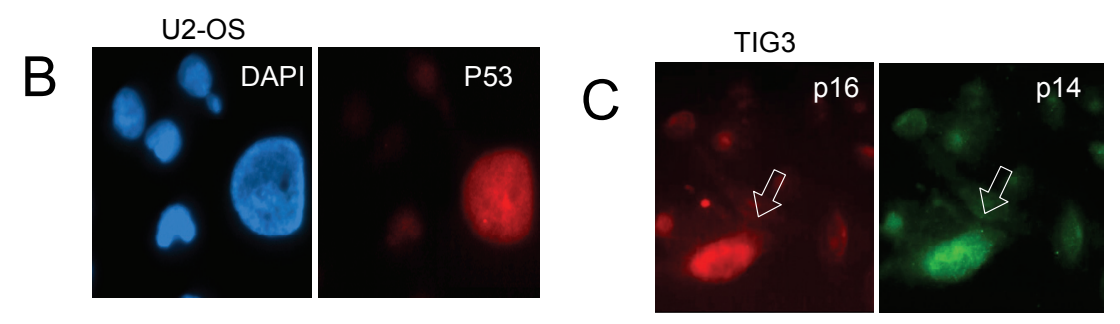

Figure 5.S3.B+C Role of MK3 in senescence pathways. 


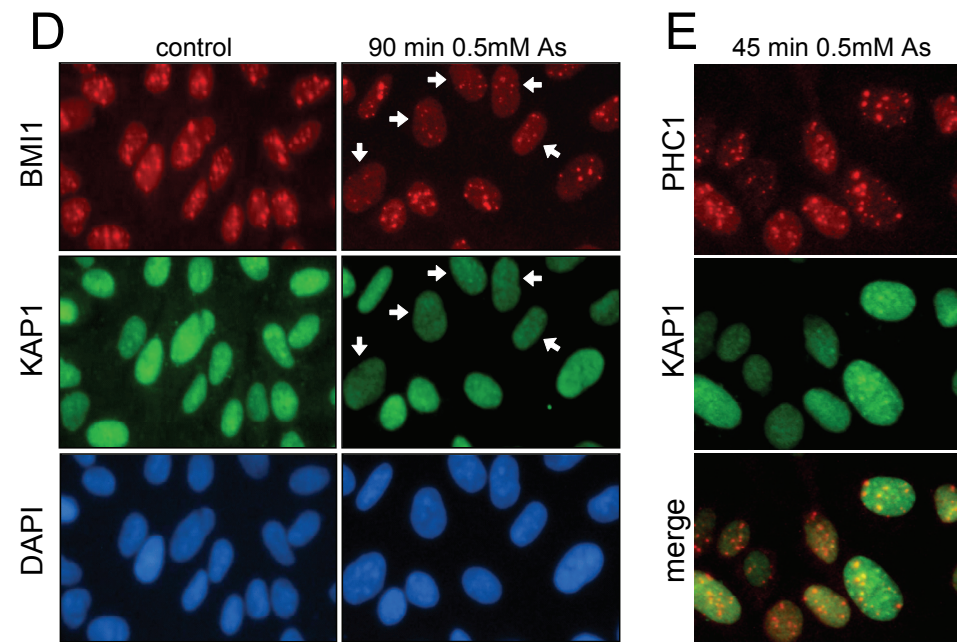

Figure 6.1.D+E Bmi1-Py and KAP1 phosphorylation and association upon Arsenite exposure.
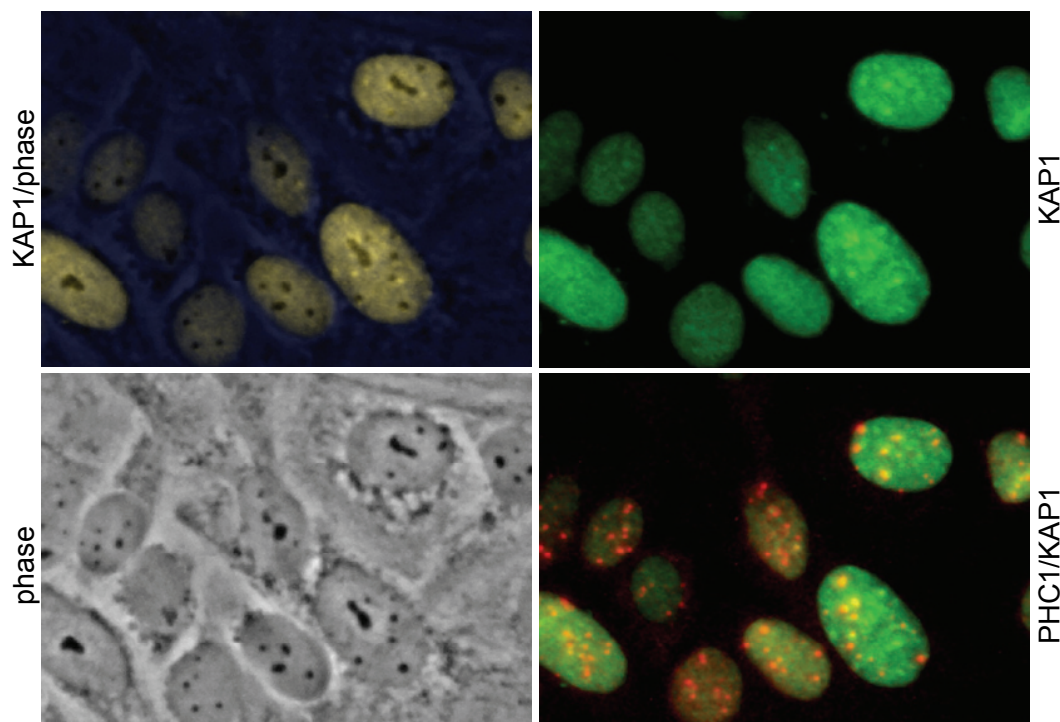

$\frac{2}{\underline{4}}$
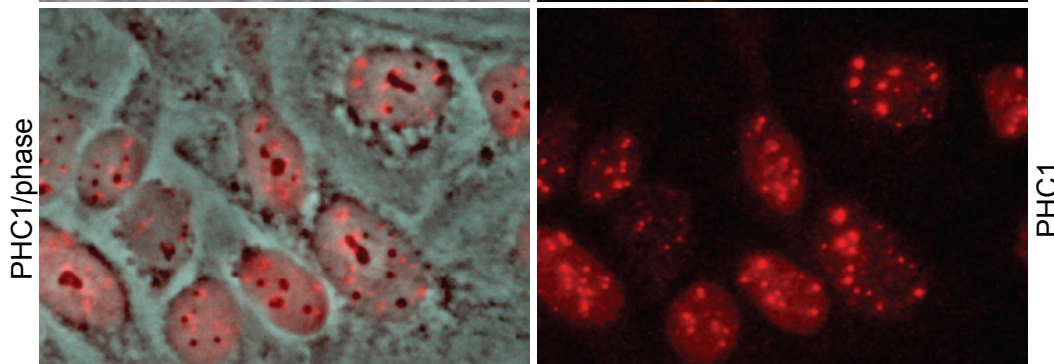

Figure 6.S1. PHC1 and KAP1 concentrate around nucleolar structures. 


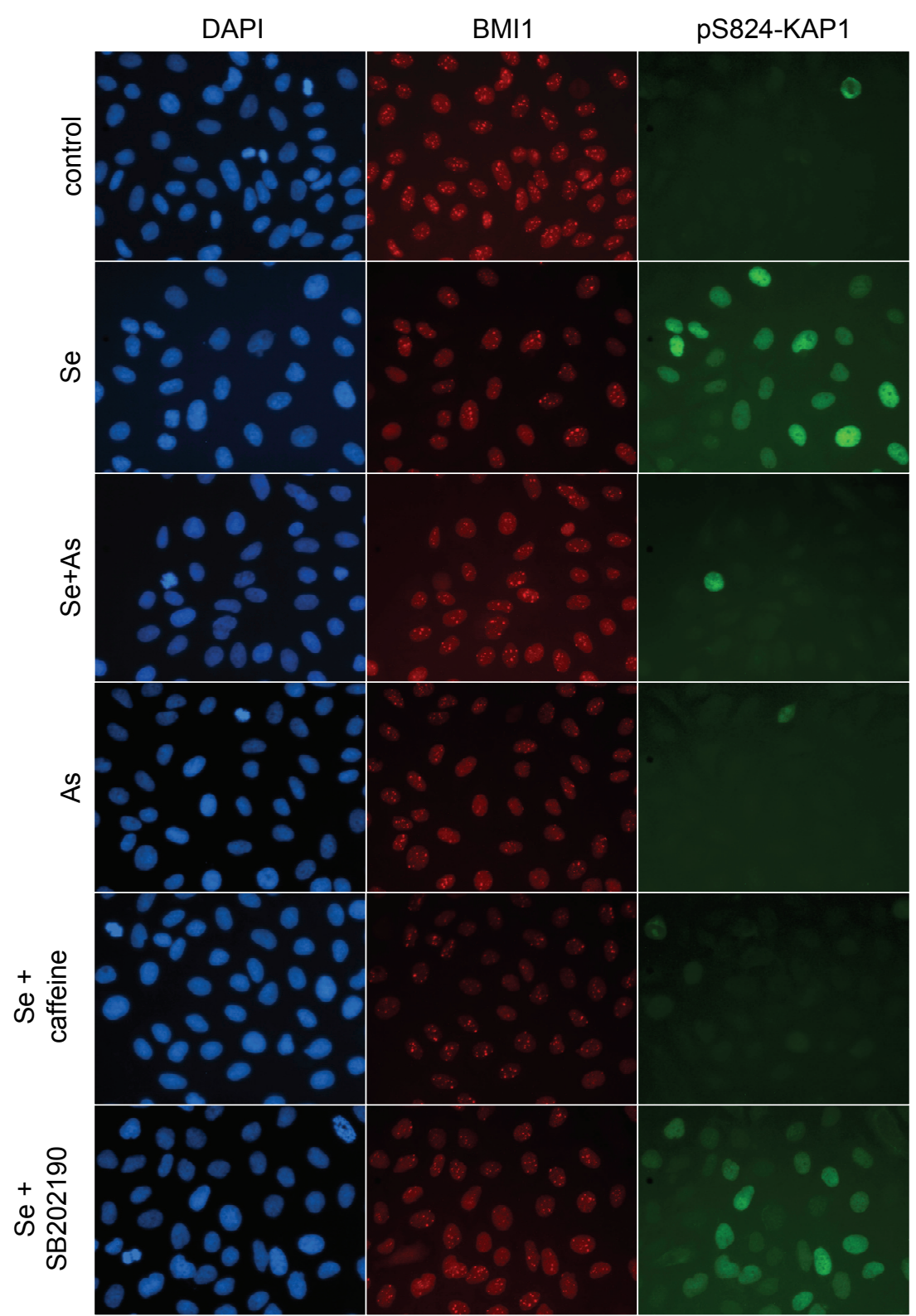

Figure 6.S7. Localization of BMI1 and KAP1 in stressed cells. 


\section{Colour figures}

A

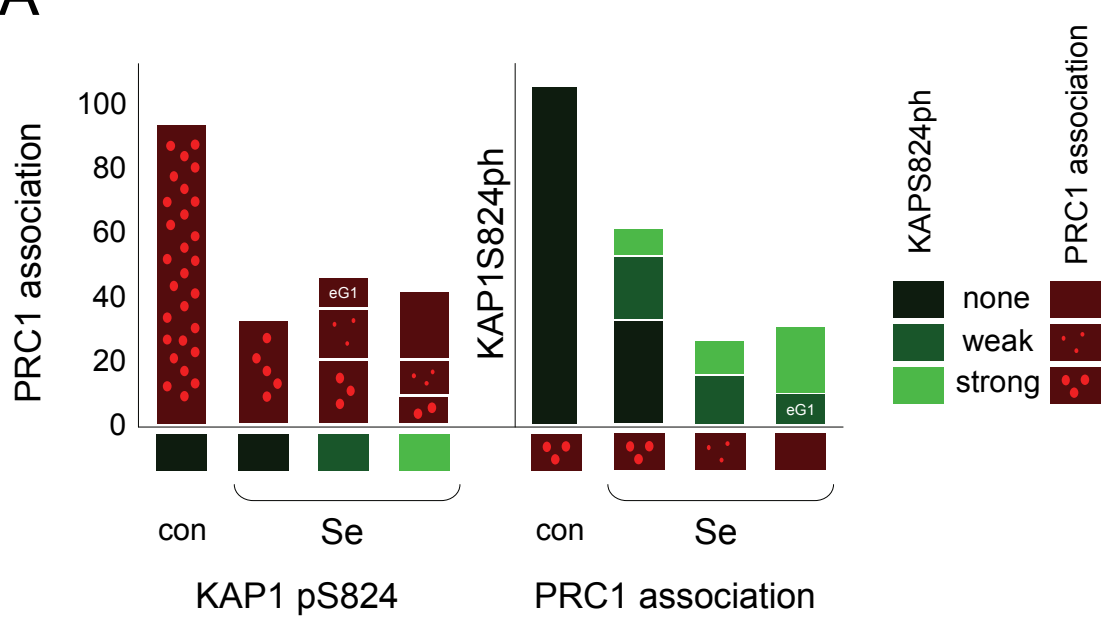

B

Figure 6.S8. BMI1 and pS824-KAP1 do not colocalize 


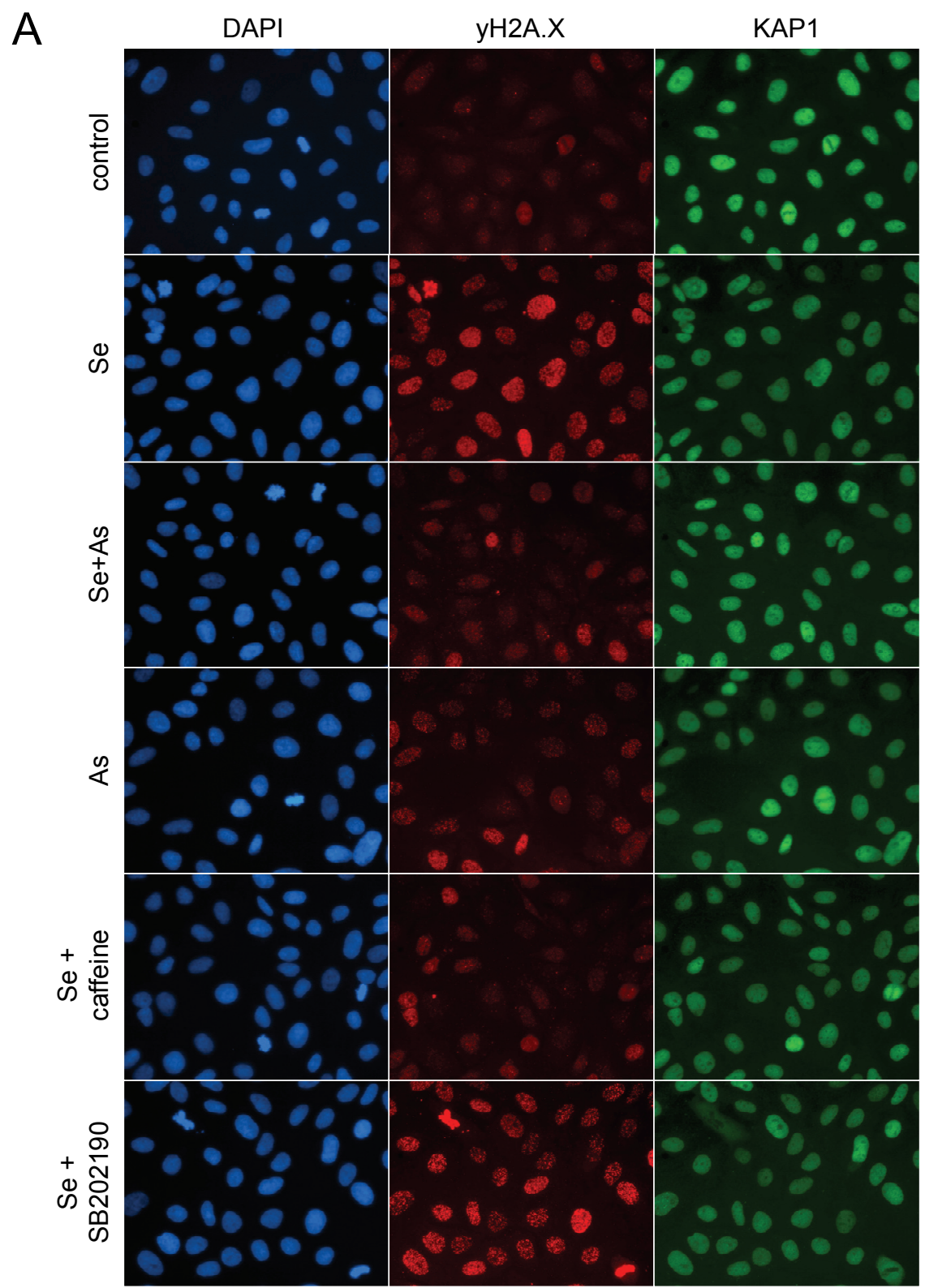

Figure 6.S9.A Localization of DNA damage and KAP1 in stressed cells. 


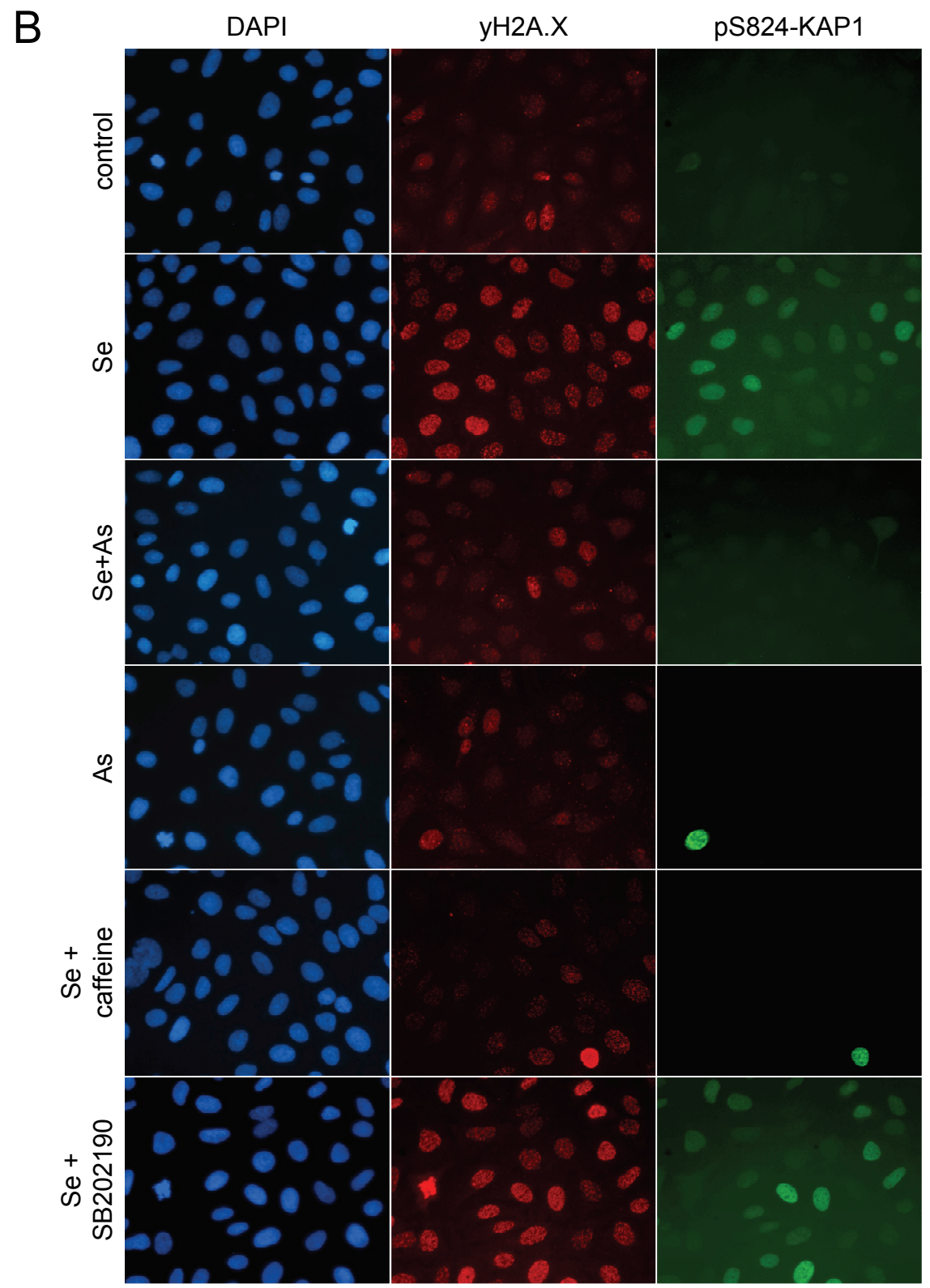

Figure 6.S9.B Localization of DNA damage and KAP1 in stressed cells. 
Seldom, very seldom, does complete truth belong to any human disclosure; seldom can it happen that something is not a little disguised, or a little mistaken.

From Emma by Jane Austen 
